\title{
Erster Beratungsgegenstand: Grundpflichten als verfassungsrechtliche Dimension
}

1. Bericht von Professor Dr. Volkmar Götz, Göttingen

Inhalt

Einleitung ...................... 8

I. Grundrechte und Grundpflichten. . . . . . . . . . . 9

1. Weimarer Verfassung . . . . . . . . . . . 9

2. Grundgesetz . . . . . . . . . . . . . 12

a) Begriff der Grundpflicht . . . . . . . . . . . . 12

b) Verhältnis von Rechten und Pflichten. . . . . . . . . 13

c) Pflichtbeiträge zur Vermeidung und Bewältigung von Grundrechtskollisionen . . . . . . . . . . . 14

d) Negative Grundrechte . . . . . . . . . . . . . . 15

e) Sozialstaatlicher Grundpflichtstatus? . . . . . . . . 16

3. Sozialistische Verfassungen . . . . . . . . . . 17

II. Politische staatsbürgerliche Grundpflichten $\ldots \ldots \ldots \ldots 21$

1. Verfassungstreue. . . . . . . . . . . . . 21

2. Wehrpflicht . . . . . . . . . . . . 23

3. Übernahme von Ehrenämtern . . . . . . . . . . . . . 26

III. Soziale Grundpflichten . . . . . . . . . . . . . 28

1. Offentliche Dienstleistungspflichten . . . . . . . 28

2. „Eigentum verpflichtet“. . . . . . . . . . . . 30
a) Unterscheidung der Ebenen des Verfassungsrechts und der gesetzlichen Eigentumsordnung . . . . . . . 30
b) Verfassungsrechtliche Gehalte des Art. 14 Abs. 2 GG . 31
c) Grundpflicht zur Steuerzahlung . . . . . . . . . . 33
d) "Steuerstaat" und Lastengleichheit . . . . . . . . . 34

Schluß ...................... 36 


\section{Einleitung}

Die „Grundpflichten“ waren fast drei Jahrzehnte lang im verfassungsrechtlichen Denken und der verfassungsrechtlichen Praxis der Bundesrepublik Deutschland nicht anwesend $^{1}$, ohne daß man sie groß vermißt hätte. Die Wiederbelebung des Grundpflichtthemas ${ }^{2}$ ist natürlich nicht zufällig. Aber wir verdanken sie wohl weniger dem Bedürfnis, eine in der verfassungsrechtlichen Praxis nachweislich empfundene Lücke zu schließen, als vielmehr höchst wandelbaren Strömungen des politischen Zeitgeistes.

Die von Peter Saladin 1976 vorgetragene Idee, den verfassungsrechtlichen Status des Unternehmens als Grundpflichtstatus zu definieren, hatte die Annahme zur Voraussetzung, $\mathrm{da}$ die Unternehmenswirtschaft über ein durch das Gemeinwesen bislang noch nicht ausgeschöpftes Kräftepotential verfügte, welches durch eine Pflichtenordnung zu Gunsten des Gemeinwohls - vor allem im Umweltschutz - nutzbar zu machen sei. Diese Annahme wagt man heute weniger zu äußern. Tests auf die Belastbarkeit der Wirtschaft werden seltener vorgeschlagen. Heute geht der Ruf nach einer Pflichtenordnung in eine andere Richtung. Die Übernahme von Pflichten wird vom Bürger schlechthin, also von allen erwartet. Pflichten werden als Abhilfe gegen das vielbeklagte ungehemmte Anspruchsdenken gesehen ${ }^{4}$. Besinnung auf die Pflichten der Menschen im Staat wird gefordert, um das Mißbrauchspotential abzubauen, das sich in der Kombination von Freiheit vom Staat und sozialen Sicherungsansprüchen an den Staat offensichtlich angesammelt hat.

${ }^{1}$ Außer bei Maunz (Deutsches Staatsrecht, zuletzt 23.A. 1980, $\$ 13$ III, jetzt Maunz-Zippelius, 24.A. 1982, § 22) wurde die Kontinuität des Grundpflichtthemas von Weimar bis Bonn am deutlichsten gewahrt von F. Klein (v. Mangoldt-Klein, Das Bonner GG, Bd. I, 2.A. 1957, S.76-78)

${ }^{2}$ H. H. Klein, DSt 14 (1975), 153 (noch weitgehend prinzipiell ablehnend), Saladin, VVDStRL 35 (1977), 7 und Diskussionsbeiträge a.a.O. von Meessen (S. 125), Suhr (S. 125, 142), Merten (S. 126), Saladin (S. 130, 143), Mußgnug (S. 133), Stern (S. 137), F. Müller (S. 138); D. Merten, BayVBl. 1978, 554; Stober, Grundpflichten und GG, 1979; Häberle, Rechtstheorie 11 (1980), 389 (412 ff.); Benda, Grundrechte - Grundpflichten (Vortrag, Esslingen), 1981. - Neuestens: Badura, DVBl. 1982 S. 861; Bethge, NJW 1982, S. 2145; Isensee, DÖV 1982, 609; Stober, NVwZ 1982, S. 473; Gusy, JZ 1982, S. 657.

3 A.a.O. (Fn. 2).

4 Benda, Tugend der Pflichterfüllung. Über das Verhältnis von Grundrechten und Pflichten. Ev. Komm. 1981, 497. 
Während der progressive Zeitgeist Gefallen an Grundpflichten der Unternehmungen und des Haus- und Grundbesitzes findet, bringt der konservative Zeitgeist in das Pflichtenthema die Sorgen um die Gesetzestreue und die Leistungsbereitschaft der breiten Schichten der Bevölkerung ein. Gegenläufige Strömungen treffen aufeinander und vereinigen sich im Zielpunkt der Grundpflichten. Wird dieser Zielpunkt erreicht, so bedeutet dies jeweils die verfassungsrechtliche Überhöhung und damit Unangreifbarkeit von Forderungen und Ordnungsmodellen. Für die verfassungsrechtliche Analyse leitet sich aus dieser Konsequenz die Notwendigkeit zurückhaltender Gewissenhaftigkeit ab. Grundpflichten sind für das geltende Verfassungsrecht der Bundesrepublik Deutschland unter der zweifachen Qualifizierung in Betracht zu ziehen, daß es sich erstens um Grund-Rechtspflichten und zweitens um solche Rechtspflichten handelt, die als verfassungsgeforderte Pflichten ihre Grundlage im Verfassungsrecht haben. Grundpflichten bedürfen einer eindeutigen verfassungsrechtlichen Ableitung. Wandelbaren Erwartungen an das Verhalten der Menschen und Unternehmungen verhilft die Verfassung nicht zu Verbindlichkeit. Auch den Verfassungserwartungen ${ }^{6}$ selbst den mit der Gewährleistung der Freiheitsrechte verbundenen Erwartungen an den Gemeinsinn und die Praktizierung staatsbürgerlicher Tugenden - verleiht die Verfassung nicht die Qualität von Rechtspflichten.

\section{Grundrechte und Grundpflichten}

\section{Weimarer Verfassung}

Grundrechte und Grundpflichten wurden im Zweiten Hauptteil der Weimarer Reichsverfassung in eine grundsätzliche systematische Verbindung gebracht, die in den Nachkriegsverfassungen von Bayern ${ }^{7}$, Bremen $^{8}$, Hessen $^{9}$, Rheinland-Pfal ${ }^{10}$ und Saarland ${ }^{11}$ zwar wiederaufgenommen, vom Grundgesetz aber aufgegeben worden ist.

${ }^{5}$ D. Merten, a.a.O. (Fn. 2), S. 556 (für Grundpflichten ,Vorbehalt des Verfassungsgesetzes").

${ }^{6} \mathrm{Zu}$ diesen s. H. Krüger, FS Scheuner, 1973, S. 285; Denninger, VVDStRL 37 (1979), 7 (22); BVerfGE 28, 36, 48 (von den Bürgern wird die Verteidigung der freiheitlichen Ordnung erwartet).

7 BayV, 2. Hauptteil „Grundrechte und Grundpflichten“, Art. $98 \mathrm{ff}$.

8 BremV, 1. Hauptteil "Grundrechte und Grundpflichten“, Art. 1 ff.

9 Art. 25, 27 ff. HV.

${ }^{10}$ RhPfV, 1. Hauptteil „Grundrechte und Grundpflichten“, Art. 1 ff.

11 SaarlV, 1. Hauptteil "Grundrechte und Grundpflichten“, Art. 1ff. 
In den Weimarer Verfassungsberatungen war es der „Versuch volksverständlicher Grundrechte" Friedrich Naumanns, der dem Grundrechtsteil der Verfassung die Komponente der Pflichten hinzugefügt hatte ${ }^{12}$. Sein wesentliches Anliegen, die Verfassung des Kulturstaates wie des Sozialstaates durch die unauflösliche Verbindung von Rechten und Pflichten zu prägen, gab dem weiteren Gang der Verfassungsgebung in diesem Punkte die entscheidende Wende ${ }^{13}$. Der unter dem Eindruck der Vorschläge Naumanns vom Verfassungsausschuß der Nationalversammlung eingesetzte Unterausschuß verband die Grundrechte mit den wirtschaftlich-sozialen Forderungen der Zeit, staatserzieherischen Grundgedanken und den Grundsätzen einer aufzubauenden Ordnung von Gesellschaft und Wirtschaft. Der sozialdemokratische Abgeordnete Simon Katzenstein war es, der - wie Konrad Beyerle berichtet ${ }^{14}$ - den Einfall hatte, ,das Ganze als Grundrechte und Grundpflichten der Deutschen $\mathrm{zu}$ überschreiben, da auch öffentlich-rechtliche Pflichten der Staatsbürger mit hineinbezogen werden sollten“. Sein Einfall hatte für die Weimarer Staatsrechtslehre die Auswirkung, daß keine der systematischen Darstellungen der Grundrechte an den Grundpflichten vorbeigehen konnte; jeder staatsrechtliche Entwurf war fortan dem Zwillingspaar „Grundrechte und Grundpflichten" gewidmet ${ }^{15}$. Erfuhren so die Grundpflichten ständig wiederholte Anerkennung ihrer Existenz, so war in der Sache die Verlegenheit, in welche die Staatsrechtslehre durch die Grundpflichten gestürzt wurde, noch weit größer als jene, welche durch die Grundrechte hervorgerufen worden war, die von der herrschenden Meinung bekanntlich, soweit sie unter Gesetzesvorbehalt standen, als

12 Vhdl. verfgeb. Dt. Nationalversammlung Aktenst. Nr. 391, in: Verfgeb. Dt. Nationalversammlung, Bd. 336, 1920. Vgl. E. R. Huber, FS Wieacker, 1978, S. 384.

${ }^{13}$ Die Entwürfe I-IV von Hugo Preuß enthielten nur die liberalen Grundrechte. S. Triepel, Quellensammlung z. Dt. Reichsstaatsrecht, 5.A. 1931, S. 6; W. Jellinek, in: Anschütz/Thoma (Hsg.), Hdb. d. Dt. Staatsrechts, Bd. I, 1930, S. 127; E. R. Huber, Dt. Verfassungsgeschichte, Bd. V, 1978, S. 1178.

${ }^{14}$ Beyerle, Zehn Jahre Reichsverfassung. Festrede zur Münchner Verfassungsfeier der Reichsbehörden am 11. August 1929, 1929, S. 21.

15 Hofacker, Grundrechte und Grundpflichten der Deutschen, 1926; Nipperdey (Hsg.), Die Grundrechte und Grundpflichten der Reichsverfassung, 3 Bde, 1929 ff.; C. Schmitt, Grundrechte und Grundpflichten, in: Verfassungsrechtliche Aufsätze aus den Jahren 1924-1954 (1958); Stier-Somlo, Grundpflichten der Reichsangehörigen, HwbRW (Hsg. Stier-Somlo/Elster), Bd. III, 1928, S. 45. 
leerlaufende Wiederholungen des Grundsatzes der Gesetzmäßigkeit der Verwaltung angesehen wurden. Zog man von dem scheinbaren Reichtum der Verfassung an Grundpflichten alle diejenigen Bestimmungen ab, die lediglich sittliche Pflichten der Staatsbürger aussprachen, Programmsätze enthielten, Staatsaufgaben formulierten oder gesetzlich schon bestehende oder einzuführende Pflichten in der Verfassung erwähnten, so blieb am Ende von den Grundpflichten als Grund-Rechtspflichten nichts übrig. Diese Konsequenz wurde durch die positivistische Lehre auch gezogen und durch Richard Thoma zum Ausdruck gebracht: die eigentlich einzige rechtliche Grundpflicht sei diejenige zum Gehorsam gegenüber den Rechtsnormen und den normgemäßen Staatsakten ${ }^{16}$. Als taugliche Grundpflichten wurden dagegen verworfen: die Pflicht jedes Deutschen, „seine geistigen und körperlichen Kräfte so zu betätigen, wie es das Wohl der Gesamtheit erfordert" (Art.163 I WRV), weil die Verfassung sie ausdrücklich als eine sittliche Pflicht bezeichnete, und die Sozialpflichtigkeit des Eigentums (Art. 153 III), weil sie als bloß sittliche Pflicht angesehen wurde. Die Inbezugnahme gesetzlicher Pflichten wie der Schulpflicht (Art. 145 WRV), der Pflicht zur Übernahme von Ehrenämtern (Art. 132 WRV) und der Pflicht zur Leistung persönlicher Dienste für Staat und Gemeinde (Art. 133 WRV) galt als verfassungsrechtlich irrelevant. Damit war das Existenzrecht der Grundpflichten, trotz ihres scheinbaren Gleichranges mit den Grundrechten, in Zweifel gezogen. Die Diskrepanz zwischen dem Anspruch und volkserzieherischen politischen Pathos der Weimarer Grundpflichten und der ihnen beigemessenen verfassungsrechtlichen Tragweite wurde nie geschlossen. Die materielle Neuorientierung, die die Grundrechte insbesondere durch Rudolf Smend erfahren sollten, führte zwar die Dimensionen der Sozialethik und das Pflichtethos in die Deutung der Grundrechte ein ${ }^{17}$. Aber sie bezog ihre Grundlage nicht aus den von der Weimarer Verfassung ausdrücklich formulierten Grundpflichten ${ }^{18}$.

16 In: Nipperdey (Hsg.), a.a.O. (Fn. 15), Bd. I, 1929, S. 1 (29).

17 Vgl. Link, JöR N.F. Bd. 30, S. 1, 10.

18 Anders offenbar Badura, a.a.O. (Fn. 2), S. 867 (Grundpflichten als Gegenstand des Methodenstreits). Zu Smend s. insbes. Bürger und Bourgeois im deutschen Staatsrecht, in: Staatsr. Abhdlgen, 2.A. 1968, S. $309,318 \mathrm{f}$. 


\section{Grundgesetz}

Für das Grundgesetz stellt sich das Problem der Grundpflichten gegenüber Weimar neu. Der Bestand an Pflichtennormen der Verfassung hat sich gelichtet. Was den subjektiven Willen des Verfassungsgebers betrifft, so muß es hier mit der Feststellung sein Bewenden haben, da 3 die Entstehungsgeschichte des Grundgesetzes keinen Beleg für eine bewußte Absage an Grundpflichten ergibt ${ }^{19}$. Der Wegfall der Weimarer systematischen Verknüpfung von Grundrechten und Grundpflichten mit all ihren Unklarheiten bietet die Chance, das Verhältnis von Grundrechten zu den verfassungsnotwendigen Pflichten der Bürger von den Prinzipien der freiheitlichen Ordnung her zu bestimmen.

\section{a) Begriff der Grundpflicht}

Dies setzt an erster Stelle eine Verständigung über den Begriff der Grundpflichten voraus. Grundpflichten sind verfassungsrechtlich geforderte Pflichtbeiträge zum Gemeinwohl. Sie sind $\mathrm{zu}$ begreifen als verfassungsverbindlich gemachte Aktivierung und Mobilisierung der den Grundrechtsinhabern zustehenden Freiheiten und Vermögenspotentiale für die Zwecke des Gemeinwohls ${ }^{20}$.

Wenn das Wesen der Grundpflichten darin zu erblicken ist, daß die Verfässung vom Bürger bestimmte Beiträge zum Gemeinwohl nicht nur erwartet, sondern rechtlich fordert, die dieser aus der Fülle seiner Freiheiten und Rechte heraus erbringen soll, dann hat dies auch zur Folge, daß verfassungsrechtliche Grundpflichten nicht in den Schranken der Grundrechte aufgehen.

Grundrechtsbegrenzungen ${ }^{21}-\mathrm{d} . \mathrm{h}$. verfassungsimmanente Bereichsgrenzen ${ }^{22}$ der grundrechtlichen Gewährleistungen so-

${ }^{19}$ So auch: Isensee, a.a.O. (Fn. 2), S. 611. Näher: Parl.Rat, Ausschuß für Grundsatzfragen, 6. Sitzg., 5. 10. 1948, Sten.Prot. GrF 6, 67.

${ }^{20} \mathrm{Zu}$ diesem (keine Begrenzung auf staatsbezogenes Gemeinwohl) vgl. Häberle, Öffentliches Interesse als juristisches Problem, 1970; Scholz, Die Koalitionsfreiheit als Verfassungsproblem, 1971, S. 220 f.; Schmitt Glaeser, VVDStRL 31 (1973), 179 (191 f.) m. w. N.

${ }^{21}$ Im Sinne v. Hesse, Grundzüge des VerfR d. BRep. Deutschland, 13.A. 1982, Rdnr. 308 ff.

${ }^{22}$ Vgl. dazu Hesse, a.a.O. (Fn. 21), Rdnr. 310; Fr. Müller, Die Positivität der Grundrechte, 1969; ders., Freiheit der Kunst als Problem der Grundrechtsdogmatik, 1969, S. 29 ff.; H. van Nieuwland, Darstellung und Kritik der Theorien der immanenten Grundrechtsschranken, Diss. iur. Göttingen, 1981. Kritisch: Schwabe, Probleme der Grundrechtsdogmatik, 1977, S. 152 ff. 
wie gesetzliche Schranken und Einschränkungen der Grundrechte - führen zur wechselseitigen Zuordnung ${ }^{23}$ und Abgrenzung verschiedener Freiheitsbereiche, Rechtsgüter und Gemeinwohlbelange. Die Einordnung individueller Freiheiten in die durch Verfassung und Gesetz abgesteckten und wechselseitig abgegrenzten Räume ist nicht das Thema der Grundpflichten ${ }^{24}$. Es würde auch nichts einbringen, Grundrechtsbegrenzungen in Pflichten umzuformulieren. Die Postulierung einer Pflicht, die Rechte Dritter zu achten, würde beispielsweise nicht helfen, die durch die Drittwirkung der Grundrechte aufgeworfenen Kollisionsprobleme und Abgrenzungserfordernisse ${ }^{25} \mathrm{zu}$ bewältigen. „Nichtstörungspflichten“ ${ }^{“ 26}$ ergeben keinen Ertrag, der über denjenigen der Rechtsbegrenzung hinausgeht.

\section{b) Verhältnis zwischen Rechten und Pflichten}

Das Verhältnis zwischen Rechten und Pflichten wird von den Rechten des einzelnen her bestimmt. Da die Pflichten aus der Quelle der grundrechtlich gewährleisteten Freiheiten und Rechte schöpfen, sind diese insoweit vorrangig. Die freiheitliche Verfassung kann sich nicht, ohne sich mit sich selbst in Widerspruch zu setzen, zu einer „Einheit von Rechten und Pflichten" bekennen, nach der die Grundrechte von der Erfüllung von Grundpflichten abhängig sind, die Gewährleistung der Grundrechte gleichsam zurückbehalten werden muß, solange der einzelne seine Grundpflichten nicht erfüllt hat. Das Verhältnis zwischen Grundrechten und Pflichten ${ }^{27}$ folgt nicht den Kategorien von Leistung und Gegenleistungsan-

${ }^{23}$ Zum Verhältnismäßigkeitsgrundsatz als Maßstab wechselseitiger Zuordnung vgl. Hesse, a.a.O. (Fn. 21), Rdnr. 318 ff.; Grabitz, AöR 98 (1973), 568.

24 Anders wohl Badura, a.a.O. (Fn. 2), S. 870. Benda, a.a.O. (Fn. 2), unterscheidet von den Grundpflichten die von ihm „Grundrechtspflichten" benannten sonstigen Bindungen und Schranken der Grundrechte.

${ }^{25}$ Vgl. Blaesing, Grundrechtskollisionen, Diss.iur. Bochum, 1974; Bethge, Zur Problematik von Grundrechtskollisionen, 1977; Schwabe, a.a.O. (Fn. 22), 317 ff;. Starck, JuS 1981, 237 (243 ff.) m. w. N.

${ }^{26}$ Dürig, in: Maunz-Dürig-Herzog-Scholz, Komm.GG (Losebl.), Art. 1, Rdnr. 22, 23.

${ }^{27}$ Vgl. W. Huber/Tödt, Menschenrechte, Perspektiven einer menschlichen Welt. 1977, S. 106 ff.; Isensee, a.a.O. (Fn. 2), S. 615. 
spruch $^{28}$. Die Verfassung der freiheitlichen Demokratie ist gewissermaßen so unvorsichtig, allen die gleichen politischen Rechte und Menschenrechte als Vorleistung zu gewährleisten. Die Pflichten folgen den Rechten nach. Die Vielfältigkeit der durch die Grundrechte eröffneten Freiheit ergibt sich aus der Komplexität jedes Grundrechtes als einer Einheit. Die Pflichtenvielfalt bedarf dagegen immer wieder erneuerter spezieller Anordnung des Gesetzgebers, der dabei politische Entscheidungen zu treffen hat und den Geboten der Bestimmtheit des Gesetzes und der Verhältnismäßigkeit unterliegt.

Das für die rechtsstaatliche Verfassung schlechthin konstituierende Modell der Verteilung von Rechten und Pflichten auf verschiedene Ebenen benötigt den Gesetzgeber als Motor für Gesamtverantwortung und Pflichtenordnung ${ }^{29}$. Die Herstellung der Pflichtenordnung ist Sache des Gesetzgebers. In diese Rolle des Gesetzgebers sind auch die Generalklauseln etwa des Zivil- und Arbeitsrechtes eingeschlossen.

c) Pflichtbeiträge zur Vermeidung und Bewältigung von Grundrechtskollisionen

Eine unmittelbare, gleichsam gesetzesunabhängige Ableitung von Pflichten aus Grundrechten ist damit nicht schlechthin ausgeschlossen. In der Situation der Grundrechtskollision - bei der es sich, wie dargelegt, primär nur um eine Frage der Grundrechtsbegrenzung handelt - können Pflichtbeiträge des Grundrechtsinhabers zur Vermeidung und Bewältigung der Kollision verlangt und unmittelbar aus der Grundrechtsausübung abgeleitet werden, wenn das Gesetz als Maßstab ausfällt. Hierbei ist an sehr verschiedenartige Lagen zu denken. Im Arbeitskampfrecht fällt das Gesetz aus Gründen aus, die hier nicht dargelegt zu werden brauchen. Es erscheint daher folgerichtig, daß zur Vermeidung eines ruinösen Streiks nicht nur objektive Begrenzungen der Arbeitskampffreiheit in Gestalt der Eigentumsgarantie und der Verhältnismäßigkeit anerkannt, sondern die Pflichten zu Notdienst- und Erhaltungsarbeiten unmittelbar grundrechtlich abgeleitet werden ${ }^{30}$. Be-

${ }^{28}$ Auch nicht zwischen dem Anspruch auf Schutz der Grundfreiheiten und der Wehrpflicht (mißverständlich daher BVerfGE 38, 154, 167 und $48,127,161$, soweit nicht lediglich eine Legitimation der Wehrpflicht dargestellt werden soll).

${ }^{29}$ Vgl. Isensee, a.a.O. (Fn. 2), S. 612; Badura, a.a.O. (Fn. 2), S. 868.

${ }^{30}$ Vgl. Scholz, in: Maunz-Dürig-Herzog-Scholz, Art. 9 Rdnr. 318, 372. S. auch Badura, AöR 104 (1979), 246, 263 (Herstellung von Notzeitungen während des Pressestreiks). 
urteilt das BVerfG Grundrechtskonflikte mit zivilrechtlichem Ausgangsstreit, so führt nicht eigentlich Untätigkeit des Gesetzgebers, sondern das Angewiesensein des Verfassungsgerichts auf den alleinigen Maßstab der Verfassung dazu, daß die „Ausstrahlungswirkung“ der Grundrechte fast zwangsläufig Pflichtenbelastungen in sich aufnimmt. So hat das BVerf ${ }^{31}$ den Pressepflichten - zu Sorgfalt, Wahrheit, Vollständigkeit, Sachlichkeit - schon früh eine unmittelbar verfassungsrechtliche Ableitung aus der Pressefreiheit gegeben. Man mag diese Pflichtenlast als wohl unvermeidlichen Preis der Grundrechtsexpansion und der dazugehörigen Kompetenzen des BVerfG ansehen ${ }^{32} . \mathrm{Zu}$ warnen wäre nur davor, solche für das besondere Problem der Grundrechtskollision in der Drittwirkungsebene zu Hilfe genommenen Pflichten als einen „Pflichtenstatus“ zu deuten und die grundrechtliche Freiheit selbst als Pflichtenstatus mißzuverstehen. Im Presserecht hat man sich seit langem und mit Erfolg gegen das Mißverständnis verwahrt, die „öffentliche Aufgabe“ der Presse als eine Inpflichtnahme oder eine Art von öffentlichem Amt zu deuten ${ }^{33}$, 34 .

\section{d) Negative Grundrechte}

Die rechtsstaatliche Nicht-Identifikation von Freiheitsrechten und Pflichten, die Nicht-Einheit beider findet ihre folgerichtige Fortsetzung in der Anerkennung sog. negativer Grundrechte $^{35}$. Die Grundrechte gewähren auch Freiheit von Betätigungszwängen - etwa die Freiheiten, keinem Glauben

${ }^{31} B$ VerfGE 12, 113, 130 (Spiegel-Schmid).

32 Jedenfalls bleibt sie hinter der „Pflichtakzentuierung (,,Verpflichtigung") der Grundrechte zurück, die Denninger, JZ 1975, 545, 547 als Konsequenz der institutionellen und der Wertordnungsdeutung der Grundrechte erkennt. Vgl. dazu auch Kröger, Grundrechtstheorie als Verfassungsproblem, 1978, S. 26.

${ }^{33}$ Grundlegend: Mallmann, JZ 1966, 625. Jüngst: Löffler, NJW 1982, 91 (Tagungsbericht).

${ }^{34}$ Dasselbe gilt auch für die „im öffentlichen Interesse liegende Aufgabe“ (BVerfGE 44, 322, 340) der Koalitionen. Scholz, a.a.O. (Fn. 20), S. 216, warnt davor, die "öffentliche Aufgabe“ zum Einfallstor unkontrollierter Freiheitseingriffe werden zu lassen.

${ }^{35}$ Vgl. Bleckmann, Allg. Grundrechtslehren, 1979, S. 219; Merten, VerwArch 73 (1982), S. 103 (106 f.) m.w. N.; Maunz-Dürig-HerzogScholz, a.a.O. (Fn. 26), Art. 4 Rdnr. 54, Art. 5 Rdnr. 40, Art. 8 Rdnr. 34: sämtliche Grundrechte mit Ausnahme von Art. 6 II GG; Scholz, a.a.O. (Fn. 20), S. 42; Isensee, a.a.O. (Fn. 2), S. 615. 
anzuhängen ${ }^{36}$, Meinungen zu verschweige ${ }^{37}$, sich Vereinigungen $^{38}$ und Koalitionen ${ }^{39}$ nicht anzuschließen. Wenn das $\mathrm{BVerfG}^{40}$ kürzlich drastisch formuliert hat, Art. 12 GG gewährleiste auch „die Freiheit, überhaupt keinen Beruf zu ergreifen und auszuüben", so muß diese sicherlich zutreffende Feststellung nicht eigens vor dem Mißverständnis in Schutz genommen werden, der untätige Schmarotzer entspreche dem Menschenbild des Grundgesetzes oder einem sozialpolitischen Leitbild. Die Bejahung des negativen Grundrechts steht auch nicht in Widerspruch zur bekannten Menschenbildformel ${ }^{41}$, die zur Verdeutlichung von Grenzen der Grundrechte und als Legitimation zulässiger Grundrechtsbeschränkungen verwendet wird, aber kein Pflichtenfüllhorn darstellt.

\section{e) Sozialstaatlicher Grundpflichtstatus?}

Man wird sich natürlich die Frage vorlegen, ob unter dem Vorzeichen des Sozialstaats die beliebige Ausübung jeglicher Handlungsfreiheit von der Schlechtausübung bis hin zur Nichtausübung noch Verfassungsinhalt sein kann oder aber nur eine von vornherein sozialverpflichtete Freiheit. Enden nicht Lern-, Ausbildungs-, Fortbildungs- und Arbeitsunlust, gesundheitsschädliche Lebensweise und falsche Einstellung zu Krankheiten etc. letztlich in unnötigen Belastungen der Solidargemeinschaften des Staates und der Sozialversicherungsträger ${ }^{42}$, und erscheinen nicht deshalb diese unnötigen Belastungen ausschließende soziale Grundpflichten jedes einzelnen geradezu unvermeidlich? Wenn man die soziale Grundpflicht zur Eigenverantwortung und zur Rücksichtnahme auf die Solidargemeinschaften erwägt, so wäre es zu kurz gegriffen, nur zu denken etwa an eine verfassungsrechtliche Überhöhung der vielfältigen prozeduralen und materiellen Mitwirkungspflichten des Empfängers von Sozialleistungen nach

\footnotetext{
${ }^{36}$ BVerfGE 52, 223 (246 f.) m. w. N.

${ }^{37}$ Maunz-Dürig-Herzog-Scholz, Art. 5 Rdnr. 40; Schnur, VVDStRL 22 (1964), S. 111.

${ }^{38}$ BVerfGE 10, 89 (102); 38, 281 (298). Vgl. Maunz-Dürig-HerzogScholz, Art. 9 Rdnr. 42,88 ff. m. w. N.

${ }^{39}$ BVerfGE 50, 290 (367); Scholz, a.a.O. (Fn. 20), S. 42, 267 ff.; ders., in: Maunz-Dürig-Herzog-Scholz, Art. 9 Rdnr. 169, 226 ff. m. w.N.

40 BVerfGE 58, 358, 364.

${ }^{41}$ BVerfGE 2, 112; 4, 7, 15 f.; 6, 32, 40 f.; 8, 274, 328 f.; $12,45,51 ; 27,344$, 350 f.; $30,1,20 ; 30,173,193 ; 32,373,379 ; 33,1,10$ f.; 33, 303, 334; 35, 202, $225 ; 39,334,367 ; 45,187,227 ; 50,290,353 \mathrm{f}$.

${ }^{42}$ Starck, ZRP 1981, 97.
} 
dem SGB ( $\$ 60$ ff. SGB-ĀT ${ }^{43}$ ), der dem Arbeitslosen zumutbaren Beschäftigung ( $\$ 103 \mathrm{AFG}^{44}$ ) oder der dem Sozialhilfeempfänger zumutbaren Arbeit ( $\$ 25 \mathrm{BSHG}^{45}$ ). Man käme gewissermaßen zu spät, wenn man erst den sozial Hilfebedürftigen in die Grundpflicht nähme, müßte vielmehr konsequent die gesamte Lebensführung aller so in die Pflicht nehmen, daß vermeidbare Inanspruchnahmen der Solidargemeinschaft wirklich vermieden würden. Es gäbe dann nicht nur Schulpflicht, sondern auch Lernpflicht, die Pflicht, sich zu einem Beruf auszubilden, zu arbeiten, die Pflicht zur Erhaltung der eigenen Gesundheit. Im Ergebnis wäre damit Eigenverantwortung in einen komplexen und zu ständiger Ausdehnung tendierenden sozialen Pflichtenstatus verwandelt. Diese „Verpflichtigung" wäre nicht nur freiheitsgefährdend, sie würde auch zu einer Verkrampfung der Sozialpolitik führen. Den verfassungsrechtlichen Zusammenhang der Erhaltung und Stärkung der Eigenverantwortung ${ }^{\mathbf{4 6}}$ wird man daher in anderer Weise als in der Gestalt von Grundpflichten sehen müssen. Das Sozialstaatsprinzip egalisiert Freiheit nicht mit Grundpflichten ${ }^{47}$, sondern stellt dem Gesetzgeber die Aufgabe, Solidarverantwortung, Eigenverantwortung und solidarische Rücksichtnahme auf die Solidargemeinschaften einander zuzuordnen, wie dies u. a. durch die erwähnten sozialrechtlichen Pflichten geschieht.

\section{Sozialistische Verfassungen}

Als Gegentypus zu der beschriebenen Rangfolge von Grundrechten und Pflichten ist die Stellung der Grundpflichten zu

43 Vgl. N. Henke, VSSR 4 (1976), 41; Rüfner, VSSR 5 (1977), 347.

44 Vgl. v. Maydell, JbSozR 2 (1980), 217, 220.

45 Zur Verfassungsmäßigkeit s. BVerwGE 12, 129.

46 Vgl. Lerche, SchR d.dt. SGVbd. 9 (1972), 94, 96; Beiträge von W. Schmitt, Braun, Starck (= ZRP 1981, 97), Ecker, Krause, in: Braun (Mitverf.), Selbstverantwortung in der Solidargemeinschaft, 1981; Zacher, VSSR 4 (1976), 1, 23 (zur Notwendigkeit pluralistischer Sozialpolitik).

${ }^{47}$ Vgl. Zacher, Sozialstaat und Verfassung im ersten Jahrzehnt der BRep. Deutschland, 1980, S. 694: „eine echte Grundpflicht ergibt die Sozialstaatsdeklaration unter keiner Auslegung"; Isensee, a.a.O. (Fn. 2), S. 613; Badura, a.a.O. (Fn. 2), S. 870. 
den verfassungsmäßigen Rechten ${ }^{48}$ der Bürger in den sozialistischen Staaten anzusehen. Die sozialistischen Verfassungen bedienen sich des Instruments der Grundpflicht mit steigender Frequen $z^{49}$, voran die Verfassung der UdSSR von 1977, deren Pflichtenkatalog nicht nur die klassischen Pflichten zur Arbeit, zur Landesverteidigung, zur Achtung des sozialistischen Eigentums sowie die in allen sozialistischen Verfassungen anzutreffende Grundpflicht zur Einhaltung der Verfassung und der Gesetze enthält, sondern darüber hinaus eine Reihe neuer Verfassungspflichten, wie z. B. „unversöhnlich gegenüber gesellschaftsfeindlichen Handlungen zu sein und zum Schutz der öffentlichen Ordnung in jeder Weise beizutragen" (Art.65), die Pflicht der Bürger (nicht nur der Eltern), die Kinder ,auf eine gesellschaftlich nützliche Arbeit vorzubereiten und sie zu würdigen Mitgliedern der sozialistischen Gesellschaft zu erziehen" (Art. 66), sowie die Pflichten zum Naturund Denkmalschutz (Art. 68, 69). Der für das Verfassungsrecht der sozialistischen Verfassungen geltende Grundsatz der Einheit von Rechten und Pflichten ${ }^{50}$ besagt zum einen, daß dem Bürger aus den Rechten der Verfassung die Verpflichtung erwächst, „,von diesen Rechten aktiv Gebrauch zu machen, um zur Stärkung der sozialistischen Staatsmacht, zur Mehrung des gesellschaftlichen Reichtums, zur Höherentwicklung der Gesellschaft beizutragen", wie es der offizielle Kommentar zur DDR-Verfassung ausdrückt ${ }^{51}$. Der Grundsatz der Einheit von Rechten und Pflichten erhält also zunächst seine Tragweite schon aus dem Pflichtcharakter der verfassungsmäßigen Rechte selbst. Ob damit schlechthin Identität von Rechten und Pflichten gegeben sei, ist eine Frage, die in der Theorie

${ }^{48}$ Zur Grundrechtskonzeption des sozialistischen Verfassungsrechtes Akademie für Staats- und Rechtswissenschaft der DDR (Hsg.), Staatsrecht der DDR, 1978; Brunner, Politische Soziologie der UdSSR, Teile I und II, 1977; ders., Karl Marx und die Grundrechte in der DDR (bisher unveröff. Manuskript); Mampel, Die sozialistische Verfassung der DDR, 2.A. 1982, S. 536 ff.

${ }^{49} \mathrm{Vgl}$. Brunner, Neuere Entwicklungen in der sowjetischen Konzeption der Menschenrechte, in: Brunner (Hsg.), Grundrechte und Rechtssicherheit im sowjetischen Machtbereich. Ausgew. Beitr. z. 2. Weltkongr. f. Sowjet- und Osteuropastudien, 1982, S. 9 ff.: „massive Erweiterung des Pflichtenkataloges".

${ }^{50}$ Vgl. „Staatsrecht der DDR“, a.a.O. (Fn. 48), S. 190; Brunner, in: Zieger/Brunner/Mampel/Ermacora, Die Ausübung staatlicher Gewalt in Ost und West nach Inkrafttreten der UN-Konvention über zivile und politische Rechte, 1978, S. 37 (48 ff.); ders., Osteuropa-Recht, 1978, 70 (77); Mampel, a.a.O. (Fn. 48), S. $545 \mathrm{f}$.

${ }^{51}$ A.a.O. (Fn. 48), Bd. 2 Art. 19 Erl. 3, S. 13. 
Anlaß zu Erörterungen gegeben hat ${ }^{52}$, die hier indessen vernachlässigt werden kann. Da die Grundrechte nur nach Maßgabe der politischen, ökonomischen, ideologischen und gesetzlichen Garantien gewährleistet sind, nehmen sie die in diesen Gewährleistungen mitenthaltenen Pflichtenordnungen ohne weiteres in sich auf.

Die Einheit von Rechten und Pflichten im sozialistischen Verfassungsrecht bezieht sich weiterhin auf die in der Verfassung ausdrücklich benannten und Grundrechten korrespondierenden Grundpflichten. Der Klassiker aller sozialistischen Grundpflichten ist die Pflicht zur Arbeit. Die erste Sowjetverfassung der Russischen Sozialistischen Föderativen Sowjetrepublik vom 10. Juli $1918^{53}$ verkündete in ihren Grundrechtsartikeln (Art. 18): „Die Russische Sozialistische Föderative Sowjetrepublik erklärt die Arbeit zur Pflicht aller Bürger der Republik und verkündet die Losung: ,Wer nicht arbeitet, soll auch nicht essen"“. In den Beratungen der Weimarer Verfassungsgebenden Nationalversammlung findet man den deutlichen Nachhall dieser ersten Sowjetverfassung ${ }^{54}$ und besonders ihrer Arbeitspflicht. Die Konsequenzen einer Arbeitspflicht, nämlich Streikverbot, Ausschluß der Freiheit der Berufswahl, Verbot des eigenmächtigen Wechsels der Arbeitsstelle und Bestrafung von Bummelanten, äußerstenfalls auch Zwangsarbeit ${ }^{55}$ sieht man damals in den deutschen Verfassungsberatungen wohl nicht mit vollerDeutlichkeit. Friedrich

52 Vgl. T. Schönrath, StuR 1972, 1715, 1720: Einheit von Rechten und Pflichten nicht als ihr Zusammenfallen, sondern Zusammenwirken; anders noch Klenner, Studien über Grundrechte, 1964, S. 97 f.: Identität von Grundrechten und Grundpflichten. Nach Poppe (StuR 1968, 532,540 ) soll die „wohlüberlegte, sparsame Regelung ausdrücklicher Rechtspflichten“ zeigen, „daß der Grundrechtsteil der mitunter geäuBerten Ansicht von der durchgängigen Identität von Rechten und Pflichten, die bedeutende sozialistische Errungenschaften völlig überflüssig mit dem Attribut staatlicher Erzwingbarkeit behaften würde, keine tragfähige Grundlage bietet."

${ }^{53} \mathrm{Dt}$. Institut für Rechtswissenschaft, Die Verfassungs-Gesetzgebung des Sowjetstaates, Berlin (Ost), o. J.; Meder, Das Sowjetrecht, 1971 , S. $49 \mathrm{ff}$.

${ }^{54}$ Sie war nach Fr. Naumann (Einführungsrede zur Beratung der Grundrechte) die ,direkte Konkurrenz der Verfassung, die wir herstellen“. S. auch Katzenstein, a.a.O. (Fn. 12), S. 391.

${ }_{55}$ Vgl. zur Verfassung der UdSSR von 1936 Maurach, Hdb. d. Sowjetverfassung, 1955, S. 80; Brunner, Politische Soziologie der UdSSR, Teil I, 1977, S. 108 (Disziplinarrecht zur Durchsetzung der Arbeitsverpflichtungen, bis 1956 in der UdSSR Strafbarkeit des Verlassens des Arbeitsplatzes). 
Naumann verleibt den Satz ,Wer nicht arbeiten will, der soll auch nicht essen" - bei dem es sich sowohl um ein Bibelzitat $(2$. Thessalonicher 3,10$)$ als auch um eines aus der Sowjetverfassung handelte - seinen „,volksverständlichen Grundrechten" ein. Im Verfassungstext kehrt die Arbeitspflicht in Art. 163 Abs. 1 wieder, freilich bar aller rechtlichen Verbindlichkeit oder gar Rigorosität abgesichert durch den doppeiten Vorbehalt, daß nur „unbeschadet seiner persönlichen Freiheit" jeder Deutsche die „sittliche" Pflicht habe, seine geistigen und körperlichen Kräfte so zu betätigen, wie es das Wohl der Gesamtheit erfordert ${ }^{56}$.

In der Verfassung der DDR von 1968/1974 haben die ausdrücklich benannten Grundpflichten eine Aufwertung erfahren. Sie kommt im Text der Verfassung in der Formel „Grundrechte und Grundpflichten der Bürger" und weiter dadurch zum Ausdruck, daß in der offiziellen Erläuterung des Grundsatzes der Einheit von Grundrechten und Grundpflichten auf die „sehr sparsame, aber ausdrückliche Regelung verfassungsmäßiger Grundpflichten “"57 verwiesen wird. Neben der Verteidigungspflicht (Art. 3 I S. 2 DDR-V), der Arbeitspflicht (Art. 24 II DDR-V), der Pflicht der Jugendlichen, einen Beruf zu lernen (Art. 25 IV DDR-V), gibt es die Pflicht zum Schutz und zur Mehrung des Volkseigentums (Art. 10 II DDR-V).

In der Verfassung der UdSSR von $1977^{58}$ wird schließlich die Einheit von Rechten und Pflichten als allgemeine Abhängigkeit jeglicher Rechtsgewährung von der Erfüllung der Pflichten eines Sowjetbürgers proklamiert (Art. 59) ${ }^{59}$. Die Sowjetverfassung läßt es nicht an der wünschenswerten Deutlichkeit ihrer Absichten fehlen, wenn sie durch eine ausdrückliche Bestimmung den Sowjetbürgern klarmacht, daß sie nicht nur die Verfassung und die Gesetze zu halten haben, sondern auch „die Regeln des sozialistischen Gemeinschaftslebens achten und sich des hohen Namens Bürger der UdSSR würdig erweisen müssen“, und daß dies die Voraussetzung für die „Verwirklichung der Rechte und Freiheiten" ist (Art. 59).

${ }^{56}$ Vgl. E. R. Huber, Dt. Verfassungsgeschichte, Bd. 6, 1981, S. $117 \mathrm{f}$.

57 „Staatsrecht der DDR“, a.a.O. (Fn. 48), S. 190.

58 Text und Sachbeiträge s. Osteuropa-Recht 1978, H. 1-2.

${ }^{59}$ Vgl. Brunner, a.a.O. (Fn. 49). Zur Bedeutung der Pflichten in der neuen Sowjetverfassung für die Unterdrückung der Bürgerrechtsbewegung s. Luchterhandt, UN-Menschenrechtskonventionen, owjetrecht - Sowjetwirklichkeit, 1980, S. 310 f. (311: Pflichten als Ausdruck der durch das ZK proklamierten „grenzenlosen Ergebenheit“ gegenüber der Partei und dem sozialistischen Vaterland). 


\section{Politische staatsbürgerliche Grundpflichten}

In den Verfassungen der westlichen Demokratien stellen Grundpflichten Elemente verfassungsrechtlicher öffentlicher Ordnung dar, die nicht zu einer Verpflichtigung der freiheitlichen Ordnung führen. Sieht man einmal ab von der Besonderheit der verfassungsrechtlichen Verankerung und Bestätigung des kulturstaatlichen Besitzstandes der allgemeinen Schulpflicht, den zahlreiche ausländische Verfassungen wie diejenigen der deutschen Bundesländer kennen, so sind die zwei Bereiche der politischen Grundpflichten und der Sozialpflichten zu unterscheiden.

Die Abhängigkeit der Verwirklichung der Demokratie von ständigen aktiven Beiträgen der Bürger, wie - neben vielem anderen - ihrem Engagement in politischen Parteien und öffentlichen Ämtern nimmt das GG mit der in dieser Frage angebrachten Selbstverständlichkeit nicht zum Anlaß, Verfassungspflichten zur Mitwirkung am demokratischen Prozeß einzuführen, auch nicht in der allenfalls denkbaren Form der Inkorporation von staatsethischen Bürgerpflichten in die Verfassung ${ }^{59 a}$. Mit staatsethischer Indifferenz der Verfassung sollte dies nicht verwechselt werden.

\section{Verfassungstreue}

In der Entstehung des GG war die Einführung einer Verfassungstreuepflicht des Bürgers der eigentliche Gegenstand der Debatte um die Grundpflichten ${ }^{60}$. Diese hatte sich von ihrem Ausgangspunkt, den Pflichten in der sozialen Ordnung, abgekehrt und fand im Parlamentarischen Rat einen neuen Bezugspunkt in dem Postulat des Schutzes der Verfassung. Die Verpflichtung des Bürgers zur Treue gegenüber der Verfassung ist die auffallende Neuerung in den sonst noch nach Weimarer Muster entworfenen Katalogen von Grundrechten und Grundpflichten der Verfassungen von Bayern ${ }^{61}$, Bremen (Art. 9), Hessen und Rheinland-Pfalz; in Hessen sogar zur Pflicht des Bürgers zum sowohl vorbeugenden als auch repressiven Widerstand gegen Verfassungsbrüche gesteigert ${ }^{62}$. Das GG hat in

59a Anders: Art. 26 Abs. 3 bad.-w.V (Wahlrecht ist Bürgerpflicht).

60 S. o. Fn. 19.

${ }^{61}$ Art. 117 bayV. Vgl. dazu Nawiasky/Leusser/Schweiger/Zacher, Die Verf. d. Freistaates Bay., Komm., Losebl. (1964 ff.) Art. 117; Zacher, JöR Bd. 15 (1966), S. 390.

${ }^{62}$ Vgl. Zinn/Stein, Verf. d. Landes Hessen, Komm. (Losebl.), Bd. 2, Art. 146, 147. 
Abweichung davon und vom Herrenchiemsee-Entwurf (Art. 19) eine allgemeine Treueklausel nicht aufgenommen ${ }^{60}$, sondern verwirklicht ein anderes Konzept des Schutzes der Verfassung.

Verfassungstreue der Bürger wird als notwendig für den Bestand der Verfassungsordnung vorausgesetzt und erwarte $^{63}$, aber nicht als Grund-Rechtspflicht verordnet ${ }^{64}$. Der rechtsstaatliche Verfassungsschutz baut nicht auf einer Verfassungstreuepflicht der Bürger auf, sondern ist als Verfassungs-Gefahren-Abwehrrecht konzipiert. Nicht Inpflichtnahme des Bürgers für die Verfassung, sondern Freiheit als Prinzip der Gewährleistung der Verfassung und der Freiheit „verhältnismäßig“ zugeordnete Verfahren zum Schutz der Verfassung, die auf der Ebene des Verfassungsrechtes selbst (Art. 9 Abs. 2, 18, 21 Abs. 2 GG), des Strafrechtes oder Verwaltungsrechtes angesiedelt sein können. Verfassungsschutz ist rechtsstaatlich begrenzte Freiheitsbegrenzung, nicht Heranziehung des Bürgers für den Schutz der Verfassung. Genau besehen, richtete sich auch die Diskussion im Parlamentarischen Rat über die allgemeine Treueklausel nur auf den Schutz der Verfassung als Freiheitsbegrenzung, und es muß daher als folgerichtig angesehen werden, daß dieses Ziel nicht durch eine allgemeine Treueklausel, sondern durch differenzierte Verfassungs-Gefährdungs-Tatbestände und Verfahren verwirklicht wird $^{65,66}$.

${ }^{63}$ S. o. Fn. 6.

${ }^{64}$ Ebenso: Denninger, VVDStRL 37 (1979), 8 (50) LS 7; H. H. Klein, VVDStRL 37 [1979, 53 (80 f.)]; Roellecke, DÖV 1978, 457 (459, 461); Stober, a.a.O. (Fn. 2), S. 30; Benda, a.a.O. (Fn. 2). In der Sache auch $B$ VerfGE 39, 334 (373).

${ }^{65}$ Die Treueklauseln der Landesverfassungen weisen zwar in die Richtung einer darüberhinausgehenden Verfassungstreuepflicht, sind aber zu ihrer Effektuierung auf das Staatsschutzstrafrecht angelegt und angewiesen (vgl. Nawiasky/Leusser/Schweiger/Zacher, a.a.O., Art. 117 Rdnr. 6: Strafgesetzgebung als Erfüllung des Pflichtenprogramms des Art. 117 bayV), wie sich für Art. 146 hessV (vgl. dazu Zinn/ Stein, a.a.O. [Fn. 62]; Denninger, a.a.O. [Fn. 64] S. 22; Schmitt Glaeser, Mißbrauch und Verwirkung von Grundrechten im politischen Meinungskampf, 1968, S. 282) aus $\$ 31 \mathrm{ff}$. HessStGHG v. 12. 12. 1947, GVBl. 1948, S. 3 ergibt.

${ }^{66}$ Auch „Mißbrauch“ der Grundrechte (vgl. dazu H.-U. Gallwas, Der Mißbrauch von Grundrechten, 1967; Schmitt Glaeser, a.a.O., Fn. 65), ist ein Tatbestand, der, soweit Mißbrauchsgrenzen und Mißbrauchsverbote der Grundrechte bestehen, Grundrechtsbegrenzungen markiert. Die Annahme eines allgemeinen, die Grundrechte aus sich heraus begrenzenden Verfassungsvorbehaltes der Verfassungstreue ( $R$. Ar- 


\section{Wehrpflicht}

Die allgemeine Wehrpflicht ist im GG, anders als in den früheren deutschen und vielen ausländischen Verfassungen, nicht in die kraftvolle Form einer staatsbürgerlichen Grundpflicht, sondern in einen grundrechtlichen Gesetzesvorbehalt gekleidet und dort sinnwidrig in einem Atemzug mit der dem Gesetzgeber eröffneten Möglichkeit genannt, Wehrpflichtige auch zu Dienstleistungen im Bundesgrenzschutz und in Zivilschutzverbänden heranzuziehen (Art. 12 a I). Dennoch ist die allgemeine Wehrpflicht eine verfassungsrechtliche Grundpflicht ${ }^{67}$ der männlichen deutschen Bürger. Sie ist es auf Grund der verfassungsrechtlichen Grundentscheidung für die militärische Verteidigung (Art. 12 a I, 73 Nr. 1, 87 a I S. 1 GG). Diese Entscheidung schließt die Einführung der Wehrpflicht ein. Für die Wehrpflicht hat sich die Verfassung allerdings nicht unbedingt entschieden, vielmehr unter dem militärpolitisch bislang theoretisch gebliebenen Vorbehalt der Alternative, das Wehrpflichtheer durch ein Freiwilligenheer zu ersetzen $^{68}$. Solange dieser Vorbehalt nicht ausgeübt wird, bedeutet die bestehende Wehrpflicht eine verfassungsrechtliche Grundpflicht. Ihre Verfassungsverbindlichkeit erfaßt nur die Deutschen $^{69}$. Sie ist staatsbürgerliche Grundpflicht. Die Wehr-

nold, Verfassungstreue und Grundgesetz, BayVBl. 1978, 520; A. Stein$k a m m$, Nichtübernahme von Verfassungsgegnern in den öffentlichen Dienst, in: Gössel/Hermann/Steinkamm/Doehring, Der freiheitliche Rechtsstaat und seine Grenzen - Mittel und Grenzen der Abwehr, 1979, S. 77 [90]) geht dagegen zu weit. Auch Verfassungsschutz ist im Rechtsstaat gesetzliche Begrenzung der Freiheit. Auf die limitierende Wirkung, die Verfassungsgebundenheit usw. des Gesetzes kann nicht verzichtet werden. Hierin liegen allgemein die Bedenken gegen „Mißbrauchs"-Grenzen.

${ }^{67}$ Ebenso Stober, a.a.O. (Fn. 2), S. 43; Benda, a.a.O. (Fn. 2), (,Grundpflicht"). Den verfassungsrechtlichen Charakter der Wehrpflicht erkennen ebenfalls an Martens, Grundgesetz und Wehrverfassung, 1961, S. 123 f.; K. Ipsen/J. Ipsen, in: Bonner Komm. GG (Losebl.), Art. 12 a (1976) Rdnr. 28, BVerfGE 28, 243, 261 (Wehrpflicht als verfassungsrechtliche Pflicht), BVerfGE 48, 127, 163 (Wehrpflicht als verfassungsrechtlich verankerte Pflicht, sich an der bewaffneten Landesverteidigung und damit insoweit an der Sicherung der staatlichen Existenz zu beteiligen. Dagegen (nicht überzeugend) Merten, BayVBl. 1978, 554, 558; Gusy, JZ 1982, 657, 660 .

${ }^{68}$ BVerfGE 48, 127, 160.

${ }^{69}$ A. A. Stober, a.a.O. (Fn. 2), S. 44. 
pflicht für Ausländer ist möglich, aber nicht verfassungsgefor$\operatorname{dert}^{70}$.

Allgemeine Wehrpflicht und das Grundrecht der Kriegsdienstverweigerung aus Gewissensgründen stehen sich auf der gleichen rechtlichen Ebene des Verfassungsrechts gegenüber, sind aber über ihren offenbaren inhaltlichen Gegensatz hinaus wesensverschiedene Bestandteile der Verfassung. Das GG richtet mit der allgemeinen Wehrpflicht ein Stück allgemeiner öffentlicher Ordnung ein, läßt aber dessen Durchsetzung enden an der besonderen Situation des in Gewissensnot befindlichen Individuums ${ }^{71}$. Dies geschieht in der offenbaren Erwartung, daß die Grundentscheidung für die Landesverteidigung in ihrer Verwirklichung durch das Recht der Kriegsdienstverweigerung nicht beeinträchtigt wird. Eine solche Verfassungserwartung kann durch tatsächliche Entwicklungen ins Wanken geraten oder gar widerlegt werden. Dazu könnte in der nahen Zukunft das Ansteigen der Zahlen der Kriegsdienstverweigerer und der Rückgang der Geburten oder schon jeder dieser Faktoren beitragen. Herstellung der Vereinbarkeit zwischen dem Verfassungsgebot der Landesverteidigung und dem Grundrecht der Kriegsdienstverweigerung aus Gewissensgründen ist die Aufgabe des Gesetzgebers, der dafür in Art. 4 III S. 2, 12 a I, II GG einen klaren Auftrag der Verfassung hat. Dabei geht es nicht um eine in Art. 4 III GG nicht vorgesehene Einschränkung des Grundrechtes. Der Gesetzgeber verfügt aber verfassungsrechtlich über einen ausreichend großen Spielraum, um die Situation eines innerhalb der Verfassung entstehenden und dort ungelösten Konfliktes ${ }^{72}$ zwischen Landesverteidigung und allgemeiner Wehrpflicht einerseits und dem Grundrecht aus Art. 4 III GG abzuwenden. Der Schutz des Grundrechtes aus Art. 4 III GG ist bislang, wenn wir von dem umstrittenen Verfahren der Anerkennung der Gewissensentscheidung absehen, in dreifacher Hinsicht extensiv gehandhabt worden: 1. Das Grundrecht ist auf den Kriegsdienst mit der Waffe begrenzt, bleibt also

70 Zur völkerrechtlichen Seite und zur Rechtsvergleichung vgl. Doehring, in: Strupp-Schlochauer, Wb. d. VöR, 3. Bd., 1962, S. 812; O'Connell, Intern. Law, 2nd ed., 1970, vol. 2, p. 703. Eine RVO nach $\S 2$, die Wehrpflicht für Ausländer anordnet, besteht bisher nicht. In Westeuropa unterliegen nur in Italien die dort ansässigen Ausländer der Wehrpflicht (s. St.Sekr. Dr. Penner, BT-Drucks. 9/1049).

${ }^{71} \mathrm{Vgl}$. BVerfGE 28, 243, 260; 48, 127, 163 (,Das Grundrecht setzt selbst der verfassungsrechtlich verankerten Pflicht... eine unüberwindliche Schranke entgegen").

${ }^{72} \mathrm{Vgl}$. dazu auch BVerfGE 28, 243, $260 \mathrm{ff}$. 
durch einen waffenlosen Dienst in den Streitkräften unberührt $^{73}$. Das WPflG geht darüber hinaus. Waffenloser Dienst in der Bundeswehr ist zwar vorgesehen ( $\$ 25 \mathrm{~S} .2$ ), aber nur auf Antrag. Tatsächlich gibt es solchen waffenlosen Dienst bisher nicht $^{74}$. 2. Daß sich das Grundrecht nicht nur auf den Kriegsdienst, sondern notwendig auch auf die Erlernung des Kriegshandwerkes in Friedenszeiten erstreckt, entspricht vorherrschender Auffassung ${ }^{75}$, ist aber vom BVerfG ${ }^{76}$ mit einem Fragezeichen versehen worden: die Leistung von Wehrdienst in Friedenszeiten falle nicht schlechthin in den Kernbereich des Grundrechts aus Art. 4 Abs. 3 GG. 3. Das Grundrecht erstreckt sich nicht auf den Dienst in Zivilschutzverbänden ${ }^{77}$. Eine durch Art. 12 a I GG ermöglichte Zivilschutzdienstpflicht besteht aber bisher generell nicht ${ }^{78}$. Durchweg gibt es in den genannten Fragen sachlich vertretbare Gründe für den vom Gesetzgeber praktizierten großzügigen Schutz der Kriegsdienstverweigerung aus Gewissensgründen, so daß sich ein Problem ihrer Vereinbarkeit mit dem Verfassungsgebot der Landesverteidigung nicht stellt. Ob dies so bleibt, hängt von der weiteren Entwicklung ab. Gegenwärtig ist vom Gesetzgeber als einzige Form der Heranziehung der Kriegsdienstverweigerer der Ersatzdienst nach Art. 12 a II GG vorgesehen, den das ZivildienstG als Zivildienst ausgestaltet. Seit 1978 werden alle anerkannten Kriegsdienstverweigerer zu diesem Dienst einberufen ${ }^{79} .1981$ waren dies über $31000^{80}$ Zivildienstleistende gegenüber der Zahl von Wehrdienstleistenden, die zwischen 220000 und 230000 liegt. Die Zahl der Zivildienstplätze betrug $198148000^{80}$.

Der Zivildienst ist ein Sozialdienst und unterscheidet sich dadurch vom Wehrdienst. Die Ersatzdienstpflicht (Art. 12 a II

${ }^{73}$ Vgl. Herzog, in: Maunz-Dürig-Herzog-Scholz, a.a.O., Art. 4 Rdnr. $172 \mathrm{f}$.

${ }^{74}$ Hahnenfeld, WPfiG, Komm., Losebl. \$27 Anm. 1.

${ }^{75} \mathrm{Vgl}$. Gusy, JuS 1979, $254 \mathrm{~m}$. umf. Nachw. Demgegenüber legt Doehring, Staatsrecht, 2.A. 1980, S. 305 f., dar, daß die Ausbildung mit der Waffe bei Kriegsdienstverweigerern nicht notwendig sinnlos sein müßte.

${ }^{76}$ E 48, 127, 164.

${ }^{77}$ K. Ipsen/J. Ipsen, a.a.O. (Fn. 67), Art. 12 a Rdnr. 79 ff.

${ }^{78}$ Die Errichtung des Zivilschutzkorps, für das Dienstpflicht vorgesehen ist (ZSKG v. 12. 8. 1965, BGBl. I, 782), ist unbefristet aufgeschoben (Art. 17 Nr. 3 FinanzÄndG v. 21. 12. 1967, BGBl. I, 1259).

${ }^{79}$ Parl. StSekr. Buschfort, BT-Drucks. 9/163.

${ }^{80}$ Bundesamt für den Zivildienst, in: Das Parlament,31. Jg., Nr. 32 v. 8. 8. 1981 . 
S. 1 GG) ist aus der Wehrpflicht abgeleitet, ohne diese für den Kriegsdienstverweigerer vollständig $\mathrm{zu}$ verdrängen. Sie tritt zur Wehrpflicht hinzu, weil deren regulärer Vollzug gehindert ist. Die verfassungsrechtliche Existenzgrundlage des Zivildienstes ist ohne Zweifel das Prinzip der Pflichtengleichheit ${ }^{81}$. Der Zivildienst ermöglicht die durch den Gleichheitssatz gebotene Pflichtengleichheit zwischen Wehrpflichtigen, die Wehrdienst leisten, und Wehrpflichtigen, die den Wehrdienst aus Gewissensgründen verweigern. Dies bedeutet zunächst auch, $\mathrm{da} ß$ der Zivildienst, so gemeinschaftsnützlich die in ihm verrichteten Dienstleistungen sind, nicht um dieser Gemeinschaftsnützlichkeit selbst willen existiert. Wäre es anders, so wäre es schwer zu begreifen und zu rechtfertigen, daß Frauen zu diesem Dienst nicht verpflichtet sind. Denn so gut wie alles, was im Zivildienst verrichtet wird ${ }^{82}$, eignet sich als Tätigkeit auch für Frauen. Daß der Zivildienst von Verfassungs wegen ein Surrogat des Wehrdienstes ist ${ }^{83}$, hindert andererseits aber nicht die notwendige Anerkennung des Gemeinwohl-Eigenwertes dieses Dienstes, der in der Ausgestaltung des Dienstes zu verwirklichen ist.

Das zwischen Wehrdienst und Zivildienst bestehende Band der Pflichtengleich heit hat nicht identische, sondern durchaus verschiedene Modi einer Pflichterfüllung zum Gegenstand. Die Art- und Strukturunterschiede zwischen Wehr- und Zivildienst erschweren ihre Vergleichbarkeit, eröffnen damit aber dem Gesetzgeber einen eher größeren Spielraum innerhalb des Gleichheitsgebotes. Die Dauer des Zivildienstes wird man daher in dem Rahmen, der zwischen dem geltenden Recht $(\$ 24$ ZDG) mit einer Mindestdauer von 16 Monaten und der Höchstdauer des Grundwehrdienstes und der Wehrübungen, insgesamt 24 Monate, gesetzt ist (Art. 12 a II S. 2 GG), als der politischen Gestaltung offen ansehen müssen.

\section{3. Übernahme von Ehrenämtern}

Zum Kanon der politischen Grundpflichten der Deutschen gehört die Pflicht zur Übernahme von ehrenamtlichen Tätig-

${ }^{81}$ Das Gegenteil behauptet Gusy, JuS 1979, 254, 256.

${ }_{82}$ U. a. Pflegehilfe und Betreuungsdienste (46,3\%), Umweltschutz $(0,9 \%)$, Krankentransport und Rettungswesen (12,6\%), Kaufmännische und Verwaltungstätigkeiten (12,6\%). Quelle: Bundesminister für Jugend, Familie und Gesundheit, „Der Zivildienst im Überblick“ (6. 11. 1981).

${ }^{83}$ K. Ipsen/J. Ipsen, a.a.O. (Fn. 67), Art. 12 a Rdnr. 97. 
keiten. Sie war nach Art. 132 WRV Grundpflicht und ist es weiterhin nach einem Teil der Landesverfassungen (Bayern Art. 121, Bremen Art. 9, Hessen Art. 25, Rheinland-Pfalz Art. 21, Saarland Art. 19). Die Pflicht besteht nur, soweit sie durch Gesetz aktualisiert ist ${ }^{84}$. Es wäre der näheren Untersuchung wert, inwieweit diese Grundpflicht für die heutige Staatspraxis nur vertraute Selbstverständlichkeiten wie den ehrenamtlichen Richter oder den Wahlhelfer und Volkszähler abdeckt oder vielmehr darüber hinaus eine wachsende Zahl von ehrenamtlichen Tätigkeiten, insbesondere in der Kommunal-, Sozial-, Wirtschafts-, Wehr- und Schulverwaltung ${ }^{85}$. Hans Peters ${ }^{86}$ hat noch die Ehrenamtspflicht der Reichsverfassung als eine wichtige verfassungsrechtliche Stütze des gesamten Gebiets der sog. politischen und wirtschaftlichen Selbstverwaltung gewürdigt. Auf der Ebene des Bundesverfassungsrechtes ist heute die Ehrenamtspflicht nicht normiert. Aber der verfassungsrechtliche Kontext Weimars und der Landesverfassungen ist für das GG insofern wichtig, als aus ihm einwandfrei erschlossen werden kann, daß zwischen Ehrenamts- und Dienstpflichten unterschieden werden $m u \beta^{87}$, und das im GG an die Stelle der früheren Grundpflicht zu Dienstleistungen für den Staat (Art. 133 WRV) getretene Grundrecht auf Freiheit von Arbeitszwang (Art. 12 II) somit nicht auf die ehrenamtlichen Tätigkeiten für Staat und Selbstverwaltungskörperschaften ausgreift.

${ }^{84} \mathrm{~S}$. auch $\S 82 \mathrm{VwVfG}$.

${ }^{85}$ Sowohl nichtbeamtete ehrenamtliche Tätigkeit als auch Ehrenbeamtenverhältnisse können einer gesetzlichen Übernahmepflicht unterliegen; vgl. Stober, Der Ehrenbeamte in Verfassung und Verwaltung, 1981, S. $20 \mathrm{ff}$., $34 \mathrm{f}$.

${ }^{86}$ Art. 132 und 133 Abs. 1, in: Nipperdey (Hsg.), a.a.O. (Fn. 15), Bd. 2 (1930), S. 290 (299).

${ }^{87}$ Vgl. Nawiasky, a.a.O. (Fn. 61), Art. 121 Rdnr. 3; Scholz, in: MaunzDürig-Herzog-Scholz, Art. 12 Rdnr. 481; Meyer-Borgs, Komm. VwVfG, 2.A. 1982, \& 82 Anm. 3; Stober, a.a.O. (Fn. 85), S. 43; Bay VGH 7, 80. Als Abgrenzungskriterium wird seit Peters, a.a.O. (Fn. 86), S. 300, angesehen, daß organschaftliches Handeln für den Staat zum Ehrenamt gehört im Unterschied zu der zu Gunsten des Gemeinwesens erbrachten Dienstleistung. Da das GG aber, anders als die WRV, einen Zwang zu öffentlichen Dienstleistungen im allgemeinen untersagt, kann eine rein formale Ausgestaltung des Pflichtdienstes als „Amt" nicht ausreichen, um ein verfassungsrechtlich zulässiges Ehrenamt anzunehmen. Vielmehr wird es für die verfassungsrechtliche Zulässigkeit eines Ehrenamtes zusätzlich darauf ankommen, ob legitime Gründe, wie Laienbeteiligung, Selbstverwaltung, vorliegen. Beispielsweise wäre dagegen eine Polizeidienstpflicht als „Ehrenamt" unzulässig. 


\section{Soziale Grundpflichten}

Soziale Grundpflichten ziehen die ökonomisch verwertbaren Güter aller für die Zwecke des Gemeinwesens heran. Sie stellen Pflichtbeiträge dar, die aus der Arbeitskraft und dem Vermögen der Grundrechtsinhaber zu Gunsten der Arbeit des Gemeinwesens zu erbringen sind.

\section{Offentliche Dienstleistungspflichten}

Das GG verzichtet weitgehend darauf, Arbeitskraft und Freizeit der Menschen mit Pflichtbeiträgen zu Gunsten des Staates zu belasten. Es läßt öffentliche Dienstleistungspflichten nur als Ausnahmen vom Grundrecht auf Freiheit von Arbeitszwang (Art. 12 II) zu und begrenzt diese auf herkömmliche Dienstleistungspflichten ${ }^{88}$. Damit sind gewisse lokale Rückzugsgebiete von Dienstleistungspflichten aufrechterhalten, ohne daß ihre tatsächliche Existenz gewährleistet wäre. Hand- und Spanndienste sind durch die kommunale Gebietsreform zum Absterben verurteilt. Feuerwehrdienstpflichten dienen nicht als Instrument zur Rekrutierung des Personalbedarfs der Feuerwehr, sondern zur Auferlegung von Feuerschutzabgaben ${ }^{89}$. Zulässig bleibt auch die schon zu Art. 133 WRV zu den öffentlichen Dienstleistungspflichten gerechnete Nothilfepflicht bei Unglücksfällen. Sie wird durch einige Landesverfassungen ${ }^{90}$ zur Grundpflicht erhoben. Die Notstandsverfassung kennt Ermächtigungen an den Gesetzgeber zur Einführung von Dienstleistungspflichten, erfaßt aber damit wesentlich nur Wehrpflichtige (Art. 12 a III GG), während Frauen erst im Verteidigungsfall für Sanitäts- und Heilwesen und die Lazarettorganisation verpflichtet werden können (Art. 12 a IV GG).

Der weitgehende Verzicht des GG auf öffentliche Dienstleistungspflichten hat seine historische Zielrichtung als AntiArbeitsdienst-Gesetz. Er wirkt aber außerdem in die Gegenwart als ständige Erprobung der Bereitschaft der Bürger, freiwillige und meistens unbezahlte Gemeinschaftsdienste zu übernehmen. Diese Probe scheint bislang erfolgreich zu verlaufen, wenn beispielsweise die Gesamtzahl der in der Freien Wohlfahrtspflege tätigen freiwilligen oder - wie sie dort heißen - „ehrenamtlichen“ Helfer mit rund 1,5 Millionen ermittelt

${ }^{88}$ Näher v. Mangoldt-Klein, a.a.O. (Fn. 1), Art. 12 Anm. VII; Scholz, in Maunz-Dürig-Herzog-Scholz, Art. $12 \mathrm{Rdnr}, 476 \mathrm{ff}$.

${ }^{89}$ BVerfGE 9, 299; 13, 171; BayVGHE 6, 75; 15, 34.

90 Art. 122 bayV, 10 brV, 22 rhpfV, 19 saarlV. 
wurde ${ }^{91}$, es rd. 800000 freiwillige Mitglieder der Feuerwehren gibt, das Technische Hilfswerk $75000^{92}$ und die übrigen Katastrophenschutzorganisationen (Arbeiter-Samariterbund, Johanniter-Unfall-Hilfe, Malteser-Hilfsdienst) zusammen noch einmal 75000 Helfer haben ${ }^{93}, 94$.

Im selben Zuge, in dem die öffentlichen Dienstleistungspflichten fast zum Verschwinden gebracht wurden, wuchsen die mit Berufsausübung und Unternehmenstätigkeit verbundenen öffentlichen Indienstnahmen ständig an. Industrie- und Handelskammern und Steuerzahler-Bund pflegen sie als „unbezahlte Hilfsarbeiten der Wirtschaft für den Staat"،95 in die Öffentlichkeit zu tragen. Ihr Gewicht als Kostenfaktor ist für die Unternehmen beträchtlich. Es geht dabei um zunehmende administrative Pflichten im Personalbereich sowie Meldepflichten für statistische Zwecke. Diese Berufs- und Unternehmenspflichten sind soziale Lasten unternehmerischer Erwerbstätigkeit. In ihnen drückt sich eine andere Seite des Sozialstaatsprinzips aus als in einer Dienstleistungspflicht als Grundpflicht. Es handelt sich um sozialstaatliche Verantwortlichkeit des Unternehmens für den eigenen Bereich der Unternehmenstätigkeit, nicht um einen diesen Bereich überschreitenden Gemeinwohlbeitrag. Die Berufs- und Unternehmenspflichten werden daher folgerichtig als verfassungsrechtlich zulässige Berufsausübungsregelungen (Art. 12 I 2 GG) angese-

91 Nach einer im Auftrage der Bundesarbeitsgemeinschaft der Freien Wohlfahrtspflege durchgeführten Untersuchung des Instituts für Demoskopie Allensbach (1979). - Zum Umfang ehrenamtlicher Tätigkeit insgesamt vgl. Schmidt-Jortzig, Komm. Organisationshoheit, 1979 , S. $50 \mathrm{ff}$.

${ }^{92} 120000$ werden benötigt; Hahnenfeld, a.a.O. (Fn. 74), §13 a Rdnr. 20.

${ }^{93}$ Zahlenangaben nach Beßlich u. a., Allgemeine Grundlagen des Zivilschutzes und der Zivilverteidigung. Organisation in Übersichten. 3.A. 1979 (Zivilschutz und Zivilverteidigung. Handbücherei für die Praxis). Rechtsverhältnisse der Helfer: $\$ \$ 9$ ff. ZSchG, 8 ff. KatSG.

${ }_{94}$ Die Zahl der vom Wehrdienst freizustellenden Helfer im Zivilund Katastrophenschutz ( $\$ \S 8$ II KatSG, 13a WPflG) ist begrenzt (1977: 17000 ; s. Hahnenfeld, a.a.O., $\$ 13$ a Rdnr. 40).

${ }^{95}$ IHK Koblenz, Unbezahlte Hilfsarbeiten der Wirtschaft für den Staat - Steuerbonus als Ausweg? 1976 (Maschinenskript); Klein-Blenkers, Die Belastung von Industrieunternehmen durch administrative Leistungen für den Staat, 1980. 
hen $^{96}$ und von den öffentlichen Dienstleistungspflichten (Art. 12 II GG) unterschieden.

\section{2. „Eigentum verpflichtet“}

a) Unterscheidung der Ebenen des Verfassungsrechts und der gesetzlichen Eigentumsordnung

Mit Art. 14 Abs. 2 hat das GG ein Stück des Weimarer Grundpflichten-Kanons (Art. 153 III WRV) ${ }^{97}$ inkorporiert ${ }^{98}$, und ist die Kontinuität der Idee der Grundpflicht im GG und damit zugleich der Pflichtenaspekt im Sozialstaat am deutlichsten zum Ausdruck gelangt. Für die Frage nach dem Inhalt der Grundpflicht ist zunächst die Prämisse klarzustellen, daß zwischen der Ebene des Verfassungsrechts und der gesetzlichen Eigentumsordnung exakt unterschieden werden muß. Der Vorrang der Verfassung beruht, wie Rainer Wahl ${ }^{99}$ jüngst hervorhebt, auf der „Eigenständigkeit des Verfassungsrechts und seiner Distanz zum Gesetz". Eigentümerrechte und -pflichten der gesetzlichen Eigentumsordnung dürfen nicht mit verfassungsrechtlichen Rechten und Pflichten identifiziert werden. Das BVerfG hat es in den letzten Jahren zweimal mit großer Entschiedenheit abgelehnt, frühere Bestände der Eigentumsordnung für Unternehmens- und Bodeneigentum als verfassungsfest anzuerkennen (im Mitbestimmungs ${ }^{100}$ und im Grundwasserurteil ${ }^{101}$ ). Das Gericht hat den Versuch zurückgewiesen, den Verfassungsbestand des Eigentums von einer vorgegebenen „,Wirtschaftsverfassung ${ }^{\star 100}$ oder im Bodenrecht von der Eigentumsverfassung des BGB $^{101}$ her zu definieren. Dasselbe hat folgerichtig - erst recht - für Eigentümerpflichten zu

${ }^{96}$ Scholz, in: Maunz-Dürig-Herzog-Scholz, Art. 12 Rdnr. 478; BVerfGE 22, 380 (Kuponsteuer); 44, 103 (Kirchensteuer); BVerwGE 41, 261 (Ärztlicher Notfalldienst); von Indienstnahmen im Bereich genuiner Unternehmensverantwortlichkeit unterscheidet sich die Erdölbevorratungspflicht (BVerfGE 30, 292): Erfüllung einer staatlichen Aufgabe durch Naturalleistungspflicht der Unternehmen, Vgl. auch Ossenbühl, VVDStRL 29 (1971), 137, $175 \mathrm{ff}$.

97 Zur Ideengeschichte des Art. 153 III: Kübler, AcP 159 (1960), 236, insbes. $241 \mathrm{ff}$. (lutherische Eigentumsethik).

${ }_{98}$ Zur Entstehungsgeschichte: JbÖffR n. F. Bd. 1, S. 145 ff.; Kimminich, Bonner Komm. GG, Losebl., Art. 14 Anm. I, S. 3 ff. (Zweitbearbeitung 1965).

${ }_{99}$ DSt 20 (1981), 485, 513.

${ }^{100}$ BVerfGE 50,290, $336 \mathrm{ff}$.

101 BVerfGE 58, 300, $334 \mathrm{f}$. 
gelten. Die Pflichten der gesetzlichen Eigentumsordnung sind nicht als solche Verfassungspflichten. Das Eigentum im Sinne der gesetzlichen Eigentumsordnung ist gleichzeitig rechteund pflichtenhaltig. Es ist nur scheinbar etwas Neues, wenn das BVerfG ${ }^{102}$ festhält, daß öffentlich-rechtliche Normen, die den Umfang der Eigentümerbefugnisse beschränken, Eigentumsinhalt darstellen. So hat beispielsweise Eberhard Schmidt-Aßmann ${ }^{103}$ das Bodeneigentum als ein Rechte- und Pflichten-System zutreffend gewürdigt. Die Pflichtenhaltigkeit der Eigentumsordnung kann kein grundsätzlicher rechtlicher Streitpunkt sein, insbesondere kein verfassungsrechtlicher. Sie ist die Realität des öffentlichen Rechts im Gesetzgebungsstaat. Historisierende Rückgriffe zur Begründung pflichtgebundenen Eigentums, wie sie in der Vergangenheit üblich waren, etwa in Gestalt germanistisch-romanistischer Kontroversen, wirken heute eher desorientierend ${ }^{104}$. Während die gesetzliche Eigentumsordnung Rechte und Pflichten des Eigentümers im Boden- und Wirtschaftsrecht verbindet, ist auf der davon zu unterscheidenden Ebene der verfassungsrechtlichen Eigentumsgarantie eine Einheit von Recht und Pflicht ausgeschlossen. Das Verhältnis zwischen Eigentumsgrundrecht und Sozialpflichten kann kein prinzipiell anderes sein als zwischen anderen Grundrechten und Pflichten. Der besondere Schutz, den das Eigentum in der Gestalt des Grundrechtes genießt - beispielsweise durch die komplementäre Rechtsschutzgarantie oder in Verbindung mit der Institutsgarantie, die dem Gesetzgeber in der Ausgestaltung der Eigentumsordnung Schranken setzt ${ }^{105}$ - schützt in spezifischer Weise nur die Rechte des Eigentümers.

\section{b) Verfassungsrechtliche Gehalte des Art. 14 Abs. 2 GG}

Die der Eigentumsgarantie zugeordnete Grundpflicht „Eigentum verpflichtet" unterscheidet sich im Ansatz wesentlich von den übrigen Grundpflichten, den staatsbürgerlichen ebenso wie den öffentlichen Dienstleistungspflichten. Diese sind allgemeine Pflichten, die im Prinzip jedermann treffen sollen, und diese ihre Allgemeinheit stellt sie teils - wie die Wehr-

${ }^{102}$ BVerfGE 52, 1, 27; 58, 300, 330 .

${ }^{103}$ Grundfragen des Städtebaurechts, 1972, S. 95f.

${ }^{104}$ Kritisch zu $v$. Gierkes ,germanischem Eigentumsbegriff": Kroeschell, FS Thieme, 1977, S. 34.

${ }^{105}$ Vgl. BVerfGE 58, 300, 339. Zur Substanzgarantie: BVerfGE 50, 290,$341 ; 52,1,30$. 
pflicht - in den Zusammenhang der Allgemeinheit des demokratischen Prinzips, teils - wie Dienstleistungspflichten - in den Zusammenhang der Allgemeinheit der öffentlichen Ordnung. Der Satz „Eigentum verpflichtet“ dagegen ist Ausdruck der besonderen Bindungen, die dem Eigentum auferlegt sind, aber praktisch doch nicht allgemein jedem Eigentum, sondern dem Eigentum in der Boden- und der Wirtschaftsverfassung. „Eigentum verpflichtet“" ist in der Gestalt einer Grundpflicht ${ }^{106}$ eine Grundsatznorm der Boden- und der Wirtschaftsverfassung. Über Notwendigkeit und juristischen Ertrag einer solchen Grundsatznorm konnte man von Anfang an geteilter Auffassung sein. Schon in den Weimarer Verfassungsberatungen wurde erkannt, daß für Boden- und Wirtschaftsverfassung nicht die Naumannschen Grundpflichten, sondern die gesetzgebende Gewalt der maßgebliche Faktor war ${ }^{107}$. Demgemäß hatte der Sozialdemokrat Katzenstein in der Nationalversammlung die Streichung der Klausel „Eigentum verpflichtet“ beantragt ${ }^{108}$. Der Grundsatzcharakter der Norm „Eigentum verpflichtet" hindert, daß aus ihr als solcher, ohne die Vermittlung durch die gesetzliche Eigentumsordnung, justitiable, konkret einforderbare Eigentümerpflichten abgeleitet werden ${ }^{109}$. Im Zivilrecht hat man eine Zeitlang mit dem Gedanken gespielt, Art. 14 II GG als Generalklausel zu verwerten ${ }^{110}$, arbeitet aber inzwischen wirkungsvoll und systematisch richtig mit den Genralklauseln der unterverfassungsmäßigen Rechtsordnung. Der heute allgemein akzeptierte Wandel in der Beurteilung der Rechtsqualität der Norm „Eigentum verpflichtet“, die anders als in Weimar nicht als lediglich sittliche Pflicht, sondern als Rechtspflicht angesehen wird ${ }^{111}$, hat insofern im Ergebnis nichts geändert. Die relevanten Wandlungen sind zweifacher Art. Zum einen wird in Art. 14 II GG der Sitz eines

${ }^{106}$ Für Grundpflicht: Kimminich, Bonner Komm. GG, Losebl., Art. 14 Rdnr. 8 (Drittbearbeitung 1976); Stober, a.a.O. (Fn. 2), S. 50; Benda, a.a.O. (Fn. 2); a. A. Merten, a.a.O. (Fn. 2), S. 558.

${ }_{107}$ Dies auch für die Deutsche Demokratische Partei Naumanns. Vgl. E. R. Huber, a.a.O. (Fn. 12); ders., VerfGsch. Bd. V, 1978, S. 1199 f.

${ }^{108}$ Vhdlg. a.a.O. (Fn. 12), S. 509.

109 Vgl. Isensee, a.a.O. (Fn. 2), S. 613.

${ }^{110}$ Vgl. Kübler, AcP 159 (1960), 236; Erwin Stein, FS Gebh. Müller, 1970, S. 503, 523 f.; Wolff/Raiser, Sachenrecht, 10.A. 1957, § 52 I 3, S. 179 betr. Verkehrssicherungspflicht; Breuer, Die Bodennutzung im Konflikt zwischen Städtebau und Eigentumsgarantie, 1976, S. $42 \mathrm{~m}$. Fn. 133. - Dagegen schon: Dürig, FS Nawiasky, 1956, S. 157, 172 f.

${ }_{111}$ Vgl. Kimminich, a.a.O. (Fn. 106), Rdnr. 116; Breuer, a.a.O. (Fn. 110), S. 42 m. w. N. Zuerst: Dürig, JZ 1953, 193. 
an den Gesetzgeber gerichteten „Sozialgebots“ zur Gestaltung der Eigentumsordnung gesehen ${ }^{112}$. Zum anderen gibt es in der Theorie - ich beziehe mich auf Kirchhof ${ }^{113}$ - den aussichtsreichen Versuch, dem Art. 14 II GG in Verbindung mit der finanzstaatlichen Steuerkompetenz des Staates eine Grundpflicht zur Steuerzahlung zu entnehmen. Diese These hat die Eigentums-Relevanz der Besteuerung zur Prämisse, wofür ich hier auf „Innsbruck 1980“ verweisen kann ${ }^{114}$.

\section{c) Grundpflicht zur Steuerzahlung}

Die Verankerung einer „Grundpflicht zur Steuerzahlung“ in Art. 14 Abs. 2 GG ist von dieser Prämisse ausgehend folgerichtig, andererseits aber von der ursprünglichen Zielrichtung des Satzes „Eigentum verpflichtet“ beträchtlich entfernt. Durch seine steuerstaatliche Ausdeutung erhält dieser Satz erstmals die Wendung zur allgemeinen Grundpflicht, so wie Art. 123 bayV ${ }^{115}$ sie ausdrückt, daß nämlich ,alle im Verhältnis ihres Einkommens und ihres Vermögens und unter Berücksichtigung ihrer Unterhaltspflicht zu den öfentlichen Lasten heranzuziehen" sind. Die verfassungsrechtsdogmatischen Konsequenzen der Annahme einer Grundpflicht zur Steuerzahlung können hier nur angedeutet werden:

Die ursprünglich angenommene Indifferenz der Besteuerung gegenüber dem Eigentumsgrundrecht, die man treffend auch Immunität des Steuerrechts ${ }^{116}$ genannt hat, wird zwar aufgegeben, aber das Steuerrecht geht nicht ersatzlos in dem Kreise beliebiger anderer Eigentumsbindungen auf. Die steu-

${ }^{112}$ BVerfGE 37, 132, 140; 38, 348, 370; 50, 290, 340; 52, 1, 29; 58, 137, $147 ; 58,300,338$.

${ }^{113}$ Kirchhof, JZ 1982, 305, 307. - Kirchhof sieht das Verhältnis zwischen Art. 14 II 2 und S. 1 GG in einer gesteigerten Sozialpflichtigkeit des Eigentumsgebrauchs. Nach seiner Entstehungsgeschichte wurde S. 2 als Erläuterung der Sozialpflichtigkeit verstanden (vgl. Kübler, a.a.O. [Fn. 97], S. 241).

${ }^{114}$ Kirchhhof, VVDStRL 39 (1981), S. 213; v. Arnim, VVDStRL 39 (1981), S. 286; Friauf, DÖV 1980,480 m. w. N.

115 „Programmatische Grundpflicht": Nawiasky-Leusser-SchweigerZacher, a.a.O. (Fn. 61), Art. 123 Erl. I. Dagegen wurde Art. 134 WRV nicht als Grundpflicht, sondern seinem Wortlaut entsprechend als steuerverfassungsrechtliches Gleichheitsgebot, insbes. als Lastengleichheit und Verbot von Steuerprivilegien angesehen; vgl. Bühler, in: Nipperdey (Hsg.), a.a.O. (Fn. 15), Bd. II, S. 313.

${ }_{116} J$. Hensel, Die Verfassung als Schranke des Steuerrechts, 1973,S. 135. 
erverfassungsrechtlichen Grenzen der Besteuerung sind durch das Gegenüber von Eigentumsgrundrecht und verfassungsrechtlicher Grundpflicht zur Steuerzahlung determiniert. Sie müssen insofern vollkommen eigenständiger Natur sein. Dazu gehört meines Erachtens neben anderem die Unanwendbarkeit des Institutes der Enteignung ${ }^{117}$, die Substanzgarantie, Besteuerung nach der Leistungsfähigkeit, steuerspezifische Anwendung des Gleichheitsgrundsatzes. $\mathrm{Zu}$ all dem ist hier nicht in Einzelheiten zu gehen.

\section{d) ,Steuerstaat" und Lastengleichheit}

Was das Verhältnis der Steuerpflicht zu anderen Sozialpflichten betrifft, so ist zunächst zu konstatieren, daß der Sozialstaat als Steuerstaat ${ }^{118}$ dazu tendiert, die von den Bürgern rechtlich abgeforderten Gemeinwohlbeiträge auf die Zahlung von Steuern zu konzentrieren und zu reduzieren ${ }^{119}$. Das gilt jedenfalls für solche Beiträge, die über das hinaus gefordert werden, was im direkten Umfeld der sozialen Verantwortlichkeit von Unternehmungen, Vermietern, Bodeneigentümern etc. liegt. Der finanzstaatliche Modus der Pflichterfüllung des Bürgers gegenüber seinem Staat ist nicht nur eine Tatsache. Er wird außerdem als rechtsstaatliche Idealform der Sicherung sowohl von Freiheit als auch von proportionaler Gleichheit beschrieben ${ }^{120}$. Er bedeutet aber andererseits auch die äußerste Entleerung der Pflicht von irgendwelchem Ethos. Dem in der Steuerpflicht eingeschlossenen Grundsatz der steuerlichen Lastengleichheit ${ }^{121}$ wird neuestens eine offensive Stoßrichtung gegeben, indem er über den Bereich der Steuerpflichten hinaus herangezogen wird, um nicht-steuerliche Belastungen als gleichheitswidrig zurückzuweisen ${ }^{121}$. „Steuerstaat" also nicht mehr nur als Diagnose der regelmäßigen Pflichtenbeziehung des Menschen zum Staat, sondern als verfassungsrechtliches „Steuerstaatsprinzip“"122, welches die

${ }^{117}$ Vgl. Friauf, DÖV 1980, 480, 487. Zum Begriff der Enteignung jetzt: BVerfGE 52, 1, 27.

${ }^{118}$ Forsthoff, VVDStRL 12 (1954), S. 8, 31 f.; Isensee, Umverteilung durch Sozialversicherungsbeiträge, 1973, S. 74; ders.,FS Ipsen, 1977, S. 409; Kirchhof, JZ 1982, 305.

119 Isensee, FS Ipsen, S. $423 \mathrm{ff}$.

120 Vgl. Leisner, Der Gleichheitsstaat, 1980, S. $158 \mathrm{ff}$.

121 Friauf, FS Jahrreiß, 1974, S. 45.

122 Scholz, in: Maunz-Dürig-Herzog-Scholz, Art. 12 Rdnr. 155; ders., NVwZ 1982, 337, 343. 
nichtsteuerlichen Indienstnahmen und Naturalleistungspflichten ${ }^{123}$ und die vielfach in ihrem Gefolge auftretenden Sonderabgaben verfassungsverbindlich grundsätzlich verdrängt, jedenfalls intensiven Rechtfertigungszwängen und -kriterien unterwirft, wie sie das BVerfG im Urteil zur Ausbildungsplatzabgabe ${ }^{124}$ nicht nur entworfen, sondern in vollem Umfang verfassungsgerichtlicher Entscheidung unterstellt hat. Diese Vorstellung vom „Steuerstaatsprinzip“ läuft Gefahr, die verfassungsrechtliche Reichweite von Steuerstaat und steuerlicher Lastengleichheit zu überzeichnen. Die steuerliche Lastengleichheit ist keine materielle Gleichheit, sondern abhängig von der Dezision des Steuergesetzgebers, der Gestaltungsfreiheit darüber hat, ,welche Elemente der zu ordnenden Lebensverhältnisse er dafür maßgebend ansieht, sie im Recht

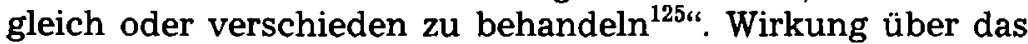
Steuerrecht hinaus ist der steuerlichen Lastengleichheit daher nicht beizumessen. Richtig ist, daß der vom Gleichheitssatz und der Eigentumsgarantie ausgehende Zwang zur Rechtfertigung von Eigentumsbelastungen, insbesondere ihrer Zumutbarkeit $^{126}$, sich steigert, wenn diese Belastungen nicht mehr lediglich die soziale Verantwortlichkeit im unmittelbaren Bereich und Umfeld eines Unternehmens oder sonstigen Eigentums realisieren, sondern darüberhinausreichende Gemeinwohlbeiträge abverlangen ${ }^{127}$ - wie beispielsweise die Waldeigentümer sie erbringen, indem sie ihren Wald der Allgemeinheit zur Erholung offenhalten müssen. Insofern sind zur Rechtfertigung die Kriterien der "Sachnähe“ der belasteten Gruppe zu einer bestimmten Aufgabe, der ,spezifischen Beziehung " etc. verwendbar ${ }^{128}$. Aus steuerlicher Lastengleichheit wird man sie aber nicht ableiten können.

${ }^{123}$ Von solchen spricht das BVerfG bei der Schwerbeschädigtenpflichtplatzquote (E 57, 39, 170) und beim Pflichtexemplar (E 58, 137, 144).

124 BVerfGE 55, 274.

125 BVerfGE 55, 57, 77 m. w. N. (st. Rspr.).

${ }^{126} \mathrm{Zu}$ dieser BVerfGE 58, 137, 150.

${ }^{127}$ Eine Konsequenz des Grundsatzes „Das Maß und der Umfang der dem Eigentümer von der Verfassung zugemuteten und vom Gesetzgeber zu realisierenden Bindung hängt ... wesentlich davon $a b, o b$ und in welchem Ausmaß das Eigentumsobjekt in einem sozialen Bezug und in einer sozialen Funktion steht" (BVerfGE 58, 137, 147 m. w. N.).

${ }^{128}$ Wohingegen die Forderung nach "Gruppennützigkeit" der Verwendung des Abgabeaufkommens nicht verallgemeinerungsfähig ist, wie $B$ VerfGE $57,139,169$ zeigt. 


\section{Schluß}

Wenn wir abschließend eine vorläufige Bewertung der Dimension der Grundpflichten im Verfassungsrecht der Bundesrepublik Deutschland versuchen, so sind einerseits das Existenzrecht der Grundpflichten im gegenwärtigen Verfassungsrecht, zum anderen aber einige Abgrenzungen hervorzuheben.

Während eine liberalistisch-positivistische Auffassung einst materiale Grundpflichten nicht zu erkennen vermochte und den Pflichtenstatus des Bürgers auf seine Gehorsamspflicht Gehorsam gegenüber Gesetz und sonstigem obrigkeitlichen Staatsakt - reduzierte ${ }^{129}$, hat die Weimarer Reichsverfassung unter sozialstaatlichem, nationalstaatlichem und kulturstaatlichem Vorzeichen den Gedanken verfassungsrechtlicher Grundpflichten materialen und je spezifischen Inhalts in das Verfassungsrecht unseres Jahrhunderts eingeführt. Sie hat dabei sozialstaatlich-neuartige Pflichten wie die Sozialpflichtigkeit des Eigentums mit traditionellen Pflichtenbeständen wie Schulpflicht ${ }^{130}$, Wehrpflicht, Pflicht zu öffentlichen Dienstleistungen verbunden und zum Bestandteil des Verfassungsrechts erhoben. Der Fortbestand solcher materialer Grundpflichten im gegenwärtigen Verfassungsrecht blieb lange dadurch verdunkelt, daß das GG auf die ausdrückliche Verwendung des Begriffes der Grundpflicht verzichtet und außerdem eine Reihe von Pflichten in den Kompetenzbereich der Länder und ihrer Verfassungen abschichtet. Umgekehrt sichert erst das Verfassungsrecht der Gegenwart die eigenständige verfassungsrechtliche Bedeutung der Grundpflichten gegenüber den seinerzeitigen positivistischen $Z$ weifeln $a b$, die sich aus dem Angewiesensein jeder Grundpflicht auf eine gesetzliche Regelung - der Schulpflicht auf das Schulpflichtgesetz, der Wehrpflicht auf das Wehrpflichtgesetz, der Sozialpflichtigkeit des Eigentums auf das Verwaltungsrecht - ergaben und die zur Behauptung der bloß ,erzählenden“ oder programmatischen Natur der Grundpflichten geführt hatten. Hier schließt die Figur des Gesetzgebungsauftrages der Verfassung die Lük$\mathbf{k e}^{131}$.

Die Grundpflichten sind an den Bürger adressiert, aber sie fordern zugleich den Staat und sein Handeln - so die Schulpflicht die öffentliche Schule, die Wehrpflicht die Armee.

129 Wie R. Thoma (s. o. Fn. 16) schon G. Jellinek, System der subjektiven öffentlichen Rechte, 1905, S. 197f.

${ }^{130} \mathrm{Zu}$ dieser: Heckel/Seipp, Schulrechtskunde, 5.A. 1976, S. 269 ff.

${ }^{131}$ Dazu jetzt J. Lücke, AöR 107 (1982) S. 15, 22 (m. w. N. a.a.O. Fn. 44). 
Grundpflichten beziehen den einzelnen unmittelbar in die Erfüllung staatlicher Aufgaben ein. (Die Elternpflicht - über die Herr Hofmann etwas sagen wird - mag insofern ein abweichender Sonderfall sein.) Sind Grundpflichten somit auch ein Instrument zur Hervorbringung von Staatlichkeit, so brauchen sie doch nicht eigens bemüht zu werden, um Elemente der Staatlichkeit und Verfassungspflichten des Staates zu begründen. Die Gesetzesbindung des Bürgers ergibt sich nicht erst aus dem Umweg über eine Grundpflicht, sondern sie folgt aus den Gesetzen ${ }^{132}$, und wiederum folgt das Recht des Staates, verbindliche Gesetze zu erlassen, aus seiner gesetzgebenden Gewalt. Was sich als verfassungsrechtliches Problem einer „Friedenspflicht““133 stellt, ist die Pflicht des Staates, durch seine Gesetzgebung die Friedensordnung zu setzen und sie durchzusetzen.

Die verfassungspolitischen Erwartungen an die Dimension der Grundpflichten dürften wahrscheinlich das übersteigen, was sich bei nüchterner Betrachtung als verfassungsrechtlicher Pflichtenbestand festhalten läßt. Um diesen Erwartungshorizont abzudecken, müßte das Thema der Grundpflichten aber wieder in dasjenige der Grundrechte zurückverwandelt werden. Die weithin geteilte Sorge, daß die Selbstverantwortung des Menschen durch Hypertrophien des Sozialstaates gefährdet werden könnte, führt nicht zur Pflicht, sondern zur Freiheit als Grenze der Sozialstaatlichkeit; denn Selbstverantwortung ist nichts anderes als Freiheit und die Übernahme der mit der Freiheit verbundenen Risiken. Weiterhin: Die sittlichen Pflichten des Bürgers gegenüber seinem Staat vertraut das GG vollständig den grundrechtlich gewährleisteten Freiheiten an, nicht eigens dafür angesetzten Grundpflichten. Es sind die Grundrechte, die dem Gedanken des dem Staat sittlich verpflichteten Bürgers ${ }^{134}$ Raum geben, was selbstverständlich das Risiko einschließt, daß dieser Raum nicht genutzt wird. Die Wiederentdeckung der Grundpflichten kann daher nicht mit der Erwartung verbunden werden, daß es möglich sein werde, der Offenheit und damit den Risiken des freiheitlichen Prinzips in die Determination der Pflichten zu entrinnen.

${ }^{132}$ Nach C. Schmitt (a.a.O., s. o. Fn. 15, S. 217) hat „die allgemeine Pflicht zum Gehorsam gegen die Gesetze... außer dem Inhalt, der sich aus den einzelnen zu befolgenden Gesetzen ergibt, keinen weiteren Inhalt". - Isensee (a.a.O., s. o. Fn. 2, S. 612) spricht vom Gesetzesgehorsam als "apriorischer Grundpflicht".

${ }^{133}$ Isensee, a.a.O. (Fn. 2), S. 616.

${ }^{134}$ Grundlegend: Smend, a.a.O. (Fn. 18). 
Leitsätze des Berichterstatters über:

\section{Grundpflichten als verfassungsrechtliche Dimension}

\section{Grundrechte und Grundpflichten}

1. Grundpflichten sind verfassungsrechtlich geforderte Pflichtbeiträge zum Gemeinwohl. Sie stellen die verfassungsverbindlich gemachte Aktivierung und Mobilisierung der den Grundrechtsinhabern zu eigenem Recht zustehenden Freiheiten und Vermögenspotentiale für die Zwecke des Gemeinwohls dar.

2. Grundpflichten sind von Grundrechtsbegrenzungen, insbesondere von Grundrechtsschranken zu unterscheiden.

3. Das Grundgesetz enthält keine Absage an Grundpflichten.

4. In der Verfassung der freiheitlichen Ordnung können Grundrechte und Pflichten nicht im Verhältnis der Einheit, der Symmetrie oder des Synallagmas stehen. Pflichten folgen den Rechten nach. Die Pflichtenvielfalt bedarf immer wieder erneuerter politischer Entscheidungen des Gesetzgebers, der dabei den Geboten der Bestimmtheit des Gesetzes und der Verhältnismäßigkeit unterliegt.

5. Ein Gegenmodell bildet der Grundsatz der Einheit von Rechten und Pflichten in den sozialistischen Verfassungen OstEuropas mit den Elementen: a) Pflichtcharakter der Grundrechte, b) wechselseitige Abhängigkeit von Grundrechten und ihnen zugeordneten Pflichten, c) allgemeine Abhängigkeit der Rechtsgewährung von einem durch Pflichterfüllung gegenüber der sozialistischen Gemeinschaft würdigen Verhalten.

6. Werden bei Grundrechtskollisionen in der Drittwirkungsebene Pflichtbeiträge zur Kollisionsvermeidung oder -bewältigung unmittelbar aus der Grundrechtsausübung abgeleitet, so stellt grundrechtliche Freiheit auch in dieser Situation keinen Pflichtenstatus dar.

7. Die rechtsstaatliche Nicht-Identifikation von Freiheitsrechten und Pflichten findet ihre folgerichtige Fortsetzung in der Anerkennung sog. negativer Grundrechte. 
8. Die Auflösung von Spannungen, die zwischen den Freiheitsgarantien und den durch ihre Ausübung bedingten vermeidbaren Belastungen der Solidargemeinschaften entstehen können, bewirkt das Sozialstaatsprinzip nicht durch soziale Grundpflichten, sondern indem es dem Gesetzgeber die Aufgabe stellt, Solidarverantwortung, Eigenverantwortung und solidarische Rücksichtnahme auf die Solidargemeinschaften einander zuzuordnen.

\section{Politische staatsbürgerliche Grundpflichten}

9. Die Verfassung wirkt als Impuls und Appell, die für die Verwirklichung der Demokratie erforderlichen Beiträge zu erbringen. Fehlende Verfassungsinkorporation staatsethischer Bürgerpflichten bedeutet nicht staatsethische Indifferenz der Verfassung.

10. Verfassungsschutz im Sinn des Grundgesetzes baut auf der Erwartung der Verfassungstreue der Bürger, aber - von der Treuepflicht der Beamten abgesehen - nicht auf einer Verfassungstreuepflicht als Grund-Rechtspflicht auf, sondern ist als Verfassungs-Gefahren-Abwehrrecht konzipiert. Verfassungsschutz ist rechtsstaatlich begrenzte Freiheitsbegrenzung, nicht pflichtenvollziehende Heranziehung des Bürgers für den Schutz der Verfassung.

11. a) Die allgemeine Wehrpflicht ist eine Grundpflicht.

b) Allgemeine Wehrpflicht und das Grundrecht, den Kriegsdienst mit der Waffe aus Gewissensgründen zu verweigern, stehen sich auf der Ebene des Verfassungsrechts gegenüber. Das Grundgesetz richtet mit der allgemeinen Wehrpflicht ein Stück allgemeiner öffentlicher Ordnung ein, läßt aber dessen Durchsetzung enden an der besonderen Situation des in Gewissensnot befindlichen Individuums.

c) Der Gesetzgeber verfügt verfassungsrechtlich über einen ausreichend großen Spielraum, um einen Konflikt zwischen dem Verfassungsgebot der Landesverteidigung und dem Grundrecht aus Art. 4 Abs. 3 GG abzuwenden.

d) Die Ersatzdienstpflicht (Art. 12 a Abs. 2 S. 1 GG) ist aus der Wehrpflicht abgeleitet, ohne diese für den Kriegsdienstverweigerer vollständig zu verdrängen. Sie tritt zur Wehrpflicht hinzu, weil deren regulärer Vollzug gehindert ist.

e) Das zwischen Wehrdienst und Zivildienst bestehende Band der Pflichtengleichheit hat beträchtlich verschiedene Modi einer Pflichterfüllung zum Gegenstand. Die starken Struk- 
turunterschiede zwischen Wehrdienst und Zivildienst erschweren ihre Vergleichbarkeit, eröffnen damit aber dem Gesetzgeber einen eher größeren Spielraum innerhalb des Gleichheitsgebotes.

12. Die Pflicht zur Übernahme von Ehrenämtern hat in einigen Bundesländern (Landes-)Verfassungsrang. Allgemein gilt, daß sie durch das Grundrecht auf Freiheit von Arbeitszwang (Art. 12 Abs. 2 GG) unberührt geblieben ist.

\section{Soziale Grundpflichten}

13. Soziale Grundpflichten ziehen die ökonomisch verwertbaren Güter aller für die Zwecke des Gemeinwesens heran. Sie stellen Pflichtbeiträge dar, die aus der Arbeitskraft und aus dem Vermögen der Grundrechtsinhaber zu erbringen sind.

14. a) Das Grundgesetz verzichtet weitgehend darauf, Arbeitskraft und Freizeit der Menschen mit Pflichtbeiträgen zu Gunsten des Gemeinwesens zu belasten (Art. 12 Abs. 2 GG).

b) Der weitgehende Verzicht des GG auföffentliche Dienstleistungspflichten wirkt als dauernde Erprobung der Bereitschaft der Bürger, freiwillige und meistens unbezahlte Gemeinschaftsdienste zu übernehmen.

c) Die ständig anwachsenden, mit Berufsausübung und Unternehmenstätigkeit verbundenen Indienstnahmen (,unbezahlte Hilfsarbeiten der Wirtschaft für den Staat") sind als Berufsausübungsregelungen von öffentlichen Dienstleistungspflichten unterschieden.

15. a) Die Pflichtenhaltigkeit der (einfach-)gesetzlichen Eigentumsordnung ist die Realität des öffentlichen Boden- und Wirtschaftsrechts im Gesetzgebungsstaat.

b) Davon zu unterscheiden ist das Verhältnis von Eigentümerrechten und -pflichten auf der Ebene des Verfassungsrechts. Es ist kein anderes als sonst im Bereich der Grundrechte (s. Leitsatz 4).

16. „Eigentum verpflichtet" ist in der Gestalt einer Grundpflicht eine Grundsatznorm der Boden- und der Wirtschaftsverfassung.

17. Durch seine steuerstaatliche Ausdeutung als Sitz einer Grundpflicht zur Steuerzahlung erhält der Satz „Eigentum verpflichtet" erstmals die Bedeutung einer allgemeinen Grund- 
pflicht. Die steuerverfassungsrechtlichen Grenzen der Besteuerung sind durch das Gegenüber von Eigentumsgrundrecht und verfassungsrechtlicher Grundpflicht zur Steuerzahlung determiniert.

18. Der Grundsatz der steuerlichen Lastengleichheit wirkt nicht über das Steuerrecht hinaus.

19. Der Sozialstaat tendiert als Steuerstaat dazu, die den Bürgern abgeforderten Gemeinwohlbeiträge auf Steuern zu konzentrieren und zu reduzieren. Nichtsteuerliche Indienstnahmen, Naturalleistungspflichten und die vielfach in ihrem Gefolge auftretenden Sonderabgaben werden weder praktisch noch kraft verfassungsrechtlicher Notwendigkeit grundsätzlich verdrängt. Diese nichtsteuerlichen Gemeinwohlbeiträge bedürfen unter dem Blickwinkel des Gleichheitssatzes und der Eigentumsgarantie jeweils der Rechtfertigung. 


\section{Grundpflichten als verfassungsrechtliche Dimension}

2. Mitbericht von Professor Dr. Hasso Hofmann, Würzburg*

Inhalt

I. Methodische Vorbemerkungen . . . . . . . . Seite

II. Über Zufälligkeit und Notwendigkeit der Asymmetrie von Rechten und Pflichten in der Verfassung der Freiheit . . . . 49

1. Der Grundrechtsindividualismus des Bonner Grundgesetzes . . . . . . . . . . . . . . . 49

2. Das Verfassungsprinzip der Freiheit $\ldots \ldots \ldots \ldots$. . . 54

III. Zur Geschichte der Grundpflichten . . . . . . . . . . 58

1. Die klassischen Grundpflichten . . . . . . . . . . . 58

2. Neuere Entwicklungen . . . . . . . . . . . . . 65

IV. Dogmatische Folgerungen . . . . . . . . . . . . . 68

1. Zum Rang der Grundpflichten . . . . . . . . . . . . 68

2. Vom Grund der Grundpflichten . . . . . . . . . . . 71

3. Grundpflichten und Grundrechtsschranken. . . . . . 76

4. Über den programmatischen Charakter der Grundpflichten. . . . . . . . . . . . . . 77

v. Offene Fragen $\ldots \ldots \ldots \ldots \ldots \ldots \ldots \ldots \ldots$

* Der Verf. dankt seinen Mitarbeitern, v. a. den Herren Assessoren R. Wiestner u. H. Dreier, für ihre Hilfe. 


\section{Methodische Vorbemerkungen}

Der Korreferent darf das Privileg in Anspruch nehmen, den Erstbericht durch einige Bemerkungen allgemeinerer Art lediglich zu ergänzen. So fragt dieser Versuch im Horizont freiheitlicher Verfassungstradition mehr verfassungstheoretisch nach den Möglichkeiten einer Grundpflichtendogmatik. Dabei können die Umstände einer solchen Fragestellung nach Jahrzehnten reiner Grundrechtsdogmatik nicht unbedacht bleiben. Zweifellos birgt unser Thema Bezüge zur politischen Situation. Über Pflichten zu reden, hat eine gewisse konjunkturelle Aktualität. Folglich ist Vorsicht geboten.

Auf Schwierigkeiten stößt die juristische Behandlung des Grundpflichtenproblems schon deshalb, weil eine Reihe von Umständen die Frage nach solchen Pflichten allzu leicht und einseitig als Frage nach einem bisher vernachlässigten Teil der Staatsethik erscheinen läßt. Im einzelnen sind drei Gründe zu nennen.

$\mathrm{Da}$ ist zunächst die durch die Grundwertedebatte der letzten Jahre vorgegebene Perspektive ${ }^{1}$. Wenn es richtig ist, daß die zentrifugale Gruppengesellschaft mangels anderer übergreifender Richtmaße einer gemeinsamen politischen Kultur am Ende nach allgemeiner grundsätzlicher Orientierung durch die Verfassung verlangt ${ }^{2}$ und wenn die Grundwertedebatte demzufolge über die Grundrechte nach dem ,gemeinsamen sozialethischen Nenner" suchte ${ }^{3}$, dann liegt die Überlegung nahe, ob zu dem, was man da als ethischen Mindeststandard beschwor, außer subjektiven Rechten und objektiven Werten nicht auch originäre Pflichten gehören. Als Gustav Radbruch im Jahre 1929 in einer Rede zur Verfassungsfeier nach dem fragte, was denn alle Deutschen noch eine, da rekurrierte er nicht auf die Grundrechte, sondern auf die Erziehungsziele der Weimarer Reichsverfassung und suchte die Antwort in einer „Republika-

${ }^{1}$ Vgl. neuestens $A$. Hollerbach in: Akten des IV. Internat. Kongresses für Kirchenrecht Fribourg 1980, hg. v. E. Corecco u. a., 1981, S. 811, mit Nachw. Krit. zu diesen Auseinandersetzungen E. Denninger, VVDStRL 37 (1979) S. 7 (11 ff.); P. Häberle, Erziehungsziele und Orientierungswerte im Verfassungsstaat, 1981, S. $19 \mathrm{ff}$. Über die evang. Vorbehalte gegenüber der Grundwerte-Diskussion $M$. Honecker in: Grundwerte, Bd. 168 d. Schriftenreihe d. Bundeszentrale f. polit. Bildung, 1980, S. 69.

${ }^{2}$ Vgl. H. Steinberger in FS f. W. Geiger, 1974, S. 243.

3 J. Isensee, NJW 1977, S. 545. 
nischen Pflichtenlehre“4. Gewiß: auch aus Werten lassen sich Pflichten deduzieren. Das Bundesverfassungsgericht hat es in seiner Abtreibungsentscheidung ja demonstriert ${ }^{5}$. Diese Art, Handlungsanleitung zu gewinnen, hat sogar eine sehr alte Tradition. Seit den griechischen Klassikern orientiert sich die abendländische Moralphilosophie vornehmlich an Gütern oder Werten, namentlich an der Dreiheit von Seele, Leib und äußeren Dingen ${ }^{6}$. Tugenden und Pflichten - die beiden anderen Erscheinungsformen des Sittlichen - werden meist von da aus hergeleitet. Indessen gibt es daneben Ethiken, die ihren systembildenden Begriff in dem der Tugend oder eben in dem der Pflicht haben. So durchstimmt der Pflichtgedanke die Stoa und den für den Prozeß der nachmittelalterlichen Staatsbildung bedeutsamen Neustoizismus, die reformatorische Moral und die praktische Philosophie der deutschen Aufklärung bis zur Pflichtenethik Kants. Von daher besteht die Gefahr, daß die Frage nach den Grundpflichten als eine Fortsetzung der Grundwertedebatte mit anderen Begriffen mehr protestantisch-preußischer Prägung aufgefaßt wird.

Hinzu kommt zum zweiten, daß ein freiheitliches Gemeinwesen von den politischen und sozialen Tugenden seiner Bürger lebt und daß es in einem manifesten Prozeß sozialer Destabilisierung damit nicht eben zum besten zu stehen scheint ${ }^{7}$. Die Frage nach den Grundpflichten läuft folglich Gefahr, für den Kampf gegen das Anspruchsdenken politisch vereinnahmt zu werden. Diese Konstellation ist um so problematischer, als die Frontstellung so einfach gar nicht ist. Gibt es doch nicht nur ein soziales, sondern auch ein liberales Anspruchsdenken ${ }^{8}$.

4 G. Radbruch, Republikanische Pflichtenlehre (1929). Vgl. zu diesem Ansatz neuestens $P$. Häberle in FS f. H. Huber, 1981, S. 211 (bes. S. 238); ders., Erziehungsziele (FN 1). Über Grundpflichten als staatliche Erziehungsaufgabe jetzt auch $J$. Isensee, DOV 1982, S. 609 (616). Zur Notwendigkeit demokratischer Tugenden der Bürger ders. in: Essener Gespräche zum Thema Staat und Kirche, 1977, S. 92 (102 ff.); U. Matz in: Regierbarkeit, hg. v. W. Hennis u. a., Bd. 2, 1979, S. 211 (215 ff.).

${ }^{5}$ BVerfGE 39, 1 (44 ff.). Ganz in diesem Sinne spricht Chr. Starck (Vom Grund des Grundgesetzes, 1979, S. 12) von „verpflichtenden Grundwerten".

${ }^{B}$ Hierzu u. zum folg. R. Brandt in: Rechtsphilosophie der Aufklärung, hg. v. dems., 1982, S. 79.

7 Vgl. H. Klages, Die unruhige Gesellschaft, 1975.

${ }^{8}$ Für das Anspruchsdenken allein den Sozialstaat verantwortlich zu machen, ist zwar üblich, greift aber historisch und sozialpsychologisch zu kurz. 
Hauptsächlich aber - und das ist der dritte Punkt - sind es historisch-theoretische Gesichtspunkte, welche die Fruchtbarkeit einer juristischen Behandlung der Grundpflichten in Frage stellen. Ist doch nicht zu übersehen, daß die Weimarer Staatsrechtslehre Friedrich Naumanns richtungsweisende Idee einer verfassungsrechtlichen Einheit von Rechten und Pflichten ${ }^{9}$ in der Tradition des Rechtspositivismus alsbald wieder mit der Antithese von Recht und Moral konterkariert hat. So sprach Nawiasky den Grundpflichten die Qualität von Rechtsnormen weitgehend ab und verwies sie in ein „System der Staatsbürgerkunde "10. Thoma reduzierte sie nach überliefertem Muster auf den Grundsatz des Gesetzesgehorsams ${ }^{11}$, sah sie also "leerlaufen“. Komplementär dazu hat man der Weimarer Verfassung in völkisch-konservativer Polemik vorhergesagt, sie werde an ihrer Geringschätzung des Pflichtgedankens zugrundegehen ${ }^{12}$.

Trotz allem blieben die Grundpflichten infolge ihrer expliziten verfassungsgesetzlichen Proklamation eine nicht gänzlich zu vernachlässigende Kategorie des Weimarer Verfassungsrechts. Und hierin mehr als in einem Wegfall einzelner Pflichtigkeiten liegt die eigentliche Differenz zum Verfassungsrecht der Bundesrepublik. Denn bei aller Reserve des Parlamentarischen Rates gegenüber dem Pflichtenpathos der Vergangenheit kann keine Rede davon sein, daß das Grundgesetz keine Grundpflichten kenne ${ }^{13}$ oder gar ausdrücklich gegen Grundpflichten sich entschieden habe ${ }^{14}$. Wo anders als in verfas-

${ }^{2}$ Dazu E. $R$. Huber in FS f. F. Wieacker, 1978, S. 384; P. Badura, DVBl. 1982, S. 861 (865 ff.).

${ }^{10} \mathrm{H}$. Nawiasky, Die Grundgedanken der Reichsverfassung, 1920, S. 124.

1 . Thoma in: Die Grundrechte und Grundpflichten der Reichsverfassung, hg. v. H. C. Nipperdey, 1. Bd., 1929, S. 1 (2).

${ }^{12}$ A. Frhr. v. Freytagh-Loringhoven, Die Weimarer Verfassung in Lehre und Wirklichkeit, 1924, S. 328.

${ }^{13}$ H. Schneider, NJW 1954, S. 937 (941): Von den Grundpflichten eines jeden Bürgers sei im GG leider nicht die Rede. Ähnlich $A$. Hamann/H. Lenz, Das Grundgesetz, 3. Aufl., 1970, Einf. C 2. Dagegen mit Recht schon H. v. Mangoldt/F. Klein, Das Bonner Grundgesetz, Bd. I, 1966, Vorbem. B XI 2 u. 3.

14 So aber Wernicke, der in der Erstbearb. des Bonner Kommentars in Bem. II 3 d zu Art. 5 von einem für den Grundrechtskatalog des GG "aufgestellten Grundsatz der Nichterwähnung von Pflichten" spricht u. Art. 5 III 2 GG daher eine "systemwidrige Bestimmung" nennt. $R$. Stober (Grundpflichten und Grundgesetz, 1979) dagegen liest aus dem GG 16 Grundpflichten heraus, während es die Weimarer Staatsrechtslehre seinerzeit je nach Zählweise nur auf 3 bis 9 brachte: Freytagh- 
sungsrechtlichen Pflichtigkeiten können alle unsere Verbindlichkeiten gründen, wenn Verwaltungsrecht „konkretisiertes Verfassungsrecht" ist und jede rechtliche Belastung einer verfassungsmäßigen Grundlage bedarf? So hat der Verzicht des Grundgesetzes auf die Kategorie der Grundpflicht fast zwangsläufig gewisse begriffliche Kompensationen provoziert $^{15}$. $\mathrm{Zu}$ elementar - um nicht zu sagen: trivial - ist die Einsicht, daß es Rechte nicht ohne Pflichten gibt, ja daß es vornehmlich unsere Pflichten sind, in denen wir die Allgemeinheit unserer sozialen und politischen Existenz erfahren. Als solche Kompensationen fungieren die Drittwirkungsleh$\mathrm{re}^{16}$, die Auffassung von der Pflicht $\mathrm{zu}$ bestimmter Grundrechtsausübung ${ }^{17}$ und besonders die Rechtsprechung des Bundesverfassungsgerichts zum „Menschenbild des Grundgesetzes"18.

Im Gegensatz zu alledem fragt unser Thema nach der Möglichkeit, die Kategorie der Grundpflicht wieder explizit als eine verfassungsrechtliche Kategorie und nicht nur als Inbegriff ethischer Verfassungsvoraussetzungen neben die der Grundrechte zu stellen. Dieser Versuch kann kaum anders als beim Grundpflichtenbegriff von Weimar ansetzen. Hier sind

Loringhoven (FN 12), S. 328 ff., zählte nur 3: Pflicht zu ehrenamtl. Tätigkeit, zur Leistung persönlicher Dienste $u$. zur Tragung öffentl. Lasten; H. Gmelin (Einführung in das Reichsverfassungsrecht, 1929, S. 58) rechnete die Schulpflicht hinzu. F. Stier-Somlo (Deutsches Reichs- und Landesstaatsrecht I, 1924, 522 f.; ebenso in: Handwörterb. d. Rechtswiss., hg. v. dems. u. A. Elster, Bd. 3, 1928, S. 45 ff.) kam auf 8 Grundpflichten zu Gehorsam, Treue, Abgaben, persönl. Diensten, Ehrenämtern, Wehrdienst, Arbeit, Schulbesuch. W. Hofacker (Grundrechte und Grundpflichten der Deutschen, 1926, S. 62 ff.) nahm den Grundsatz der Pflichtengleichheit noch hinzu.

${ }^{15}$ Siehe schon W. Wertenbruch, Grundgesetz und Menschenwürde, 1958, S. 57, $62 \mathrm{ff}$.

${ }^{16}$ Gerade weil diese Lehre aus Grundrechten Pflichten folgerte, wurde sie kritisiert; vgl. z. B. G. Püttner, Toleranz als Verfassungsprinzip, 1977, S. 22.

${ }_{17}$ Vgl. W. Geiger, Grundrechte und Rechtsprechung, 1959, S. 53; ders. in FS f. G. Leibholz, Bd. II, 1966, S. 187 (202); H. Krüger, Allgemeine Staatslehre, 2. Aufl., 1966, S. 504 ff., 526 ff., 569; ders. in FS f. F. Berber, 1973, S. 247; ders. in FS f. U. Scheuner, 1973, S. 285; ders. in FS f. E. R. Huber, 1973, S. 95. Berechtigte Kritik hieran bei $H$. H. Klein, Der Staat 1975, S. 153 (160 ff.); E. Denninger, Staatsrecht 2, 1979, S. 185 ff.; D. Merten, Verw. Arch. 1982, S. 103 (106 ff.); H. Bethge, NJW 1982, S. 2145 (2147).

${ }^{18}$ Vgl. die Entwicklung der Formulierung von E 4, 7 (15 f.) über E 12, 45 (51) bis E 48, $127(161,163,168)$. 
seinerzeit traditionelle sowohl wie neuartige verfassungsrechtliche Pflichtenmomente erstmals verfassungsgesetzlich unter dem (geistesgeschichtlich freilich sehr viel älteren) Namen der Grundpflichten zusammengefaßt worden.

Daher liegt es nahe, unter Grundpflichten zunächst diejenigen verfassungsrechtlichen Vorschriften zu verstehen, welche in Korrelation zu den Grundrechten den einzelnen zur Erhaltung der gemeinsamen politischen Existenz für den Staat in Anspruch nehmen, quasi Grundrechte der staatlichen Gemeinschaft gegenüber dem Individuum statuieren und so nächst den individuellen grundrechtlichen Ansprüchen auch einen status passivus ${ }^{19}$ der Rechtsgenossen verfassungsrechtlich definieren oder wenigstens vorsehen ${ }^{20}$.

Nun gibt es aber nicht nur Schwierigkeiten, die Frage nach den Grundpflichten methodisch als eine spezifisch verfassungsrechtliche durchzuhalten. Darüber hinaus ist die Thematik mit einer Hypothek belastet, die aus der üblichen antithetischen Gegenüberstellung von Rechten und Pflichten resultiert. Von daher scheint jeder Rekurs auf Pflichten eine den Freiheitsrechten entgegengesetzte Absicht zu verfolgen. Dieser Aspekt gehört - ob begründet oder nicht - zum politischen Profil unseres Problems - und das von jeher.

Natürlich waren den Vätern der Menschen- und Bürgerrechtserklärungen des ausgehenden 18. Jahrhunderts elementare soziale und politische Pflichten des Menschen selbstverständlich. Für die Amerikaner war eine besondere Aufstellung ihrer Pflichten aber nicht nur unnötig zur naturrechtlichen Begründung ihrer Souveränität; in der historischen Perspektive der altenglischen Freiheitsbriefe hätte sie auch die politi-

${ }^{19}$ G. Jellinek, System der subjektiven öffentlichen Rechte, 2. Aufl., 1905, S. 197.

${ }^{20}$ In diesem Sinne K. Roth-Stielow, Grundgesetz und Rechtsanwendung, 1972, S. 76 ff.; D. Merten, BayVBl. 1978, S. 554 (555); Stober (FN 14), S. 12 ff.; E. Benda, Grundrechte - Grundpflichten, hg. v. Rotary International, 1981, S. 8. Nicht ist hier also die Rede von der „Grundpflicht" des Staates, die Menschenwürde zu achten und zu schützen; so $P$. Häberle, VVDStRL 30 (1972) S. 43 (94); ders. in FS f. H. Huber, S. 410 f., 414. Andererseits sollte man nicht jede aus einem Verfassungsrechtssatz ableitbare indiv. Verpflichtung Grundpflicht nennen $u$. daraus so eine rein formale Kategorie machen. So sind die Vorschriften über den Amtseid von Bundespräsident und Bundeskanzler amtsbezogen und nicht allgemein statusbestimmende Normen und beinhalten daher keine Grundpflichten; a. A. Stober a.a.O. S. $67 \mathrm{ff}$. 
sche Bedeutung der Rechteerklärungen gemindert ${ }^{21}$. In Frankreich waren es 1789 die Vertreter der alten Mächte, vor allem der Kirche, die eine solche Ergänzung verlangten. Die Mehrheit akzeptierte das Postulat bürgerlicher Selbstdisziplin und den Bestand von Verbindlichkeiten gegenüber den Mitbürgern; aber schon der Gedanke an Pflichten gegenüber dem (noch immer monarchischen) Staat als einem eigenständigen Wesen schien ihr Verrat an der Idee der Freiheit ${ }^{22}$. Und als man nach der jakobinischen Schreckensherrschaft in der Direktorialverfassung des Jahres 1795 dem Katalog der Rechte zum erstenmal in der Verfassungsgeschichte im Zeichen der Goldenen Regel des "Was du nicht willst, das man dir tu ..." mit dem Gebot des Gesetzesgehorsams, einem allgemeinen Tugendappell und der Notwendigkeit des Wehrdienstes einen solchen der Pflichten beigab (ohne damit sachlich irgend etwas Neues zu sagen), da geschah dies, um dem französischen Volk, wie einer der Mitverfasser später schrieb, contre-poison zu verabreichen, ein „Gegengift“ gegen die voraufgegangenen Deutungen des Freiheitsgedankens ${ }^{23}$. Dem Denken in Ansprüchen gegenübergestellt, könnte die Frage nach den Grundpflichten heute ähnlich aufgefaßt und damit im Sinne einer Art Gegen-Doktrin mißverstanden werden. Unter diesem Aspekt müßte sie - wie damals auch - zu der ganz und gar unbehelflichen Forderung von Verfassungsergänzungen zur Förderung der Bürgertugenden führen. Denn man bedenke: Nach der Einsicht, welche Kant dahin formuliert hat, daß die Verfassung in der Moral eines Volkes gründet, diese Moral aber wiederum auch abhängt von der Güte der Verfassung, wird dem Grundgesetz ja nicht weniger vorgeworfen, als daß es uns in seiner angeblichen Pflichtvergessenheit aus dem „totalitären Staat" in den „totalen Egoismus" geführt habe ${ }^{24}$.

${ }^{21}$ Dazu G. Jellinek in: Zur Geschichte der Erklärung der Menschenrechte, hg. v. R. Schnur, 1964, S. 1 (14).

${ }^{22} \mathrm{Vgl}$. B. Schickhardt, Die Erklärung der Menschen- und Bürgerrechte von 1789-91 in den Debatten der Nationalversammlung, 1931.

${ }^{23}$ A.-C. Thibaudeau: Mémoires sur la Convention et le Directoire, Vol. 1, 1824, p. 180. Vgl. dazu A. Aulard, Politische Geschichte der Französischen Revolution, Bd. I, 1924, S. 471; H. R. Sandmeier, Der Mensch und der Bürger im Staat, Diss. Bern 1951, S. 214 ff.

${ }^{24}$ H.-D. Ortlieb, Vom totalitären Staat zum totalen Egoismus, 1978, S. 71: „Unser Grundgesetz hat uns Staatsbürgern leider das Wichtigste vorenthalten: Es sichert uns zwar Rechte zu, aber es schweigt (von der sozialen Verpflichtung des Eigentums abgesehen) von unseren Pflich. ten." 


\section{II. Über Zufälligkeit und Notwendigkeit der Asymmetrie von Rechten und Pflichten in der Verfassung der Freiheit}

\section{Der Grundrechtsindividualismus des Bonner Grundgesetzes}

Die Kritik am Bonner Grundrechtsindividualismus ist so alt wie das Grundgesetz selbst. Theodor Maunz hat die „höchst stiefmütterliche" Behandlung der Grundpflichten in unserer Verfassung von jeher beklagt ${ }^{25}$. Und ein alsbald hohen Ämtern zustrebender Doktorand gibt einer damals unter den Jüngeren noch verbreiteten Stimmung ${ }^{26}$ Ausdruck, wenn er in seiner Dissertation über Grundrechte und Grundpflichten 1949 schreibt, der Grundrechtskatalog des Grundgesetzes habe die beiden aktuellen Probleme übersehen, nämlich die Frage der materiellen, wirtschaftlichen Sicherung des Freiheitsgebrauchs und die Frage der Grundpflichten; deswegen sei dieser Teil des Grundgesetzes im Hinblick auf die Realität „ein bedenkliches, antiquiert anmutendes Werk ${ }^{\text {‘22 }}$.

In der Tat: in seiner Geburtsstunde steht das Grundgesetz ein wenig außerhalb seiner Zeit und unserer Geschichte. In einem von außen angehaltenen historischen Moment geht der Grundrechtsteil des Bonner Grundgesetzes mit der weitgehenden Reduktion aller Sozialitätspostulate auf die eine Zielbestimmung der Sozialstaatlichkeit hinter die Verfassung von Weimar zurück ${ }^{28}$. Im Gegensatz zur Verfassung der 4. französischen Republik weiß das Grundgesetz in seinen materiellen Grundsätzen nichts von den Nöten der Zeit, ruft es anders als die italienische Verfassung von 1947 nicht auf zur Solidarität. Traumatisch an die nationalsozialistische Verachtung des Individuums und seiner Freiheit gebunden, steigert das Grundgesetz im wesentlichen mit den Mitteln, welche man schon in der Weimarer Zeit ,die alten konstitutionellen Inventarstücke“ genannt hatte, die Verfassungsgewährleistungen für den Schutz des einzelnen auf ein Höchstmaß - womit es zugleich den sozialen status quo weitgehend fixiert und die Entfaltung des Sozialstaatsgedankens hemmt ${ }^{29}$. In historisch einmaliger

${ }^{25}$ Deutsches Staatsrecht, 1. Aufl. 1951, S. 80, bis zur 23. Aufl. 1980, S. 117.

${ }^{26} \mathrm{Vgl}$. E. Heimann, Freiheit und Ordnung, 1950, S. 12.

${ }^{27} \boldsymbol{R}$. Barzel, Die verfassungsrechtliche Regelung der Grundrechte und Grundpflichten des Menschen, Diss. Köln 1949 (Masch.), S. 54.

${ }^{28}$ Hierzu und zum folgenden $H$. P. Ipsen, Über das Grundgesetz (1949), 2. Aufl. 1964, S. 14 ff. Siehe auch F. Klein, ZgesStW 106 (1950) S. $390(400,403 \mathrm{f}$.$) .$

${ }_{29}$ Entgegen H.-H. Hartwich (Sozialstaatspostulat und gesellschaftlicher status quo, 3. Aufl. 1978, S. 281) ist das nicht nur eine Frage der GG-Interpretation. 
Weise schlägt das Grundgesetz die Brücke zurück zum naturrechtlichen Ausgangspunkt der Menschen- und Bürgerrechtserklärungen, welche - aus der älteren pflichtenethischen Tradition herausführend - von einem vorgesellschaftlich aufgefaßten und mit naturwüchsigen Rechten begabten Individuum her dachten, ,, das von Aufgaben und Pflichten völlig freigesetzt ist und dem Staat in reiner Anspruchshaltung gegenübertritt ${ }^{‘ 30}$. Daß so viel Anachronismus gleichwohl Zukunft hatte, deutete sich freilich schon $1949 \mathrm{an}^{31}$. Ein erster Konjunkturauftrieb entschärfte bei relativ niedrigem Erwartungshorizont die sozialen Spannungen. Mit wachsendem Wohlstand blüht die Grundrechts- und Rechtsstaatskultur wie nie zuvor, erleben die individuellen Rechtsschutzmöglichkeiten eine bislang unbekannte Verfeinerung, vielleicht Überfeinerung - nicht ohne Rückwirkung wiederum für das Verfassungsverständnis. Eine gewisse Veränderung der Bewußtseinslage bringt dann allerdings die Wiedereinführung der allgemeinen Wehrpflicht ${ }^{32}$.

Natürlich blieb das alles nicht ohne Rückwirkung auf Gehalt und Gestalt der Länderverfassungen. Die älteren aus den Jahren 1946 und 1947 folgen zumeist noch dem Vorbild von Weimar und bewahren so die Kategorie der Grundpflicht ${ }^{33}$. In Süddeutschland setzen die Bundesländer mit ihren Grundpflichtenregelungen auch partikulare Traditionen des Landesverfassungsrechts der 1 . Republik fort ${ }^{34}$. Praktische Bedeu-

${ }^{30}$ H. Maier, Die Grundrechte des Menschen im modernen Staat, 2. Aufl. 1974, S. 23. Vgl. ebd. auch S. $41 \mathrm{ff}$.

${ }^{31}$ Vgl. D. Berg-Schlosser in: Vorgeschichte der Bundesrepublik Deutschland, hg. v. J. Becker u. a., 1979, S. 93 (102 ff., 114).

32 Bezeichnend die These von W. Martens (Grundgesetz und Wehrverfassung, 1961, S. 124), daß mit Art. 12a GG den Grundrechten erstmals eine spezielle Grundpflicht gegenübergestellt worden sei. $H$. Rumpf sprach schon 1958 von einer „Wende“ für die Bundesrepublik: Der ideologische Gehalt des Bonner Grundgesetzes, S. 34.

${ }^{33} \mathrm{Vgl}$. die entsprechenden Überschriften in der bad. Verf. v. 1947 (Zweiter Hauptabschnitt), der Verf. v. Württ.-Hohenz. v. 1947 (Abschnitt III), der bay. Verf. v. 1946 (Zweiter Hauptteil), der brem. Verf. v. 1947 (Erster Hauptteil), der hess. Verf. v. 1946 (Teil III), der rhpf. Verf. v. 1947 (Erster Hauptteil) und der saarl. Verf. v. 1947 (1. Hauptteil).

${ }^{34}$ Genannt seien aus diesem bislang vernachlässigten Kapitel der deutschen Verfassungsgeschichte (vgl. jetzt aber $E$. $R$. Huber, Deutsche Verfassungsgeschichte, Bd. 6, 1981, S. $744 \mathrm{ff}$.) außer der in den Verfassungen von Baden v. 21. 3. 1919 ( $\$ 19 \mathrm{~V} 1$ ), Bayern v. 14. 8. 1919 (\$ 21 II), Braunschweig v. 6. 1. 1922 (Art. 50 S. 2), Hamburg v. 7. 1. 1921 (Art. 70 S. 2) und Mecklenburg-Schwerin v. 17. 5. 1920 (\$ $19 \mathrm{II})$ enthaltenen Schulpflicht die Normierungen der allg. Steuerpflicht ( $\$ 10$ bad. Verf.; $\$ 7 \mathrm{~S} .2$ Verf. v. Mecklb.-Schwerin), der Wehrpflicht in $\$ 86 \mathrm{der}$ 
tung erlangt das jedoch kaum - und zwar aus zwei Gründen nicht $^{35}$. Zum einen reduzieren und nivellieren die Freiheitsrechte des Bundes die Pflichten kraft Länderverfassungsrecht. Nur ein Beispiel: Da die Widerstandspflicht der hessischen und der bremischen Verfassung die Bürger mit unabsehbaren Risiken belastet, die sie nach dem Grundgesetz schwerlich zu tragen verpflichtet sind, steht sie im Widerspruch zur Bundesverfassung ${ }^{36}$. Zum zweiten ist die Realisierung der Grund-

bay. und $\S 12$ der bad. Verf. sowie der Sozialpflichtigkeit des Eigentums (Baden § 14 I 2: „Rücksicht auf die gemeinwirtschaftlichen Interessen“; § 59 II württ. Verf. v. 25. 9. 1919: „Beschränkung zum Zwecke der Bewirtschaftung für die Allgemeinheit") und der Eigentumsabtretungspflicht ( $\$ 10$ II Verf. v. Mecklb.-Schwerin; § 13 S. 2 oldenb. Verf.; $\S 59$ II württ. Verf.). Die bad. und die braunschw. Verf. machen darüber hinaus die Ausübung des Wahlrechts zur Pflicht (\$3 II 2 bzw. Art. 2 II 2). Die braunschw. Verf. kennt ferner eine allg. demokratische Mitwirkungspflicht (Art. 2 II 1: „Niemand darf sich der Pflicht zur Mitwirkung bei der Ausübung der Staatsgewalt entziehen.").

${ }^{35}$ Zum folgenden $J$. Kratzer in FS f. W. Laforet, 1952, S. 107 (121, 133); $H$. Zacher in: Nawiasky/Leusser u. a., Die Verfassung des Freistaates Bayern, 1966 ff., RN 6 zu Art. 117.

${ }^{36}$ Im übrigen engt das GG die Tragweite aller Bestimmungen über Eigentumsabtretung, Sozialpflichtigkeit des Eigentums, Bodenreform und Sozialisierung - vgl. die Verf. von Baden v. 22. 5. 1947 (Art. 15 II, III, 45), Württ.-Baden v. 28. 11. 1946 (Art. 8 III, IV, 28 I) und Württ.Hohenz. (Art. 15 II, III, 98 I), Bayern (Art. 103 II, 158, 159, 160, 161 I), Berlin (Art. 15 II: nur Eigentumsabtretungspflicht), Bremen (Art. 13, 42, 45), Hessen (Art. 39 I, II, 45 II), Nordrh.-Westf. (Art. 27 I: nur spez. Eigentumsabtretungspflicht), Rhl.-Pfalz (Art. 60, 61, 63, 64) und des Saarlandes (Art. 51, 52, 55 II) - über Dienstpflichten (vgl. Art. 21 II, rhpf. Verf.; Art. 25 S. 1 hess. Verf. Interessant Art. 19 II saarl. Verf.: „Die Verpflichtung zur Leistung persönlicher Dienste für Staat und Gemeinde kann nur mit der für ein verfassungsänderndes Gesetz vorgeschriebenen Mehrheit beschlossen werden.") und die Pflicht zur Arbeit (Art. 166 III bay. Verf.) - soweit sie nicht ohnedies nur als sittliche Pflicht konzipiert ist (Art. 37 I 2 Bad. Verf. v. 22. 5. 1947; Art. 20 I 1 Württ.-Bad. Verf. v. 28. 11. 1946 und Art. 90 I 1 Württ.Hohenz. Verf. v. 20. 5. 1947) - von vornherein auf das ein, was Art. 12, 14 u. 15 GG an derartigen Freiheitsbeschränkungen erlauben. Dasselbe gilt mit Rücksicht auf Art. 2, 5, 9 II, 18, 21 II, 33 IV GG für die Treue, welche die Verfassungen von Bayern (Art. 117 S. 1), Bremen (Art. 9), Hessen (Art. 146) und Rheinland-Pfalz (Art. 20) in der Tradition des 19. Jh. über den Gesetzesgehorsam hinaus verlangen. Die nach dem Vorbild der bad. Verf. (Art. 58 II) und der württ.-bad. Verf. (Art. 49 IV) allein in Baden-Württemberg (Art. 26 III) für alle Wahlen und Abstimmungen des Staatsvolks (nicht auch für die Wahlen und Abstimmungen in den Kommunen) statuierte Wahlpflicht ist mit Art. 38 GG unvereinbar. Die Lit. weicht mit dem Hinweis auf die fehlende Sanktionierung aus; vgl. Paul Feuchte in: Spreng/Birn/Feuchte, Die Verfas- 
pflichtenbestimmungen eine Frage der Gesetzgebungszuständigkeit. Und die liegt für die in Betracht kommenden Materien ganz oder teilweise beim Bund ${ }^{37}$ und nur für die Schulpflicht ${ }^{38}$ allein bei den Ländern. Unter diesen Umständen ist es nicht verwunderlich, daß die jüngeren Länderverfassungen kaum noch Grundpflichten enthalten oder auf verfassungsrechtliche Statusbestimmungen für die Rechtsunterworfenen überhaupt verzichtet haben.

Der wichtigste Grund für den vergleichsweise so stark ausgeprägten Individualismus des Grundgesetzes ist schon genannt worden: die Reaktion gegen die Vergangenheit des „Dritten Reiches". Man muß sich vergegenwärtigen, daß jene maßlos mißbräuchliche Überanstrengung, Täuschung und Enttäuschung von Gemeinsinn und Opferbereitschaft und daß der Terror juristisch im Zeichen der Verhöhnung des liberalrechtsstaatlichen Rechtsdenkens, des Kampfes gegen das subjektive Recht für volksgenössische, vom Primat der Rechtspflicht $^{39}$ beherrschte Rechtsverhältnisse gestanden hatten ${ }^{40}$. sung des Landes Baden-Württemberg, 1954, Anm. 5 zu Art. 26; G. Lang: Das Problem der Wahl und Stimmpflicht, seine Lösung im geltenden Recht der europäischen Staaten und seine Grundlagen in der Bundesrepublik Deutschland, Diss. Freiburg/Br. 1962, S. 256.

${ }^{37}$ Gegenstandslos daher die Notstandspflichten in den Verfassungen von Bremen (Art. 10), Saarland (Art. 19), Berlin (Art. 11) und Rheinland-Pfalz (Art. 22). - Die Ausübung von Ehrenämtern gilt nicht als Arbeit und wird daher von Art. 12 GG nicht berührt. Insbesondere für das Kommunalrecht also weiterhin von Bedeutung Art. 121 bay. Verf., Art. 9 S. 3 brem. Verf., Art. 25 S. 1 hess. Verf., Art. 21 I rhpf. Verf., Art. 19 I saarl. Verf. Vgl. dazu R. Stober, Der Ehrenbeamte in Verfassung und Verwaltung, 1981. - Zur Steuerpflicht der bay. Verf. (Art. 123 I) vgl. Zacher (FN 35).

${ }^{38}$ Art. 14 I b. w. Verf. v. 11. 11. 1953; Art. 129 I bay. Verf. v. 2. 12. 1946; Art. 30 I brem. Verf. v. 21. 10. 1947; Art. 56 S. 1 hess. Verf. v. 1. 12. 1946; Art. 8 II nrw. Verf. v. 18.6. 1950; Art. 6 I schlh. LS v. 15.3. 1962. Daneben normieren die b. w. (Art. 12 II), die bay. (Art. 126 I), die brem. (Art. 23 I 1), die hess. (Art. 55 S. 1) u. die nrw. Verf. (Art. 8 I 2) die elterliche Erziehungspflicht. Zwar die Erziehungs-, nicht aber auch die Schulpflicht regeln die rhpf. (Art. 25 I 1, 27 I) u. die saarl. Verf. v. 15. 12. 1947 (Art. 24 I). Art. 13 S. 1 bad. Verf. v. 22. 5. 1947 hatte proklamiert: „Jeder junge Mensch hat, seiner Begabung entsprechend, das Recht auf Bildung und die Pflicht zur Bildung."

${ }^{39}$ H. Lehmann in FS f. R. Deinhardt, 1940, S. 108.

${ }^{40}$ Vgl. zu dieser Bewegung, die - von der den 1. Weltkrieg zum „Kampf gegen die Ideen von 1789“ hochstilisierenden Kriegsliteratur abgesehen - an eine ältere genossenschaftlich-sozialrechtliche und pflichtenorientierte, übrigens nicht auf Deutschland beschränkte Tradition (Ihering, Gierke, Duguit) anknüpfen konnte, eindringlich $P$. Thoss, Das subjektive Recht in der gliedschaftlichen Bindung, 1968. 
Man bedenke, daß die öffentlichrechtliche Rechtsstellung des einzelnen, insbesondere nach der sog. totalen Mobilmachung, im wesentlichen bloß noch als eine schier grenzenlos vielfältige Pflichtenstellung bestimmbar ${ }^{41}$ und daß der Mensch nur nach Maßgabe seiner Pflichterfüllung für den totalitären Führerstaat als Träger von Rechten anerkannt war ${ }^{42}$.

Über das hierin liegende Motiv der späteren Reserve gegenüber dem Pflichtgedanken besteht Einigkeit. Aber das kann nicht der einzige Grund gewesen sein. Wie wäre sonst zu erklären, daß die vorhergehenden, den Geschehnissen noch näherstehenden Länderverfassungen ein anderes Bild zeigen? Richtig ist wohl, daß die Kategorie der Grundpflichten in einer scheinbar paradoxen Weise ein Opfer zugleich der Vorläufigkeit wie der juristischen Perfektion des Grundgesetzes geworden ist ${ }^{43}$. Es war einerseits zu wenig Zeit, um zwischen den heterogenen politischen Kräften dort zu einer Einigung zu kommen, wo die Grundpflichten der Weimarer Reichsverfassung hauptsächlich ihr Feld hatten: in der Ordnung von Schule, Bildung, Arbeit und Wirtschaft. Andererseits schien die Sicherung der Rechtsstellung des einzelnen ebenso dringlich wie fürs erste ausreichend. Insoweit aber strebte man nach Perfektion. Endlich war schon in Herrenchiemsee der Gedanke geäußert worden, es gebe gar keine „echten“ Grundpflichten $^{44}$, womit in jenem naturrechtlichen Rekurs auf vorstaatliche Rechte offenbar gemeint war, daß diesen Menschenrechten keine gleich ursprünglichen Pflichten entsprächen. Die damit aufgeworfene Frage führt ins Zentrum der verfassungstheoretischen Problematik.

${ }^{41}$ Vgl. W. Weber, Die Dienst- und Leistungspflichten der Deutschen, 1943.

${ }^{42}$ Vgl. R. Freisler, Grundlegende Denkformen des Rechts im Wandel unserer Rechtserneuerung, 1941, S. 23. Siehe auch schon $O$. Koellreutter, Grundriß der Allgemeinen Staatslehre, 1933, S. 49.

${ }^{43} \mathrm{Vgl}$. Schriftl. Bericht des Abg. Dr. von Mangoldt über den Abschn. I. Die Grundrechte, in: Schriftl. Bericht zum Entwurf des Grundgesetzes für die Bundesrepublik Deutschland = Anlage z. stenogr. Bericht der 9. Sitzung des Parlamentar. Rates am 6. 5. 1949, S. 5. Vgl. auch die Åßßerung des Abg. Dr. Schmid in dieser Sitzung (a.a.O. S. 172). Siehe dazu V. Otto, Das Staatsverständnis des Parlamentarischen Rates, 1971, S. 67, 77, $88 \mathrm{ff}$.

${ }^{44} \mathrm{Vgl}$. H. Nawiasky, Die Grundgedanken des Grundgesetzes für die Bundesrepublik Deutschland, 1950, S. 30. 


\section{Das Verfassungsprinzip der Freiheit}

Tatsächlich kann es in einer rechtsstaatlichen Verfassung der Freiheit keine Symmetrie von Rechten und Pflichten geben. Das hat seinen Grund in der schlichten aristotelischen Wahrheit, daß ein und dasselbe nicht von zwei Prinzipien prinzipiiert werden kann. Rechtsprinzip jeder rechtsstaatlichen Verfassung aber ist die Freiheit, die Autonomie des einzelnen. So kann es nicht zugleich seine rechtliche Bindung an etwas außer ihm selbst, eine rechtliche Verpflichtung zu etwas sein. Der Grundsatz individueller Freiheit ist freilich nur ein normatives Prinzip, kein ontologischer, soziologischer oder historischer Befund, wie es der Wortlaut des Art. 1 Abs. 2 GG erscheinen läßt. Es ist dieses Prinzip der Selbstbestimmung, was den Menschenwürdegehalt der Grundrechte ausmacht ${ }^{45}$. Bei Kant und Fichte war denn konsequenterweise überhaupt nicht von verschiedenen Freiheitsrechten, sondern nur von einem, dem Urrecht der Freiheit die Rede ${ }^{46}$. Und Kant erläuterte: „Nicht das princip der allgemeinen Glükseeligkeit sondern Freyheit nach allgemeinen Gesetzen macht das princip der Staatserrichtung und die Idee davon aus '447.

Historisch richtet sich das bekanntlich gegen die Staatszwecklehre des aufgeklärten Absolutismus ${ }^{48}$; sachlich schließt dieses Freiheitsprinzip indes jede rechtliche Inanspruchnahme des Menschen für letzte Güter, Ziele, Zwecke oder Werte aus, die ihn übersteigen, deren personaler Träger nicht der einzelne ist. Die Idee persönlicher Freiheit meint freilich nicht grenzenlose Beliebigkeit. Sie ist gedacht als Freiheit moralischer Selbstbestimmung. Sie gibt - noch einmal kantisch gesprochen - Raum, sich selbst zu vervollkommnen und die anderen glücklich werden zu lassen (nicht umgekehrt). Menschliche Entfaltung ist Sache des einzelnen, genauer: der

45 Vgl. G. Dürig in: Maunz/Dürig u. a., Grundgesetz-Kommentar, RN $80 \mathrm{zu}$ Art. 1. Vgl. dazu M. Kriele, Befreiung und politische Aufklärung, 1980, S. 49 ff. Zum folg. E. Grabitz, Freiheit und Verfassungsrecht, 1976, S. 137 ff., 235 ff.; H. Böckerstette, Aporien der Freiheit und ihre Aufklärung durch Kant, 1982, S. 306 ff., 349 ff.

${ }^{46}$ Kant, Metaphysik der Sitten (Ed. Vorländer), S. 43; Fichte, Grundlage des Naturrechts (Ed. Medicus/Zahn), S. $110 \mathrm{ff}$.

${ }^{47}$ Reflexionen zur Rechtsphilosophie Nr. 7955 = Akad.-Ausg. XIX, S. 564 .

${ }^{48}$ Vgl. U. Scheuner in Gedächtnisschr. f. H. Conrad, 1979, S. 467 (481 ff.); ders., Der Beitrag der deutschen Romantik zur politischen Theorie, 1980, S. 13, 25. 
einzelnen miteinander ${ }^{49}$, nicht unmittelbar mehr Sache des Rechts und der politischen Gemeinschaft, welche nur noch Zwecke des gemeinsamen Lebens verfolgt und auch das nur noch in einer spezifisch rechtlichen, $d . h$. den Bereich der Gesinnung aussparenden Weise. Die Gründung der Rechtsordnung auf das Verfassungsprinzip der Freiheit bedeutet so zugleich das „Äußerlichwerden“ des Rechts ${ }^{50}$. Die andere Seite dieser Reduktion des Rechtsbegriffs ist bekanntlich seine Verschmelzung mit dem Zwangsmoment ${ }^{51}$.

Alles dies - das Prinzip der individuellen Freiheit mit dem daraus folgenden Postulat der Bestimmtheit und Begrenztheit der Eingriffsmöglichkeiten, das Äußerlichwerden des von der Moral getrennten Rechts und die Einschmelzung des Zwangsmoments in den Rechtsbegriff - machen den Begriff der Pflicht juristisch höchst problematisch ${ }^{52}$ und engen die Möglichkeiten einer freiheitlichen Verfassung, den Status der Rechtsgenossen auch durch Rechtspflichten zu definieren, a priori weitgehend ein. Denn unter solchen Voraussetzungen ist die Pflicht allemal ein sekundärer, ein bedingter und abgeleiteter, kein konstituierender Begriff. Eben dies demonstriert das Bonner Grundgesetz. Je lapidarer und damit konstitutionsförmiger, aber eben auch unbestimmter eine Pflichtenerklärung ausfällt, um so zweifelhafter wird ihr Rechtscharakter. Und diejenigen Pflichten, um deretwillen der deutsche Idealismus das Urrecht der Freiheit als Prinzip der Rechtsverfassung propagiert hat, sind als ,bloß" moralische Pflichten überhaupt nicht mehr rechtssatzfähig und vermögen die Konsequenzen des Verfassungsprinzips der Freiheit auf die Dauer nicht auszubalancieren. Als Robert v. Mohl seiner Staatslehre eine "Staats-Sittenlehre" zuordnete und deren Notwendigkeit mit dem Hinweis begründete, daß Errichtung und Erhaltung des Staates nicht nur der (notfalls erzwingbaren) Erfüllung der Forderungen des Rechts bedürften, sondern in gleichem Maße "von jedem Einzelnen" allein kraft des sittlichen Gewissens „einen vernünftigen Willen ... in Beziehung auf das Zusammenleben" verlangten ${ }^{53}$, da stand er wissenschaftlich längst

$49 \mathrm{Vgl}$. K. Löwith, Das Individuum in der Rolle des Mitmenschen, 1928; D. Suhr, Entfaltung der Menschen durch die Menschen, 1976.

${ }^{50} \mathrm{Vgl}$. Kant, Metaphysik der Sitten (Ed. Vorländer), S. 33 ff.

51 Vgl. H. Hofmann in: Rechtsphilosophie der Aufklärung (FN 6), S. 27 ff.; z. folg. ders., Legitimität und Rechtsgeltung, 1977, S. 24 ff., $36 \mathrm{ff} ., 71$.

52 Vgl. statt aller H.-L. Schreiber, Der Begriff der Rechtspflicht, 1966; V. Kubes, Die Rechtspflicht, 1981.

${ }^{53}$ R. v. Mohl, Encyklopädie der Staatswissenschaften, 2. Aufl. 1872, S. 504. 
auf verlorenem Posten. Georg Jellinek hat Mohls ,Staats-Sittenlehre" dann nicht nur als "Sammlung von Trivialitäten“ abgetan, sondern - und das bedeutete für die juristische Fachwelt das eigentliche wissenschaftliche Todesurteil - als Teil der Politik bezeichnet ${ }^{54}$.

Die Summe dieser Entwicklung hat Carl Schmitt in einigen Bemerkungen über die Grundpflichten der Weimarer Reichsverfassung zu ziehen unternommen ${ }^{55}$. Diese gern zitierten Sätze sind allerdings nicht ganz zuverlässig. Insbesondere ist die Sentenz, daß „prinzipiell unbegrenzte Pflichten“ der „Idee des bürgerlichen Rechtsstaats" widersprächen ${ }^{56}$, so nicht ganz richtig. Die Pflicht, keine Gewalt anzuwenden zum Beispiel, ist eine Rechtspflicht, und zwar keine begrenzte. Aber sie hebt den Rechtsstaat nicht auf, sondern ist eines seiner konstituierenden Elemente. Im Unterschied zu solchen Unterlassungspflichten sind es also nur prinzipiell unbegrenzte Leistungspflichten, welche in der Tat der Idee des Rechtsstaats widersprechen. Und sie tun es deshalb, weil unbegrenzte Leistungspflichten eine unbedingte Inanspruchnahme des Individuums voraussetzen. Der rechtsstaatlichen Verfassung aber liegt ein kategorischer Satz über die Freiheit des Menschen zugrunde. Und dies schließt aus, daß sie den Menschen für ein Ziel über dem Menschen - es heiße Gemeinwohl, Staat, Volk, Rasse oder Klasse - ebenso unbedingt positiv in Anspruch nimmt.

Ganz anders verhält es sich folglich dort, wo dies geschieht: in den Verfassungen der sozialistischen Staaten ${ }^{57}$. Hier stehen

${ }^{54}$ G. Jellinek, Allgemeine Staatslehre, 7. Neudr. der 3. Aufl., 1960, S. 99 FN 1.

${ }^{55}$ C. Schmitt in: Handb. d. Dt. Staatsrechts, hg. v. G. Anschütz u. R. Thoma, Bd. II, 1932, S. 572 (597), teilw. abgedr. in: Verfassungsrechtliche Aufsätze, 1958, S. 181 (216).

${ }^{56}$ C. Schmitt, Verfassungslehre, 1928, S. $174 \mathrm{f}$.

${ }^{57} \mathrm{Vgl}$. Abschn. II Kap. 1 (Grundrechte und Grundpflichten der Bürger) der Verf. der DDR v. 6. 4. 1968 i. d. F. v. 7. 10. 1974, v. a. Art. 21 III 1 (,Die Verwirklichung dieses Rechts der Mitbestimmung und Mitgestaltung ist zugleich eine hohe moralische Verpflichtung für jeden Bürger."), Art. 23 I (,Der Schutz des Friedens und des sozialistischen Vaterlandes und seiner Errungenschaften ist Recht und Ehrenpflicht der Bürger der Deutschen Demokratischen Republik. Jeder Bürger ist zum Dienst und zu Leistungen für die Verteidigung der Deutschen Demokratischen Republik entsprechend den Gesetzen verpflichtet."), Art. 24 II (,Gesellschaftlich nützliche Tätigkeit ist eine ehrenvolle Pflicht für jeden arbeitsfähigen Bürger. Das Recht auf Arbeit und die Pflicht zur Arbeit bilden eine Einheit."), Art. 25 IV (,In der Deutschen Demokratischen Republik besteht allgemein zehnjährige Oberschulpflicht... Alle Jugendlichen haben das Recht und die 
die Grundpflichten wie die Grundrechte in gleicher Weise unter der Behauptung objektiver gesellschaftlicher Bedürfnisse und Entwicklungsgesetze. Sozialistische Grundrechte und Grundpflichten ,orientieren die Bürger“, wie es heißt, ,,auf ein gesellschaftlich notwendiges Handeln ${ }^{* 58}$. In dieser Relativierung werden Rechte, Pflichten und moralische Anforderungen prinzipiell ununterscheidbare Momente behaupteter „objektive(r) gesellschaftliche(r) Gesetzmäßigkeiten" "59. Die Einheit von Grundrechten, Grundpflichten und sozialistischer Moral, welche die republikanische Errungenschaft einer spezifisch rechtlichen Sicherung individueller Freiheit beseitigt, gilt denn auch als besonderes Kennzeichen des Sozialismus ${ }^{60}$. Wenn gleichwohl immer wieder betont wird, es sei der Mensch, der bei alledem im Mittelpunkt stehe, so ist das kein Widerspruch. Geht es dabei ja nicht um den Menschen, wie er ist, sondern um den Menschen als das künftige Produkt all jener Gesetzmäßigkeiten, so daß die sozialistischen Verfassungen, kantisch gesprochen, ganz konsequent diejenigen glücklich werden lassen, welche den anderen zu der für sie vorgesehenen Vollkommenheit verhelfen ${ }^{61}$.

Das prinzipiell andere Konstruktionsprinzip freiheitlicher Verfassungen bedeutet nun freilich nicht, daß ein freiheitlicher Staat bloß ein Not- und Verstandesstaat ist. Menschliche Freiheit bedarf zu ihrer Entfaltung vorgeformter Möglichkeiten und institutioneller Stabilisierung ${ }^{62}$. Es folgt aus jenem Bau-

Pflicht, einen Beruf zu erlernen."). - S. ferner W. N. Kudrjawzew u. a., Verfassung der UdSSR, 1980, S. 127 ff., und den Überblick über den Pflichtenkatalog der neuen Verf. der UdSSR von 1977 bei G. Brunner in: Osteuropa 1978, S. 70 (75). Zum folgenden ders. in: Gottfried Zieger u. a., Die Ausübung staatlicher Gewalt in Ost und West nach Inkrafttreten der UN-Konvention über zivile und politische Rechte, 1978, S. $37 \mathrm{ff}$.

${ }^{58}$ E. Poppe, NJW 1978, S. 326.

59 Ebd. - Ebenso H. Klenner in: Marxistisch-leninistische Staatsund Rechtstheorie, hg. v. Inst. f. Theorie d. Staates u. d. Rechts d. Ak. d. Wiss. d. DDR, 3. Aufl. 1980, S. 408 (417): „. . . die gesetzgeberische Fixierung von Bürgerrechten und -pflichten (ist) nur der orientierende Ausgangspunkt erforderlicher Gesellschaftsveränderungen."

${ }_{60}$ Vgl. Ak. f. Staats- und Rechtswiss. d. DDR (Hg.): Staatsrecht der DDR, 1977, S. 190 f. Zum folgenden auch I. Szabó u. a., Socialist Concept of Human Rights, 1966 , bes. S. 53-81.

${ }_{61}$ Klenner (FN 59), S. 416: „Die sozialistische Gesellschaft ... ist nicht das ökonomische und politische System, das allen Leuten am meisten recht ist."

${ }^{62}$ Vgl. dazu E.-W. Böckenförde, Der Staat als sittlicher Staat (1978), S. 15 ff.; $O$. Höffe in: Wie frei ist der Mensch? Hg. v. J. Splett, 1980, S. $54 \mathrm{ff}$. 
prinzip aber auch nicht die Unmöglichkeit rechtlich relevanter Grundpflichten. Daß die Dimension der Grundpflichten gegenüber dem Urrecht der Freiheit theoretisch eine sekundäre ist, besagt nicht, daß diese Grundpflichtendimension nur die der Volkspädagogik, der rechtlich nicht sanktionierten öffentlichen Sittlichkeit sein könnte. Die geschichtlichen Ursprünge lehren es anders ${ }^{63}$.

\section{Zur Geschichte der Grundpflichten}

\section{Die klassischen Grundpflichten}

Verfassungsrechtlich festgelegte Grundpflichten, so ist befremdlicherweise gelegentlich $\mathrm{zu}$ lesen, habe es vor der Weimarer Reichsverfassung „so gut wie überhaupt nicht" gegeben $^{64}$. Eher schon scheint die These zuzutreffen, daß die Redeweise der Weimarer Verfassung von den Grundrechten und Grundpflichten der Deutschen ,etwas gänzlich neues" war $^{65}$. In der Tat erscheint der Terminus „Grundpflicht“ als eine aus dem Sozialethos der Weimarer Nationalversammlung geborene komplementäre Prägung zu dem auf das Frankfurter Vorparlament zurückgeführten Begriffsnamen „Grundrecht" ${ }^{466}$. Und bei dieser vermeintlich älteren Frankfurter Wortschöpfung von den Grundrechten, welche den verfassungsrechtlichen und -politischen Bedürfnissen der Zeit auf das glücklichste entgegenkam ${ }^{67}$, handelt es sich um eine Entsprechung zu den subjektiven Umprägungen und Ausmünzungen der alten

${ }^{63}$ Die Geschichte der Grundpflichten ist noch nicht geschrieben. Einige Vorarbeiten zu den deutschen Verfassungen zwischen 1806 und 1918 bietet die Würzburger Diss. v. H. Saffert: Geschichte der Grundpflichten, 1959. Ansonsten ist zurückzugreifen auf $A$. Voigt, Geschichte der Grundrechte, 1948, u. G. Oestreich, Geschichte der Menschenrechte und Grundfreiheiten im Umriß, 2. Aufl. 1978.

6. vangoldt/Klein (FN 13), Vorbem. A V 1; Chr. Gusy, JZ 1982, S. 657.

${ }^{65}$ J. V. Bredt, Der Geist der Deutschen Reichsverfassung, 1924, S. 263; ebenso Thoma (FN 11), S. 28.

${ }^{66}$ Vgl. G. Kleinheyer in: Geschichtliche Grundbegriffe, hg. v. O. Brunner u. a., Bd. 2, 1975, S. 1047 (1076 ff.).

${ }^{67}$ Dazu E. Eckhardt, Die Grundrechte der Deutschen, Diss. Tübingen 1913, S. 88, 95 f.; U. Scheuner in FS f. E. R. Huber, 1973, S. 139 (149 ff.), jetzt auch in: Staatstheorie und Staatsrecht, 1978, S. $633 \mathrm{ff}$. 
leges fundamentales ${ }^{68}$ in England, Nordamerika und Frankreich $^{69}$.

Unbekannt scheint jedoch zu sein, daß sich in Deutschland bereits seit 1769 die Redeweise von den "Grundrechten und Grundpflichten des Menschen" findet - allerdings nicht bei den Fachjuristen, versteht sich, sondern in der praktischen Philosophie, welche bekanntlich die Behandlung des Naturrechts einschloß. Dem Schema vernunftrechtlicher Deduktion folgend beginnt der Göttinger Philosophieprofessor Feder den naturrechtlichen Teil seines Lehrbuches der praktischen Philosophie mit der Erörterung des Naturzustandes ${ }^{70}$. Aber anders als Hobbes, Locke und die zeitgenössischen Physiokraten fragt Feder nicht nur oder vor allem nach den Rechten des Menschen vor jeder Vergesellschaftung, sondern zugleich auch nach seinen ursprünglichen Rechtspflichten. Dies entspricht einer vernunftrechtlichen Tradition, welche über Christian Wolff bis Grotius zurückreicht und die vor allem Pufendorf geprägt hat, einer Tradition, der mit Svarez auch das Preußische Allgemeine Landrecht verpflichtet ist. Jene ursprünglichen Rechtspflichten stellt Feder den "Grundrechten" ausdrücklich als „Grundpflichten“ zur Seite. Er versteht darunter die aus der ursprünglichen Rechtsgleichheit folgenden (unbegrenzten) negativen Pflichten des einzelnen, die selbst in Anspruch genommenen Grundrechte bei den anderen nicht zu verletzen. Funktionell entspricht Feders Terminus "Grundpflicht" den bei anderen Autoren im Gegensatz zu den Bürgerpflichten gebrauchten Bezeichnungen "Menschenpflicht" oder „Naturpflicht" ${ }^{\text {"71 }}$. Der Sache nach ist damit nur die Not-

${ }^{68}$ Zum Begriff und seiner Herkunft G. Jellinek, Allg. Staatslehre, S. $508 \mathrm{ff}$; Chr. Link, Herrschaftsordnung und bürgerliche Freiheit, 1979, S. 179 ff. Zum folg. G. Stourzh in: Grund- und Freiheitsrechte im Wandel von Gesellschaft und Geschichte, hg. v. G. Birtsch, 1981, S. 59.

${ }^{69}$ Bei den Physiokraten ist diese Wendung ins Subjektive für 1770 belegt; vgl. Oestreich (FN 63), S. 66; Kleinheyer (FN 66), S. 1076.

${ }^{70}$ Johann Georg Heinrich Feder, Lehrbuch der praktischen Philosophie (1769). Benutzt habe ich die 2. Aufl. Göttingen und Gotha 1771 (S. 199 ff. des 1. Teils, S. 14 ff. des 2. Teils) und die 4. Aufl. Frankfurt und Leipzig 1781 (S. 179 ff., 279 ff., 407 ff.), eingesehen außerdem die 3. Aufl. Hanau und Leipzig 1775, die 4. Aufl. Frankfurt und Leipzig 1781, ferner 2 Wiener Ausgaben von 1779 und 1791. - Zum Naturzustandstheorem vgl. Hofmann in: Rechtsphilosophie der Aufklärung (FN 6), S. 12.

${ }^{71}$ Vgl. J. A. Schlettwein, Die Rechte der Menschheit oder der einzige wahre Grund aller Gesetze, Ordnungen und Verfassungen, 1784, S. 121, 161 u. ö.; C. F. Bahrdt, Handbuch der Moral für den Bürgerstand, 1789 , S. $134,188$. 
wendigkeit der Gemeinverträglichkeit jeder Rechtsausübung, die Mißbrauchsschranke der Rechte als Bedingung der Möglichkeit gleicher Rechte für alle formuliert. Feder spricht denn selbst von der Einschränkung des Rechts durch die Pflicht. Dem Pufendorfschen Schema folgend werden alsdann die (relativen) Rechte und Pflichten des sog. hypothetischen, durch die Vornahme bestimmter Handlungen charakterisierten Naturzustandes besonders bezüglich des Eigentums- und Vertragsrechts vorgeführt. Davon abgehoben erscheinen die aus der Denkfigur des Unterwerfungsvertrages für den staatlichen Zustand folgenden Rechte und Pflichten der Untertanen einschließlich insbesondere der Gehorsamspflicht, ohne daß insoweit noch von Grundrechten und Grundpflichten die Rede wäre. Beide Erörterungen wiederum sind streng geschieden von der Behandlung der moralischen Pflichten einschließlich der Bürgertugenden.

Nach der vernunftrechtlichen Theorie des Gemeinwesens sind die wirklich ursprünglichen Pflichten also gleichbedeutend mit den immanenten Schranken der elementaren Freiheitsrechte. Folgerichtig hat die Mehrheit der französischen Nationalversammlung im August 1789 eine eigene Pflichtenerklärung mit der Begründung abgelehnt, in einem freiheitlichen Gemeinwesen seien die Pflichten mit den Grenzen der Rechte identisch ${ }^{72}$. Indessen beschränkt sich die Tragweite dieses Arguments auf den angenommenen Bereich vorstaatlicher Individualrechtsbeziehungen, das sog. natürliche Privatrecht also $^{73}$, dessen staatlicher Sanktionierung Grundrechtserklärungen ebensogut dienen können wie Strafgesetze und Bürgerliche Gesetzbücher ${ }^{74}$. Diese elementaren Rechte und Pflichten finden ihre Sanktionierung mit anderen Worten zunächst in den Normen, welche Montesquieu die lois civiles genannt und von den lois politiques unterschieden hatte. Alle über jene elementaren interindividuellen Pflichten hinausge-

${ }^{72}$ Vgl. Schickhardt (FN 22).

${ }^{73}$ Dazu näher Hofmann in: Rechtsphilosophie der Aufklärung (FN 6), S. 26 ff., $39 \mathrm{ff}$.

${ }^{74}$ Vgl. hierzu W. Leisner, Grundrechte und Privatrecht, 1960, 3 ff., und D. Grimms These von der Privatrechtsakzessorietät der Grundrechte in: Grund- und Freiheitsrechte im Wandel (FN 68), S. 359 (361 f.). Noch $R$. Sohm hat mit Blick auf das Privateigentum in den ersten Reichstagsberatungen des BGB-Entwurfs erklärt: „In dem Privatrecht liegt die Magna Charta unserer öffentlichen Freiheit. Weit mehr als auf der Staatsverfassung, beruht auf dem bürgerlichen Rechte das, was wir Freiheit nennen" (B. Mugdan, Die gesamten Materialien zum BGB, I. Bd., 1899, S. 909). 
henden positiven Leistungspflichten persönlicher und sachlicher Art gehören nach der zweistufigen Sozialtheorie der Aufklärung dem Kreis „,politischer Gesetze“ zu, treffen also nicht den Menschen als solchen, sondern den Bürger und gründen entweder unmittelbar in der auf dem Prinzip der Gleichheit basierenden Konstruktion vertraglicher Rechtfertigung des Staates oder in positiver staatlicher Gesetzgebung. Der Versuch, die Grundpflichten i. S. der absoluten (Unterlassungs-) Pflichten des absoluten Naturzustandes verfassungsgesetzlich zu positivieren, führt 1795 in der Direktorialverfassung also ganz konsequent zur Proklamation des Gegenseitigkeitsprinzips der Goldenen Regel ${ }^{75}$. Konkretisiert und sanktioniert werden diese Pflichten und die sog. relativen Pflichten des hypothetischen Naturzustandes, d. h. die Grundsätze des Eigentums-, Vertrags-, Familien- und Gesellschaftsrechts ebenso folgerichtig in den Unterlassungs-, Duldungs- und Leistungspflichten des Bürgerlichen und insbesondere den Unterlassungspflichten des Strafrechts: sie formulieren als die notwendigen allgemeinen Gesetze die Schranken der Freiheit. Dieses Verständnis der Grundpflichten erklärt auch, warum die grundlegenden sozialen Gebote der 2. Tafel des Dekalogs niemals unter die verfassungsgesetzlichen Pflichten aufgenommen worden sind. Das ist an sich ja um so weniger selbstverständlich, als die Schutzgüter des 5., 7. und 10. Gebots jedenfalls von Haus aus mit denen der Forderung nach Schutz von life, liberty und property identisch sind. Man muß sich nur vergegenwärtigen, daß das Gebot „Du sollst nicht stehlen“ nach seinem ursprünglichen Wortsinn die Freiheitsberaubung verbietet, das also, was Joseph von seinen Brüdern widerfuhr.

Diejenigen Pflichten nun, welche seit dem ausgehenden 18. Jahrhundert in Gestalt der Gehorsams-, der Eigentumsabtretungs-, der Wehr- und Steuerpflicht den Grundrechten verfassungsgesetzlich zur Seite traten und denen am Ende die Weimarer Verfassung den Namen Grundpflichten gegeben hat, liegen nach dem ursprünglichen konstitutionellen Verständnis als Bürgerpflichten zur Erhaltung des die individuel-

75 Art. 2: Tous les devoirs de l'homme et du citoyen dérivent de ces deux principes, gravés par la nature dans tous les coeurs: Ne faites pas à autrui ce, que vous ne voudriez pas, qu'on vous fit. Faites constamment aux autres le bien, que vous voudriez recevoir. Vgl. dazu $L$. $J$. Philippidis, Die „Goldene Regel“ religionsgeschichtlich untersucht, Diss. Leipzig 1929; H. Reiner, Zeitschr. f. philosoph. Forsch. 1948, S. 74; ders., Die philosophische Ethik, 1964, S. $186 \mathrm{ff}$; A. Dihle, Die Goldene Regel, 1962; G. Spendel in FS f. F. v. Hippel, 1967, S. 491. 
le Freiheit ermöglichenden und schützenden Gemeinwesens auf einer anderen Regelungsebene als die Sätze über menschliche Freiheit und Gleichheit samt den zugehörigen Grundpflichten i. S. des Vernunftrechts: sie sind nicht als Schranken individueller Rechte, sondern als positive Verpflichtungen gegenüber dem Gemeinwesen gedacht. Unter Berufung auf den Sozialvertrag erklärt 1780 die Verfassung von Massachusetts in Art. 10, daß in der Konsequenz seines Anspruches auf Schutz durch die Gemeinschaft ein jeder verpflichtet sei, durch persönliche Dienste oder ein Äquivalent zur Organisation dieses Schutzes beizutragen ${ }^{76}$. Auch die berühmte Déclaration von 1789 erinnert in ihrer Präambel nicht nur an die natürlichen Rechte des Menschen, sondern auch an die Pflichten der Mitglieder einer Gesellschaft. Sie tut das konkret, insofern sie in dem nach Vorgeschichte und Theorie der Revolution kritischsten Falle, nämlich dem von Vorladung und Verhaftung unter der Voraussetzung gesetzlicher Begründung Gehorsam befiehlt, die allgemeine Steuerpflicht nach Maßgabe der individuellen Möglichkeiten für die Unterhaltung der Streitkräfte und für die Kosten der Verwaltung proklamiert und die Eigentumsaufopferungspflicht für die Fälle gesetzlich definierter öfentlicher Notwendigkeit statuiert. Deklaration und Verfassungsgesetz von 1793 sahen darüber hinaus neben der Widerstandspflicht die allgemeine Wehrpflicht vor. Die Verfassung von 1795 verallgemeinert die Gehorsamspflicht, bettet die Wehrpflicht in eine allgemeine öffentliche Dienstpflicht ein und wiederholt die Eigentumsabtretungspflicht ${ }^{77}$.

Die Quadriga der ursprünglichen verfassungsgesetzlichen Grundpflichten im Sinne republikanischer ${ }^{78}$ Bürgerpflichten ist damit komplett: Gesetzesgehorsam, allgemeine Wehr- und Steuerpflicht, Eigentumsabtretungspflicht. Die letztgenannte Verbindlichkeit wird freilich meist übersehen, obwohl sie seit

${ }^{76}$ Each individual of the society has a right to be protected by it in the enjoyment of his life, liberty and property, according to standing laws. He is obliged, consequently, to contribute his share to the expense of this protection; to give his personal service, or an equivalent, when necessary. Verfehlt daher $H$. Bayer, Entstehung und Bedeutung wirtschaftlicher Grundrechte und Grundpflichten, Diss. Frankfurt a. M. 1937, S. 14, demzufolge die Grundpflichten letztlich „dem Geist des absolutistischen Obrigkeitsstaates" entstammten.

${ }^{77}$ Im übrigen entfällt die Pflichtenerklärung der Direktorialverfassung infolge des neuerlichen politischen Frontwechsels: Nun war die bürgerliche Freiheit wieder von den alten Mächten, nicht mehr von den Unterschichten bedroht.

${ }^{78} \mathrm{Zu}$ diesem Begriff J. Isensee, JZ 1981, S. 1. 
1789 fester Bestandteil aller Verfassungsurkunden ist und ihr nach dem vernunftrechtlichen Konzept des Sozialvertrages gerade zum Schutz des Eigentums zentrale Bedeutung zukam. Historisch dürfte der Grund dafür in der zivilrechtlichen Deutung der Enteignung liegen ${ }^{79}$.

Neben der Eigentumsabtretungspflicht werden auch die anderen republikanischen Grundpflichten seit $1807^{80}$ in die Verfassungsurkunden der deutschen Staaten übernommen. Allerdings verändern diese Pflichten im Verlauf der Verstaatlichung der aufklärerischen Menschenrechtserklärungen ihren Charakter. In diesem Prozeß, in dem die Revolutionsfurcht die Menschenrechte zu staatlich gewährten, weitgehend unpolitischen Volksfreiheiten verkürzt ${ }^{81}$, in dem Gewährleistungen und Verpflichtungen nicht mehr anknüpfen an den abstrakt vernunftrechtlichen Begriff des Bürgers, sondern an dem des Volkes (d. h. der „organischen“ Stellung des einzelnen), am Begriff des Untertanen, am Indigenat, und endlich an der Staatsangehörigkeit ${ }^{82}$ - in diesem Proze $\beta$ degenerieren die Pflichten der Bürger zur Erhaltung ihres freiheitlichen Gemeinwesens zu Pflichten von Untertanen monarchischer Staatsanstalten. Steuer- und Wehrpflicht verlieren ihren einstigen programmatischen Zusammenhang mit der Sicherung der Menschen- und Bürgerrechte ${ }^{83}$. Die Grundsätze der allgemeinen Wehrpflicht und der allgemeinen direkten und progressiven Besteuerung sind in den deutschen konstitutionellen Monarchien des 19. Jahrhunderts primär Programme und Instrumente der Obrigkeit zur Schaffung einer egalitären staatsbür-

${ }^{79}$ Schon Montesquieu hatte sie den lois civiles und nicht den lois politiques zugerechnet: Vom Geist der Gesetze XXVI 15. Zur zentralen Bedeutung der Enteignungsregelung für den 3. Stand $H$. Kutscher, Die Enteignung, Bd. 1, 1938, S. 20 ff.

${ }^{80}$ Erstmals in Art. 16 u. 53 (Steuergleichheit und Wehrpflicht) der Westfälischen Konstitution v. 15. 11. 1807.

${ }^{81} \mathrm{Vgl}$. Grabitz, Freiheit und Verfassungsrecht, S. 174 ff.; R. Wahl, Der Staat 1979, S. 321 (323). Gegen eine gewisse Ideologisierung dieser Perspektive z. B. bei J. Gaile, Menschenrecht und bürgerliche Freiheit, 1978, H. Brandt in: Grund- und Freiheitsrechte im Wandel (FN 68), S. 460 (462 ff.).

${ }^{82}$ Dazu näher W. $v$. Rimscha, Die Grundrechte im süddeutschen Konstitutionalismus, 1973, S. 15, 42, 77; Scheuner, FS f. E. R. Huber, S. 143 f.; Kleinheyer (FN 66), S. 1070 ff.; $R$. Grawert, Staat und Staatsangehörigkeit, 1973, S. $123 \mathrm{ff}$., $174 \mathrm{ff}$.

${ }_{83}$ Th. Heuss bezog sich mit seiner vielzitierten Äußerung im Parlamentarischen Rat, die allgemeine Wehrpflicht sei ein legitimes Kind der Demokratie, denn auch nur auf Frankreich: JöR NF 1 (1951) S. 77. 
gerlichen Gesellschaft; soweit sie unmittelbare Rechtswirkung entfalten, liegt diese in der Beseitigung wehrrechtlicher Exemtionen und steuerlicher Privilegien ${ }^{84}$. Der republikanische Gesetzesgehorsam schließlich wird regelmäßig überhöht durch eine zu beschwörende dynastische Treuepflicht ${ }^{85}$. Übrig bleibt davon am Ende der Diensteid der Beamten. Inhaltlich handelt es sich bei dem sehr alten Rechtsbegriff der Treue, der eine „ungemessene Dienstpflicht“ meint, über den bloßen Gehorsam hinaus von jeher um zweierlei: um die negative Verpflichtung, dem Herrn nicht zu schaden, das zu unterlassen, was man Majestätsbeleidigung, Hoch- und Landesverrat nennt - und positiv um die Pflicht, von sich aus zum Nutzen dessen zu handeln, dem man die Treue schuldet. In dem Maße, in dem der Verfassungsstaat sich durchsetzt, schrumpft die Treueforderung auf jene Unterlassungspflichten. Mehr als dies verlangt er am Ende von Rechts wegen nur noch von seinen Amtsträgern. Indem der staatsrechtliche Positivismus der 2. Hälfte des 19. Jahrhunderts die Grundpflichten ebenso wie die Grundrechte mit dem Begriff der Staatsangehörigkeit verknüpft, kann er die Treuepflicht in ihrer positiven Bedeutung als subjektiven Ausdruck der staatlichen Personalhoheit rationalisieren, d. h. zur Begründung der nur den Staatsangehörigen obliegenden Pflichten verwenden; alle anderen Verbindlichkeiten lassen sich dann unschwer auf die Gehorsamspflicht reduzieren ${ }^{86}$. Manche Autoren lassen die fragwürdig gewordene Treuepflicht freilich überhaupt beiseite und begreifen alle

${ }^{84}$ Vgl. E. R. Huber, Deutsche Verfassungsgeschichte, Bd. 1, 2. Aufl. 1967, S. 351 ff.; Scheuner in FS f. E. R. Huber, S. 139 (140); ders. in: Von der ständischen Gesellschaft zur bürgerlichen Gleichheit (Beihefte zu „Der Staat“ 4), 1980, S. 105 (107 f.); ders. in: Grund- und Freiheitsrechte im Wandel (FN 68), S. 376 ff.; v. Rimscha (FN 82), S. 8 ff., 12, 51 ff., 79, $124 \mathrm{ff}$.

${ }^{85}$ Vgl. Tit. X § 3 Bay. Verf.-U. v. 1818; § 20 württ. Verf.-U. v. 1819; $\S 120$ Verf.-U. Sachsen-Coburg-Saalfeld v. 1821; § 28 Verf.-U. SachsenCoburg-Gotha v. 1852; Art. 11 Verf.-U. Sachsen-Meinigen-Hildburghausen-Saalfeld v. 1829 ; $\$ 71$ II Verf.-U. Sachsen-Altenburg v. 1831; $\S 139$ Verf.-U. des Königreichs Sachsen v. 1831; § 25 braunschw. Neue Landschaftsordnung v. 1832. - Zum folgenden $R$. Wiesmann, Treueeid und Treuepflicht der Untertanen im deutschen Staatsrecht, 1911; V. Ehrenberg, Deutsche Rundschau 1884, S. 39; H. Mitteis/H. Lieberich, Deutsche Rechtsgeschichte, 16. Aufl. 1981, S. 76, 94, 99 f., 170, 196.

${ }^{86} \mathrm{Vgl} \mathrm{J}$. Pözl, Lehrbuch des Bayerischen Verfassungsrechts, 1851, S. 85 ff.; P. Laband, Das Staatsrecht des Deutschen Reiches, 1. Bd., 5. Aufl. 1911, S. 140 ff.; ähnlich $H$. Schulze, Lehrbuch des Deutschen Staatsrechts, 1881, S. 354 ff. (356); Ph. Zorn, Das Reichs-Staatsrecht, 1. Bd., 2. Aufl. 1895, S. 375. 
Verbindlichkeiten der Untertanen unter dem Titel der Gehorsamspflicht ${ }^{87}$. Weithin üblich war es, neben die Gehorsamspflicht der Untertanen Wehr- und Steuerpflicht als deren wichtigste Ausprägung zu stellen ${ }^{88}$. Diese drei Verbindlichkeiten sind es auch, die Hermann Schulze in seinem Preußischen Staatsrecht den „Grundrechten der Staatsbürger" fast 50 Jahre vor Weimar ausdrücklich als deren „Grundpflichten“ voranstellt ${ }^{89}$.

\section{Neuere Entwicklungen}

Wenn im Blick auf die Preußische Verfassung heute von den „drei großen staatsbürgerlichen Grundpflichten“ die Rede ist, welche „zum Wesen moderner Staatlichkeit gehören“ und damit außer der Wehr- und Steuerpflicht die allgemeine Schulpflicht herausgehoben wird ${ }^{90}$, so ist das eine historische Akzentverschiebung aus deutscher Perspektive. Zwar ist auch die sog. allgemeine Schulpflicht zweifellos ein wesentliches Moment in der Hervorbringung einer egalitären staatsbürgerlichen Gesellschaft. Noch das Verbot privater Vorschulen in der Weimarer Verfassung dient im Verein mit der Volksschulbesuchspflicht ja dem Zweck, Reste einer zwar längst nicht mehr herrschaftsständischen, aber immer noch sozialständischen Gesellschaft zu beseitigen. Der ursprünglich zugrundeliegende Gedanke der Vorsorge für die notwendige Unterrichtung

${ }^{87}$ Vgl. Jellinek, System der subj. öffentl. Rechte, S. 187; G. Meyer/G. Anschütz, Lehrbuch des Deutschen Staatsrechts, 6. Aufl. 1905, S. 818 ff.; E. Walz, Das Staatsrecht des Großherzogtums Baden, 1909, S. $16 \mathrm{ff}$.

${ }^{88}$ Vgl. L. v. Rönne, Das Staatsrecht der preußischen Monarchie, 1. Bd., 1856, S. 407 ff.; J. Held, Staat und Gesellschaft vom Standpunkte der Geschichte der Menschheit und des Staats, 3. Teil, 1865, S. 493 ff., 519 ff., 637 ff.; W. Schücking, Das Staatsrecht des Großherzogtums Oldenburg, 1911, S. 27; neben der Erwähnung der Treuepflicht ebenso Pözl (FN 86), Zorn (FN 86), S. 373 ff. und M. v. Seydel, Bayerisches Staatsrecht, 1. Bd., 2. Aufl. 1896, S. 293 f.

${ }_{89}$ H. Schulze, Das Preussische Staatsrecht, 1. Bd., 1872, S. 365. Er bemerkte dazu: „Es ist ein weitverbreiteter Fehler unserer modernen gesellschaftlichen Anschauung, immer nur an die Rechte des Individuums dem Staate gegenüber zu denken und darüber fast zu vergessen, dass das Verhältnis des Bürgers zum Staate in erster Linie ein Pflichtverhältnis ist, welches auch im Systeme durchaus an die Spitze gehört."

S. 101 . 
der Kinder ist jedoch älter als alle Menschenrechtsproklamationen und entstammt utilitaristisch-patriarchalisch-wohlfahrtsstaatlichem Denken ${ }^{91}$. Und auch seine relativ späte verfassungsgesetzliche Fixierung in den Frankfurter Grundrechtserklärungen und der insoweit ihr folgenden Preußischen Verfassung gehört einer anderen verfassungsrechtlichen Entwicklungsstufe an als die ursprünglichen republikanischen Grundpflichten. Obwohl die sog. Schulpflicht anders als nach Art. 145 I WRV zunächst nicht die Verpflichtung zum Besuch von Schulen beinhaltet, sondern nur Unterrichtszwang bedeutet ${ }^{92}$, korrespondiert ihr im Gegensatz zu dem gemeinsamen Vorbild der Belgischen Verfassung von 1831 kein Grundrecht auf Staatsfreiheit des Unterrichts; die Regelung bleibt eingebettet in die deutsche Tradition unmittelbarer Schulhoheit des Staates, bleibt Teil kompensatorischer staatlicher Fürsorge ${ }^{93}$. Die verfassungsgesetzliche Hervorhebung der Unterrichtspflicht ist ein Moment der kulturstaatlichen Modernisierung des Unterrichtswesens und sie erscheint 1848 zugleich als ein Versuch bundesstaatlicher Homogenisierung.

Die republikanischen Pflichten zu Gesetzesgehorsam, Abgaben, Wehrdienst und Eigentumsopfern sowie die kulturstaatliche Schulpflicht - dies ist der Standard, auf dem die Nationalversammlung in Weimar aufbaut. Sie ergänzt die Schul-

${ }^{91}$ Vgl. A. Eisenhut, Die Entwicklung der Schulgewalt und ihrer Stellung im Verwaltungsrecht in Deutschland, Diss. Jena 1932, S. 6 ff.; Th. Oppermann, Kulturverwaltungsrecht, 1969, S. 42.

${ }^{92}$ Vgl. M. Müller, Die Lehr- und Lernfreiheit, 1911, S. 215 ff., 232, $236 \mathrm{ff}$; ferner $M$. v. Seydel, Bayerisches Staatsrecht, 3. Bd., 2. Aufl. 1896, S. 624 ff. (647 f.), K. Göz, Das Staatsrecht des Königreichs Württemberg, 1908, S. 471; Walz, Das Staatsrecht des Großherzogtums Baden, S. 431 ff. (434); G. Anschütz, Die Verfassungsurkunde für den preußischen Staat usw., Bd. 1, 1912, S. 383 ff. - „Nur ausnahmsweise“ ließ das Grundschulgesetz der verfassunggebenden Deutschen Nationalversammlung v. 28.4. 1920 (RGBl. S. 851) "für besondere Fälle“ noch Privatunterricht statt des Schulbesuchs zu. - Im einzelnen sind 5 Stadien der Entwicklung zu unterscheiden: 1. Staatlicher Unterrichtszwang; 2 . durch gemeindliche und private Initiativen bedingte Steigerung zur Schulbesuchspflicht; 3. Schulbesuchspflicht bei Verpflichtung der Gemeinden zur Volksschulunterhaltung mit Ausnahmen zugunsten privater Unterrichtsanstalten und eines entsprechenden Privatunterrichts; 4. Ausnahmen von der Schulbesuchspflicht nur noch in besonderen Fällen; 5. Pflicht zum Besuch staatlicher oder privater Volksschulen mit Ausnahmen nur noch für den Besuch weiterführender Schulen.

${ }^{93}$ Vgl. W. Landé in: Die Grundrechte und Grundpflichten der Reichsverfassung, hg. v. H. C. Nipperdey, Bd. 3, 1930, S. 1 (3 f.). 
pflicht, der nun auch die demokratische Aufgabe der Homogenitätssicherung zuwächst ${ }^{94}$, durch die elterliche Erziehungspflicht (Art. 120), nimmt die mehr aus dem Kommunal- als aus dem Verfassungsrecht bekannte Pflicht zur Übernahme von Ehrenämtern auf (Art. 132) und fügt spezifisch sozialstaatliche Grundpflichten hinzu: Duldung entschädigungsloser Enteignungen (Art. 153 II 2), Sozialpflichtigkeit des Eigentums, besonders des Grundeigentums (Art. 153 III, 155 I) sowie Bodennutzung als Pflicht der Grundbesitzer (Art. 155 III). Sogar die Treuepflicht wird in sozialstaatlicher Wendung neu belebt: „Jeder Deutsche“, heißt es in Art. 163, „hat, unbeschadet seiner persönlichen Freiheit, die sittliche Pflicht, seine geistigen und körperlichen Kräfte so zu betätigen, wie es das Wohl der Gesamtheit erfordert." Die aus der systematisch fragwürdigen Stellung dieses Artikels resultierende Apostrophierung als „Arbeitspflicht" wird seinem Inhalt nicht ganz gerecht. Hervorzuheben bleibt, daß die Pflicht zum Gesetzesgehorsam, die ohnedies nie eine rein formale Pflicht $w^{2}{ }^{95}$, nunmehr eine spezifisch parlamentarisch-demokratische Dimension gewinnt. Auch die allgemeine Dienstpflicht des Art. 133 I, welche in der Vorgeschichte nur sporadisch auftaucht, ist nun ebenfalls in diesem Zusammenhang zu sehen.

Das Grundgesetz hat von alledem letztlich mehr bewahrt, als es auf den ersten Blick erkennen läßt. Es hat den republikanisch-demokratischen, kultur- und sozialstaatlichen Grundpflichten sogar neue Ausprägungen hinzugefügt, nämlich den Treuegedanken in positiver Form für die Beamten und nach der negativen Seite in spezifisch gruppendemokratischen Vorkehrungen politischer Wehrhaftigkeit durch Art. 5 III, 9 II, 18

${ }^{94}$ F. Ossenbühl, Das elterliche Erziehungsrecht im Sinne des Grundgesetzes, 1981, S. 105 f.; Isensee, DOV 1982, S. 617 f.

${ }^{95}$ Die Auffassung Isensees (ebd. S. 612: "formale Grundpflicht") weicht davon nur scheinbar ab, weil er die Friedenspflicht i. S. des Verbots privater Gewaltanwendung im Gegensatz zum Text gesondert neben die Gehorsamspflicht stellt (vgl. jetzt auch in FS f. K. Eichenberger, 1982, S. 23) und die Frage der Befolgung rechtswidriger Anordnungen ausklammert. 
und 21 sowie die der Absage an den Machtstaatsgedanken entspringende Friedenspflicht des Art. 26 GG $^{96}$.

\section{Dogmatische Folgerungen}

\section{Zum Rang der Grundpflichten}

Die bisherigen Überlegungen erlauben einige dogmatische Schlußfolgerungen allgemeiner Art.

Die Verfassungsgeschichte, welche den vernunftrechtlichen Begriff von Grund-, Natur- oder Menschenpflichten einerseits und Pflichten des status civilis andererseits durch die Vorstellung einiger weniger Pflichten der Gewaltunterworfenen gegenüber dem Staat verdrängt hat, macht gewisse $Z$ weifel verständlich, ob solchen Grundpflichten derselbe Rang zukommen kann wie den als vorstaatlich angesehenen Grundrech$\operatorname{ten}^{97}$. Indessen bezeichnet die sog. Vorstaatlichkeit der Grundrechte nach dem Verfassungsprinzip der Freiheit keinen ontologischen oder genetischen Vorsprung oder Vorrang der Grundrechte ${ }^{98}$, sondern nur den nichtstaatlichen Sinn staatlicher Organisation. Zur konkreten Realisierung einer Verfassung der Freiheit bedarf es indessen positivrechtlicher Pflichtbindungen nicht weniger als der Rechtsgarantien. Und wenngleich das 19. Jahrhundert die Grundpflichten aus ihrem ursprünglichen republikanischen Sinnzusammenhang gelöstund zu Untertanenpflichten verkürzt hat - Pflichten gegenüber den Mitbürgern wie gegenüber dem Ganzen bleiben elementare Bedingungen der Lebensfähigkeit auch und gerade einer

${ }^{98}$ Wie die bloß national gedachte rechtsstaatliche Friedenspflicht ist auch die weltbürgerliche Friedenspflicht des internationale Verantwortung übernehmenden Verfassungsstaates jedenfalls als individuelle Grundpflicht nur eine Unterlassungspflicht; vgl. Stober, Grundpflichten und Grundgesetz, S. 55 ff.; K. Stern, Das Staatsrecht der Bundesrepublik Deutschland, Bd. 1, 1977, S. 375 f. m. weit. Nachw. zum Streitstand; neuestens G. Frank in: Unsere Bundeswehr? Red. R. Steinweg, 1981, S. 106 ff. - Der an dieser Stelle geplante rechtsvergleichende Überblick mußte aus Zeitgründen entfallen. Einiges konnte in der Diskussion nachgetragen werden. Herr Koll. Prof. Dr. K. J. Partsch hat mich darüber hinaus dankenswerterweise auf die American Declaration of the Rights and Duties of Man der 9. Konferenz der Amerikanischen Staaten, Bogotá 1948, hingewiesen.

${ }^{97}$ Man vgl. Hamann/Lenz (FN 13), S. 54.

${ }^{98}$ Eine Sammlung solcher Auffassungen bietet $K$. Kübler, Über Wesen und Begriff der Grundrechte, Diss. Tübingen 1965; vgl. dazu $D$. Schefold in: Begründungen des Rechts II, hg. v. K. v. Bonin, 1979, S. 33; E. Denninger, JZ 1982, S. 225. 
rechtsstaatlich-freiheitlichen Demokratie. Wenn allerdings Freiheit Prinzip der Verfassung ist, so bedeutet das verfassungstheoretisch einen Vorrang der Grundfreiheiten vor den Grundpflichten, weil jene dem Zweck der Verfassung unmittelbar, diese aber nur mittelbar dienen, indem sie die Koexistenz gleicher Freiheiten ermöglichen und die einzelnen für die Organisation zu deren Schutz in Anspruch nehmen. Verfassungsrechtlich dagegen sind Rechte und Pflichten gleichrangige und gleichwertige Verankerungen von Existenzbedingungen einer freiheitlichen Ordnung. Was bliebe verfassungsrechtlich vom Prinzip der Freiheit, die als gleiche Freiheit aller nur gesetzmäßige Freiheit sein kann, wenn die Achtung der Gesetze für zweitrangig erklärt würde? Schließlich: Unbeschadet der verfassungsrechtlichen Gleichrangigkeit und Gleichwertigkeit der verfassungsrechtlichen Verankerung von Grundrechten und Grundpflichten ist ihr verfassungsgesetzlicher Regelungsgehalt aus rechtsstrukturellen Gründen höchst ungleichgewichtig.

Probe auf den etwas vernachlässigten Gesichtspunkt verfassungsrechtlicher Gleichrangigkeit der Grundpflichtenverankerung ist die Frage nach der Abänderbarkeit der expliziten wie der implizierten verfassungsgesetzlichen Grundpflichtenregelungen. Gewiß: der Garantie erschwerter Abänderbarkeit unterfallen auch sie. Aber wie steht es mit der den Kern der Verfassung betreffenden „Ewigkeitsklausel“? Diese Frage ist nicht generell zu beantworten. So könnte die Pflicht zum verfassungsmäßigen Gehorsam - gleichviel ob sie explizit niedergelegt ist oder nicht - natürlich durch keine Vorschrift aufgehoben werden, ohne daß damit der Rechtsstaat und die Garantie gleicher Grundrechtsfreiheiten beseitigt würden. Die Problematik des Art. 20 Abs. 4 demonstriert dies. Auch der Grundsatz allgemeiner (und im Prinzip progressiver ${ }^{98}$ ) Besteuerung - ob er nun verfassungsgesetzlich formuliert ist oder nicht $^{99}$ - könnte nicht negiert werden, ohne daß der Gleichheitsgrundsatz und das Sozialstaatsprinzip verletzt würden;

989 Unverzichtbar ist freilich nur der darin steckende Gerechtigkeitsgedanke einer nach den Verhältnissen wachsenden Belastung, nicht die Art und Weise unserer derzeitigen, in der Tat sehr fragwürdigen progressiven Einkommensbesteuerung; vgl. W. Engels/J. Mitschke/ B. Starkloff, Staatsbürgersteuer, 1973, bes. S. 11, 91. Dies zu K. Vogel in: Bericht über die Fachtagung 1980 des Inst. der Wirtschaftsprüfer, 1980, S. 155 (164 f.).

${ }^{99} \mathrm{Ob}$ er für das GG positiv aus Art. 14 I 2, 14 II 1, 14 II 2, aus den Kompetenzvorschriften der Art. $105 \mathrm{ff}$. oder aus einem ungeschriebenen Verfassungsvorbehalt herzuleiten ist, kann hier also dahinstehen. 
denn der Sozialstaat des Grundgesetzes ist Steuerstaat ${ }^{100}$. Die Erziehungspflicht der Eltern ist die Kehrseite ihres Erziehungsrechts; sie steht und fällt mit ihm. Art. 7 I u. V GG sind unantastbar, insofern sie die allgemeine Schulpflicht implizieren. An ihr muß die Bundesrepublik nicht nur in dem völkerrechtlich festgelegten Mindestumfang und nicht nur aus völkerrechtlichen Gründen festhalten ${ }^{101}$. Die bundesverfassungsrechtliche Preisgabe der allgemeinen Schulpflicht und die damit für die Bundesländer verbundene Möglichkeit, aus ihrer diesbezüglichen Vereinbarung auszuscheren, würde nicht nur die Basis bundesstaatlicher wie demokratischer Homogenität, sondern auch das Grundrecht der Kinder auf gleiche Entwicklungsmöglichkeiten ${ }^{102}$ gefährden ${ }^{103}$. Dieverfassungsgesetzliche Statuierung der allgemeinen Wehrpflicht dagegen ist eine verfassungspolitische Frage der historischen Lage ohne eine derartige zwingende unmittelbare Verbindung mit einem der Schutzgüter des Art. 79 III GG ${ }^{104}$. Anders wieder verhält es sich mit den gruppendemokratischen Grundpflichten der Art. 5 III, 9 II, 18, 21 II und 33 IV GG. Diese Pflichten finden in Art. 79 III nicht nur ihre Legitimation, sondern verleihen der prinzipiellen Absage an den grenzenlosen Mehrheits-Relativismus besondere Gestalt und Wirkung. Sie könnten nicht ohne Veränderung der spezifisch grundgesetzlichen Entscheidung für die Demokratie beseitigt werden.

${ }^{100}$ Vgl. J. Isensee in FS f. H. P. Ipsen, 1977, S. 409 (432 ff.).

101 Vgl. Art. 13 Nr. 2a des Internationalen Paktes über wirtschaftliche, soziale und kulturelle Rechte von 1966.

${ }^{102}$ Dieses Recht folgt aus Art. 1 I, 2 I und 3 I GG; dazu H.-U. Evers, Die Befugnis des Staates zur Festlegung von Erziehungszielen in der pluralistischen Gesellschaft, 1979, S. 58 ff.; G. Dürig in Maunz/Dürig, GG, RN 91 ff. zu Art. 3 I; ferner $E$. Denninger, Staatsrecht 1, 1973, S. 159 ff.; K.-D. Heymann/E. Stein, AöR 1972, S. 185 (202 ff.). Vgl. weiter Art. $13 \mathrm{Nr} .1$ des Int. Paktes über wirtschaftl., soziale u. kulturelle Rechte v. 1966 und Art. 8 I 1 nrh.-westf. Verf. Als Gemeinschaftswesen bedarf das Kind der Erziehung in der Gemeinschaft und für sie: $L$. v. Stein, Die Verwaltungslehre, 5. Teil, 2. Aufl. 1883, S. 139; vgl. auch Evers a.a.O. S. 62 und Ossenbühl (FN 94), S. 103 ff.

${ }_{103}$ Über Grundrechtsgefährdungen als Grundrechtsverletzung $H$. Hofmann, Rechtsfragen der atomaren Entsorgung, 1981, S. $328 \mathrm{ff}$.

${ }^{104}$ So auch U. de Maizière in: Regierbarkeit, Bd. 2, S. 254 (258). Chr. Grimm, Allgemeine Wehrpflicht und Menschenwürde, 1982, S. 28; ausführlich mit anderem Ergebnis W. Leisner, Demokratie - Selbstzerstörung einer Staatsform? 1979, S. $100 \mathrm{ff}$. 


\section{Vom Grund der Grundpflichten}

Die bisherigen Feststellungen erlauben zugleich eine genauere Bestimmung des Grundes der Grundpflichten.

Seit der Mitte des vorigen Jahrhunderts hat sich, wie erwähnt, die Lehre herausgebildet, daß die allgemeinen oder Grundpflichten des einzelnen im Staate als Pflichten gegenüber dem Staat, im wesentlichen also die Gehorsamspflicht mit ihren hauptsächlichen Ausprägungen in der Militär- und der Steuerpflicht, sich aus der Staatsangehörigkeit herleiteten. $\mathrm{Da} ß$ auch Ausländer ihr unterliegen, wurde teilweise als bloß faktischer Umstand erklärt; andere suchten den Unterschied in der allein den Staatsangehörigen zusätzlich obliegenden Treuepflicht ${ }^{105}$. Daß diese eine eigene rechtliche Bedeutung habe, war indes längst zweifelhaft ${ }^{106}$. Auch konnte man nicht übersehen, daß die daraus abgeleiteten Unterlassungspflichten wiederum auch Ausländer betrafen. Es mußte diese Erstreckung daher als rein politisches Kampfmittel ohne den Charakter der Ahndung einer Rechtsverletzung erklärt werden $^{107}$. Die Reduktion der Grundpflichten auf das Staatsangehörigkeitsverhältnis hat trotz solcher Ungereimtheiten noch in der Weimarer Zeit nachgewirkt. So hat man - der in diesem Punkte der süddeutschen Auffassung entgegengesetzten preuBischen Tradition folgend ${ }^{108}$ - mitunter sogar die elterliche Erziehungspflicht des Art. 120 WRV ausschließlich auf Reichsangehörige bezogen, weil der Staat kein Interesse daran habe, „daß auch Ausländer in diesen Beziehungen ihre ,natürlichen Pflichten erfüllen" ${ }^{\text {"109. }}$.

Bei alledem gehen offenbar zwei Fragen ineinander, nämlich die Frage der Grundpflichtensubjektivität und die Frage der Grundpflichtenqualität, die Frage, wen die Pflichten treffen und worin sie ihren Grund haben ${ }^{110}$.

\footnotetext{
${ }^{105}$ Vgl. Schulze, Dt. Staatsrecht, S. 354 f.; Zorn (FN 86), S. 374 f.; Laband (FN 86), S. 128, 130 f.

${ }^{106}$ Vgl. v. Seydel, Bayer. Staatsrecht, Bd. 3, S. 387; G. Meyer, Lehrbuch des deutschen Verwaltungsrechts, 3 . Aufl. 1910, S. 666; Jellinek, System der subjektiven öffentlichen Rechte, S. 187; auch Walz (FN 87), S. 17; Schücking (FN 88), S. 27 f.; Wiesmann (FN 85), S. 96.

${ }_{107}$ Vgl. Laband (FN 86), S. 130. Kritisch dazu Wiesmann (FN 85), S. 85 ff.

${ }^{108}$ Vgl. statt aller F. Stier-Somlo, Handbuch des komm. Verfassungsund Verwaltungsrechts in Preußen, 2. Bd./1. Teil, 1916, S. 446.

${ }^{109}$ E. Hubrich, Das demokratische Verfassungsrecht des deutschen Reiches, 1921, S. 192.

${ }^{110}$ Zur parallelen Unterscheidung von Grundrechtssubjektivität und Grundrechtsqualität vgl. v. Mangoldt/Klein (FN 13), B V 1, und Hofmann in: Rechtsphilosophie der Aufklärung (FN 6), S. 33, 45 f.
} 
Was zunächst den personellen Anwendungsbereich der Grundpflichten betrifft, so ist für die elterliche Erziehungspflicht und den Schulzwang heute klar, daß sie nicht mit der Staatsangehörigkeit verknüpft sind ${ }^{111}$. Aber auch die anderen Grundpflichten, insbesondere die des Gehorsams und der Abgaben, betreffen nicht nur Deutsche i. S. des Grundgesetzes, wenngleich der Inhalt dieser Pflichten für Inländer und Ausländer in einer mit den Stichworten von der Personal- und der Territorialhoheit charakterisierbaren Weise verschieden ist. Sub specie des subjektiven Anwendungsbereichs sind die Grundpflichten also in der Tat - wie man früher sagte - Untertanenpflichten, $d . h$. Verbindlichkeiten der dauernd oder zeitweilig, ganz oder nur in bestimmten Beziehungen Rechtsunterworfenen $^{112}$. Eine Ausnahme macht nach seinem Wortlaut noch nicht einmal Art. 12 a GG, der die Möglichkeit der Wehrpflicht ja nicht nur für deutsche Männer vorsieht, obwohl der Militärdienst schon aus völkerrechtlichen Rücksichten traditionell als Staatsbürgerpflicht angesehen wird ${ }^{113}$. Indessen zeigen die $\S \S 1$ und 2 WPflG, daß das materielle Verfassungsrecht der Bundesrepublik sich durchaus in dem herkömmlichen, jetzt überdies durch Art. 25 GG gesicherten personellen Anwendungsbereich der Wehrpflicht hält ${ }^{114}$.

Wenn nun in der Literatur namentlich im Hinblick auf Art. 6 II 1 GG gelegentlich von Menschenpflichten die Rede ist, dann pflegt damit jedoch mehr und anderes gemeint zu sein, als ein erweiterter subjektiver Anwendungsbereich der Grundpflich-

${ }^{111}$ Vgl. statt aller Maunz in Maunz/Dürig, GG-Komm., RN $22 \mathrm{ff.} \mathrm{zu}$ Art. 6. - Zur Schulpflicht ders., ebd., RN $10 \mathrm{zu}$ Art. 7; OVG Münster NJW 1976, S. 341.

${ }^{112}$ C. Schmitt, Verfassungslehre, S. 175: „Die Grundpflichten sind keine Menschenpflichten im Allgemeinen, sondern nur Pflichten der Staatsangehörigen oder Staatsunterworfenen, d. h. solcher Menschen, die im Bereich der staatlichen Machtsphäre stehen." Nur für das GG verneint Stober „echte Staatsbürgerpflichten“: Grundpflichten und Grundgesetz, S. 75 f.; a. A. wohl Merten (FN 20), S. 559.

${ }^{113}$ Vgl. Schulze, Dt. Staatsrecht, S. 356; Meyer/Anschütz (FN 87), S. 821; W. Husing, Die neue deutsche Wehrverfassung, 1920, S. 26; W. Schätzel in FS f. H. Kraus, 1954, S. 179; G. Jaenicke und K. Doehring, ZaöRuVR 1955/56, S. 523; K. Doehring in FS f. Schlochauer, 1981, S. 45 (53).

${ }^{114}$ Bei wortgetreuer Auslegung wäre Art. 12a mit Art. 25 GG nicht vereinbar: $D$. Walz, Die Wehrpflicht von Ausländern usw., Diss. Heidelberg 1969, S. 155, 200 ff., der überdies die Repressalienregelung des $\S 2$ WPflG wegen mangelnder zeitlicher und sachlicher Beschränkung für völkerrechtswidrig (S. 122 ff./152) und im Hinblick auf Art. 1 I und 3 GG auch für verfassungswidrig hält (S. 173 ff., 177 ff.). 
tenbestimmungen. Der Terminus Menschenpflicht soll darüber hinaus eine aus dem gegenüber der Staatsbürgerpflicht andersartigen Legitimationsgrund herrührende besondere Qualität der Pflicht bezeichnen. Dies mag mitunter ontologisch-naturrechtlich gedacht sein ${ }^{115}$, kann aber mit Hilfe einer aus der Theologie bekannten dialektischen Denkfigur auch auf den Umstand abheben, daß bestimmte elementare Pflichten der Menschen gegenüber ihren Mitmenschen, besonders der Eltern und Kinder, bestünden, auch wenn es keinen Staat und keine staatliche Rechtsordnung gäbe ${ }^{116}$. Gerade Art. 6 II 1 GG beweist indessen schwerlich, was er beweisen soll, wiewohl er die Erziehungspflicht der Eltern ausdrücklich als Korrelat ihres natürlichen Erziehungsrechts nennt. Gewiß: die Pflicht der Eltern ist aus den natürlichen Umständen ohne Rekurs auf den Staat, seine Verhältnisse und Bedürfnisse als eine moralische wohl zu begründen. Aber da es nach dem Prinzip der Freiheit nicht Sache des Staates ist, den Menschen zu bessern, wie das Bundesverfassungsgericht sagt ${ }^{117}$, kann es nicht Aufgabe der Verfassung sein, sittliche Pflichten bloß der Tugend wegen zu sanktionieren. Daß die Verfassung den Eltern die Erziehung ihrer Kinder zur Pflicht macht (auch wenn sie dies in Wahrung der prinzipiellen Asymmetrie nur durch Ausschluß der negativen Grundrechtsfreiheit der Nicht-Erziehung tut ${ }^{118}$ ), muß also einen anderen, spezifisch verfassungsstaatlichen Grund haben. Und der ist darin zu erkennen, daß der Staat, der die Grundrechte auch der Kinder garantiert, es nicht offen lassen kann, ob das nach dem Prinzip der Freiheit primär den Eltern zugestandene Erziehungsrecht ausgeübt

${ }^{115}$ So bei H. Kipp, Staatslehre, 2. Aufl. 1949, S. 202 ff.; Saffert (FN 63) S. 9 ff.

${ }^{118}$ In diesem Sinne Maunz, Staatsrecht (23. Aufl.), S. 118, der insbesondere auf den "vorstaatlichen" Charakter der elterlichen Erziehungspflicht und der Sozialpflichtigkeit des Eigentums verweist. Für die Erziehungspflicht ebenso $v$. Mangoldt/Klein (FN 13), Vorbem. B XI 4; H. Peters: Geschichtliche Entwicklung und Grundfragen der Verfassung, 1969 , S. 305.

117 BVerfGE 22, 180 (220).

118 Dies gegen die nicht sehr klare Formulierung des BVerfG (E 24, 119/143) in Ubereinstimmung mit A. Lüderitz, AcP 1978, S. 263 (267 ff.); E.-W. Böckenförde in: Essener Gespräche zum Thema Staat und Kirche 14, 1980, S. 54 (65 ff., 74, 76); teilweise auch mit Ossenbühl (FN 94), S. $58 \mathrm{ff}$., $68 \mathrm{f}$. (anders S. $51 \mathrm{ff}$.), und mit P. Saladin in FS f. H. Heinderling, 1976, S. 175 (198 ff.). A. A. Isensee, DÖV 1982, S. 614: „anomale Symmetrie" von Elternrecht und Elternpflicht. - Über die negative Seite der Grundrechte A. Bleckmann, Allgemeine Grundrechtslehren, 1979 , S. 218 f. 
wird oder nicht. Wegen seiner Grundrechtsgarantenstellung muß der Staat die Eltern in die Pflicht nehmen - und er müßte es selbst dann tun, wenn ihr keine sittliche Verpflichtung entspräche. Es ist derselbe Gesichtspunkt der Staatsverantwortung, der im Falle der Grundrechtsgarantien für Institutionen wie Rundfunkanstalten und Universitäten die Ausübung des Rechts zur (ungeschriebenen) Pflicht macht ${ }^{119}$.

Wenn die Grundpflichten nach dem Verfassungsprinzip der Freiheit aber weder aus einer transpersonalen Staatsidee deduziert noch aus der Staatsangehörigkeit hergeleitet oder naturrechtlich begründet werden können - wo liegt ihr Fundament dann?

Verfassungsstaatliche Freiheit bedeutet Sicherung der Autonomie der Person, deren Begriff das Gegenüber einschließt. Verfassungsstaatliche Freiheit heißt folglich Freiheit im Miteinander, Zueinander und Gegeneinander mit anderen, welche in gleicher Weise frei sind ${ }^{120}$. Die Annahme gewisser elementarer Unterlassungs-, Duldungs- und Leistungspflichten ist die notwendige Konsequenz der Aufgabe, die gleichen Freiheitsansprüche aller miteinander verträglich zu machen und gegeneinander zu sichern, sowie die Erfüllung aller anderen Gemeinschaftsaufgaben zu organisieren. Den beiden Dimensionen der Aufgabe entspricht ihre durch die zweistufige Sozialtheorie der Aufklärung vorgeformte Lösung auf der Ebene des Straf-, Privat- und Prozeßrechts einerseits und auf der Ebene des Verfassungs- und Verwaltungsrechts in Gestalt der Grundpflichten im engeren Sinne andererseits. Gemeinsamer verfassungsrechtlicher Grund aller gesetzlich entfalteten Sozialpflichtigkeiten des Individuums und Grund insbesondere der nicht explizierten Pflicht zu verfassungsmäßigem Rechtsge-

${ }^{119}$ Dazu Bethge, NJW 1982, S. 2148.

${ }^{120}$ Gegen die vordergründige politische Mode, das Freiheitspostulat gegen den Gleichheitsgrundsatz auszuspielen, muß an den (freilich spannungsvollen und problembeladenen) Zusammenhang von Freiheit und Gleichheit erinnert werden; vgl. dazu H. P. Ipsen in: Die Grundrechte, hg. v. F. L. Neumann u. a., 1954, S. 111 (126); R. Scholz, Die Koalitionsfreiheit als Verfassungsproblem, 1971, S. 116, 326; ders., AöR 1975, S. 80, 265 (283); H. J. Rinck in FS f. W. Geiger, 1974, S. 677 (680); M. Greiffenhagen, Freiheit gegen Gleichheit? 1975; H. Willke, Stand und Kritik der neueren Grundrechtstheorie, 1975; Suhr, Entfaltung der Menschen, S. 112 f., 135 ff.; G. Luf, Freiheit und Gleichheit, 1978; Kriele, Befreiung und politische Aufklärung, S. 57 ff.; wichtig auch die Beiträge v. H. Ryffel, P. Graf Kielmansegg, I. Fetscher, W. Schild, J. Schwartländer und O. Höffe in: Menschenrechte und Demokratie, hg. v. J. Schwartländer, 1981. 
horsam sind daher hinter der Entscheidung für den sozialen Rechtsstaat subjektivrechtlich Art. 2 I mit dem darin ausgesprochenen Gegenseitigkeitsprinzip und der allgemeine Gleichheitsgrundsatz des Art. 3 GG $^{121}$. Die verfassungsrechtliche Dimension der Grundpflichten ist demnach keine andere als diejenige der in ihrer Konkurrenz, Koexistenz, Sicherungsund Organisationsbedürftigkeit begriffenen Grundrechte ${ }^{122}$. Es ist die Einengung des Blicks auf das Verhältnis Individuum-Staat und den status negativus des einzelnen, der dies bisweilen vergessen macht. Zumal mit dem Gleichheitsgrundsatz hängen die Grundpflichten so eng zusammen, daß man meinen könnte, sie enthielten gar keine Pflichten, sondern seien in Wahrheit Grundrechte auf gleiche Lastenverteilung ${ }^{123}$.

Auch die Grundpflichten sind (mit Ausnahme der Wehrpflicht) nicht nur nach ihrem personellen Anwendungsbereich Pflichten eines jeden Menschen, sondern können auch nach ihrer Qualität Menschenpflichten genannt werden, wenn damit nicht mehr gesagt sein soll, als daß sie in der Mitmenschlichkeit des Menschen begründet sind. Doch haben sie nicht in demselben Umfang und in derselben Weise teil an dem nichtstaatlichen Sinn staatlicher Organisation, den wir im qualitativen Begriff der Menschenrechte zum Ausdruck bringen. Die beste Kennzeichnung der Grundpflichten war sonach noch die als Bürgerpflichten in dem klassischen (freilich auch abstrakten und daher mißverständlichen) Sinn der Teilhabe am status civilis.

Die in der Ausdifferenzierung der Rechtsgebiete verloren gegangene rechtliche Einheit der Sozialpflichtigkeit des einzelnen ist nur noch in den diese Sonderungen übergreifenden Grundrechtsschranken bewahrt. Der damit angesprochenen Verwandtschaft von Grundrechtsschranken und Grundpflichten haben wir uns nun zuzuwenden.

${ }^{121}$ Gewichtig zu diesem zentralen Punkt G. Dürig in: Maunz/Dürig, GG-Komm., RN 20 ff. zu Art. 2 I und RN 138, 156 ff. zu Art. 3 I; $P$. Häberle, Rechtstheorie 1980, S. 389 (412 ff.), der v. a. auf Art. 1 GG abhebt. Rechtstheoretisch erfrischend anspruchsvoll umkreist $D$. Suhr in seinen Veröffentlichungen das Kernproblem; vgl. Entfaltung der Menschen, S. 67 ff., 146, 203, und zuletzt in: Soziale Grundrechte, hg. v. E.-W. Böckenförde, 1981, S. 111 (113, 115 ff.).

122 Ähnlich Badura, DVBl. 1982, S. 869.

${ }^{123}$ So W. Stahlwery, Studien zur rechtlichen Bedeutung der Grundrechte, Diss. Bonn 1922 (MS), S. 56; Huber, Dt. Verfassungsgesch. III, S. 101. Dagegen bezüglich der allgemeinen Steuerpflicht gem. Art. 123 bay. Verf.: BayVerfGHE NF 2, 170 (178); 3, 15 (25); 6, 75 (83). 


\section{Grundpflichten und Grundrechtsschranken}

Grundpflichten laufen stets in irgendeiner Form darauf hinaus, daß sie individuelle Freiheit einengen - sei es durch verfassungsunmittelbare Verbindlichkeiten, mittelbar durch Gesetze oder als soft law durch ihren Appellcharakter. Unter dem abstrakten Gesichtspunkt ihrer negativen Wirkung sind Grundpflichten und Grundrechtsschranken folglich nicht unterscheidbar, kann man Grundpflichten also der Kategorie der Grundrechtsschranken unterordnen. Ebenso gut ist es möglich, die Grundrechtsschranken als Grundpflichten im weiteren Sinne denen im engeren Sinne zur Seite zu stellen ${ }^{124}$. Verfassungs- und theoriegeschichtlich verhält es sich freilich so, daß man von den in den Unterlassungs- und Duldungspflichten gegenüber den Mitbürgern ausgeformten Grundrechtsschranken als den ursprünglichen Grundpflichten ausging, während die staatsbezogenen persönlichen und sachlichen Leistungspflichten des Verfassungsrechts sie erst später aus dieser zentralen theoretischen Position verdrängt haben. Unter diesem Aspekt wird der abstrakt-rechtstheoretisch nicht definierbare Unterschied zwischen Grundpflichten in dem geschichtlich geprägten engeren, staatsbezogenen Sinne einerseits und Grundrechtsschranken andererseits bis $\mathrm{zu}$ einem gewissen Grade wenigstens phänomenologisch faßbar. Anders als alle Arten von Grundrechtsschranken, welche in je besonderer Weise dafür Vorsorge treffen, daß der jeweils spezifische Freiheitsgebrauch mit den legitimen Interessen der anderen und des Gemeinwesens verträglich bleibt, konstituieren die Grundpflichten, gegenläufig von bestimmten legitimen Zwecken des Gemeinwesens ausgehend, mehr oder minder große Bereiche der Heteronomie. Sind die Grundpflichten nicht ausnahmsweise nur einem einzelnen Grundrecht als Vorbehalt zugeordnet, wie das bei der elterlichen Erziehungspflicht, der Sozialpflichtigkeit des Eigentums und Art. 14 III GG der Fall ist, so übergreifen die Grundpflichten als selbständige Pflichtnormen jeweils den Bereich mehrerer grundrechtlicher Freiheiten. Dem andersartigen Ansatzpunkt der Grundpflichten entspricht zudem qualitativ eine gewisse Vielfalt der Auswirkungen auf die Freiheitssphäre, die weder als Einschränkung eines Grundrechts noch als Institutionalisierung von Freiheit angemessen $\mathrm{zu}$ verstehen sind. So setzen Grundpflichten nicht nur Abwehrrechte außer Kraft, sondern fordern regelmäßig Leistungen, $z$. $T$. in der Form, daß sie eine negative Grundrechtsfreiheit aufheben. Und die Eigentumsab-

124 So Benda (FN 20), S. 8. 
tretungspflicht verlangt im Einzelfall Preisgabe des ansonsten geschützten Rechts. Die angemessene Vorstellung des Verhältnisses von Grundrechten und selbständigen Grundpflichten ist daher nicht die der Einschränkung oder institutionellen Ausgestaltung einzelner Grundrechte, sondern die der partiellen, zeitweiligen oder okkasionellen Kollision und des entsprechenden Vorranges der Pflicht.

\section{4. Über den programmatischen Charakter der Grundpflichten}

Voraussetzung solcher Kollisionen ist freilich regelmäßig, daß der Gesetzgeber die verfassungsrechtlichen Bestimmungen über die Grundpflichten konkretisiert hat. Erzwingbare Rechtspflichten sind die Grundpflichten der Verfassung - von den bloß negativen Wirkungen des elterlichen Erziehungsrechts und den gruppendemokratischen Treuepflichten abgesehen - nur nach Gesetz. Rechtsstrukturell sind die Grundpflichten also nächst den grundrechtlichen Gesetzesvorbehalten $^{125}$ den sozialen Grundrechten ${ }^{126}$ verwandt. Wegen ihres programmatischen Charakters beinhalten die Grundpflichten stets einen ungeschriebenen Gesetzesvorbehalt ${ }^{127}$. Die in ihnen definierten Gemeinschaftszwecke steuern die gesetzliche Ausgestaltung und machen sie durch die Zweckbindung nach den allgemeinen rechtsstaatlichen Regeln des Übermaßverbotes kontrollierbar. Auf der anderen Seite stellen die Proklamationen selbständiger Grundpflichten bezüglich des Wehrdienstes, der öffentlichen Abgaben oder des Schulbesuchs besonde-

${ }^{125}$ Vgl. dazu F. Müller, Die Positivität der Grundrechte, 1969; Th. Wulfing, Grundrechtliche Gesetzesvorbehalte und Grundrechtsschranken, 1981.

${ }^{126}$ Mit dem Unterschied, daß Grundpflichten noch eher im Verfassungsgesetz selbst konkretisiert und vollziehbar gemacht werden könnten. Zum Problem der sozialen Grundrechte neuestens mit weit. Nachw. W. Schmidt in: Instrumente der sozialen Sicherung und der Währungssicherung in der Bundesrepublik Deutschland und Italien, hg. v. R. Grawert, 1981, S. 9 ff.; E.-W. Böckenförde u. a. (Hg.), Soziale Grundrechte, 1981; J. Lücke, AöR 1982, S. 15 ff.

${ }^{127}$ Hieraus folgert Gusy (JZ 1982, S. 657) aufgrund seiner Voraussetzung, wonach eine lex imperfecta keine lex sei, daß das GG keine Grundpflichten enthalte, ja, da $\$$ es eine eigene verfassungsrechtliche Kategorie der Grundpflicht gar nicht gebe. Nach demselben Argumentationsmuster hat man noch vor 100 Jahren bestritten, daß eine Verfassung subjektive Rechte gewähre oder auch nur gewähren könne. Der springende Punkt: Erschöpft sich die verfassungsrechtliche Bedeutung der Grundrechte denn in ihrem Anspruchscharakter? 
re Inanspruchnahmen des einzelnen - wenn auch nicht im Detail -, so doch im Prinzip gegen jeden grundrechtlichen Einwand unzulässiger Freiheitseinschränkung sicher. Diesen Sinn der verfassungsrechtlichen Pflichtenvorbehalte hat seinerzeit sehr klar die Badische Verfassung von 1947 ausgedrückt, in der es hieß:

„Jedermann ist verpflichtet, die durch Verfassung oder

Gesetz rechtsgültig auferlegten staatsbürgerlichen Pflich-

ten zu erfüllen; niemand darf ihre Erfüllung unter Berufung

auf verfassungsmäßig gewährleistete Rechte und Freiheiten verweigern."

So wie Grundrechte als „negative Kompetenznormen“ ( $H$. Ehmke) begriffen werden können, sind Grundpflichten folglich als qualifizierte Kompetenznormen, genauer: als Verstärkung von Kompetenzvorschriften zu verstehen, die deren Wahrnehmung gewissermaßen ,grundrechtsfest" machen.

Von sekundärer Bedeutung ist die Typologie dieser verfassungsgesetzlichen Proklamationen. Sie umfaßt Grundsatzerklärungen, welche die das Parlament verpflichtende Ankündigung gesetzlicher Regelung i. S. einer Konkretisierung in sich schließt, daneben auch prinzipielle Regulative für eine zu schaffende gesetzliche Ordnung. Musterbeispiel ist einmal die Verkündung der Schulpflicht oder der Wehrpflicht, andererseits der Grundsatz allgemeiner direkter Besteuerung bei gleichzeitiger Festlegung auf das Prinzip progressiver Belastung ${ }^{128}$. Solche Ausgestaltungen institutionalisieren öffentliche Interessen. Daneben kann die Verfassung eine Grundpflicht auch in der Weise präformieren, daß sie bestehende gesetzliche Pflichten ohne Zwang zu ihrer Beibehaltung sanktioniert oder den Gesetzgeber ermächtigt, die Rechtsunterworfenen für bestimmte staatliche Zwecke in Pflicht zu nehmen. Das eine ist in Art. 12 Abs. 2, das andere in Art. 12 a GG ${ }^{129}$ geschehen. Gleichzeitig reguliert die letztgenannte Bestimmung eine etwaige Dienstpflichtgesetzgebung in relativ groBem Umfang.

Bliebe nur noch hervorzuheben, daß die Realisierung der verfassungsrechtlichen Grundpflichtenprogrammatik ausschließlich dem Gesetzgeber übertragen ist. Natürlich sind Grundpflichten, insofern sie Gemeinschaftsinteressen institu-

${ }^{128}$ Siehe z. B. Art. 123 I bay. Verf.: „Alle sind im Verhältnis ihres Einkommens und Vermögens und unter Berücksichtigung ihrer Unterhaltspflicht zu den öffentlichen Lasten heranzuziehen." Vgl. dazu Zacher (FN 35).

${ }^{129}$ Dazu BVerfGE 48, 127 (160 f.). 
tionalisieren, auch Richtlinien der Rechtsauslegung und -anwendung, zumal im Grundrechtsbereich. Dies bedeutet aber nicht, daß Verwaltungsbehörden und Gerichte die Grundpflichten unmittelbar in rechtsverbindliche Anordnungen umsetzen dürften. Nur scheinbar paradox hat die verfassungsrechtliche Festlegung von Grundpflichten im System der Sicherung individueller Freiheit nämlich noch eine besondere Funktion. Schließt es die Existenz bestimmter, den Gesetzgeber ermächtigender Pflichtenvorbehalte doch aus, die Grundrechte mit der Begründung einem allgemeinen und jederzeit aktualisierbaren Gemeinwohlvorbehalt zu unterstellen, daß ,jeder Mensch Pflichten gegenüber der Gemeinschaft (hat), in der allein die freie und volle Entwicklung seiner Persönlichkeit möglich ist", wie es die Allgemeine Erklärung der Menschenrechte von 1948 sagt $^{130}$. Es bleibt Sache des Gesetzgebers, die Freiheit der einzelnen untereinander und mit den Gemeininteressen durch Pflichtbindungen nach den Prinzipien der Gegenseitigkeit (Art. 2 I GG) und der gleichen Freiheit aller (Art. 3 I GG) zu vermitteln. Dem entspricht die zentrale Stellung, die der Begriff des Gesetzes in den klassischen Menschenrechtserklärungen innehat, welche von dem Gedanken gleicher Freiheit aller und dem Glauben an die Rationalität und Realisierungskraft des repräsentativen Gesetzgebers getragen waren. Dieser Glaube hat die Zeiten nicht ganz unbeschädigt überdauert; und die Schwäche des Pflichtgedankens korrespondiert mit der Schwäche des gruppendemokratischen Gesetzgebers.

Letztlich ist die verfassungsrechtliche Dimension der Grundpflichten nach alledem die der konstitutionellen Programmatik. Dies ist kein Widerspruch zu der früher aufgestellten These, daß es ein und dieselbe verfassungsrechtliche Dimension ist, welche Grundrechte und Grundpflichten umschließt. Man muß sich nur vergegenwärtigen, daß auch die Grundrechte programmatischen Gehalt haben. Daran hat sich gegenüber den Anfängen, in denen die Rechteerklärungen als Grundsatzproklamationen gar nicht Teil der eigentlichen Konstitution waren, nichts geändert. Nach ihrer verfassungsgesetzlichen Gestalt haben die Grundrechte heute keine andere

${ }^{130}$ Auch Naumanns Idee der Korrelation von Rechten und Pflichten beruht auf dem Gedanken, durch ,größere Bestimmtheit" der Pflichten angesichts wachsender Macht des Staates die individuelle Freiheit besser zu sichern, und nicht auf Hegels Dialektik der Totalität (so aber E. R. Huber, FN 9, S. 397), auch wenn Naumann in seinen Leipziger Semestern auf Anregung Wundts eifrig Hegel gelesen hat. 
Normqualität als damals und die Grundrechte keine andere als die Grundpflichten. Als programmatische Grundsätze beweisen die Grundrechte ihre schier unerschöpfliche Konkretisierungsfähigkeit und Aktualisierbarkeit bis auf den heutigen Tag. Was sich geändert hat gegenüber den Anfängen, liegt außerhalb der Erscheinungsform der Grundrechte: Es ist dies einmal die (noch gar nicht so lange selbstverständliche) Lehre von den Grundrechten als subjektiv öffentlichen Rechten, welche die Grundfreiheiten dem einzelnen als Ansprüche, namentlich als Abwehrrechte gegen die Verwaltung verfügbar machte $^{131}$. Und es ist zum anderen Art. 1 III GG, der (selbst eher ein Programmsatz) für die Grundrechte (aber auch nur für sie) das Konkretisierungsmonopol des Gesetzgebers endgültig zugunsten der Rechtsprechung bricht. Hinsichtlich der Grundpflichten bleibt es im Regelfall bei dem rechtsstaatlich begründeten Verbot unmittelbarer Umsetzung durch die Rechtsanwendungsorgane und damit in dem geläufigen Sinne bei der reinen Programmatik.

Will man an dieser Stelle nicht auf die positivistische Antithese von Recht und Moral zurückfallen, hält man an der Hypothese einer spezifisch verfassungsrechtlichen Bedeutung der Grundpflichten fest, so liegt es nahe, sie dort zu suchen, wo auch den Grundrechten jenseits des ihnen beigelegten Charakters unmittelbar anwendbaren Rechts noch eine spezifisch verfassungsrechtliche Funktion zugesprochen wird. Konkret ist die Frage also die, ob die Grundpflichten vielleicht gleich den Grundrechten als Grundwerte unter die sachlichen Integrationsfaktoren zu rechnen sind ${ }^{132}$. Daß gemeinsame Pflichterfüllung Gemeinschaftsgefühl bewirkt, sei nicht bezweifelt. $\mathrm{Da} \beta$ Grundsatzerklärungen über elementare Pflichten oder deren Lektüre Gemeinschaftsschauer im Sinne der Integrationslehre hervorrufen, scheint indes eher unwahrscheinlich. Es kann auch nicht der Sinn solcher Proklamationen sein, die Bürger Gemeinschaftstugenden zu lehren; denn das würde bedeuten, sie als Gesetzgebungsermächtigung für Volkspädagogik zu verstehen. (Daß die Grundpflichten wenigstens zum Teil Erziehungsziele einschließen, steht auf einem ganz anderen Blatt.) Am ehesten dürfte die tiefere verfassungsrechtliche Bedeutung von Grundpflichtenerklärungen in der ursprünglichen Perspektive aller Verfassungsprogrammatik sichtbar

${ }^{131}$ Vgl. den Überblick bei $F$. Giese, Die Grundrechte, 1905, S. 27 ff., $35 \mathrm{ff}$., $43 \mathrm{f}$., $91 \mathrm{f}$.

${ }^{132} \mathrm{Vgl}$. R. Smend, Verfassung und Verfassungsrecht, jetzt in: Staatsrechtliche Abhandlungen, 2. Aufl. 1968, S. 119 (141, 160 ff.). 
werden: Sie formuliert in dem Sinne etwa, in dem Kant über das Verhältnis von Vernunftrecht und staatlich sanktioniertem Recht gesprochen hat, provisorisches oder präsumtives Recht ${ }^{133}$, man könnte auch sagen ,potentielles Recht ${ }^{\text {"134 }}$ oder: zu setzendes Recht. D. h.: die verfassungsrechtlichen Programme formulieren weder Normen sozialethisch guten Verhaltens noch treffen sie selbst rechtliche Regelungen. Vielmehr suchen sie rechtliche Voraussetzungen, Notwendigkeiten und Sinnperspektiven gesetzlicher Regelungen zu vermitteln ${ }^{135}$. Allerdings erschöpft sich - und hier schlägt noch einmal die besprochene prinzipielle Asymmetrie durch - die Potentialität der Grundpflichtenerklärungen wegen ihrer Begrenztheit rechtlich und sozialpsychisch eher als die anderer Proklamationen. Gleichwohl prägen sie allesamt ein bestimmtes Verfassungsverständnis und Verfassungsbewußtsein aus - in der Erwartung, daß sie das soziale Bewußtsein wesentlicher Beweggründe, Dimensionen und Implikationen der Verfassungsschöpfung über die spezialgesetzlichen Positivierungen hinaus erhalten und reproduzieren. Das scheint nicht viel zu bedeuten und ist für den juristischen Alltag gewiß ganz unnütz. Wie viel es wirklich bedeutet, zeigt sich erst, wenn etwa im Bereich der Grundpflichten die Folgen von Defiziten des allgemeinen Verfassungsbewußtseins sichtbar werden.

\section{v. Offene Fragen}

Insgesamt muß diese Sicht der verfassungsrechtlichen Dimension der Grundpflichten Erwartungen enttäuschen, es könnten von hier aus im Wege des unmittelbaren interpretatorischen Verfassungsvollzugs Lösungen für gewisse offene Fragen gesteigerter Sozialpflichtigkeit bei der den Bereich des Privaten überschreitenden Wahrnehmung grundrechtlicher Freiheiten entwickelt werden. Zur Kennzeichnung des damit angedeuteten Problemfeldes muß es hier genügen, an unsere Heidelberger Diskussion über den „verfassungsmäßigen

${ }^{133}$ Kant, Metaphysik der Sitten (Ed. Vorländer), S. 65 f.

134 Mit diesem Ausdruck hat $R$. Koselleck die allgemeinen Vorschriften des PrALR charakterisiert in: Staat und Gesellschaft im deutschen Vormärz 1815-1848, hg. v. W. Conze, 1962, S. 79 (82); R. Wahl (Der Staat 1979 , S. 338) hat ihn auf die in ihrer Durchsetzung gehemmten Grundrechte der süddeutschen Verfassungen des Vormärz übertragen.

${ }^{135} \mathrm{Vgl}$. dazu Hofmann, Legitimität und Rechtsgeltung, S. $53 \mathrm{ff}$. 
Pflichtstatus der Unternehmen" zu erinnern ${ }^{136}$, die Stichworte: „Sozialpflichtigkeit der Verbände“137 und „Verbändegesetz“138 zu zitieren und den Komplex der Grundrechte und Grundpflichten bei Großdemonstrationen zu nennen, von dem das OVG Lüneburg gesprochen hat ${ }^{139}$. Kern der angedeuteten Probleme ist allemal der Umstand, daß die korporative oder sonstwie gemeinschaftliche Ausübung individueller grundrechtlicher Freiheiten durch das Maß ihrer Wirkungen auf öffentliche Interessen und die Grundrechte anderer die Qualität solchen Freiheitsgebrauchs verändern kann. Daß größerer Macht höhere Verantwortung entspricht, ist moralisch kaum eine Frage; sie als gesteigerte Sozialpflichtigkeit rechtlich faßbar zu machen, etwas ganz anderes. Es bedürfte dies gesetzlicher Konkretisierungen, deren Opportunität im übrigen nicht in allen Fällen außer Frage steht.

Eher schon könnten die hier angestellten Überlegungen etwas beitragen zu Problemen, die sich - nicht ganz ohne Zusammenhang mit dem einen oder anderen der eben genannten Stichworte - aus der Realisierung großtechnischer Projekte ergeben. Hier ist die Situation die, daß nicht ein bestimmtes Gemeinschaftsinteresse gegen ein bestimmtes Grundrecht oder allein gegen eine geschlossene Phalanx paralleler Abwehrrechte steht, daß es sich auch nicht nur darum handelt, private Sphären gegeneinander abzugrenzen, sondern daß verschiedenartige öffentliche Interessen untereinander und mit einander entgegengesetzten grundrechtlichen Ansprüchen ausgeglichen werden müssen ${ }^{140}$. Diese Problematik hat einen materiellrechtlichen und einen verfahrensrechtlichen Aspekt. Zur materiellrechtlichen Seite sei hier lediglich vermerkt, daß das Bundesverfassungsgericht in seiner Kalkar-Entscheidung

${ }^{136}$ Vgl. P. Saladin und H.J. Papier, VVDStRL 35 (1977), S. 7 ff., und bes. die um Saladins These Nr. 3 kreisende Diskussion.

${ }_{137}$ Vgl. H. Lemke, DƠV 1975, S. 253; H. Leßmann, Die öffentlichen Aufgaben und Funktionen privatrechtlicher Wirtschaftsverbände, 1976, S. 233 ff. E.-W. Böckenförde in: Regierbarkeit, Bd. 1, S. 223; K. $v$. Beyme in FS f. D. Sternberger, 1977, S. 22 (33); J. Knebel, Koalitionsfreiheit und Gemeinwohl, 1978.

${ }^{138} \mathrm{Vgl}$. K. M. Meessen, Erlaß eines Verbändegesetzes als rechtspolitische Aufgabe? 1976; R. Wimmer, DVB1. 1977, S. 401; Die Verbände in der Demokratie und ihre Regelungsprobleme, in: Verhandlungen des 52. DJT, 1978, Bd. II, Teil P.

${ }^{139}$ OVG Lüneburg Beschl. v. 28. 2. 1981, DÖV 1981, S. 461, mit Anm. v. P. Jacob. Dazu Badura, DVBl. 1982, S. 870.

${ }_{140}$ Vgl. P. Lerche, atw 1982 , S. 389 (390); z. B. des Atomrechts Hofmann, Rechtsfragen der atomaren Entsorgung, S. $295 \mathrm{ff}$., $317 \mathrm{ff}$. 
den Ausgleich konfligierender Unternehmerfreiheiten und grundrechtlicher Schutzansprüche aus Art. 2 II GG mit der Annahme einer ungeschriebenen Grundpflicht bewerkstelligt hat. Ist es doch ohne Rückgriff auf den Gesetzesvorbehalt dieses Grundrechts davon ausgegangen, da $ß$ wir alle von Verfassungs wegen verpflichtet seien, gewisse Risiken als „,sozialadäquate Lasten" unserer technischen Zivilisation zu tragen $^{141}$. Der prozedurale Aspekt ist deswegen so bedeutsam, weil die Ordnung der angedeuteten vielfältigen Rechtsbeziehungen nicht anders als in einem komplizierten Verfahren wechselseitigen Ausgleichs gefunden werden kann. Und weil das so ist, geht es für den einzelnen darum, daß seinen Grundrechten als Momenten einer komplexen Entscheidung durch entsprechende Verfahrensvorkehrungen Beachtung gesichert wird $^{142}$. Nimmt der Grundrechtsträger solchen Grundrechtsschutz durch Verfahren in Anspruch, so muß bedacht werden, daß er dies in derartigen Fällen regelmäßig in Konkurrenz zu Rechten anderer und nicht nur im Widerstreit mit staatlichen Interessen tut. Ist das so, und wird ihm ein faires Verfahren geboten, so hat er die aus Art. 2 I und 3 GG folgende Grundpflicht der Rücksichtnahme auf die Grundrechtsverwirklichung anderer. Diese Grundpflicht erlegt ihm eine gewisse Verfahrensdisziplin auf und kann ihn mit Mitwirkungspflichten belasten.

Vielleicht vermag dieser Ausblick auf das Verwaltungsverfahren als besonderes oder gesteigertes Pflichtenverhältnis die beiden Themen unserer Tagung wenigstens andeutungsweise miteinander zu verknüpfen.

141 BVerfGE 49, 89 (143). Kritisch zur Anwendung auf das Atomrecht Hofmann, Rechtsfragen der atomaren Entsorgung, S. 322 ff.; ders. demnächst in den BayVBl.

${ }^{142}$ Vgl. dazu den Mühlheim-Kärlich-Beschl. des BVerfG (E 53, 30/ $59 \mathrm{ff}$.) und neuestens $F$. Ossenbühl in FS f. K. Eichenberger, 1982, S. 183, sowie Lerche (FN 140). 
Leitsätze des Mitberichterstatters über:

\section{Grundpflichten als verfassungsrechtliche Di- mension}

\section{Methodische Vorbemerkungen}

1. Schwierigkeiten für eine spezifisch juristische Behandlung des Grundpflichtenproblems ergeben sich daraus, daß eine Reihe von Umständen die Frage nach solchen Pflichten allzu leicht und einseitig als Frage nach einem bisher vernachlässigten Teil der Staatsethik erscheinen läßt.

2. Im Gegensatz dazu zielt das Thema darauf, die Grundpflichten wieder explizit als eine verfassungsrechtliche Kategorie und nicht nur als Inbegriff ethischer Verfassungsvoraussetzungen neben die der Grundrechte zu stellen.

3. Ausgangspunkt einer solchen Rekonstruktion kann nur der Grundpflichtenbegriff der Weimarer Reichsverfassung sein.

4. Trotz gewisser historisch-politischer Belastungen darf dieser Begriff nicht von vornherein als Gegensatz zu dem der Grundrechte aufgefaßt werden.

II. Über Zufälligkeit und Notwendigkeit der Asymmetrie von Rechten und Pflichten in der Verfassung der Freiheit

5. Der schon früh beklagte Grundrechtsindividualismus des Bonner Grundgesetzes ist historisch bedingt durch eine besonders scharfe Ausprägung der prinzipiellen Asymmetrie von Rechten und Pflichten in einer jeden Verfassung der Freiheit. Er hat Rückwirkungen auf das Verfassungsrecht der Länder.

6. Im Gegensatz zur rechtsstaatlichen Asymmetrie von individuellen Rechten und Pflichten steht die Inanspruchnahme des Individuums für überindividuelle Zwecke in den Verfassungen der sozialistischen Staaten. 


\section{Zur Geschichte der Grundpflichten}

7. Verfassungs-, Begriffs- und Theoriegeschichte zeigen, daß die Asymmetrie von Rechten und Pflichten in einer Verfassung der Freiheit nicht von vornherein eine Abdrängung aller Pflichten in den Bereich der Moral zur Folge hat.

8. Nach der zweistufigen Sozialtheorie der Aufklärung werden die Verbindlichkeiten des einzelnen im Staat einerseits durch die ,zivilen“, andererseits durch die ,politischen" Gesetze bestimmt.

9. In der Epoche der Französischen Revolution bildet sich mit Gesetzesgehorsam, Militärdienst, Steuer- und Eigentumsabtretungspflicht ein klassisches Ensemble republikanischer Bürgerpflichten heraus. Die Übernahme in die Verfassungsurkunden der deutschen Staaten verändert ihren Charakter.

10. Der Kanon republikanischer Grundpflichten wird 1848 durch die kulturstaatliche Schulpflicht, 1919 durch sozialstaatliche Grundpflichten erweitert. Gleichzeitig gewinnen ältere Grundpflichten zusätzliche demokratische Bedeutung. Das Grundgesetz hat von dieser Überlieferung weit mehr bewahrt, als es auf den ersten Blick erkennen läßt, und sie durch gruppendemokratische Grundpflichten bereichert.

\section{Dogmatische Folgerungen}

11. Bei der Gegenüberstellung von Grundrechten und Grundpflichten sind die Fragen des verfassungstheoretischen und verfassungsrechtlichen Rangverhältnisses sowie der rechtsstrukturellen Ungleichgewichtigkeit zu unterscheiden.

12. Welcher verfassungsrechtliche Rang den Grundpflichten zukommt, zeigt am besten die Frage nach der Möglichkeit ihrer Aufhebung.

13. Bei der Qualifikation der Grundpflichten ist (wie bei den Grundrechten) zwischen Grundpflichtensubjektivität und Grundpflichtenqualität zu unterscheiden.

14. Grundpflichten sind nicht auf Staatsangehörige beschränkt.

15. In dem durch die verfassungsstaatliche Tradition geprägten engeren Sinne gibt es keine vorstaatlichen Grund- 
pflichten: Auch der verfassungsrechtlichen Erziehungspflicht der Eltern kommt eine solche Qualität nicht zu.

16. Ihren verfassungsrechtlichen Grund haben die Grundpflichten in dem Gegenseitigkeitsprinzip des Art. 2 Abs. 1 GG und in dem Prinzip gleicher Freiheit aller (Art. 3 Abs. 1 GG). Die verfassungsrechtliche Dimension der Grundpflichten ist keine andere als diejenige der in ihrer Konkurrenz, Koexistenz, Sicherungs- und Organisationsbedürftigkeit begriffenen Grundrechte.

17. Grundpflichten und Grundrechtsschranken sind nur phänomenologisch, nicht aber prinzipiell rechtstheoretisch unterscheidbar.

18. Die Grundpflichten beinhalten regelmäßig einen Gesetzesvorbehalt. Die in ihnen definierten Gemeinschaftszwecke steuern die Ausgestaltung und machen sie durch diese Zweckbindung nach den allgemeinen rechtsstaatlichen Regeln des Übermaßverbotes kontrollierbar, andererseits im wesentlichen „grundrechtsfest".

19. Die Existenz von Grundpflichten schließt es aus, die Grundrechte einem allgemeinen, durch alle Staatsorgane aktualisierbaren Vorbehalt der Sozialpflichtigkeit zu unterstellen. Es ist Sache des Gesetzgebers, die Freiheit der einzelnen untereinander und mit den Gemeininteressen durch Konkretisierung der Pflichtbindungen nach den Prinzipien der Gegenseitigkeit und der gleichen Freiheit aller zu vermitteln.

20. Zusammen mit den Grundrechten gehören die Grundpflichten der Dimension konstitutioneller Programmatik an. Die Grundpflichten entfalten verfassungsrechtliche Wirkung, indem sie zu setzendes Recht begründen.

\section{Offene Fragen}

21. Die Auswirkungen kollektiver oder sonstwie sozial mächtiger Grundrechtsausübungen werfen die Frage gesteigerter Sozialpflichtigkeit auf.

22. Grundrechtsschutz durch Verfahren bringt die statische Frage nach der Möglichkeit gleicher Grundrechtsfreiheit aller unter einen neuen prozeduralen Aspekt. 


\section{Aussprache und Schlußworte \\ Grundpflichten in verfassungsrechtlicher Dimension}

Vorsitzender (Schmitt Glaeser): Ich eröffne die Aussprache über den ersten Beratungsgegenstand und darf Sie dazu sehr herzlich begrüßen. Im Einverständnis mit den Referenten möchte ich auf die Vorgabe einer Gliederung oder auch nur von „Diskussionsrahmenrichtlinien“ verzichten, weil wir meinen, daß Diskussionsgliederungen in den letzten Jahren nicht sehr viel Nutzen gebracht haben. Die Kollegen sind zu „unbändig“, als daß man ihre Darlegungen in eine Gliederung bringen könnte. Ich darf aber vielleicht ein paar Stichworte angeben, die uns für die Diskussion $u$. a. als besonders interessant erscheinen würden: einmal Verhältnis Grundrechte - Grundrechtspflichten - Grundpflichten, Einheitsthese?; sodann: rechtsstaatliches Verteilungssystem, Stichwort bei Herrn Hofmann: unbegrenzte Unterlassungsgrundpflichten - hängt zusammen mit Staatsidee und Verfassungsstruktur; außerdem: Schulpflicht, Abgabenpflicht und Wehrpflicht als spezifisch deutsche Klassiker der Grundpflichten und schließlich noch die Frage: Gibt es eine Generalklausel der Grundpflichten, gibt es ein Grundpflichtensystem?

Nun zum Ablauf der Diskussion. Das ist bekanntlich ein Problem der Beitragslänge bzw. der Redezeitbegrenzung. Zunächst darf ich Ihr Einverständnis voraussetzen, daß wir an der Übung festhalten, auch unmittelbare Erwiderungen zuzulassen; ich will sie einmal "Spontanbeiträge" nennen. Soweit Sie solche Spontanbeiträge beabsichtigen, bitte ich um das Heben beider Hände. Es versteht sich von selbst, daß von dieser Möglichkeit nur sparsam Gebrauch gemacht werden sollte und dabei die prägnante Kürze besonders erwünscht ist. Wir müssen uns hier darauf verständigen, daß zwei Minuten nicht überschritten werden dürfen. Für die Regulärbeiträge möchte ich an der üblichen Redezeitbegrenzung auf vier bis fünf Minuten festhalten. Ich wäre Ihnen allen sehr zu Dank verpflichtet, wenn Sie dieser Bitte Folge leisten könnten. Drängen Sie mich nicht in die Rolle des pingeligen Zeitmessers und Zeitmahners.

Sehr verehrter Herr Kollege Ipsen, ich bitte Sie, die Diskussion zu eröffnen. 
H. P. Ipsen: Herr Vorsitzender, meine Herren Kollegen! Ich spreche hier nicht als erster, um meinen Nachholbedarf von Trier zu decken, sondern deshalb, weil ich vom Vorstand hierzu aufgefordert worden und gewohnt bin, Wünsche des Vorstandes nachzukommen. Ich wollte lediglich später einen Beitrag leisten zu dem, was ich unter Punkt 2 jetzt zu sagen habe - alles andere ist improvisiert. erwarten Sie also von mir nicht eine Introduktion à la Scheuner.

$Z u$ 1: Ich frage mich, ob ein Widerspruch zwischen den Referenten besteht, in bezug auf die Begriffsbestimmung von Grundpflichten und darin, ob sie nur originär kraft Verfassung bestehen oder nur wirksam werden durch Verfassungsvollzug im Wege der Gesetzgebung. Dazu hat Herr Götz nach seiner Begriffsbestimmung These 1 erklärt, die Pflichtenvielfalt erfordere politische Entscheidungen des Gesetzgebers. Er sieht also offensichtlich eine Unterscheidung zwischen Pflichtbegründungen kraft Verfassung oder auch durch Gesetz. Bei Herrn Hofmann erschien mir die Vorstellung näherliegend, nur von verfassungsoriginären Pflichtbegründungen zu sprechen (daher: Grundpflichten?), wozu er Bezug genommen hat auf Art. 1 und 3 I GG, damit aber dann als Grundlage für zu setzendes Recht. Ich würde zur Systematisierung unserer Vorstellungen eine Klarstellung in dieser Frage begrüßen.

$\mathrm{Zu}$ 2: In den Ausführungen von Herrn Götz hat eine nicht geringe Rolle gespielt seine Abgrenzung zwischen Grundpflichten und (wie er sie genannt hat) Indienstnahmen, die er unter These $14 \mathrm{c}$ mit einer Klammerdefinition bezeichnet hat als unbezahlte Hilfsarbeiten der Wirtschaft für den Staat. Er hat sie unter Abgrenzung von seinem Begriff der Verfassungsgrundpflichten als Berufsausübungsregelungen i.S. des Art. 12 GG gekennzeichnet. Hierzu bewegt mich einmal die Frage, in welcher Art Grundpflichten, die nicht unmittelbar in der Verfassung ihren Inhalt ausgewiesen erhalten, zu klassifizieren sind. Zum andern: Herr Götz hat Indienstnahmen der Wirtschaftsunternehmen in Parallele gesetzt zur Pflicht des Waldbesitzers, den Waldspaziergang zu dulden. Ich kann mir kaum größere Gegensätze vorstellen. Das einzige, was beide Erscheinungen verbinden würde, wäre eine Pflicht des Waldbesitzers, Spazierwege vorzuhalten, womit aus dieser Pflichtbegründung ein Anspruch Dritter auf Leistung und Rechtsausübung erwüchse.

Was mich bei solcher Zuordnung von Herrn Götz (Herr Hofmann hat das Thema wohl nicht berührt) bewegt, ist die Frage: Ist es gerechtfertigt, solche Indienstnahmen aus dem Pflichtenkomplex, von dem hier die Rede sein soll, auszugrenzen, 
weil sie keine Grundpflichten sind? Ich habe meine Zweifel. Und wenn diese Indienstnahmen in Art. 12 GG als Berufsausübungsregelungen angesiedelt werden, soll sich daraus automatisch ergeben, daß der Verpflichtete sie unentgeltlich zu erbringen hat, und so habe ich Herrn Götz verstanden. Dieses Thema hat uns beschäftigt, seit der Gedanke gesetzlicher Indienstnahme von Wirtschaftsunternehmen akut geworden ist und ein Versuch ihrer Dogmatisierung unternommen wurde. Ich will dafür vier Beispiele nennen, die mir geläufig sind und die ich historisch abfolgen kann.

Zuerst bei der Währungsumstellung nach dem Kriege, als die privaten Banken und Kreditinstitute die Aufgabe der Währungsumstellung für den Staat durchzuführen hatten, sodann die Bevorratungsverpflichtung der Mineralölunternehmen, und in diesem Zusammenhang dann ein Kreis von Pflichten der Unternehmen, gewisse Steuerverwaltungspflichten zur Entlastung des Staates und seiner Finanzämter - Steuereinbehalt, Steuerabführung bis hin zur Versicherungssteuer. Der vierte Fall war die Indienstnahme von Verkehrsunternehmen, aus sozialen Gründen gewisse Beförderungsleistungen zu erbringen zu Sozialtarifen. In allen Fällen solcher gesetzlichen Pflichtbegründungen zur Entlastung des verwaltenden Staates ist die Entgeltfrage akut geworden. Es wird Sie nicht überraschen, wenn ich darauf hinweise, daß das europäische Gemeinschaftsrecht uns darüber belehrt hat, solche Indienstnahmen lösten Entgeltansprüche aus, und zwar zugunsten der Verkehrsunternehmen. Dadurch ist uns der Blick für diese Erscheinungen geschärft worden. Sie sind auch in den Mineralölbevorratungs-Entscheidungen des Bundesverfassungsgerichts erfaßt worden.

Ich wäre also dankbar, wenn die Abgrenzung von Herrn Götz zwischen Grundpflichten in der Verfassungsebene und diesen Indienstnahmen allgemein und in der Entgeltfrage verdeutlicht werden würde.

Vorsitzender: Herzlichen Dank, Herr Ipsen, für diesen wichtigen Beitrag. Als Nächster hat sich Herr Zacher gemeldet. Bitte, Herr Zacher.

Zacher: Zunächst eine Bemerkung: Ich habe das Wort „Last" heute vermißt. Ich glaube, Grundpflichten erweisen sich zumindest in der Realität weitgehend als Lasten: darin, daß man gewisse Vorteile nur in Anspruch nehmen kann, wenn man gewisse Grundpflichten erfüllt. Ich glaube, diese Unterscheidung sollte hinzugefügt werden. 
Angesichts der sehr eindrucksvollen Referate fällt es einem natürlich schwer, nun Dringlicheres und Umfassenderes zu sagen. Gleichwohl möchte ich einen Kritikpunkt anbringen. Mir waren die Grundraster, die heute verwendet worden sind, zu wenig einfach.

Ich möchte erstens ausgehen von der Definition, die ich gerne für Grundrechte anwende, weil ich glaube, daß sie rechtshistorisch und rechtsvergleichend sozusagen über die Grenzen und die Zeiten hin trägt: Grundrechte finden den allgemeinsten Nenner darin, da $\beta$ sie elementare Aussagen über wichtige Probleme in der Konfliktsbeziehung zwischen Gemeinwesen und Individuum sind. Und ich glaube, daß Grundpflichten diese Gemeinsamkeit teilen, daß auch sie wichtige Aussagen in diesem Verhältnis sind. Wenn ich nun dieses Verhältnis zwischen Gemeinwesen und Individuum ganz bestimmen möchte, dann brauche ich in der Tat Aussagen über Grundrechte und Grundpflichten, wobei natürlich die Grundrechte den Vorrang haben, weil sie auch für die Definition des Individuums gegenüber dem Gemeinwesen einen ganz anderen Rang haben. Warum, Herr Hofmann - da konnte ich Ihnen nicht ganz folgen - warum zur Umschreibung dieser Grundposition des Individuums nicht gleichermaßen Rechte und Pflichten komplementär herangezogen werden können, hat mir nicht eingeleuchtet. Das war sicher rechtsphilosophisch gedacht. Aber nun bin ich eben keine philosophische Natur; und darum kann ich das nicht nachvollziehen. Wichtig scheint mir zu sein, daß das Ganze im Grundkonflikt Individuum - Gemeinwesen gesehen wird und daß Grundrechte und Grundpflichten als sich ergänzende Umschreibungen der Position des Individuums in dieser Konfliktsituation zu sehen sind.

Wenn ich nun diese Aussagen zu machen suche, dann stellt sich die Kontextfrage: In welchem Kontext mach' ich diese Aussagen? Ich kann das Gemeinwesen betonen, und ich kann die Pflichten betonen. Das wurde eben sichtbar bei den sozialistischen Verfassungen. Der Gegensatz liegt in der freiheitlichen Verfassung, wo wir das Individuum betonen und die Rechte betonen. Aber hieraus ergibt sich der formell rechtsstaatliche Kontext. Er ist, wahrscheinlich weil es zu selbstverständlich erschien, zu sehr ausgespart worden. Ich habe hier ein Regel-Ausnahme-Verhältnis, und zwar ein doppeltes Regel-Ausnahme-Verhältnis. Erstens, daß ich das Grundrecht so anlegen kann, maximal so anlegen kann, daß es gewährt wird, bis es vom Gesetzgeber eingeschränkt, widerrufen oder zurückgenommen wird. Die Grundpflicht kann ich so nicht ,aus- 
werfen“. Das zweite Regel-Ausnahme-Verhältnis ist, daß ich das Grundrecht unmittelbar subjektivieren kann, so daß ich nicht nur die objektive Aussage behalte, und daß ich die Grundpflicht auf der anderen Seite nicht unmittelbar subjektivieren kann, sondern hier die objektive Dimension allein wesentlich bleibt. Das wären die ganz einfachen Grundmuster, die vielleicht aus Selbstverständlichkeit nicht ausgesprochen worden sind.

Nun komme ich aber noch zu einem zweiten Kritikpunkt. Er betrifft die konkrete Nachfrage nach den Grundpflichten. Warum ist denn die Nachfrage nach Grundpflichten so unterwegs? Entscheidend ist die Verfassungsgeschichte der Nachkriegszeit. In der Situation von 1949 hat man das Gemeinwesen vernachlässigt gegenüber dem Subjekt und die Pflicht vernachlässigt gegenüber dem Recht; und was herausgekommen ist, ist, daß beides zusammengewachsen ist zu dem Konsens, daß der wesentliche Gemeinwesensauftrag ein Dienst an den Rechten des Individuums ist. Ich glaube, es ist diese Steigerung, um deren Zurücknahme es bei dieser Diskussion geht.

Es stellt sich aber auch nicht nur diese generelle Verortungsfrage, sondern auch die spezielle Sachfrage: Welche Grundpflichten sind gefragt? Wenn ich zurückgehe auf die Definition, daß Grundpflichten wichtige Aussagen über das Verhältnis des Individuums zum Gemeinwesen sind, dann stellt sich nämlich auch die Themenfrage. Das verhält sich analog wie bei den Grundrechten. Grundrechte sind historisch konkret gewachsen. Sie haben sich z. T. ausgeweitet, so, wie die allgemeine Handlungsfreiheit. Das konnte ihren konkreten Ursprung verdecken. Aber im wesentlichen sind sie historisch konkret entstanden - so, wie schon in der Magna charta libertatum die Freiheit vom Brückenbau und die Freiheit von der Ablieferung von Holz und endlich im Grundgesetz die allgemeine Zugänglichkeit von Informationen. Sie sind konkret entstanden. Und ich glaube, das ist etwas, was wir bei der konkreten Nachfrage nach Grundpflichten auch sehen müssen. Wo werden Probleme gesehen, wo jetzt solche Aussagen notwendig sind? Ich glaube nicht, daß Ihre klassische Quadriga diese Fragen beantworten kann. Zum Beispiel die Schulpflicht: Das ist heute so wenig das Thema mehr etwa wie die Auswanderungsfreiheit ein Thema ist auf der Grundrechtsseite. Heute entsteht die Nachfrage nach Grundrechten etwa und nun bin ich natürlich sozusagen bei meinem Hausressort: beim Sozialrecht - für die Vorsorgepflicht, für die primäre Selbstversorgungslast, daß man zunächst einmal für sich selbst aufkommen muß, und dann natürlich auch für die allgemeine Dienstpflicht. 
Damit komme ich aber zurück auf das Primat des Verhältnisses Individuum - Gemeinwesen. Keine Grundpflicht kann das Gemeinwesen davon entlasten, daß es sich selbst ernst nimmt. Nur wenn das Gemeinwesen die Grundpflichten einfordert, dann werden sie realisiert. Genauso wie die Grundrechte nur realisiert werden, wenn der einzelne sie einfordert, so werden die Grundpflichten nur realisiert, wenn das Gemeinwesen sie einfordert. Ich glaube, der entscheidende Nachholbedarf entsteht hier beim Gemeinwesen. Und ich würde hier vor allem eine Grundpflicht nennen, die von Herrn Götz so intensiv behandelt worden ist, nämlich die Wehr- und Ersatzdienstpflicht. Wenn ein Gemeinwesen sich so vielfach ungeschickt anstellt wie unsere Bundesrepublik bei der Einforderung dieser Pflicht, dann kann auch keine Verfassung daran etwas ändern, daß diese Pflicht nicht lebendig ist.

Häberle: Herr Vorsitzender, verehrte Kollegen! Die beiden bedeutsamen Referate von heute vormittag geben uns eine besondere Chance: Sie ermöglichen eine Verknüpfung von geistesgeschichtlichen und verfassungstheoretischen Tiefendimensionen, auch Klassikertexten, Herrn Hofmanns Ansatz einerseits mit der harten verfassungsdogmatischen Arbeit an Rechtstexten, auch unterverfassungsrechtlicher Art nach dem Vorbild von Herrn Götz andererseits. Überdies habe ich heute gelernt, daß bei den Grundpflichten nicht nur der demokratische Gesetzgeber eine wesentliche Konkretisierungsleistung zu erbringen hat, sondern daß eine solche auch die Staatsrechtslehre im Sinne „wissenschaftlicher Vorratspolitik“ erbringen kann. Auf diesem Hintergrund möchte ich versuchen, drei Ebenen anzuleuchten, auf denen wir die Grundpflichtenproblematik weiter verfolgen sollten:

Erstens auf der positivrechtlichen, rechtsdogmatisch $\mathrm{zu}$ bewältigenden Ebene. Zweitens auf der rechtsvergleichenden, internationalrechtlichen Ebene; Stichwort ist hier der Typus des demokratischen Verfassungsstaates, wobei wir als Beispiele neuere Verfassungsurkunden etwa von Portugal (1975) und Spanien (1978) einbeziehen sollten, auch einige jüngere bzw. neu geplante Schweizer Kantonsverfassungen (etwa Jura bzw. Basel/Landschaft, Entwurf von 1982), die neben den Grundrechten Grundpflichten kennen und sie damit belegen, daß Grundpflichten durchaus ein wesentlicher Bestandteil freiheitlicher Verfassungen sein können; lassen Sie mich auch auf den Menschenrechtspakt über bürgerliche und politische Rechte von 1966 Bezug nehmen, der im letzten Absatz seiner Präambel und auch sonst von „Pflichten“ spricht, ebenso wie 
die EMRK „normale Bürgerpflichten“ (Art.4 Abs. 3) und „Pflichten und Verantwortung“ (Art. 10 Abs. 2) kennt. Stichwort meiner dritten Ebene ist die Frage, ob sich das Problem der Grundpflichten bei uns mittelfristig nur als Aspekt der politischen Kultur und auf längere Sicht nur im Wege bewußter Verfassungspolitik behandeln läßt, die einzubeziehen mit zu den Aufgaben der Staatsrechtslehre und unserer Vereinigung gehört, wobei die Rechts- bzw. Verfassungsvergleichung mithelfen kann.

Zunächst zum ersten Punkt: Dank des überaus glücklichen Begriffs von Herrn Hofmann von den Grundpflichten als Teil der „,konstitutionellen Programmatik“ (Leitsatz 20) lassen sich innere Zusammenhänge zwischen den wichtigsten Verfassungsprinzipien des Grundgesetzes und konkreten Grundpflichten herstellen. So bestehen Beziehungen zwischen der freiheitlichen Demokratie und der Grundpflicht, ein Ehrenamt zu übernehmen; entsprechendes gilt für den Gleichheitssatz; Herr Hofmann hat mit Recht in Leitsatz 16 erarbeitet, daß dieser die Seite der Grundpflicht in sich birgt, je nach Situation des Verfassungsstaates gehört auch die allgemeine Wehrpflicht hierher. Dem Prinzip des Rechtsstaates ist z. B. die allgemeine Zeugenpflicht der einfach-gesetzlichen Prozeßordnungen zuzuordnen; sie besteht zwar dem Text nach nicht auf GG-Ebene, aber sie ergibt sich aus einer Verbindung von Rechtsstaatsprinzip und unterverfassungsgesetzlichem Recht durchaus auf Verfassungsebene; Sie, Herr Götz, haben den "Selbststand" des einfachen Rechts sehr stark betont (etwa in Leitsatz 15 a), während ich auf dem Felde ,konstitutioneller Programmatik" von Grundpflichten (z. B. Art. 14 Abs. 2 GG) und ihrer Realisierung durch einfaches Recht eine intensivere Verbindung zwischen beiden Ebenen sehe, etwa auf der Linie der Arbeit unseres Vorsitzenden Peter Lerche in der ersten Festschrift für Maunz (Stichwort „Konzentrat des einfachen Rechts"); auch sonst sind hier Grundpflichtigkeiten erkennbar: neben der Hilfeleistungspflicht etwa in Elementen des Verwaltungsrechtsverhältnisses, die ins Verfassungsrecht hinaufreichen. Dem Sozialstaatsprinzip sind ebenfalls Aspekte einer Grundpflichtigkeit des Menschen zu entnehmen, wie sie der verehrte Herr E. R. Huber, den ich hier und heute vor mir sehe, schon in den 50er Jahren etwa als „Gemeinwohlverträglichkeit" entwickelt hat. -

Ein Wort zum zweiten Punkt, zur rechtsvergleichenden Ebene. Überzeugend haben beide Referenten das Gegenbild des totalitären Staates von links nachgezeichnet, wir müßten hinzufügen die totalitären Staaten von rechts, etwa das frühere 
Portugal und Franco-Spanien. Doch sollten jetzt auch die lehrreichen Grundpflichten-Abschnitte der neuen verfassungsstaatlichen Verfassungen Portugals (,soziale bzw. kulturelle Rechte und Pflichten“) bzw. Spaniens („Bürgerrechte und -pflichten") vergleichend ausgewertet werden, ich folge dabei der Verwandtschaftsthese zwischen sozialen Grundrechten und Grundpflichten. Wir lernen aus den iberischen demokratisch-politischen Bürgerpflichten bzw. sozialen und kulturellen Grundpflichten, daß Grundpflichten eine mögliche verfassungsstaatliche Kategorie sind und da $ß$ hier das verfassungsstaatliche Erbe an Grundpflichten beispielhaft fortgeschrieben worden ist. Bei all dem kommt es freilich auf Verfassungsverständnis und -kultur an. Dem GG dürfen wir kein Füllhorn an Grundpflichten unterlegen. Wir müssen sehr behutsam vorgehen, so, wie dies trotz ihrer unterschiedlichen Ausgangspunkte im Ergebnis beide Referenten getan haben. -

Damit komme ich zum dritten Punkt, zur Frage von Verfassungskultur und Verfassungspolitik. Es ist ja merkwürdig, daß das Thema "Grundpflichten" recht plötzlich auf der Tagesordnung steht. Herr Zacher hat eben ähnlich gefragt. Warum besteht heute bei uns ein Bedürfnis nach "Grundpflichten“, warum gab es bis vor kurzem ein Defizit an Verfassungs- und Problembewußtsein für sie, warum dieser Wandel? Vielleicht als Gegenbewegung gegen manche Überdehnung eines stark materialistisch praktizierten Freiheitsbegriffs und wegen des Wegfalls mancher „selbstverständlicher" kultureller Einbindungen? Dennoch sollte die Staatsrechtslehre nicht damit beginnen, jetzt überall Grundpflichten anzusammeln, zumal Verantwortung eher gelebt als erzwungen werden kann. Aber wir müssen doch fragen, ob Aspekte der Menschenbildjudikatur des Bundesverfassungsgerichts (Stichwort „Gemeinschaftsgebundenheit") sowie der differenzierten Grundrechtsschrankensystematik Elemente von Grundpflichtigkeiten enthalten, wenn man sie vom Positiven her sieht. Gewiß könnten wir noch andere Felder im ,gesicherten Rechtsbestand“ entdecken, wo wir Ansätze zu Grundpflichten erkennen, ich denke etwa an die Kulturstaatsklausel bzw. Art. 6 Abs. 2 GG. - Das führt mich zur letzten Überlegung, zur Verfassungspolitik. Uns bleibt die Frage, ob und wie wir mittel- und langfristig in Deutschland in einer etwaigen Revision von Grundgesetz und Länderverfassungen oder im Blick auf eine gesamtdeutsche Verfassung die Grundpflichten in einer dem demokratischen Verfassungsstaat angemessenen Weise so normieren, daß sie weder die Verfassung der Freiheit gefährden noch zum Mißverständnis verantwortungsloser Freiheit führen. Im Rahmen dieser ver- 
fassungspolitischen Gratwanderung daher ein doppelter Vorschlag: Zum einen könnten und sollten Grundpflichten sehr generalklauselartig in den Verfassungs-Präambeln mit ihrer spezifischen Verbindlichkeit einen guten Platz finden, in Präambeln also, die durchaus Substanz haben können, mein eingangs zitiertes Beispiel kommt dem nahe. Zum anderen sollten Grundpflichten in den Erziehungszielen normiert werden, etwa als „Gemeinsinn“, „Rücksichtnahme“ etc., Begriffe, die wir in üppigem Reichtum aus deutschen Länderverfassungen kennen. Der junge Bürger muß und kann so gerade im Verfassungsstaat in die in republikanischer Tradition selbstverständliche Idee der Grundpflichtigkeit und Verantwortung des Menschen erzieherisch hineinwachsen, ohne daß damit der Weg in Erziehungsdiktaturen totalitärer Staaten freigegeben würde. Von Grundpflichten in Textgestalt von Präambeln und Erziehungszielen ist in Deutschland nichts zu befürchten; zugleich bliebe aber der Pflichtaspekt als für den demokratischen Verfassungsstaat und sein Bürger-Staat-Verhältnis ,wesentlich" schon in dessen Urkunde erkennbar und glaubwürdig.

Oppermann: Ich kann mich an das Letzte anschließen. Wir alle zollen dem Vorstand ein Kompliment dafür, dieses Thema aufgegriffen zu haben. Warum liegt es in der Luft, so hat auch Herr Häberle gefragt. Wenn man die Frage auf Deutschland beschränkt, habe ich zunehmend den Eindruck, daß wir bei den verschiedenen Fragen zu Grundgesetzrevisionen $u$. ä. uns in einem Zeitpunkt befinden, in dem man verstärkt darüber nachdenkt, ob gewisse Dinge, die in der Weimarer Verfassung vorhanden waren, jetzt doch, entgegen der vielleicht etwas zu starken Abstinenz von 1949, im Grundgesetz, sei es ausdrücklich, sei es im Wege der Interpretation wieder aufgegriffen werden sollten. Ein aktuelles Beispiel ganz anderer Art ist im Augenblick die Frage des Auflösungsrechts des Bundestages. Auch da tritt sozusagen ein wirklicher oder vermeintlicher „Webfehler" des Grundgesetzes plötzlich hervor. Diese Frage eines „Zurück zu Weimar?“" kommt hier unter ganz anderen Gesichtspunkten auf: Grundpflichtdefizit des Grundgesetzes? $\mathrm{Ob}$ in diesem Zusammenhang das Grundgesetz partiell oder etwas stärker wieder "weimarisiert" werden sollte, scheint mir der eigentliche Hintergrund zu sein, weshalb das Thema, etwas im Gegensatz zu Ihnen, Herr Hofmann, nicht nur konjunkturell i.S. kurzfristiger Verfassungspolitik, sondern mindestens mittelfristig wirklich aktuell ist. Was ist nun herausgekommen heute morgen, was tragen wir mit nach Hause? 
Im ersten Moment ist meine ursprüngliche Befürchtung, daß es beim Grundpflichtenbegriff sich um einen der öffentlichrechtlichen „Nebelbegriffe“ handelt, verstärkt worden, als ich nicht nur die Referate, sondern auch die Begleitaufsätze in den Zeitschriften auf mich habe wirken lassen. Was sind Grundpflichten? „Verfassungsrechtlich geforderte Pflichtbeiträge von eigenständiger verfassungsrechtlicher Bedeutung" (Herr Götz); „klassische Bürgerpflichten im Sinne des Status civilis" (Herr Hofmann); „Verfassungsvoraussetzungen und -erwartungen“ (Herr Isensee); ,,austauschbare Werkzeuge des Verfassungsgebers" (Herr Badura) - um nur einige Zitate zu nennen! Es werden da - wie soll ich sagen - im Rand- und Nebelfeld der Verfassung befindliche Begriffe sehr häufig verwendet. Aber der Nebel beginnt sich eigentlich doch etwas zu lichten nach dem, was wir heute morgen gehört haben. Ich möchte vor allem drei Punkte festhalten: Erstens ist aus beiden Referaten deutlich geworden, daß die Grundpflichten eine Mittelstellung zwischen der Aktion der Gesamtheit, sprich: des Gesetzgebers insbesondere, und der individuellen Angesprochenheit des Bürgers einnehmen. Herr Götz hat gesagt (ich möchte seine Formulierung umkehren): Staatliches Handeln wird gefordert bei der Verwirklichung von Grundpflichten, aber es ist zugleich eine an den Bürger adressierte Pflicht. - Weiter die Frage nach der „Austauschbarkeit der Werkzeuge“, wie sie Herr Badura am Ende seines Aufsatzes angesprochen hat, ob man nicht Grundpflicht, Staatszielbestimmung, Gesetzgebungsauftrag $u$. ä. mehr oder weniger nach den Bedürfnissen austauschen kann. Ich meine: im Grundsatz schon, das besonders Individualisierte der Staatsaufgabe, das ist es wohl doch, was die Grundpflichten auszeichnet. Die Grundpflicht als eine individualisierte Staatsaufgabe oder Staatszielbestimmung. In dieser Richtung scheinen mir die Dinge zu gehen. Die Grundpflicht kann nicht an der individuellen Einklagbarkeit des Art. 1 Abs. 3 GG teilhaben, das ist auch ganz deutlich geworden. Aber auf der anderen Seite will sie doch etwas stärker den einzelnen Ansprechendes sein, als eine ganz allgemeine Staatszielbestimmung, wie etwa die Sozialstaatsklausel.

Zweiter Punkt: Ich frage mich, ob man nicht zwischen Grundpflichten und Staatspflichten unterscheiden muß. Die Beispiele auf der einen Seite: Wehrpflicht - Schulpflicht Erziehungspflicht bei Art. 6 GG, da ist dieses individualisierte Moment sehr stark. Ob das bei der Friedenspflicht, Herr Götz, in derselben Art und Weise der Fall ist - man kann sie als Unterlassungspflicht des einzelnen begreifen - muß doch sehr fraglich erscheinen. Ohne Zweifel handelt es sich hier um eine 
eminente Pflicht, nicht nur zu unterlassen, sondern auch, daß die Aktion der Gesamtheit zugunsten der Friedenswahrung erfolgt. Gibt es also nicht neben den Grundpflichten auch Staatspflichten? Auch darüber lohnt es sich noch weiter nachzudenken.

Dritter und letzter Punkt: Ich bin ziemlich unbekehrt geblieben, trotz mancher Bemerkungen heute morgen und in den Aufsätzen, daß nicht doch, Herr Hofmann hat es ähnlich gesehen, eine sehr starke Konnexität zwischen Grundrechten und Grundpflichten besteht. Der Art. 6 Abs. 2 GG ist immer so schnell beiseitegeschoben worden. Gerade aber das Erziehungsrecht der Eltern hängt eng mit der Erziehungspflicht zusammen. Wenn ich an die anderen Beispiele denke, etwa an den Art. 14 Abs. 2 GG, frage ich mich, ist es da wirklich so anders, wenn man die Sozialpflichtigkeit des Eigentums, wie man es vielleicht tun kann, als Causa im weiteren Sinne für Enteignungsmöglichkeiten $u$. ä. begreift. Ist da nicht eine graduell vielleicht unterschiedliche, aber in der Qualität durchaus vergleichbare enge Konnexität zwischen dem Grundrecht und den Pflichten, die dieses sachliche Substrat „Eigentum" verursacht, vorhanden? Ist es bei der öffentlichen Aufgabe der Presse und den Pflichtigkeiten, die sie hervorbringt, näher als es in manchen Bemerkungen heute den Anschein gehabt hat, und das führt mich zu der Schlußfolgerung, verfassungspolitisch etwa im Sinne von Herrn Häberle: Bei der Überlegung, Verfassungen wie das Grundgesetz, um lange Grundpflichtenkataloge anzureichern, befindet man sich auf dem Holzwege. Der sicherlich in manchem unvollkommene Versuch der Weimarer Verfassung, im heute vielzitierten Art. 163, durch eine Generalklausel auf diese allgemeine Verbindung zwischen Grundrecht und Grundpflicht hinzuweisen und daraus Maßstäbe für die richtige Auslegung der Grundrechte zu setzen, könnte der Weg sein, der weiter bedacht werden sollte. Conclusio meinerseits: Es war wirklich Zeit für das, was Herr Götz die WiederEntstehung der Grundpflichten genannt hat. Eine zu starke "Weimarisierung des Grundgesetzes" in dieser Richtung sollte nicht das Ziel sein, aber gewisse behutsame Schritte in Richtung einer stärkeren (generalklauselartigen?) Besinnung auf den Pflichtengehalt von Grundrechten scheint die Richtung zu sein, in der wir uns bewegen sollten.

Bachof: Ich möchte an einen Punkt anknüpfen, den Herr Ipsen schon angesprochen hat. Mir scheint, daß Herrn Hofmanns Leitsatz 16 (in Verbindung mit Leitsatz 20) einen zentralen Punkt seiner Ausführungen bildet: Ihren verfassungs- 
rechtlichen Grund haben die Grundpflichten in dem Gegenseitigkeitsprinzip und in dem Prinzip gleicher Freiheit aller. Herr Hofmann hat freilich hinzugefügt: Gegenseitigkeitsprinzip „des Art. 2 Abs. 1 GG“ und gleiche Freiheit gemäß „Art. 3 Abs. 1 GG“. Diese Normen mag man hier anführen, das ist sicher richtig. Man könnte aber auch noch auf das Sozialstaatsprinzip hinweisen, aus dem ich - man soll sich nicht selbst zitieren, aber hier muß ich es einmal tun - vor fast 30 Jahren in meinem Sozialstaatsreferat eine „Verpflichtung zu sozialer Verantwortung" hergeleitet habe. Ich würde das heute vielleicht eher die Grundpflicht zu einem Mindestmaß an Solidarität nennen. Das ist wohl dasselbe, was Herr Hofmann mit dem Gegenseitigkeitsprinzip meint. Dieses Prinzip liegt eigentlich jeder Staatlichkeit, ja überhaupt jeder Gemeinschaft zugrunde, schon vor Art. 2 und 3 GG.

Keine Gemeinschaft kann existieren, ohne daß ein Mindestma $ß$ an Solidarität vorhanden ist, an wechselseitiger Achtung; ein Mindestma $\beta$ an Bemühen, andere nicht zu schädigen, nicht zum Nachteil und nicht auf Kosten anderer zu leben. Ich habe in einem der Aufsätze zur Vorbereitung dieser Tagung - ich weiß nicht, ob von einem Mitglied der Vereinigung - unter anderem gelesen, Grundrechte seien lediglich „Angebote" an den einzelnen; er könne sie annehmen, er könne sie ablehnen, er brauche keinen Gebrauch davon zu machen. Daraus ergebe sich, daß man ihm auch keine Grundpflichten auferlegen könne. Das allerdings, meine Herren Kollegen, halte ich für falsch. In der heutigen Industriegesellschaft gibt es niemanden mehr, der von den Angeboten, die die Gemeinschaft ihm macht, keinen Gebrauch machen kann und keinen Gebrauch machen will. Das fängt bei den einfachsten Dingen an: bei der Luft, die wir atmen und beim Wasser, das wir trinken. Das ist ja nicht mehr die schöne Waldesluft der Romantiker oder der kühle Quell: Es ist die Luft, die erst mal gereinigt wurde auf Kosten des Steuerzahlers oder eines Produzenten und damit letztlich - über den Preis - auf Kosten der Konsumenten. Wir alle zahlen also für die Luft, die wir atmen. Und Wasser trinken wir, das durch zwanzig Mägen gelaufen ist und zur Trinkbarkeit erst wieder aufbereitet werden muß. Das alles zahlt die Gemeinschaft. Wer heute erklärt, er brauche diese und andere „Angebote“ nicht, der könnte allenfalls wie ein Robinson auf einer einsamen Insel leben; aber die gibt es leider nicht mehr. Mit anderen Worten: Jeder, der heute in einer staatlichen Gemeinschaft lebt, profitiert von dieser Gemeinschaft; dieses Leben durch Gebrauchmachen von den Angeboten der Gemeinschaft verpflichtet ihn, seinerseits auf 
alle anderen Rücksicht zu nehmen. Das heißt, er muß alles unterlassen, was solche „Solidarität" verletzt. Also: Solidaritätspflicht als „Grundpflicht".

Herr Hofmann hat die einzelnen Grundpflichten - Militärpflicht, Steuerpflicht, Eigentumsabgabepflicht, Schulpflicht letzten Endes reduziert auf die Pflicht zum Gesetzesgehorsam als eine Pflicht, die ebenfalls jeder staatlichen Gemeinschaft vorgegeben ist, sie erst konstituiert. Ich halte das für richtig, aber das greift mir noch etwas zu kurz. Ich meine: Gesetzesgehorsam, schön und gut; aber geht die Solidaritätspflicht, so wie ich sie eben zu entwickeln versucht habe, nicht noch darüber hinaus? Gibt es nicht auch Pflichten des Sich-solidarischVerhaltens, die nicht gesetzlich normiert sind? Hören sie bei fehlender Vergesetzlichung auf, Pflichten zu sein, und zwar Rechtspflichten, nicht blo $\beta$ sittliche Pflichten? Ich habe den Eindruck, daß einigen Vorbereitungsaufsätzen die Auffassung zugrundeliegt, eine Pflicht höre auf, eine Rechtspflicht zu sein, sie werde zu einer bloß sittlichen Pflicht, wenn sie nicht durchsetzbar, wenn sie nicht zwangsbewehrt ist. Meine Herrn Kollegen, wir kennen doch seit langem die lex imperfecta! Ich habe seinerzeit in meinem Sozialstaatsreferat betont, daß die Verpflichtung zu sozialem Verhalten selbstverständlich nicht erzwingbar sei; ich bin aber trotzdem gar nicht auf den Gedanken gekommen, daß sie deswegen eine bloß sittliche Pflicht sei; ich habe sie vielmehr stets als eine verfassungsrechtliche Pflicht angesehen. Ich meine, wer krank feiert, ohne krank zu sein; oder wer als Motorradfahrer die Anlegung des Schutzhelms und als Autofahrer die des Gurtes ablehnt - es mag Gründe dafür geben, dies abzulehnen; aber wer es ablehnt mit der Begründung: „Das ist ja meine Privatangelegenheit, wenn ich verunglücke, wen geht das etwas an?" - der verkennt, daß er auch hier wieder die Lasten auf die Gemeinschaft abwälzt, auf alle ihre Mitglieder. Denn die Krankenhauskosten, die Versicherungskosten usw., die zahlen ja andere. Sie mögen sagen, diese Beispiele seien vielleicht nicht ganz glücklich gewählt, weil ja doch das Krankfeiern nicht erlaubt sei und weil eine Pflicht zum Anlegen des Schutzhelms und des Gurtes bestehe. Aber ich meine, die Verpflichtung, sich in diesen Fällen „solidarisch" $z$ u verhalten, bestünde unabhängig davon, ob sie gesetzlich positiviert sei oder nicht. Sie können aber auch ein anderes Beispiel nehmen, in dem nun keine gesetzliche Pflicht besteht: Wer es absichtlich und obwohl er dazu in der Lage ist, unterläßt, irgendeine Vorsorge für sein Alter, für Krankheiten, für andere Schwierigkeiten zu treffen und sagt: „Da wird ja die Gemeinschaft einspringen, die zahlt dann ja für 
mich", der verhält sich solidaritätswidrig und verstößt gegen eine von jeder Staatlichkeit vorausgesetzte Grundpflicht; diejenige Grundpflicht eben, die m. E. der Gesetzesgehorsamspflicht noch vorgelagert ist.

Nun noch ganz kurz zu Herrn Hofmanns Leitsatz 20: Ganz sicher bedarf die Grundpflicht zu solidarischem Verhalten und bedürfen alle daraus weiter abgeleiteten Grundpflichten zu ihrer vollen Wirkung einer Positivierung. Die Grundpflichten, so sagt Herr Hofmann, ,entfalten verfassungsrechtliche Wirkung, indem sie zu setzendes Recht begründen“. Er meint wohl: „begründen“ im Sinne von ,legitimieren“, „zur Rechtsetzung berechtigen". Ich stimme dem zu. Nur hat Herr Hofmann - es steht so nicht in den Leitsätzen - auch noch gesagt, die Grundpflichten bewegten sich im Bereich der „,reinen“ Programmatik. Hier habe ich doch leichte Zweifel. Auch die Grundrechte haben sich doch, als sie in der Weimarer Verfassung nur sog. „Programmsätze“ waren, keineswegs nur im Bereich einer Programmatik bewegt; immer waren sie auch schon Auslegungsrichtlinien und vieles andere mehr. Deshalb frage ich nur - ich will das hier nicht entscheiden -: Wenn Rechte und Pflichten, sei es zwischen einzelnen untereinander oder zwischen einem einzelnen und dem Staat, miteinander im Streit liegen, können dann nicht unter Umständen auch ungeschriebene Grundpflichten und insbesondere die ungeschriebene Solidaritätspflicht mit in die Interessenabwägung und in die Entscheidung einbezogen werden?

Doehring: Herr Vorsitzender, meine lieben Kollegen. Ich spreche nicht aus Pflicht, sondern aus Neigung, aus Neigung zu dem Thema, das ich für außerordentlich bedeutsam halte; auch die Referate haben sehr angeregt und waren sehr abgerundet, wenn auch vielleicht in manchen Punkten etwas zu abstrakt. Das insbesondere ist der Grund, warum ich einige Worte sagen möchte. Ich möchte ganz konkrete Fragen an die Referenten stellen.

Die Pflicht des Menschen, die Gesetze einzuhalten, ist eigentlich die einzige Grundpflicht, die ich anerkenne. Ich bin nicht ganz der Meinung, die Herr Bachof äußerte, daß nämlich vor dieser Gesetzeseinhaltungspflicht noch eine allgemeine und ungeschriebene Pflicht in der Verfassung enthalten sei. Die Folge könnte eine unbestimmte Freiheitseinschränkung sein. Es ist richtig, daß wir den Begriff der lex imperfecta kennen, aber sie ist eben imperfekt und nicht perfekt und muß also etwas anderes sein als die strikte Gesetzeseinhaltung. Die Kategorie der allgemeinen Gesetzesbefolgungspflicht möchte 
ich aber jetzt nicht betrachten; sie ist eigentlich auch keine Kategorie, denn sie besteht aus nur einer einzigen Position. Eine andere Kategorie von Grundpflichten oder von Pflichten, die wir der Verfassung entnehmen können, ist dort ausdrücklich benannt. Es handelt sich im wesentlichen um die Artikel 6, 12 a und 14 GG; vergessen wurde dabei wohl noch der Artikel 25 GG, wonach die allgemeinen Regeln des Völkerrechts nicht nur Rechte, sondern auch Pflichten erzeugen. An diese Feststellung knüpfen sich drei Fragen, die konkreter Natur sind. Wie steht es mit diesen positivierten Grundpflichten, die in der Verfassung ausdrücklich genannt sind? Gilt für sie im System des Grundgesetzes etwas Ähnliches wie für die Grundrechte, nämlich die Feststellung, daß ein Kernbereich auch der Pflichten ähnlich dem Wesensgehalt der Grundrechte aufrechterhalten und geschützt bleiben muß? Herr Hofmann hat das, glaube ich, anklingen lassen, aber ich möchte doch diese Frage noch einmal stellen. Darf der einfache Gesetzgeber an diesen positivierten Pflichten rütteln, darf er sie einschränken, etwas abbauen, oder darf er sie - und das ist wichtiger auch ausweiten und aufstocken? Das scheint mir der Klärung notwendig. Wenn man meint, diese Pflichten laufen leer, wie das in der Verfassung von Weimar für die Grundrechte angenommen wurde, dann braucht man natürlich solche Überlegungen nicht anzustellen. Der Gleichheitssatz aber löst diese Frage nicht, denn es kann ein einzelner Fall auftreten, der mit anderen nicht vergleichbar ist. Die zweite Frage ist: Wie verhalten sich diese positivierten Grundpflichten eigentlich zu dem, was wir institutionelle Garantien nennen? Der Ruf etwa von Pressevertretern, Journalisten und Redakteuren, sie hätten doch nicht nur ein Recht gem. Art. 5 GG, sondern auch die Pflicht zur Information der Öffentlichkeit, ist doch eine Berufung auf eine verfassungsmäßige Pflicht. Wie weit geht hier dann die Einschränkbarkeit oder auch die Ausweitungsmöglichkeit einer solchen Pflicht? Es ist sicherlich ein Unterschied, ob man sich auf ein Recht oder eine Pflicht beruft. Für die Gewerkschaften besteht gem. Art. 9 GG wohl eine ähnliche Problematik. Hier fehlen offenbar noch die dogmatischen Abgrenzungen. Gibt es solche Pflichten eigentlich, oder - wie im Mitbestimmungsurteil des $B V e r f G$ gesagt - gehen sie auf im Begriff der institutionellen Garantie, die aber letztlich auch nur der Individualfreiheit zu dienen hat? Jedenfalls bleiben hier bezüglich der Pflichten recht ungeklärte Probleme. Meine letzte Frage bezieht sich auf das Folgende: Wir haben Rechte, Kompetenzen, Hoheitsrechte auf die Europäischen Gemeinschaften in recht großem Umfang übertragen. Dabei ist einmal 
die Frage aufgetaucht, ob wir durch die Hoheitsrechtsübertragung auch Grundrechte zur Einschränkung freigegeben haben; ich erinnere an die Eurocontrol-Entscheidung des BVerfG zu Art. 24 GG, die Grenzen aufzeigt. Der Wesensgehalt soll auch hier gewahrt sein, aber die Umkehrung der Medaille ist problematisch. Wenn wir uns unserer Hoheitsrechte entäuBern, übertragen wir dann auch die allgemeine Gehorsamspflicht oder nur spezielle Pflichten auf andere Institutionen, oder das Recht auf andere Institutionen, uns in Pflicht zu nehmen? Wieviel ist hier übertragbar? Von einem Staat wissen wir, daß ein enges staatsbürgerliches Band besteht zwischen protectio und subjectio. Bei der Übertragung von Hoheitsrechten auf eine supranationale Organisation fehlt bisher eine Abgrenzung der Pflichtigkeit, nämlich hinsichtlich der Frage, ob solche Pflichten übertragen werden können, zum anderen, ob dann auch ein Wesensgehalt Bestandsschutz behält, wie das bei den Rechten der Fall ist, die das BVerfG in seinen Entscheidungen immer noch in einem Kernbereich unserem Staat reserviert hat. Vielen Dank!

Grimm: Ich fürchte, ich kann mich nicht so stark in den Sog des Themas ziehen lassen wie meine Vorredner. Zur Erläuterung meiner Skepsis knüpfe ich an die wichtige Frage von Herrn Hofmann an: Was ist eigentlich der Grund für Grundpflichten? Und zur Präzisierung der Antwort erlaube ich mir, seine Frage für einen Moment umzukehren und zu überlegen, was eigentlich der Grund für Grundrechte ist. Grundrechte verstehen sich ja nicht von selbst, denn alles, was grundrechtlich gewährleistet werden kann, läßt sich ebenso auf einfachgesetzlicher Ebene gewährleisten. Aus diesem Grund bezweifelten auch einige Mitglieder der französischen Nationalversammlung im Jahre 1789, daß es angesichts der freiheits- und gleichheitsfeindlichen Rechtsordnung des Ancien régime sinnvoll sei, mit der Ausarbeitung von Grundrechten zu beginnen. Sie forderten stattdessen, zunächst einmal die für den einzelnen bedrückenden Gesetze zu ändern und erst dann zur Sicherung der neuen Ordnung Grundrechte darüberzusetzen. Die Nationalversammlung entschied sich damals für die Priorität von Grundrechten, und zwar deswegen, weil sie auch den Gesetzgeber, der die Definitionsmacht über Individualfreiheit ausübte, bei seiner Reformarbeit dauerhaft an das Freiheitsziel binden wollte. Der Grund für Grundrechte liegt also in der überlegenen Macht des Staates, die sich angesichts des staatlichen Gesetzgebungsrechts auf einfachgesetzlicher Ebene nicht wirksam begrenzen läßt. Nun also zurück zu der Frage: 
Was ist denn der Grund für Grundpflichten? Für Grundpflichten fehlt, wenn ich es richtig sehe, ein solcher Grund. Denn der Staat hat ohnedies die Möglichkeit, seine Bürger zu verpflichten, und diese Pflichten auch durchzusetzen. Sie stehen ihm nicht mit überlegener Macht gegenüber. Die Pflichten des Bürgers bedürfen deswegen nicht derselben Verstärkung, auf die seine Rechte angewiesen sind. Aus diesem Grunde möchte ich davor warnen, leichtfertig mit Grundpflichten zu operieren. Damit wende ich mich nicht gegen Pflichten, auch nicht gegen Bürgerpflichten, die sich aus der Verfassung ergeben, wohl aber gegen Grundpflichten. Wenn diesem Begriff überhaupt ein verfassungsrechtlicher Sinn innewohnen soll, kann er eigentlich nicht mehr als akzessorisch zu den Grundrechten sein. Er beinhaltet dann für den einzelnen die Pflicht, die gleiche Freiheit der anderen zu respektieren. Eben diese Pflicht konkretisiert aber, angeleitet und begrenzt durch die Grundrechte, der Gesetzgeber. Deswegen würde ich mich in der Kontroverse, die sich zwischen Herrn Götz und Herrn Hofmann darüber anzubahnen schien, ob Grundpflichten mehr sein können als Schranken der Grundrechte, auf die Hofmann'sche Seite schlagen und behaupten, daß sie keine zusätzliche Leistung erbringen. Jede zusätzliche Leistung wäre im Gegenteil gefährlich. Die Gefahr sehe ich darin, daß Exekutive und Judikative aus dem grundgesetzlich gar nicht vorgesehenen Begriff der Grundpflichten unter Umgehung des Gesetzgebers Rechtspflichten ableiten könnten, die dem Status rechtsstaatlich und demokratisch gesicherter Freiheit nicht zuträglich wären.

Vogel: Die Referenten haben ihr Thema verfassungs- und ideengeschichtlich so reichhaltig untermauert, - ganz besonders Herr Hofmann -, daß wohl nur wenige von uns aus dem Stand an ihrer Darstellung fundierte Kritik werden üben können; ich jedenfalls kann es nicht. Immerhin scheint es mir wichtig, einen Gesichtspunkt hervorzuheben, in dem, wenn ich recht sehe, beide Referenten einig sind und der nicht verloren gehen sollte: das, was Herr Hofmann die „Asymmetrie" von Grundrechten und -pflichten genannt hat. Bisher haben wir doch wohl alle, wenn von Grundpflichten die Rede war, mehr oder weniger, vielleicht auch nicht durchreflektiert, an eine mit den Grundrechten gleichgewichtige Kategorie gedacht. Es hat mich überzeugt, daß man sie nicht so auf eine Ebene stellen kann.

Des weiteren möchte ich meiner Freude darüber Ausdruck geben, daß das, was mein Lehrer Gerhard Wacke sich immer. 
gewünscht hat, die Erweiterung des Staatsrechts und der Verfassungstheorie in die Dimension der Staatsfinanzen hinein (oder besser: das Ende der Ausblendung dieser Dimension), nach unseren Innsbrucker Ansätzen offensichtlich vorangeht. Und in diesem Zusammenhang möchte ich mir nun doch eine kleine Korrektur an dem Hofmann'schen Referat erlauben, die Ihnen vielleicht etwas beckmesserisch scheinen mag, die ich aber für wichtig halte. Ich möchte Sie, lieber Herr Hofmann, bitten, aus der Definition der Steuerpflicht als Grundpflicht das Wort „progressiv“ zu streichen. Gewiß gehörte das zum ideengeschichtlichen Bestand des steuerlichen Denkens im neunzehnten Jahrhundert, über das Sie berichtet haben. Aber wenn Ihr Referat kanonisiert werden sollte (was es nach meinem Dafürhalten verdient), dann würde ich es bedauern, wenn auch dieses Wort „progressiv“ mitkanonisiert würde - gerade heute, wo man von neuem darüber nachzudenken beginnt, ob progressive Steuern unter den Bedingungen der Gegenwart wirklich noch die gerechtesten Steuern sind. Ich will nur zwei kurze Gründe dafür anführen, damit das Ganze nicht zu geheimnisvoll klingt. Erstens: In einer Gesellschaft, die mehr und mehr zu einer Gleichheitsgesellschaft hin tendiert, könnte es sein, daß die progressive Besteuerung nicht mehr in dem Maße wichtig ist für die Herstellung sozialer Gerechtigkeit wie zu einer Zeit mit sehr viel größeren Einkommens- und Vermögensunterschieden. Zweitens: Eine progressive Steuer, die ja doch immer eine Einkommens- oder allenfalls Vermögenssteuer sein müßte, verlangt als ihre Basis eine Bemessungsgrundlage „Einkommen“ oder „Vermögen“, die sehr differenziert aufgebaut sein muß und die angesichts der gewährleisteten Privatautonomie die Möglichkeit gibt, durch privatrechtliche Gestaltungen Nischen der Gesetze sehr vorteilhaft auszunutzen. Bei einer Einkommens- oder Vermögenssteuer sind solche Gestaltungen unvermeidlich; relevant geworden sind sie durch die heutige Anspannung des Staatsbedarfs und infolgedessen der Steuersätze. Eine Steuer, die weittragende Möglichkeiten der Gestaltung eröffnet, wird dadurch aber unter Gerechtigkeitsaspekten problematisch: ich nenne nur das Phänomen „Abschreibungsgesellschaften“. Die Steuerpflicht ist sicherlich eine Grundpflicht, aber es braucht dafür nicht notwendig eine progressive Steuer zu sein.

Zacher: Ich schließe zunächst an die Ausführungen von Herrn Vogel an. Daß wir, Herr Hofmann, eine progressive Steuer haben, ist eine Illusion, wenn man an die Einkommensbelastung als solche denkt und die Sozialversicherungsbeiträ- 
ge, die bei der Beitragsbemessungsgrenze enden, und die indirekten Steuern mitberücksichtigt. Ich glaube wirklich, man sollte das streichen, oder man sollte wirklich ernstmachen mit „progressiv“".

Aber daß ich mich nach dem Diskussionsbeitrag von Herrn Grimm gemeldet habe, hat seinen Grund darin, daß sich hier im Dreieck zwischen Herrn Hofmann, Herrn Grimm und mir tatsächlich etwas zu klären beginnt. Sie, Herr Hofmann, sagen, Grundpflichten sind Bestandteil der Verfassungsprogrammatik. Herr Grimm sagt, Grundpflichten haben nur Sinn, wenn der Staat gebunden werden kann. Und ich meine, ganz voraus gibt es eine Aussage in der Verfassung, die von grundlegender Bedeutung für die Stellung des Individuums im Gemeinwesen ist. Diese drei Meinungen machen einen Vers, wenn die Ebenen unterschieden werden, auf denen sie angesiedelt sind. Wenn die Verfassung als Aussage über die Befindlichkeit und die Aufgaben des Gemeinwesens gedacht ist, dann ist das reine Verfassungsprogrammatik. Das ist der Standort von Herrn Hofmann. Bezieht sich diese Beschreibung der Befindlichkeit und der Aufgaben des Gemeinwesens aber auch auf die Stellung des einzelnen im Gemeinwesen, so muß die Verfassung auch Aussagen i. S. von Grundrechten und kann sie auch Aussagen i. S. von Grundpflichten aufnehmen. Das ist mein Standort. Stelle ich an die Verfassung aber mit Herrn Grimm die zusätzliche Anforderung wirklicher Verbindlichkeit und gehe ich mit dem Grundgesetz so weit, nicht unmittelbare vollziehbare Inhalte aus der Verfassung möglichst fern zu halten, so muß ich unter jenen Aussagen selektieren. Es genügt dann nicht, daß sie die Befindlichkeit und die Aufgaben des Gemeinwesens sowie die Stellung des Individuums im Gemeinwesen beschreiben. Es ist notwendig, daß sie vollziehbar sind. Das ist der Standort von Herrn Grimm.

Vorsitzender: Vielen Dank, Herr Zacher. Herr Grimm, sind Sie richtig ausgelegt? Wir sind - so meine ich - bei einem zentralen Punkt angelangt. Bitte, Herr Grimm.

Grimm: Es geht mir nicht in erster Linie um die Vollziehbarkeit. Ich halte auch Normen, die nicht unmittelbar justiziabel sind, sondern sich primär mit Aufforderungscharakter an den Gesetzgeber wenden, für Rechtsnormen. Meine Bedenken haben einen anderen Hintergrund. Wo von Grundpflichten die Rede ist, wird stets ein Pendant zu Grundrechten gesucht, das deren gemeinschaftssprengendes Potential zügelt. So wie dem einzelnen ein elementarer Freiraum gegenüber der Staats- 
macht gesichert werden soll, sollen dem Staat bestandsnotwendige Leistungen der Bürger gesichert werden. Nun gibt es zweifellos solche Leistungen, ohne die das Gemeinwesen keinen Bestand hat, und wenn man will, mag man sie „Grundpflichten" nennen. Dies aber weder in einem verfassungstheoretischen noch in einem verfassungsrechtlichen Sinn. Eine in der Verfassung verankerte Pflicht des Bürgers ist deswegen noch keine Grundpflicht, wie ja auch nicht jedes verfassungsrechtlich garantierte Recht ein Grundrecht ist. Grundrechte werden vielmehr verfassungsrechtlich gewährleistet, damit der einzelne seine Freiheit wirksam gegen die überlegene Staatsmacht verteidigen kann. Es besteht aber keine parallele Notwendigkeit, Pflichten in dieser Weise zu überhöhen, weil der Staat die Mittel, seine Bürger zur Pflichterfüllung anzuhalten, ohnehin hat, während den Bürgern die Mittel, den Staat in Schranken zu halten, erst verschafft werden müssen. Die mit dem Begriff der Grundpflichten angestrebte Angleichung an die Grundrechte ist also falsch, und wenn man trotzdem Grundpflichten in die Verfassung hineinliest, besteht die Gefahr, daß auch wieder etwas aus ihnen herausgeholt wird. Das kann dann allerdings nur etwas Freiheitsbeschränkendes sein. Nun sind Freiheitsbeschränkungen zwar unerläßlich und legitim, aber unter dem Grundgesetz doch nur im Interesse des Schutzes gleichmäßiger Verteilung und materieller Ausstattung der Freiheit. Das Programm hierfür enthalten die Grundrechte selbst. Grundpflichten werden dazu nicht benötigt.

Bullinger: Müssen wir nicht noch eine weitere Dimension berücksichtigen, die, ich glaube, Herr Hofmann, bei Ihnen anklang? Es geht um das Problem, ob Pflichten des einzelnen in der Verfassung festgelegt sind oder - nächste Stufe - ob sie so elementar erscheinen, daß sie nach Art. 79 Abs. 3 GG als unantastbar behandelt werden müssen. Wenn wir jetzt schon kategorisieren, müßten wir diese Kategorie der gewissermaBen vorgefundenen, nicht antastbaren Pflichtenstellung des einzelnen in die Überlegungen einbeziehen.

Schuppert: Herr Vorsitzender, meine Herren Kollegen! Ich glaube, es paßt jetzt gut, mein kleiner spontaner Regularbeitrag. Ich glaube, daß es wichtig ist, sich darauf zu besinnen, $\mathrm{da} ß$ es einen starken Zusammenhang gibt zwischen den Grundpflichten des Bürgers und den Grundaufgaben des Staates. Das scheint mir ein leicht belegbarer Zusammenhang zu sein. Wenn wir uns überlegen, was gemeinhin als Grundaufgabe des Staates gilt, als eine den Staat definierende Tätigkeit, 
als eine Sine-qua-non-Aktivität des Staates, dann fallen einem drei Dinge ein: Gewährleistung der Sicherheit im Innern, Gewährleistung der territorialen Integrität durch eine Möglichkeit der Landesverteidigung und Beschaffung der notwendigen finanziellen Ressourcen für die Bezahlung der zu alimentierenden Beamten und des stehenden Heeres und der hinzugekommenen Sozialaufgaben. Also drei wichtige Staatsaufgaben. Diese drei wichtigen Staatsaufgaben konstituieren, wie ich meine, die drei Grundpflichten, die hier immer im Raum stehen, und die Herr Hofmann als Viergespann bezeichnet hat. $\mathrm{Da}$ ist einmal die allgemeine Gehorsamspflicht. Sie korrespondiert der Aufgabe des Staates, Sicherheit im Innern zu gewährleisten. Nicht umsonst wird das Polizeirechtsgut „öffentliche Sicherheit" mit der Rechtsordnung identifiziert. Der Staatsaufgabe der Landesverteidigung korrespondiert die allgemeine Wehrpflicht und der Staatsaufgabe der Beschaffung von Ressourcen korrespondiert die Pflicht zur Steuerzahlung. Dieser Zusammenhang scheint mir auch dadurch belegt zu werden, daß Herr Hofmann die interessante Überlegung angestellt hat, ob man Grundpflichten abschaffen kann. Das scheint ja gerade bei diesen Grundpflichten nicht möglich zu sein. Genau so wenig, wie wir die Grundaufgaben des Staates abschaffen können; das korrespondiert miteinander. Wir können nicht die Steuerpflicht des einzelnen abschaffen, oder die Gehorsamspflicht des Bürgers, ohne damit die Grundaufgaben des Staates preiszugeben oder sie undurchführbar zu machen. So daß, wenn man das so formulieren will, die Grundpflichten es nicht so sehr mit Grundrechtsschranken, die an Grundrechte herangetragen werden, zu tun haben, sondern Grundpflichten haben nach meiner Auffassung zu tun mit dem Herrschaftscharakter des modernen Staates und hängen damit auf das engste zusammen. Man kann hier auch den Gedanken des Gesellschaftsvertrages bemühen. Herr Badura hat in seinem Einleitungsaufsatz ja darauf hingewiesen, da 3 man gewissermaßen diese Grundpflichten verstehen kann als die Eintrittskarte, die der Bürger bezahlen muß, das Eingehen dieser Grundpflichten der Preis ist für die Leistungen der staatlich verfaßten Gesellschaft, nämlich Gewährleistung der Sicherheit des Innern, Landesverteidigung und Wahrnehmung kostenintensiver Aufgaben. Und jetzt - und das ist eigentlich die kleine Anregung, die ich bringen wollte, und dazu mußte ich ein bißchen ausholen -, ist die Frage die, ob man nicht das Augenmerk lenken sollte auf ein mögliches Korrespondenzverhältnis zwischen den Grundpflichten des Bürgers und den Grundpflichten der Staatsgewalt, den Erwartungen des Bürgers 
nachzukommen, die er gehegt hat, als er seine Grundpflichten - gesellschaftsvertraglich gesprochen - eingegangen ist. Also, z. B.: Den Grundpflichten des Bürgers zum Gehorsam entspricht - so würde ich das jetzt komplementär formulieren wollen - die Pflicht des Staates, das geltende Recht auch durchzusetzen. Insofern ist also darin impliziert das Legalitätsprinzip oder - strafrechtlich gewendet - das Gebot einer funktionstüchtigen Strafrechtspflege, und es wäre - negativ gewendet - darin enthalten das Verbot eines soft law, was nicht nur bei Hausbesetzungen eine Rolle spielt, sondern auch bei der Umsetzung von Umweltschutzgesetzen gegenüber Großunternehmen. Wir könnten weiter überlegen, ob nicht auch eine Verpflichtung des Staates besteht, gewandelten Gefahrenlagen Sorge zu tragen, also die staatliche Aufgabe der Gefahrenabwehr z. B. zu ergänzen durch die Aufgabe der Gefahrenvorsorge, als einer Grundpflicht des Staates, die der Grundpflicht des Bürgers, auf Selbstverteidigung zu verzichten, entspricht. Und vielleicht könnte man das sogar noch fruchtbar machen für den Gedanken der Grenzen der Besteuerungskompetenz des Staates, indem nämlich letztlich der Gedanke der Privatnützigkeit des Eigentums darin seine Rechtfertigung findet, daß, wenn der Bürger sein Eigentum einbringt in das rechtsstaatlich verfaßte Gemeinwesen, ihm es nicht in der Folgezeit vollständig entzogen werden darf. Vielen Dank!

Berg: Sie haben, Herr Schuppert, bei Ihrer Dreiteilung der Grundpflichten wohlweislich die allgemeine Wehrpflicht nicht mit aufgezählt. Art. 12 a GG enthält eindeutig nur eine Ermächtigung an den Gesetzgeber zur Einführung einer allgemeinen Wehrpflicht, nicht einen Auftrag. Auch das Staatsziel der Demokratie erzwingt keine solche Organisation der Landesverteidigung, auch wenn sich historisch gesehen demokratische Freiheit und allgemeine Wehrpflicht in einem gewissen Zusammenhang entwickelt haben. Man kann sicher den USA oder Großbritannien die demokratische Staatsform nicht absprechen. Der einfache Gesetzgeber wäre also verfassungsrechtlich nicht gehindert, die allgemeine Wehrpflicht durch eine andere Organisationsform der Landesverteidigung zu ersetzen.

Hailbronner: Ich muß gestehen, ich habe nach wie vor etwas Schwierigkeiten mit den rechtlichen Konsequenzen einer Kategorisierung von Grundpflichten als verfassungsrechtliche Pflichten. Herr Götz hat sie formuliert als verfassungsrechtlich geforderte Pflichtbeiträge zum Gemeinwohl und sie unter- 
schieden von der bloßen Problematik der Grundrechtsbegrenzung. Meine Überlegung ist, wenn das stimmt, wenn Grundpflichten also ein verfassungsrechtlich geforderter Beitrag des Bürgers sind, dann muß doch diese Kategorisierung bedeuten, $\mathrm{da}$ sie der Disposition des einfachen Gesetzgebers entzogen sind. Man mag sich darüber streiten, wie weit ein Gesetzesvorbehalt reicht - in jedem Fall würden Grundpflichten kraft ihrer verfassungsrechtlichen Weihe gewissermaßen als Pendant zu den Grundrechten in den Olymp der verfassungsrechtlichen Wertordnung aufsteigen - mit möglicherweise weitreichenden Folgerungen nicht nur für die Dispositionsfreiheit des Gesetzgebers, sondern auch für die Auslegung von Gesetzen. Meine Frage ist also: Was sind die praktischen Konsequenzen dieser Pflichten, die Herr Götz aufgezählt hat? Ich will versuchen, das praktisch zu testen an zwei von Herrn Götz erwähnten Pflichten. Einmal die Wehrpflicht: Sie ist ganz sicher in der Verfassung erwähnt; aber auf der anderen Seite hat doch das Bundesverfassungsgericht in seiner Wehrpflichtentscheidung ausgesprochen, daß auch die Freiwilligenarmee durch die Verfassung nicht verboten ist. So stellt sich die Frage: Was bleibt eigentlich von der Grundpflicht als Individualpflicht, nicht als Staatsaufgabe, sondern als Individualpflicht, wenn man nach Art. 12 a GG auch die Staatsaufgabe, Herr Schuppert, Staatsaufgabe „Verteidigung“, durch eine Freiwilligenarmee erfüllen könnte. Zweiter Punkt: Die sozialen Grundpflichten. Herr Götz hat eine Steuerzahlungspflicht postuliert und sie an die Pflicht des Eigentümers aus Art. 14 GG geknüpft. Das scheint mir, offen gesagt, etwas zu weit zu gehen. Ich habe Zweifel, ob die Verfassung wirklich eine Steuerzahlungspflicht als verfassungsrechtlich geforderten Beitrag des Bürgers enthält. Die Konsequenzen hieraus wären $\mathrm{m}$. E. nicht nur für die Dispositionsfreiheit des Gesetzgebers unerwünscht. Auch als verfassungsrechtliche Wertentscheidung und oberste Auslegungsrichtlinie graut mir vor einer Verfassungspflicht zur Bezahlung von Steuern. Wenn man aber schon so weit gehen und die Steuerpflicht als eine Grundpflicht der Verfassung kategorisieren will, dann darf man sie jedenfalls nicht an Art. 14 GG anknüpfen und sie spezifisch als Pflicht des Eigentümers verstehen, Steuern zu bezahlen. Wenn schon Grundpflicht, dann müßte man die Steuerpflicht bei den heutigen Verhältnissen, wo die Steuer ja im wesentlichen von den Einkommensbeziehern erbracht wird, als allgemeine staatsbürgerliche Pflicht ausgestalten, aber sicherlich nicht spezifisch als Eigentümerpflicht. Im übrigen: Sollte wirklich der Gesetzgeber von Verfassungs wegen gehindert sein, die 
spezifische Besteuerung des Eigentums, z. B. des Grundeigentums als Prototyp des Eigentums ganz oder teilweise abzuschaffen?

Im Ergebnis scheinen mir bei den „Grundpflichten“ die rechtlichen Konsequenzen der verfassungsrechtlichen Kategorisierung noch unklar zu sein. Bei beiden "Grundpflichten“ scheint mir auch zweifelhaft, ob sie nicht doch in Wirklichkeit - abgesehen von den Grundrechtsgarantien - der Disposition des Gesetzgebers unterliegen. Trotzdem scheint mir die Annahme gewisser Grundpflichten nicht ganz überflüssig zu sein. Allerdings nicht als selbständig einklagbarer Beitrag des Bürgers zum Gemeinwohl, sondern als Annex zur Freiheit des Bürgers aus der Erkenntnis heraus, da $ß$ die vom Grundgesetz garantierte Freiheit in einer rechtlich verfaßten Gemeinschaft ausgeübt wird. Ich neige deshalb der Ansicht von Herrn Hofmann zu und glaube, daß die Kategorie der Grundpflicht doch ganz nützlich ist, indem sie bei der Grundrechtsbegrenzung eine wichtige Funktion zu erfüllen vermag, und zwar als Hilfsmittel zu der Erkenntnis, daß vor der Freiheit und untrennbar mit ihr der Zusammenschluß der Bürger zu einer organisierten Gemeinschaft steht. Den Gemeinschaftsvorbehalt hat auch das Bundesverfassungsgericht in mehreren Entscheidungen, etwa im Kontaktsperreurteil, betont. Gegenüber dem in seinen Konturen eher vagen Gemeinschaftsvorbehalt scheinen mir die Grundpflichten einen möglichen Weg aufzuzeigen bei der Beantwortung der Frage: „Wie weit darf der einzelne bei seiner Grundrechtsausübung gehen und wozu ist er der Gemeinschaft gegenüber bei der Wahrnehmung seiner Rechte verpflichtet?" Dies ist - glaube ich - der richtige Standort der Grundpflichten. Vielen Dank.

Zippelius: Ich wollte gern dem eindrucksvollen, geschliffenen Referat von Herrn Götz ein wenig Öl, das die Schärfe nimmt, hinzufügen, und wollte zu Leitsatz 2 sagen: Ich bezweifle die scharfe Unterscheidbarkeit von Grundrechtsgrenzen einerseits und Grundpflichten andererseits. Die Strafrechtler spinnen inzwischen so fein, daß sie sogar daran verzweifeln, Handlungs- und Unterlassungsdelikte überhaupt zu unterscheiden, weil ein unrechtes Tun wesentlich das Unterlassen einer pflichtgemäßen Verhaltenssteuerung sei. So scharfsinnig brauchen wir Staatsrechtler wohl nicht zu sein. Aber wir sollten die Janusköpfigkeit von Rechten und Pflichten sehen: Die Pflicht, etwas zu unterlassen, definiert, $d . h$. begrenzt zugleich den Spielraum des Rechts zu erlaubter Betätigung. Die in der Sozialpflichtigkeit des Eigentums liegende 
Unterlassungspflicht enthält zugleich eine Begrenzung der im Eigentumsrecht liegenden Betätigungsfreiheit; die in der Pflicht zu gemeinverträglichem Verhalten steckende Unterlassungspflicht begrenzt zugleich das Recht auf freie Entfaltung der Persönlichkeit. Insofern glaube ich mit Herrn Hofmann ganz übereinzustimmen.

Ein zweiter Punkt: Auch hinsichtlich der Konkretisierung und der Durchsetzbarkeit von Pflichten sollten wir wohl der Versuchung allzu starker Abgrenzungen widerstehen und sollten den Facettenreichtum der Pflichtenkategorie in Betracht ziehen. Neben unmittelbar vollziehbaren Verfassungspflichten, wie der elterlichen Erziehungspflicht, gibt es Pflichten, die erst einer Konkretisierung durch den Gesetzgeber bedürfen, wie die Wehrpflicht; ferner Pflichten, die erst anläßlich der Grundrechtsanwendung eines Grundrechts als Grundrechtsbegrenzungen konkretisiert werden; und es gibt schließlich wohl auch Pflichten, die nicht bis ins Letzte durchsetzbar konkretisiert werden können, wie die Pflicht zur Verfassungstreue. So erklärt sich der scheinbare Widerspruch in der Rechtsprechung des Bundesverfassungsgerichts, das einerseits von einer allgemeinen Pflicht zur Verfassungstreue sprach (was sich im Sinne einer lex imperfecta verstehen ließ) und andererseits die rechtliche Möglichkeit offenhielt, auch gegen die verfassungsmäßige Ordnung zu wirken, solange das innerhalb einer Partei geschehe, die noch nicht für verfassungswidrig erklärt wurde (was eben in dem anderen Sinn einer durchsetzbaren Pflicht gemeint war). Zusammengefaßt: Wir sollten uns vor Simplifizierungen hüten und insbesondere auch den Facettenreichtum der Pflichtenkategorie im Auge behalten.

Starck: Herr Vorsitzender, meine Herren Kollegen! Ich möchte zu den beiden schönen, sich einander ergänzenden - das ist auch ein Kompliment für den Vorstand! - Vorträgen zwei Bemerkungen machen. Zunächst zu den verschiedenen Kategorien der Grundpflichten, von denen ich drei erkenne: Das sind die Pflichten, die man aus der Verfassung herauslesen kann als unmittelbare Pflichten, die auch juristisch exakt formuliert sind. Dann die Pflichten, die die Verfassung ermöglicht, wenn der Gesetzgeber dazwischentritt und sie aktualisiert (so fast alle unserer Grundpflichten). Neben diesen rechtlich nachweisbaren Pflichten gibt es eine weitere Kategorie von Pflichten, mit denen sich beide Referenten beschäftigt haben; das sind die sittlichen Pflichten, die Voraussetzungen des Staates sind. Ich möchte beiden Referenten ausdrücklich darin zustimmen, daß wir eine scharfe Trennung machen müs- 
sen zwischen den sittlichen Pflichten - Herr Bachof hat sie die leges imperfectae genannt - und den rechtlich nachweisbaren Pflichten. Diese Frage der sittlichen Pflichten ist ein Gegenstand, der in unsere Disziplin gehört. Wir sind ja nicht nur Verfassungsrechtslehrer, die das Grundgesetz dogmatisch ausfeilen, wir beschäftigen uns auch mit der allgemeinen Staatslehre, worin über die Bedingungen des Staates nachgedacht wird; dazu gehören die sittlichen Pflichten. Diese sittlichen Pflichten kann man in der Regel nicht rechtlich festlegen; sie müssen gleichsam von selbst erfüllt werden. - Ich komme jetzt zu einem Gedanken, der noch nicht ausgesprochen worden ist, den nur Herr Häberle angetönt hat und den wir uns etwas näher vornehmen müssen. Herr Hofmann hat das Problem vorsichtig umschifft, indem er mehrfach die Schulpflicht, aber nicht die Erziehungsziele, nämlich das Materielle der Schulpflicht, erwähnt hat. Hierin steckt eine erhebliche Schwierigkeit und zugleich eine Frage an Herrn Grimm. Es scheint doch wohl auf dem Gebiete der Schule eine Umformung dieser sittlichen Pflichten zu Rechtspflichten stattzufinden. Die Lehrer sind nämlich aufgrund der Landesverfassungen gehalten, die Schüler so zu erziehen, daß sie arbeitsam, duldsam und lebenstüchtig sind, wie es in den Verfassungstexten heißt. Wie kann man das nun erklären, daß auf dem Gebiet des Staatsbürger-Werdens offensichtlich der Staat nicht darum herumkommt, solche sittlichen Pflichten zu Rechtspflichten zu machen, und zwar weniger für die Schüler, als vielmehr für die Lehrer und damit gleichzeitig mittelbar für die lehrerbildenden Anstalten.

Ein zweites Problem, das ich kurz ansprechen möchte, betrifft These 2 von Herrn Götz. Dagegen möchte ich hier im Anschluß an Herrn Zippelius Einwendungen erheben. Ich meine, daß die Grundpflichten, soweit es sich um rechtliche Grundpflichten handelt, wie ich es anfangs dargelegt habe, Erscheinungsformen bzw. verfassungsrechtliche Grundlagen von Grundrechtsschranken sind. Wenn wir uns erinnern an die schon zitierten Pflichten der Presse oder des Rundfunks, der ja vielleicht demnächst privat veranstaltet wird, so müssen wir diese Pflichten mit den Grundrechtsschranken begründen können; wir müssen aus Art. 5 Abs. 2 begründen, wenn wir Presse und Rundfunk bestimmte Pflichten auferlegen. Deswegen würde ich den Thesen $17 \mathrm{ff}$. von Herrn Hofmann folgen. Wenn ich sie richtig verstanden habe, haben Sie ja in diesen Thesen zum Ausdruck gebracht, daß die Grundpflichten Erscheinungsformen von Grundrechtsschranken sind. 
Vorsitzender: Danke, Herr Starck. Direkt dazu Herr Bachof.

Bachof: Herr Starck - nur um ein Mißverständnis zu vermeiden - ich habe die leges imperfectae nicht als eine bloß sittliche Kategorie angesehen. Ich meine, daß in der Tat die Pflicht zu einem Mindestmaß an solidarischem Verhalten, an Sozialität, an Unterlassen gemeinschaftswidrigen Verhaltens, zwar zunächst einmal eine sittliche Pflicht ist. Ich möchte sie durchaus aber auch als eine verfassungsrechtliche Pflicht ansehen.

Vorsitzender: Danke, Herr Bachof. Direkt auch dazu Herr Heckel. Zunächst aber noch die Replik von Herrn Starck.

Starck: Herr Bachof, ich habe Sie so interpretiert, daß ich Ihnen zustimmen kann. Ich glaube aber nach Ihrem Einwurf, daß wir uns im Einzelfall einigen würden, wenn wir ins Detail gingen und im einzelnen erörterten, um was für Pflichten es sich handelt.

\section{Vorsitzender: Jetzt bitte, Herr Heckel.}

Heckel: An Herrn Starcks und Herrn Bachofs Äußerung anknüpfend möchte ich die beiden Herrn Referenten in ihrer vorsichtigen Zurückhaltung gegenüber der Einführung von Grundpflichten als Verfassungspflichten bestärken. In der Diskussion scheint mir ihre Rückwirkung auf das sonstige Verfassungsgefüge noch nicht bedacht zu sein. Wenn Grundpflichten als Verfassungspflichten formuliert werden, dann eröffnet dies die Gefahr eines breiten ideologischen Einbruchs - Herr Hofmann hat das als „Versittlichung“ bezeichnet - und zwar des Einbruches einer Gruppenmoral, der vorbeigeht an den Staatswillensbildungsprozessen, die in den Wahlen und in der Formierung der Parlamente organisiert sind. Die Formulierung von Grundpflichten mag eine sich dazu berufen fühlende Richterschaft (bzw. einen Teil der Richterschaft) geradezu ermuntern, sich ohne gesetzliche Grundlage als Kulturoder Fortschrittskommissar zu gerieren. Das ist das eine, was mir an dem Institut der Verfassungspflichten sehr bedenklich erscheint, wenn es keine schärfere Umgrenzung erfährt. Die andere Frage betrifft die Rückwirkung auf die einfache Gesetzgebung: Sind Grundpflichten mit Verfassungsrang in einer gewissen Konkretheit formuliert, dann stehen sie ja unter der erschwerten Abänderbarkeit durch Zwei-Drittel-Majoritäten. Das führt dazu, daß eine schmelzende Mehrheit, die ihre Zwei-Drittel-Mehrheit im Volk verloren hat, ja die bis 
knapp über ein Drittel zusammengeschmolzen ist, ihre politischen Ziele über diesen Pflichtenkatalog gegen das Mehrheitsprinzip durchsetzen kann. Das eröffnet die Gefahr von undemokratischen Versteinerungen und die Versuchung, politische Wahlergebnisse so auszumünzen und $\mathrm{zu}$ verfestigen. Die Formulierung von Grundrechten folgt ja verfassungsrechtlich in gewisser Weise aus dem Mißtrauen gegenüber dem einfachen Gesetzgeber. Ihr Ziel ist dort die höhere Verbürgung auf breiter Konsensgrundlage. Das hat sein Gutes und Richtiges. Aber mit der Verfestigung von Grundpflichten werden neue und anders wirkende Kontraststrukturen gegen den einfachen Gesetzgeber und damit auch gegen die Willensbildungsprozesse im demokratischen Gefüge eingeführt. Das müßte bedacht werden und das mag auch zur Zurückhaltung gegenüber einem breit konkretisierten Pflichtenkatalog nötigen. - In der Tat stellt sich hier eben die Frage der Abgrenzung von sittlichen Pflichten und Rechtspflichten: Im Sinne der Verfassungspädagogik sind sittliche Pflichten unbedingt nötig als Integrationsfaktoren und unentbehrlich als Verfassungsvoraussetzungen. Aber sie lassen sich durch die Positivierung von rechtlichen Pflichtenkatalogen in der Verfassung, meine ich, nicht erreichen.

Böckenförde: Mein Beitrag schließt gut an das Votum von Herrn Heckel an. Ich möchte auch noch einmal mit dem Dank für die beiden Referate meine Skepsis gegenüber einem verfassungsrechtlichen Begriff von Grundpflichten aussprechen. Wenn ich die Diskussion recht verstanden habe, hat sie sich doch manchmal auf verschiedenen Ebenen bewegt. Wollen wir zur Klarheit gelangen, wie es Herr Ipsen in seinem ersten Votum angeregt hat, müssen wir diese verschiedenen Ebenen auseinanderhalten und unterscheiden. Man kann einmal von Grundpflichten in dem Sinne sprechen, daß sie grundlegende, für den Bestand des Gemeinwesens fundamentale Pflichten seien; dann bewegte man sich auf der Ebene von Verfassungsoder Staatsvoraussetzungen und argumentierte im Bereich der allgemeinen Staatslehre. Man kann von Grundpflichten ferner in dem Sinne sprechen - und das ist das Verständnis, was sich wohl unmittelbar nahelegt -, daß Grundpflichten ein Parallelinstitut zu den Grundrechten sind, daß sie nach Rechtsform und Rechtsgehalt eine solche Parallelität aufweisen. Dazu würde dann gehören, daß die Grundpflichten verfassungsverbürgt sind, daß sie unmittelbar aus sich gelten, ohne vorausgehende gesetzliche Ausformung, und daß sie grundsätzlich umfassend sind, d.h. auch abgesehen von den elementaren 
Nichtstörungsschranken, die aus dem Verhältnis der Grundrechte zueinander folgen, nicht erst durch Gesetze begründet, sondern nur nach Inhalt und Ausmaß näher bestimmt und begrenzt werden, nach Maßgabe bestehender Regelungsvorbehalte. Schließlich kann man noch in einem formalen Sinn von Grundpflichten sprechen, indem man sagt, alle Pflichten, die in der Verfassung als Pflichten aufgeführt sind, einerlei, ob sie umfassende oder ob sie nur Einzelpflichten sind, sind Grundpflichten. Das führt aber nicht weiter.

Wenn wir uns an den zweiten, verfassungsrechtlichen Begriff der Grundpflichten halten, also Grundpflichten als Parallelinstitut zu Grundrechten verstehen, dann sehe ich nicht, daß es solche Grundpflichten als Rechtsbegriff gibt, wenn man über die Unterlassungspflichten i. S. der elementaren Nichtstörungspflichten hinausgeht. Ich würde Herrn Hofmann konzedieren, daß man diese Unterlassungspflichten - auch die Friedenspflicht würde ich zu diesen Unterlassungspflichten zählen - theoretisch als Grundpflichten qualifizieren kann, obwohl dafür ein eigener rechtsdogmatischer Begriff nicht erforderlich ist, weil diese Unterlassungspflichten in den Grundrechtsschranken, als anerkannter dogmatischer Figur enthalten und eingebracht sind. Nachdrücklich möchte ich Herrn Hofmann zustimmen, wenn er vom Bauprinzip der rechtsstaatlichen Verfassung als einer Verfassung der Freiheit her gefolgert hat, daß in ihr eine Parallelität von Grundrechten und Grundpflichten nicht besteht, sondern daß die Asymmetrie, wie er es sehr prägnant formuliert hat, hier grundlegend ist. Die Pflichten, die es von diesem Verfassungsprinzip her geben kann, sind gesetzlich konstituierte Pflichten, gesetzlich ausgeformte Pflichten, die nach Inhalt und Umfang begrenzt sind und jeweils gegenüber den grundrechtlichen Freiheitsverbürgungen in einer Begründungs- und Notwendigkeitslast stehen, was dann in der Judikatur als Verhältnismäßigkeitsprinzip erscheint. Die "Grundpflichten", wenn man davon sprechen will, sind in diesem Sinne eben keine unmittelbar aus der Verfassung heraus geltende, grundsätzlich umfassende und erst im Einzelfall zu begrenzende Pflichten, sondern es ist gerade umgekehrt. Herr Klein (Göttingen) hat vor Jahren schon darauf hingewiesen und diese These vertreten, und ich sehe keinen Anlaß, davon heute abzugehen. Auch die Gehorsamspflicht, von der die Rede war, fügt sich hier ein, denn sie ist ja nicht umsonst gerade eine Pflicht zum Gesetzesgehorsam, und der Gesetzesgehorsam zielt eben darauf ab, daß es sich um begrenzte, inhaltlich ausgeformte Pflichten, die in Gesetzen niedergelegt sind, handelt, denen ich nachzukommen habe. 
Wir hatten früher einmal eine allgemeine Grundpflicht, die unbegrenzt war, in den besonderen Gewaltverhältnissen. In ihnen bestand die Gehorsamspflicht als Ausdruck der Gewaltunterworfenheit unmittelbar und umfassend, und rechtliche Regelungen, sofern es sie gab, dienten dazu, sie näher auszuformen und zu begrenzen. Aber eben diese Struktur ist ja dann folgerichtig abgebaut worden, um die besonderen Gewaltverhältnisse in die rechtsstaatliche Freiheitsgewähr und Freiheitssystematik einzubeziehen.

Auch von der verfassungsgeschichtlichen Entwicklung und vom verfassungstheoretischen Ansatzpunkt her hat Herr Hofmann in seiner These 20 die Sache prägnant auf den Begriff gebracht: Am Anfang sind Grundrechte und Grundpflichten gemeinsam „konstitutionelle Programmatik“ in dem Sinn, daß sie rechtliche Gestaltungsziele geben, Zielorientierungen aufweisen, aber noch nicht unmittelbar geltende, einforderbare Rechte und Pflichten darstellen. Wir wissen ja durch die Arbeiten von Herrn Scheuner und Herrn Wahl, daß auch die Grundrechtsgeltung am Ende des 18. und weit in das 19. Jahrhundert hinein eine solche von Prinzipien war, normativen Orientierungen, aber noch nicht von einklagbaren, einforderbaren subjektiven Rechten. In der weiteren Entwicklung sind dann die Grundrechte ausgeformt worden zu einforderbaren Rechtsansprüchen, an die auch die Staatsgewalten gebunden sind, Art. 1 III GG setzt da gewissermaßen den Schlußpunkt. Aber für die Grundpflichten ist eine parallele Ausformung nicht erfolgt; sie konnte und kann nicht erfolgen, solange das rechtsstaatliche Prinzip der Freiheitsgewähr Geltung hat. Was also von "Grundpflichten" bleibt, ist gewissermaßen ein verfassungstheoretischer Diskussionsbegriff, aber nicht ein verfassungsrechtlicher und -dogmatischer Begriff; etwa in dem Sinne, wie Herr Schuppert vorhin von Grundpflichten gesprochen hat, als Entsprechung zu Staatsaufgaben und als Grundlage dafür, daß Einzelpflichten gesetzlich festgelegt werden können. Nur ist die Frage: Bedarf es dazu dann dieses Begriffs, der ja leicht Mißverständnisse hervorruft, weil er immer wieder anders verstanden werden kann, eben im Sinn eines verfassungsdogmatischen Parallelbegriffs zu den Grundrechten, als welcher er unhaltbar ist.

Nicht abgetan ist damit die Frage von Grundpflichten als ethisch-sittlichen Pflichten im Sinne von Verfassungs- und Staatsvoraussetzungen. Man kann ferner staatstheoretisch die Grundfrage stellen, die bisher nicht thematisiert worden ist, ob denn das ganze System rechtsstaatlicher Freiheitsgewähr, die Asymmetrie, auf die Herr Hofmann hingewiesen hat, in sich 
begründet ist, ob dies ein richtiges Konzept der Ordnung der Gemeinschaft ist. Aber das ist dann keine verfassungsdogmatische, keine verfassungsrechtliche Diskussion mehr, sondern eine staatstheoretische Diskussion. Herr Isensee hat ja am Schluß seines Aufsatzes so etwas wohl andeuten wollen durch die Berufung auf Hegel, der dieses asymmetrische Prinzip, wenn ich recht sehe, für nicht hinreichend fundiert hält. Aber aus einer solchen Diskussion kann man nicht unmittelbar Konsequenzen ziehen in die Interpretation unseres Grundgesetzes hinein, das genau auf dem asymmetrischen Prinzip aufbaut. Insofern bin ich auch zurückhaltend gegenüber der These von Herrn Zacher, der meint, wir hätten aus der Situation von 1949 dieses starke asymmetrische Freiheitsprinzip bekommen, nun müsse man das etwas rückbilden. Das kann man vielleicht verfassungspolitisch vertreten, im Sinne einer Verfassungsrevision, aber nicht im Sinne einer Verfassungsinterpretation. Ganz prägnant ist die Formulierung im Verfassungsentwurf von Herrenchiemsee, Art. 1: „Der Staat ist um des Menschen willen da, nicht der Mensch um des Staates willen." Über dieses asymmetrische Prinzip kann man staatstheoretisch, staatsphilosophisch diskutieren, ob das eine tragfähige Grundlage für das Verhältnis von einzelnen und politischer Gemeinschaft ist, aber verfassungsrechtlich, auf dem Boden des Grundgesetzes, ist es meines Erachtens eine verbindliche Vorgabe.

Vorsitzender: Vielen Dank, Herr Böckenförde. Wenn dazu keine direkten Wortmeldungen vorliegen, dann möchte ich jetzt den beiden Referenten die Möglichkeit zu einem „Zwischenwort" geben. Zuerst bitte Herr Götz.

Götz: Herr Zacher, der leider im Augenblick nicht im Raume ist, hat gesagt: „Keine Grundpflicht kann das Gemeinwesen davon entlasten, daß es sich selbst ernst nimmt. « Bei der hier eingangs gestellten Frage, was uns heute dazu bringt, das Thema der Grundpflichten auf die Tagesordnung zu setzen, muß mitbedacht werden, daß, wo wir Grundpflichten sagen, in Wahrheit Staat und Staatshandeln gemeint sein könnten und $\mathrm{da} ß$ die Grundpflicht ein gewisser Umweg ist, auf dem wir uns dem Problem des notwendigen Staatshandelns und der Abarbeitung von Defiziten des Staatshandelns nähern. Ich bin ganz einverstanden damit, daß Herr Schuppert eine Entsprechung von Grundpflichten und Staatsaufgaben hergestellt hat. Ich würde nur selbst diese Entsprechung nicht so weit perfektionieren wollen, daß ich allen Staatsaufgaben bestimmte Grund- 
pflichten zuordne, sondern ich sehe die Grundpflichten als bestimmte Instrumente oder Elemente verfassungsmäßiger öffentlicher Ordnung. Mit ihnen wird der einzelne, das Individuum, herangezogen. Das Adressiertsein an den einzelnen kennzeichnet das spezifische Instrument der Grundpflichten.

Ich habe nach zwei Richtungen etwas zu kritischen Fragen zu sagen: Die eine Richtung ist die des Zweifels an der Tragfähigkeit der von mir angenommenen und als geltendes Recht dargestellten Grundpflichten - solche Zweifel haben Herr Grimm und Herr Hailbronner geäußert. Nach der anderen Seite hin ist mein Konzept der Grundpflichten als möglicherweise zu eng gesehen worden von Herrn Zippelius, und Herr Starck hat ihm beigepflichtet. Ich möchte zunächst zum ersten etwas sagen, zu den Zweifeln also, ob mit den angenommenen Grundpflichten und ihrer von mir behaupteten Verfassungsgeltung überhaupt etwas auszurichten sei. Ich meine, daß bei den Beispielen der Wehrpflicht oder der Abgabenpflicht Grundpflichten als verfassungsgefordert und verfassungsnotwendig vorliegen. Gleichzeitig kann aber das Durchführungsinstrument der Gesetzgebung nicht entbehrt werden. Wenn man beides logisch zusammenfügt, bedeutet das, daß mit der Grundpflicht zugleich ein Verfassungsauftrag zur durchführenden Gesetzgebung anzunehmen ist. Ebenso ist es bei der landesverfassungsrechtlich vorgesehenen Schulpflicht. Auch sie kann nur vollzogen werden, wenn das Schulpflichtgesetz verschiedene Dinge bestimmt, wie die Dauer der Schulpflicht usw. Sie zu bestimmen - nicht: in welcher Weise zu bestimmen - ist von Verfassungs wegen dem Gesetzgeber aufgetragen. Bei der Wehrpflicht haben wir die bekannte Besonderheit, daß das Freiwilligenheer als ein Modus der Erfüllung der Landesverteidigungsaufgabe denkbar wäre. Aber der Staat ist nicht verpflichtet, diesen Modus zu benutzen. Wenn er nicht benutzt wird, bedeutet das Wehrpflicht im Sinne einer verfassungsnotwendigen Pflicht. Die Anknüpfung der Steuerpflichten an die Eigentumsgarantie umschließt - hier nehme ich nur auf die Vorträge in Innsbruck Bezug - auch den Eigentumsschutz des Einkommens, so daß die Einkommensbesteuerung ebenfalls am Eigentumsschutz angeknüpft werden kann. Nun nach der anderen Richtung: Herr Zippelius hat meinen Leitsatz 2 mit einem Fragezeichen versehen. Sein Stichwort ist, daß die Ausscheidung der Grundrechtsschranken aus dem Vorstellungsbild der Grundpflichten zu einem Verlust des Facettenreichtums der Pflichtkategorie führen würde. Hier würde ich es nun genau entgegengesetzt sehen: Bestimmte verfassungsrechtliche Probleme bewältigen wir bisher mit der 
Schrankentheorie. Wenn wir an deren Stelle eine neue Figur der Grundpflicht einsetzen, kommen wir in die Gefahr, den großen Facettenreichtum abgestufter Eingriffsermächtigungen und der bekannten vielfältigen Stufungen, in denen sich Gemeinwohlbelange gegenüber Grundrechten durchsetzen können, durch eine unflexible und deshalb problematische Kategorie der Pflicht zu ersetzen. Beim Leitsatz 2 ist ja daran zu erinnern, daß - wie Herr Hofmann dargelegt hat - verfassungshistorisch zwei Schichten von Pflichten zu unterscheiden sind. Die erste setzt sich im wesentlichen aus den interindividuellen Pflichten zusammen - Pflichten, die die Abgrenzung der Rechtssphäre des einen Gliedes der Gesellschaft von der des anderen darstellen, und dazu kommt natürlich die Abgrenzung der Rechtssphäre des einzelnen nicht nur von den individuellen Rechten anderer, sondern auch von bestimmten Gemeinschaftsgütern. Die zweite Sphäre der Grundpflichten bilden die darüber hinausgehenden Leistungspflichten des einzelnen gegenüber dem Staat. Ich glaube, daß der erste Komplex heute richtiger mit der Theorie der Grundrechte und Grundrechtsschranken bewältigt wird als durch die Neueinfügung einer Pflichtenkategorie mit Pflichten zur wechselseitigen Rücksichtnahme. - Die Frage der Verfassungspolitik innerhalb unseres Themas ist von verschiedenen Diskussionsteilnehmern aufgeworfen worden - von Herrn Häberle, von Herrn Oppermann und von Herrn Doehring. Hier ist es - und damit möchte ich auch auf Herrn Bachof Bezug nehmen - ja naheliegend, das Sozialstaatsprinzip der Verfassung als einen verfassungspolitischen Hebel anzusehen, der dazu dienen kann, in der künftigen Entwicklung zu neuen verfassungsrechtlichen Grundpflichten vorzudringen. Ich habe, soweit ich etwa das Thema der sozialrechtlichen Probleme - Stichwort: Selbstversorgungslast - überblicke, den Eindruck, daß die Zeit für eine Verpflichtigung dieser Fragen nicht reif ist. Eine „Verpflichtigung“ würde meines Erachtens unnötige Verkrampfungen mit sich bringen. Diese Probleme haben wir zur Zeit noch in anderer Weise anzugehen. Daß das Sozialstaatsprinzip nicht per se eine Grundpflichten-Generalklausel ist, dürfte vielleicht auf weitgehende Zustimmung rechnen können.

Ich möchte auch noch auf die Fragen von Herrn Ipsen antworten. Es geht zunächst um die These 4, die Pflichtenvielfalt. Ich habe nicht an derivate Grundpflichten gedacht, sondern wir können uns hier die gesetzliche Pflichtenordnung vorstellen, und es ist Sache des Gesetzgebers, diese Pflichtenordnung herzustellen. Die zweite Frage betrifft die Indienstnahmen und Inpflichtnahmen der Wirtschaft für den Staat. Hier muß in der 
Tat, Herr Ipsen, differenziert werden. Es war der Sinn meiner Ausführungen, solche Differenzierungen vorzutragen. Ich möchte das präzisieren: Es muß unterschieden werden zwischen Berufsausübungsregelungen im engeren oder eigentlichen Sinn und darüber hinausgehenden Gemeinwohlbelastungen. Bei den ersten handelt es sich um das, was meines Erachtens zu recht und unabweisbar als unbezahlte Hilfsarbeiten der Wirtschaft politisch rubriziert wird, nämlich Pflichten zur Bewältigung solcher administrativer oder sozialrechtlicher Probleme, die durch die Unternehmenstätigkeit selbst veranlaßt werden, also Meldepflichten oder Abführung von Sozialversicherungsbeiträgen. Davon sind meines Erachtens Belastungen, wie z. B. die von Ihnen in der Liste Ihrer Beispiele erwähnte Erdölbevorratung, zu unterscheiden. Hierbei geht es um die Heranziehung der Unternehmung zur Lösung eines Problems, das durch die Unternehmenstätigkeit nicht veranlaßt ist, zu dessen Lösung das Unternehmen selbst nur über die Mittel - polizeirechtlich würde man sagen: über das Gegenmittel - verfügt. Die Heranziehung dazu bedeutet eine neben die Steuerpflicht tretende Naturalleistungs- oder Sonderabgabenpflicht. Die Verfassungskriterien, die das Bundesverfassungsgericht für die Auferlegung unentgeltlicher, unentschädigter Naturalleistungspflichten anbietet, sind Gleichheitssatz, Verhältnismäßigkeit, Zumutbarkeit. Innerhalb dieser Kriterien kann sich natürlich die Waagschale auch zur Notwendigkeit eines Entgeltes hin neigen.

Vorsitzender: Vielen Dank, Herr Götz. Jetzt bitte Herr Hofmann.

Hofmann: Die Äußerungen in der Diskussion, die mein Referat betreffen, waren nach meinem Eindruck so vielfältig, daß es mir schwerfällt, sie unter einige wenige Gesichtspunkte zu bringen. Ich werde daher der Einfachheit halber in der Reihenfolge der Äußerungen antworten und habe deswegen zunächst Stellung zu nehmen zu der Frage von Herrn Ipsen, ob nicht ein Widerspruch liege einerseits in der Definition der Grundpflicht, die ich versucht habe, und der später aufgestellten These, daß die Grundpflichten erzwingbare Rechtspflichten im wesentlichen nur nach Gesetz, also erst nach der Konkretisierung durch den Akt des einfachen Gesetzgebers seien. Ich bin davon ausgegangen, daß es sich bei den Grundpflichten im eigentlichen Sinne, wenn dieser Terminus, wenn der Begriff einen Sinn haben soll (was ja - das klang wiederholt an - so selbstverständlich nicht ist), um originäre Verfassungspflich- 
ten handeln muß. Allerdings bin ich der Meinung, daß von einer solchen Verfassungspflicht sinnvollerweise auch dann gesprochen werden kann, ja gesprochen werden muß, wenn die in der Verfassung selbst formulierte Pflicht keine sich selbst vollziehende ist, nicht unmittelbare Rechtswirkungen entfaltet, sondern gesetzlicher Konkretisierung bedarf. Sie hat dann - meine ich - ihre spezifisch verfassungsrechtliche Wirkung als ein Teil der konstitutionellen Programmatik, auch dann, wenn sie nur potentielles Recht ist. Ich sehe mich in dieser Auffassung bestätigt durch einige Diskussionsbeiträge, insbesondere den von Herrn Zippelius, der auf den Facettenreichtum des Pflichtenbegriffs im Bereich des Rechts hingewiesen hat. Ich glaube, daß wir doch eine ganze Menge an Substanz verlieren würden, wenn wir unsere Betrachtungen unter dieses einfache Entweder-Oder von Erzwingbarkeit und Unverbindlichkeit stellen würden. Ihr zweiter Punkt, die Inpflichtnahme Privater betreffend, zielte wohl nicht unmittelbar auf mich, sondern auf die Ausführungen von Herrn Götzich habe dazu ja nichts gesagt. Aber vielleicht erlauben Sie mir eine zusätzliche Anmerkung zu machen. Es ist mir nicht ganz klar geworden, ob bei Ihren diesbezüglichen Ausführungen, Herr Ipsen, der Gesichtspunkt der Entschädigungspflicht ein Kriterium für das Vorliegen von Grundpflichten sein sollte oder nicht. Für alle Fälle sei nur darauf hingewiesen, daß es das wohl nicht sein könnte, denn es gibt ja das Beispiel, das alte klassische Beispiel der Eigentumsabtretungspflicht schon in der Deklaration von 1789, einer Pflicht, die alles entziehbare, belastbare Eigentum potentiell in gleicher Weise belastet, eine Entschädigung aber nur für den Fall gewährt, daß diese potentielle Pflicht im Einzelfall unter Verstoß gegen den Gleichheitsgrundsatz realisiert wird. Dieser Versto $ß$ ist der Grund für die Entschädigungspflicht, was wiederum zusammenhängt mit der Verbindung aller Grundpflichten mit dem Gleichheitsgrundsatz, den ich ja in meinem Referat hervorzuheben versucht habe.

Zu Herrn Zacher: Von den genannten fünf Punkten darf ich mit Ihrer Erlaubnis drei herausgreifen. Sie haben unter anderem gesagt, Grundrechte - und von dieser Definition müsse man ausgehen, wenn man über Grundpflichten sprechen will, und diesen Ansatz teile ich vollkommen - Grundrechte enthielten elementare Aussagen über Konflikte im Verhältnis Individuum und Gemeinschaft und infolgedessen müßten auch Grundpflichten etwas damit zu tun haben. Das ist auch mein Standpunkt. Ich habe versucht, ihn in der These $11 \mathrm{zu}$ markieren, allerdings mit der Maßgabe, daß außer diesem 
verfassungsrechtlichen Verhältnis der Gleichrangigkeit und der Gleichgewichtigkeit bezüglich des Verhältnisses Individuum - Staat noch zusätzliche Bedeutungsdimensionen in Betracht gezogen werden müssen. Demgemäß habe ich versucht, davon zu unterscheiden auf der einen Seite die Frage des verfassungstheoretischen Verhältnisses - in dieser Dimension stellt sich die Frage anders und ist anders zu beantworten und nach der anderen Seite die rechtsstrukturelle Frage der Tragweite des verfassungsgesetzlichen Regelungsgehalts. Und auch da liegen die Dinge anders. Wenn man diese beiden Fragen, die rechtstheoretische und die rechtsstrukturelle Dimension ausblendet und allein auf das Verfassungsrecht abhebt, dann allerdings muß genau das herauskommen, was Sie, wie ich finde, in Bestätigung des Kerns meiner These 11 noch einmal gesagt haben. Dasselbe gilt für die Aufstellung dieser grundsätzlichen Regel-Ausnahmeverhältnisse. Zum Schluß haben Sie eine, wie nicht anders zu erwarten, ganz besonders aktuelle und interessante, in meinem Referat leider nicht behandelte Frage angesprochen, nämlich die, wo denn die Schwerpunkte der Grundpflichten heute liegen, und damit zum Ausdruck gebracht, daß mit einer Aufarbeitung, mit einer verfassungsgeschichtlichen und verfassungstheoretischen Rekonstruktion klassischer Grundpflichten des 19. Jahrhunderts ja so sehr weit wohl nicht mehr zu kommen sei. Sie haben dazu aktuelle Probleme - Stichwort: Dienstpflicht, Vorsorgelast für sich selbst - angesprochen. Das gibt mir die Gelegenheit, wenigstens einen Teil dessen nachzuholen, was ich ursprünglich konzipiert hatte und dann wieder herausstreichen mußte. Ich hatte da nämlich einen kleinen verfassungsvergleichenden Teil in meinem Konzept, und der hätte nun in der Tat Anlaß geboten zu zeigen, wie - zwar nicht in der Bundesrepublik Deutschland, aber anderwärts bei neuen Verfassungsschöpfungen, die diese Kategorie der Grundpflichten übernehmen durchaus neue Schwerpunkte gesetzt, neue Problemfelder gesehen werden. Ich darf noch einmal hinweisen auf die iberischen Verfassungen, die schon in anderem Zusammenhang hier wiederholt genannt worden sind. Sowohl die portugiesische Verfassung von 1976 wie die spanische Verfassung von 1978 enthalten nicht nur ausdrücklich ausformulierte Grundrechte auf Gesundheit, sondern zugleich Grundpflichten zur Vorsorge für die Erhaltung der eigenen Gesundheit. In der spanischen Verfassung ist das sogar, wenn ich das richtig in Erinnerung habe, verknüpft mit der Organisation solidarischer Lastentragung der Krankheitskosten. Ein weiterer Schwerpunkt in der Entwicklung der Grundpflichten der jüngsten 
Vergangenheit ist nach der portugiesischen und der spanischen Verfassung darin zu sehen, daß sie nun auch ein Grundrecht auf eine ökologisch ausgewogene Umwelt gewähren und gleichzeitig eine entsprechende Grundpflicht statuieren. Übrigens gibt es in der spanischen Verfassung noch eine ganz eigentümliche Pflicht, außerhalb allerdings des Katalogs der Grundpflichten, nämlich die Pflicht eines jeden Spaniers, das Kastilische zu kennen.

Zum Votum von Herrn Häberle: Herr Häberle, Sie haben verschiedene Ebenen unterschieden, auf denen das Problem diskutiert werden müßte. Dem kann ich nur zustimmen. Ich kann aber nun nicht, was ich im Referat nicht getan habe, hier in Form einer Erwiderung auf Ihren Diskussionsbeitrag nachholen und meinerseits zu den Grundpflichten unter dem Aspekt dieser verschiedenen Ebenen Stellung nehmen. Aber drei Punkte möchte ich doch hervorheben. Der erste knüpft unmittelbar an das an, was ich eben zu Herrn Zacher gesagt habe. Sie haben die Ebene des Verfassungsvergleichs angesprochen, haben auch Beispiele anderer Verfassungen - neuerer Verfassungen - genannt, die die Kategorie der Grundpflichten bewahrt oder neu aufgenommen haben, wiederbelebt haben. In dieser Reihe wären meines Wissens noch zu nennen die Türkei und Japan. Der zweite Punkt: Ihre Überlegungen, die teilweise auch sehr weit schon in die Zukunft gegriffen haben, Überlegungen, ob und wie weit man zu einer stärkeren, nicht $\mathrm{zu}$ einer vollständigen, aber doch $\mathrm{zu}$ einer stärkeren Symmetrie von individuellen Rechten und Pflichten in der Verfassung kommen könne, ob also diese Asymmetrie, von der ich behauptet habe, daß das Grundgesetz sie aus bestimmten historischen Gründen in einer ganz besonders scharfen Weise, prinzipiell aber unvermeidlich ausgeprägt habe, ob sie nicht abzumildern sei. Unter diesem Aspekt der Milderung des liberalen Individualismus hat man ja auch teilweise in der Literatur die Grundpflichten der Weimarer Reichsverfassung seinerzeit gesehen. - Ein Wort zwischendurch zu diesem Terminus »Asymmetrie «: Er stand in meinem Konzept, als der Aufsatz von Herrn Isensee erschien - also publiziert hat diesen Ausdruck zuerst leider Herr Isensee. Aber da ich ihn für den besten halte, sah ich keine Veranlassung, ihn nur deswegen aus meinem Manuskript wieder herauszustreichen und etwa durch Ungleichgewichtigkeit oder dergleichen, was ich vorher erwogen hatte, zu ersetzen. - Die Frage ist also, ob hier eine größere Angleichung möglich ist. Ja, das ist sicher möglich, und das war ja im Gegensatz zu anderen Vorwürfen gegen das Grundgesetz mein Einwand, daß eine so scharfe 
Ausprägung nicht sein muß und vielleicht nicht gut tut. Nur eines muß ich ganz klar sagen: Diese Annäherung kann nur bis zu dem Punkt gehen, wo es zur Prinzipienfrage des RegelAusnahme-Verhältnisses kommt, wie das auch durch Herrn Zacher klargestellt worden ist. Zum dritten und mir im Augenblick wesentlichsten Punkt: Natürlich habe auch ich mir überlegt: Was kommt am Ende überhaupt heraus bei der Grundpflichtendiskussion? Und ich bin der Meinung, sicher ist, was nicht herauskommen darf, und das hat Herr Heckel auch ganz klar gesagt: Keine Vorschläge zur Ergänzung des Grundgesetzes zwecks Aufbesserung der staatsbürgerlichen Moral. Das ist also sicher etwas, was nicht herauskommen darf, und in dieser meiner Überzeugung haben mich von Anfang an meine historischen Studien bestärkt. Nein, das nicht - aber was dann? Ich meine, daß, ausgehend von meiner These 20, die Konsequenz nur darin bestehen kann, am Text des Grundgesetzes in der Weise zu arbeiten, daß man stärker als bisher die hier diskutierten Zusammenhänge ins Bewußtsein hebt. Und das ist eine, glaube ich, wirklich hohe Verantwortung der Staatsrechtslehre.

$\mathrm{Zu}$ Herrn Oppermann: Sie sehen mir nach, daß ich auch hier nur zu zwei oder drei Punkten etwas sage. Das eine ist ein Mißverständnis gewesen, das leicht - glaube ich - aufgeklärt werden kann, nämlich: Ich habe am Anfang davon gesprochen, daß das Thema mit gewissen konjunkturellen Aktualitäten belastet sei und deswegen für den Verfassungsrechtler Vorsicht geboten sei. Dabei bleibe ich. Aber dieser mein Vorbehalt galt nur diesen vordergründigen konjunkturellen Aktualitäten, nicht dem, was Herr Oppermann angesprochen hat, nämlich den langfristigen Fragen eines stärkeren Wiederbewußtwerdens von Pflichtmomenten in der Verfassung. Das ist etwas anderes. Abgesetzt habe ich mich gegen das, was bloß im Moment politisch aktuell ist und wovon man weiß, daß es morgen oder übermorgen durch andere Aktualitäten verdrängt werden wird. Einen zweiten Punkt darf ich noch hervorheben, aus dem, was Herr Oppermann gesagt hat: Ja - ich stimme dem $z u, d a ß$ eine gewisse Austauschbarkeit in den programmatischen Elementen der Verfassung besteht - eine These, die ja Herr Badura literarisch schon vertreten hat. Das entspricht auch meiner Einschätzung. Mir scheint es jedenfalls plausibel. Allerdings sehe ich ein Stück sehr schwieriger, auch methodisch sehr schwieriger Arbeit darin, verfassungsgeschichtlich und über Verfassungsvergleich dafür im einzelnen den Nachweis zu erbringen. Herr Oppermann hat dann noch sehr betont den Zusammenhang von Grundrechten und 
Grundpflichten. Das ist bei dem, was ich unselbständige Grundpflichten genannt habe, sowieso selbstverständlich. Auch bei den selbständigen habe ich versucht, die Notwendigkeit dieses Zusammenhangs aufzuweisen, und zwar von den ersten Grundrechtsproklamationen an. Ich würde nur etwas vorsichtig sein, daraus nun gleich Schlußfolgerungen für die Auslegung und Anwendung einzelner Grundrechte zu ziehen. So weit bin ich in meinen Überlegungen nicht gegangen, was aber die These des grundsätzlichen Zusammenhangs in keiner Weise berührt.

Herrn Bachof habe ich in besonderer Weise zu danken, daß er meine Leitsätze 16 und 20 hervorgehoben hat. Um die, in der Tat, ging es mir vor allem. Wenn ich in diesem Zusammenhang nicht von Solidarität gesprochen habe, jedenfalls nicht in den Thesen, so nur deswegen, weil ich wegen der Wichtigkeit der Thesen sie so schlicht wie möglich und so eng wie möglich am Text des GG formulieren wollte. Von Solidarität aber redet das GG nicht. Sinn der von Herrn Bachof aufgegriffenen Thesen ist der, daß die Minimalpflichten politischer Solidarität im Verfassungsstaat nicht aus irgendeiner transpersonalen Staatsidee, sondern aus dem Prinzip der Freiheit selbst und das heißt konkret: aus den Grundrechten zu entwickeln sind. Ein weiterer Punkt noch: Wenn ich gesagt habe, Grundpflichten blieben im Bereich reiner Programmatik, so bezog sich das - hier gab es wohl ein Mißverständnis - nur darauf, daß bei ihnen anders als bei den Grundrechten unter dem Einfluß des Art. 1 Abs. 3 - Herr Böckenförde hat dies ja noch einmal unterstrichen und fortgeführt - eben diese Möglichkeit unmittelbarer Umsetzung fehlt.

Eine sehr präzise Frage hat Herr Doehring gestellt: „Gilt für die positiven Grundpflichten ebenfalls Schutz des Wesensgehalts? Wie weit können sie aufgehoben und abgeändert werden?" Auch die Herren Hailbronner, Schuppert, Berg und Bullinger haben diesen Punkt angesprochen. Nach meiner Meinung sind Grundpflichten in dem jetzt vorliegenden Umfang mit Ausnahme der Wehrpflicht im wesentlichen unabänderlich, weil sie mit Schutzgütern des Art. 79 Abs. 3 GG unmittelbar zusammenhängen. Nur bei der Wehrpflicht besteht ein solch unmittelbarer Zusammenhang nach meiner Meinung nicht. Die Diskussion würde jetzt natürlich weiterführen zu dem Thema "Wehrpflicht und Demokratie“. Dazu wäre sicher noch manches zu sagen.

Herrn Vogel habe ich zu danken für steuerrechtliche Belehrung. Allerdings war ich schon so vorsichtig, in meinem Referat nicht allgemeine steuerrechtliche Erkenntnisse zum besten 
geben $\mathrm{zu}$ wollen. Vielmehr habe ich mich bei diesen Formulierungen „allgemeine Steuerpflicht mit der Maßgabe progressiver Belastung" bezogen auf die verfassungsgesetzlichen Fixierungen nicht nur des 19 . Jahrhunderts, sondern auch auf neuere Formulierungen bis hin zur Bayerischen Verfassung von 1946. Und solange das Grundgesetz mich nicht zwingt, von der Formulierung der Bayerischen Verfassung abzugehen, werde ich das natürlich auch nicht tun. Ernsthaft gesprochen: Es ging bei dieser Charakterisierung der Steuerpflicht um ein Beispiel dafür, wie Verfassungsgesetze einerseits dem Gesetzgeber einen bestimmten Gesetzgebungsauftrag erteilen, nämlich Besteuerung, allgemeine direkte Besteuerung, und gleichzeitig dann noch ein Regulativ mitgeben, wie die Maßnahme ausgestaltet werden muß, nämlich als progressive Belastung. Ich werde mich hüten, mich in eine aktuelle steuerrechtliche Diskussion einzuschalten.

Vorsitzender: Vielen Dank, Herr Hofmann. Ich darf nun in der Diskussion weiterfahren. Bitte, Herr Bachof.

Bachof: Herr Götz, ich bin mit Ihnen völlig einverstanden. Das Sozialstaatsprinzip ist selbstverständlich keine Art unerschöpflichen Reservoirs für neue verfassungsrechtliche Grundpflichten, und erst recht ist es keine Grundpflichten-Generalklausel. So habe ich es nie verstanden. Woran mir lag, war, mit Herrn Hofmann die Frage zu stellen: Was ist der letzte und eigentliche Grund für eine „Grundpflicht“"? Ist es der Gesetzesgehorsam, oder kann man nicht daneben oder besser darüber hinaus auf das Solidaritätsprinzip zurückgreifen - mindestens in dem vorsichtigen Sinne, daß dieses Prinzip vielleicht nicht zu aktivem Sozialverhalten, aber jedenfalls zum Unterlassen sozialschädigenden Verhaltens verpflichtet? Und, um ein Mißverständnis zu vermeiden: Selbstverständlich handelt es sich hier nicht um eine naturrechtliche oder vorstaatliche Menschenpflicht, sondern es kann sich nur handeln um eine staatsbegründete Bürgerpflicht. Für Grundrechte mag man naturrechtlich argumentieren können, obwohl die Realisierung der Grundrechte heute nur dort möglich ist, wo der Staat sie garantiert; aber für ihren Ursprung kann man naturrechtlich argumentieren. Für die Grundpflichten kann man das sicher nicht; sie sind staatsbegründet. Aber ich meine, auch ohne gesetzliche Positivierung sind sie mit diesem Minimum, wie ich es versucht habe herauszustellen, mit dem Staat mitgedacht und mitgegeben: und zwar mit jedem Staat, weil ein Staat als Solidargemeinschaft ohne ein solches Mindestma $ß$ an Solidarität einfach nicht existieren kann. 
Zippelius: Nur einen Satz zur Klarstellung, Herr Götz. Ich habe mich natürlich nicht dafür ausgesprochen, die Schrankenproblematik durch die Pflichtenproblematik zu ersetzen, sondern ich wollte nur sagen, es gibt zumindest einen Punkt, wo beide Problemkreise sich berühren. Ich habe von der Janusköpfigkeit des Problems gesprochen: daß der Schranke auf der einen Seite die Pflicht auf der anderen Seite entspricht. Ich würde zusätzlich aber noch sagen: Das ist nur ein Berührungspunkt. Die Pflichtenproblematik greift weiter und geht in ihrem Facettenreichtum über die Schrankenproblematik hinaus: auf der einen Seite hin zum unmittelbar durchsetzbaren Recht und auf der anderen Seite zum bloßen Verfassungsprogramm.

Vorsitzender: Danke, Herr Zippelius. Bitte denken Sie daran, daß die Zeit unerbittlich fortschreitet. Ich habe hier noch zehn Wortmeldungen. Wir müssen also etwas unter fünf Minuten pro Diskussionsbeitrag bleiben. Herr Hollerbach, bitte, Sie sind der Nächste.

Hollerbach: Ich muß zunächst fragen, ob ich für das Thema des Verhältnisses von Grundrechtsbegrenzungen und Grundpflichten doch noch eine kleine Variation beitragen kann, obwohl das Thema jetzt schon mehrfach berührt worden ist. Außerdem wollte ich gern noch eine zweite Frage stellen. Eben hat Herr Zippelius, glaube ich, sehr zu Recht vor einem Mißverständnis gewarnt, und ich darf mich insoweit Herrn Zippelius anschließen. Es wird sicherlich nicht darum gehen, die Schrankenproblematik aufzulösen und die Schwierigkeiten anderswohin zu verlagern. Andererseits möchte ich gerne Herrn Starck doch widersprechen, wenn er die Formel gebraucht, daß Grundpflichten Erscheinungsformen von Grundrechtsschranken seien. Hier meine ich, wird nun nach der anderen Seite hin etwas übertrieben. Mir geht es darum, doch zu sehen, daß die Grundrechtsschranken oder Grundrechtsbegrenzungen, wenn man sie aus ihrer Vereinzelung herauszieht, auf einen oder mehrere gemeinsame Nenner zu bringen sind. Diese gemeinsamen Nenner, das ist vorhin schon sehr früh bei Herrn Bachof angeklungen, sind im Grunde nichts anderes als Pflichten, die Pflicht zur Sozialverträglichkeit, die Pflicht zur Wahrung der grundlegenden Belange des Gemeinwesens, und ich möchte noch hinzufügen, das Toleranzprinzip. Ich darf etwa erinnern an das Urteil des Bundesverfassungsgerichts im Schulgebetsstreit, wo der Toleranzgedanke als Pflicht zur Toleranz einen ganz zentralen Stellenwert bekommen hat. Ich 
möchte dann aber noch eine zweite Frage aufwerfen, die anschließt an die These 11 von Herrn Hofmann; sie führt, wenn ich das recht sehe, in das eigentliche Zentrum der Grundlagenfragen hinein. Herr Hofmann hat hier das Thema des Rangverhältnisses von Grundrechten und Grundpflichten kurz thematisiert und formuliert und er hat, wenn ich das richtig in Erinnerung habe, zur Frage des verfassungstheoretischen Rangverhältnisses von Rechten und Pflichten gesagt: Rechte sind das Primäre, Pflichten sind das Sekundäre. Er hat das begründet, sehr betont und grundsätzlich zu Recht, mit dem Verfassungsprinzip der Freiheit. Damit hängt ja auch das Grundproblem der Asymmetrie von Grundrechten und -pflichten zusammen. Ich möchte dem auch gar nicht widersprechen. Nur meine ich, wir können uns mit dieser Antwort und dieser Befundnahme nicht einfach begnügen, sondern wir müssen weiterfragen und dieses Weiterfragen gilt natürlich auch dem Freiheitsbegriff, es zielt auf die Frage nach den nun kantisch gesprochen - Bedingungen der Möglichkeit von Freiheit. Wenn man die Frage so weiterführt, dann wird natürlich deutlich, daß hier schon das Pflichtmoment - ich will es ganz vorsichtig ausdrücken - notwendigerweise hereinkommt. Mit anderen Worten: Mit dem Befund „Verfassungsprinzip der Freiheit, Asymmetrie von Rechten und Pflichten", ist das Problem noch nicht gelöst. Wir können uns nicht damit begnügen.

Kirchhof: Die Vorsicht und Behutsamkeit, mit der beide Referenten das Verhältnis Grundrechte - Grundpflichten behandelt haben, veranlaßt mich zu der Frage, ob Grundrechte und Grundpflichten eigentlich ein Gegensatz oder aber zwei rechtsstaatliche Stufen zur Freiheitsgewährleistung sind. Der Rechtsstaat wirkt, indem er Rechtsverbindlichkeiten begründet, also verpflichtet. Aus dieser Verpflichtung folgt in einem Verfassungsstaat nicht der Gehorsam gegenüber beliebiger Gesetzgebung, sondern nur der Gehorsam gegenüber einer verfassungsrechtlich angeleiteten Gesetzgebung. Tatsächliche Elementarpflichten ergeben sich zunächst aus dem Faktum, daß der einzelne in die Entwicklung seiner Rechtsgemeinschaft eingebunden ist, er an seinem Staat als Gefährdungsgemeinschaft teilhat. Der Bürger trägt die Lasten an innerem und äußerem Unfrieden, den der Staat bewirkt oder zuläßt. Er muß die Lasten aus technischen Risiken tragen, die der Staat verursacht oder gestattet. Er hat die Finanzverbindlichkeiten zu erfüllen, die der Staat eingegangen ist. Ihn treffen die Folgen des kulturstaatlichen Niveaus, das der Staat erreicht oder 
verfehlt hat. Wenn die Verfassung dieses Faktum ins Rechtliche wenden und rechtlich binden will, entstehen nicht nur Staatsaufgaben, staatliche Befugnisse und Kompetenzen, sondern zumindest potentiell auch verfassungsrechtliche Individualpflichten. Die allgemeine, in der Staatsverfassung angelegte Gefahrenbereitschaft wirkt sich unmittelbar auf die Rechtspflichten der Bürger aus. Der Tatbestand des polizeipflichtigen Störers wird verwaltungsrechtlich durch das generalklauselartig, fragmentarisch definierte Rechtsgut „öffentliche Sicherheit und Ordnung" erläutert, das seinerseits auf die verfassungsrechtlichen Aussagen über die Staatsorgane und über besonders schutzwürdige Individualrechte (die Grundrechte) verweist. Oder denken wir an das Problem der technischen Risiken, das wir einmal durch die verfassungsrechtliche Aufgabe begrenzen, dann aber auch in Gegenüberstellung mit den Grundrechten als ein "Restrisiko" definieren, das eine Duldungspflicht in Grenzen des Unvermeidbaren begründet. Staatliches Handeln nach Wahrscheinlichkeit und Vermutung begründet insbesondere im Recht der Wirtschaftslenkung und im Polizeirecht Prognoserisiken, denen die Verfassung nur das Erfordernis gesteigerter Verfahrenssorgfalt, nicht aber eine Garantie des richtigen Ergebnisses entgegensetzen kann. Wenn wir dort nicht Erfolgsrichtigkeit, sondern nur Verfahrenskorrektheit garantieren können, so ergibt sich daraus pointiert formuliert - eine Grundpflicht zur Hinnahme von rechtsstaatlich sorgfältig kontrollierten, in ihrem rechtswidrigen Erfolg nicht vermeidbaren Fehlentscheidungen und Fehlhandlungen. Die Pflicht zur Duldung der unvermeidbaren Fehlentscheidung ist Inhalt der verfassungsrechtlichen Aussagen, die Prognoseentscheidungen vorsehen.

Geht der Staat langfristige Verbindlichkeiten ein, begründet er insbesondere völkerrechtliche Verträge, lebenslängliche Dienstverhältnisse oder langfristige Kreditverträge, so treffen die Lasten dieser Verbindlichkeiten den Bürger zwar erst in der Zukunft, werden im Grundgesetz aber wegen dieser pflichtenbegründenden Wirkung bereits bei der Entstehung in verfassungsrechtliche Grenzen gewiesen.

Im Ergebnis wird der Freiheitsgehalt der Verfassung gesteigert, wenn man die aus der staatlichen Gefahrengemeinschaft folgenden Pflichten in verfassungsrechtlichen Korridoren bindet und der konkretisierten Pflicht sodann die Grundrechte entgegenstellt. Die Anerkennung von Grundpflichten auf Verfassungsebene wird insbesondere die Gleichheit vor dem Gesetz, d. h. die Gleichheit beim Vollzug der Gesetze mehren. 
Vorsitzender: Danke, Herr Kirchhof. Bitte, direkt dazu Herr Grimm.

Grimm: Ich wollte nur noch einmal, zurückkommend auf meinen ersten Beitrag, eine Klärungsfrage stellen, Herr Kirchhof. Grundpflicht muß ja etwas Zusätzliches sein gegenüber Gesetzespflicht. Und worin liegt hier das Zusätzliche gegenüber Gesetzespflicht?

Vorsitzender: Wollen Sie antworten, Herr Kirchhof?

Kirchhof: Die Grundpflichten sind elementarer und enger als die allgemeine Pflicht zum Gesetzesgehorsam. Sie haben ihren Geltungsgrund im Verfassungsrecht, insbesondere in den verfassungsrechtlichen Aussagen über die Staatsaufgaben, die dort angelegten Staatsbefugnisse und die Staatszielbestimmungen. Diese Handlungsprogramme des Staates enthalten immer potentiell auf Verfassungsebene begründete individuell belastende Verpflichtungen. Diese Individualpflichten konkretisieren wir in der Regel im Verwaltungsrecht, müssen dann aber vielfach dieses Verwaltungsrecht - insbesondere in den Generalklauseln der Gefahrenabwehr und der Gefahrenvorsorge - durch Rückgriff auf das Verfassungsrecht verdeutlichen und ausformen. Darin zeigt sich, daß der eigentliche Rechtsgrund für diese Verpflichtungen die Verfassung, das positive Verfassungsrecht ist.

Vorsitzender: Danke, Herr Kirchhof. Direkt dazu Herr Isensee.

Isensee: Von Grundpflichten kann man nur reden, soweit eine Pflicht in der Verfassung angelegt ist. Eine Grundpflicht legitimiert sich aus der Verfassung, auch wenn sie erst durch das einfache Gesetz ihren konkreten Inhalt und ihre aktuelle Verbindlichkeit erhält. Sie muß dergestalt in der Verfassung verankert sein, daß sie durch antinomische Verfassungsregelungen nicht dem Grunde nach in Frage gestellt werden kann. Diese Bedingung erfüllt die Steuerpflicht, die geradezu den Prototyp einer materialen Grundpflicht bildet. Sie wird zwar nur indirekt im Kompetenzteil angesprochen; aber sie wird von der Verfassung als notwendig vorausgesetzt und einschlußweise gewährleistet. Das einzelne Steuergesetz kann Grundrechtskonflikte mit der Eigentumsgarantie, dem Gleichheitssatz, der Berufsfreiheit auslösen. Jedoch die Steuer als Instituion - die Pflicht dem Grunde nach - kann nicht grundrechtswidrig sein, weil sie den gleichen verfassungsrechtli- 
chen Rang hat wie die Grundrechte, in deren Schutzbereich sie eingreift. - Analoges gilt für die Wehrpflicht. Sie ist nicht institutionell gewährleistet, sondern nur als gesetzlich realisierbare Option vorgesehen. Aber die gesetzlich realisierte Wehrpflicht ist verfassungsrechtlich legitimiert. Sie hat die gleiche verfassungsrechtliche Würde wie die Freiheitsgrundrechte. Es ist also ein fatales Mißverständnis des Grundgesetzes, daß die Verweigerung verfassungsrechtlich und moralisch höher stehe als die Erfüllung des Wehrdienstes, weil das erste die Ausübung eines Grundrechts sei, das zweite nur die Ausführung einer gesetzlichen Verpflichtung.

Grundpflichten sind trotz ihrer verfassungsrechtlichen Sanktion angewiesen auf das Gesetz als Vermittler. In den Grundpflichten werden das rechtsstaatliche Verteilungsprinzip und der Vorbehalt des Gesetzes nicht aus den Angeln gehoben. Sie gelten nicht wie Grundrechte verfassungsunmittelbar für den Bürger. Eine Ausnahme bildet allerdings die Grundpflicht zum Gesetzesgehorsam. Sie wird nicht durch das Gesetz eingeführt, sondern sie liegt dem Gesetz voraus. Sie ist die apriorische Bedingung seiner Wirksamkeit: gleichsam das Naturrecht, auf dem der Gesetzespositivismus aufbaut. Auch die Friedenspflicht des Bürgers gilt unabhängig davon, ob sie gesetzlich geregelt ist oder nicht. Das Verbot der privaten Gewalt ist die Grundlage des staatsbürgerlichen Zusammenlebens, das Apriori des modernen Staates schlechthin. Grundsätzlich jedenfalls sind die Grundpflichten auf das Gesetz verwiesen. Darin stimmen sie überein mit den Verfassungsaufträgen. Ihre Besonderheit liegt darin, daß sie sich nicht wie die Verfassungsaufträge in einer Inpflichtnahme des Gesetzgebers erschöpfen, sondern letztlich auf die Inpflichtnahme des Bürgers ausgehen. Grundpflichten konstituieren den status passivus des Bürgers.

Vorsitzender: Vielen Dank für diesen Beitrag. Zuerst hat sich direkt dazu gemeldet Herr Hailbronner.

Hailbronner: Zu Herrn Isensee: Ich halte es für prinzipiell bedenklich, aus Staatsziel und Staatsauftrag so unbesehen eine Grundpflicht abzuleiten. Natürlich - es ist undenkbar, daß wir hier in der Bundesrepublik Deutschland ohne Steuern leben können, ganz einfach, weil finanziell keine anderen Einnahmequellen da sind. Aber, wenn man den absurden Fall zugegeben absurden Fall - annimmt, daß wir urplötzlich viele Ölquellen hätten, warum soll es dann verfassungsrechtlich unmöglich sein, die Steuerpflicht ganz oder teilweise abzu- 
schaffen. Ich kann das nicht einsehen und möchte im Prinzip davor warnen, unbesehen Staatsziele und Staatsaufträge zur verfassungsrechtlichen Pflicht des Bürgers zu erheben und auf diese Weise gegen die Freiheit des Bürgers zu wenden.

Vorsitzender: Danke. Direkt dazu Herr Püttner.

Püttner: Ja: Ich wollte das Gleiche sagen wie Herr Hailbronner. So einfach kann man es sich nicht machen, Herr Isensee. Wenn man die Kompetenzvorschriften abschaffen würde (das könnte man ja vielleicht), dann würde Ihre These halb zusammenfallen. Ein Glück, daß wir ein föderalistischer Staat sind, kann man nur sagen, sonst hätten wir einen Teil der Grundpflichten nicht.

Dagtoglou: Die verfassungsdogmatische Fundierung der Grundrechte ist, fürchte ich, immer noch nicht ganz überzeugend. Ich stimme Herrn Grimm zu. Man könnte vielleicht sagen, daß, wie die Grundrechte Mindestgarantien sind, die Grundpflichten vielleicht Höchstgarantien sind, daß man den Gesetzgeber nicht mehr verpflichten kann als die Verfassung sagt. Wenn das nicht Sinn der Grundpflichten ist, dann kann ich mir ein verfassungsrechtliches Konzept der Grundpflichten eigentlich nicht vorstellen.

Vorsitzener: Danke, Herr Dagtoglou. Direkt dazu Herr Bachof.

Bachof: Das Beispiel mit dem Öl stimmt nicht. Dabei wurde vorausgesetzt, daß die Ölquellen im Staatseigentum stehen, aber nicht im Privateigentum. Ein Staat, der ein Privateigentum an Ölquellen garantiert, der müßte von deren privaten Eigentümern auch Steuern für die Gesellschaft erheben.

Vorsitzender: Danke, Herr Bachof. Ein Direktbeitrag von Herrn Götz.

Götz: Die Einnahmen der Ölstaaten resultieren aus Abgaben - Steuern, die von den großen Mineralölkonzernen eingenommen werden.

Vorsitzender: So, darf ich bitten: jetzt weg vom Öl! Noch ein Direktbeitrag, dann kommt Herr Erichsen. Bitte, Herr Isensee.

Isensee: Weg vom Öl, doch zurück zur Steuer! Man muß schon in Science fiction flüchten, um eine Situation zu finden, in der die Steuerpflicht nicht die Verfassungsordnung konsti- 
tuiert und der Staat des Grundgesetzes nicht Steuerstaat ist. Mit weniger Aufwand an Phantasie ließen sich im übrigen auch Verhältnisse denken, in denen die tatsächlichen Voraussetzungen einzelner Grundrechte wegfielen und diese somit obsolet würden. Doch es sind nicht die Realien, welche die Steuerpflicht als Grundpflicht ausweisen, sondern rechtliche Faktoren, und zwar die wirtschaftlichen Grundrechte. Die privaten Wirtschaftssubjekte erarbeiten das Sozialprodukt im wesentlichen auf Grund ihrer grundrechtlich gesicherten Freiheit. Der grundrechtsgebundene Staat hat darauf nur geringen Einfluß, weil er die private Verfügungsmacht über Produktionsmittel, die persönliche Arbeitsbereitschaft, die gesellschaftlich autonome Lohnpolitik und Investitionspolitik respektieren muß. Er kann seinen Finanzbedarf nur dadurch stillen, daß er am wirtschaftlichen Erfolg der Grundrechtsträger, dessen Voraussetzungen außerhalb seines Machtbereichs liegen, über die Steuer partizipiert. Die Steuer ist der notwendige Preis der wirtschaftlichen Freiheit. Dagegen wäre die Steuerpflicht keine Grundpflicht in einem Staat mit Zentralverwaltungswirtschaft: im sozialistischen Unternehmerstaat. Dort mag es auch Steuern geben. Aber die Steuer ist nur Akzidenz des Systems, die Abgabenlast keine staatskonstitutive Pflicht.

Vorsitzender: Danke! Herr Erichsen, jetzt wieder zu den regulären Beiträgen zurück.

Erichsen: Es fällt natürlich etwas schwer, jetzt zu den Regularien zurückzukehren, aber ich will es gleichwohl versuchen. Ich darf an eine Bemerkung von Herrn Oppermann anknüpfen, der schon die Frage aufgeworfen hat, was wir eigentlich am heutigen Tage an konkret Brauchbarem, an kleiner Münze für die Rechtsanwendung mit nach Hause nehmen. Dieser Frage liegt, so scheint mir, ein anderer konzeptioneller Ansatz zugrunde als dem Bemühen der beiden Referenten. Wir haben in der Diskussion gesehen - insbesondere auch die Ausführungen von Herrn Böckenförde haben es deutlich gemacht -, daß man durchaus auch anders an die Frage der Grundfreiheiten herangehen kann, an eine Frage, die, wie ich nicht verkenne, schon mit terminologischer Unschärfe behaftet war und ist, darüber hinaus mit verfassungshistorischen und ideengeschichtlichen Vorgaben. Das alles führt dazu, daß ein weites Feld zu bestellen war und daß an konkreten Aussagen in den Referaten nicht so furchtbar viel enthalten gewesen ist. Herr Götz hat einen Wechsel auf Herrn Hofmann gezogen, indem er 
darauf hinwies, daß dieser das elterliche Erziehungsrecht und anderes behandeln würde, aber dieser Wechsel ist dann jedenfalls nicht in vollem Umfang eingelöst worden. - Ich muß gestehen, daß die hier behandelten Grundpflichten mir weniger Kopfzerbrechen bereiten als die schon von Herrn Hollerbach ausgesprochene Frage nach den Bedingungen der Freiheit, und ich meine der grundrechtlichen Freiheit. Die Bedingungen verlangen eine Analyse der einzelnen Grundrechtsnormen. Ich habe Bedenken, alle grundrechtlichen Freiheitsgewährleistungen über einen Kamm zu scheren, denn die Grundrechtsnormen gewähren ja ganz unterschiedliche Freiheiten. Sie gewährleisten etwa mehr egoistische oder mehr altruistische Freiheit. Sie gewährleisten Freiheiten mit ganz unterschiedlichen sozialen Dimensionen und Auswirkungen. Es gibt die „Freiheit vom“ und die „Freiheit zu“. Alles dies zum Teil in seiner Bedeutung bisher im Rahmen der Begrenzungsdiskussion gewürdigt - ließe sich fruchtbar machen bei dem Nachdenken über die Pflichtigkeit grundrechtlicher Freiheit. Die Rechtsprechung des Bundesverfassungsgerichts hat im Zusammenhang mit dem Elternrecht des Art. 6 Abs. 2 GG die Verknüpfung von Recht und Pflicht eingefangen in dem Begriff Verantwortung. Mir scheint, dieser Begriff - so unscharf er auch ist - weist in eine Richtung, die weiter verfolgt werden sollte. Mir jedenfalls geht es sehr darum, im Zusammenhang mit der heutigen Diskussion weiter über die Entwicklung von Kriterien für die verantwortliche Ausübung grundrechtlicher Freiheit nachzudenken. Beispielhaft darf ich auf die Medienfreiheit hinweisen. Ich meine, daß man die Frage stellen muß, ob nicht grundrechtliche Freiheit, wenn man sich dazu versteht, sie als Rechtsinstitut und nicht als Ausgrenzung $\mathrm{zu}$ begreifen, auch in bestimmter Weise inhaltlich definiert werden muß. Ich treffe mich hier wohl mit Herrn Grimm in der Annahme, daß es Begrenzungen der Wahrnehmung grundrechtlicher Freiheiten geben muß. Danke schön.

Suhr: Herr Vorsitzender, meine Herren! Drei Punkte: $E r$ stens: Ich möchte einstimmen in das Plädoyer für eine differenziertere Betrachtung, und zwar sowohl bei den Grundsätzen als auch hinsichtlich der rechtstechnischen Formen, die wir im Bereich der Grundpflichten anwenden; die sittlichen Pflichten einmal ganz ausgeklammert. - Es besteht ein Unterschied zwischen geschriebenen und ungeschriebenen Grundpflichten, wobei wir sicher bei den ungeschriebenen, wenn wir sie überhaupt akzeptieren wollen, extreme Vorsicht walten lassen müssen, weil der Umgang mit ungeschriebenen Grundpflich- 
ten ein Spiel mit dem Feuer ist. Dann kann man eine Stufenleiter abgestufter Pflichtigkeiten skizzieren: beginnend bei der reinen Freistellung (die Verfassung läßt ein Verhalten indifferent) über die verfassungsrechtliche Erwartung (hier wünscht die Verfassung schon etwas, ohne es vorzuschreiben oder irgendwie zu sanktionieren) über die Lasten, die Herr Bachof angesprochen hat, und über die Obliegenheiten (wo keine Pflicht besteht, aber schon an Nicht-Ausübung Sanktionen geknüpft werden können) bis hin zu Pflichtigkeiten und schließlich zur strikten Pflicht. Die ganzen Vorbehalte, die wir gegenüber der „Identität von Recht und Pflicht“ haben, die betreffen ja genau genommen nur diesen letzten Fall, wo das, was ich darf, mir auch konkret-direkt vorgeschrieben wird: Bei Identität von Recht und Pflicht in diesem Sinne erstickt meine Freiheit in der Pflicht. Übrigens: Den verfänglichen Terminus "Identität von Recht und Pflicht" darf man mit Hegel in Verbindung bringen. Die komische Vorstellung jedoch, Recht und Pflicht seien konkret-identisch, hat mit Hegel nichts zu tun. Insoweit kenne ich meinen Hegel!

Zweitens: Ein Spiel mit dem Feuer! Wenn wir mit Grundpflichten hantieren, ist Vorsicht geboten. Nach Möglichkeit sind die sanfteren Rechtstechniken anzuwenden, die ich angesprochen habe: Erwartungen, Lasten oder Obliegenheiten mit Sanktionen, wie sie insbesondere im Sozialrecht wichtig sind, und in der Form, wie Herr Zacher sie angedeutet hat. - Aber ich will dabei gerade nicht nur das Sozialrecht ansprechen: Die besten Formen der Pflichtigkeiten und Verantwortlichkeiten zeigt uns doch das Zivilrecht! Wenn z. B. jemand seine Pflichten als Unternehmer nicht erfüllt, dann geht er in Konkurs. Dabei sind Mechanismen der Verantwortlichkeit und Pflichtigkeit am Werk, wo niemand dahinter steht und strikt sagt: „Tue dies oder das!“

Drittens: Warum bislang ein Vakuum bei der Grundpflichtdogmatik? Warum tun wir uns noch heute schwer mit den Grundpflichten? - Das hängt zusammen mit verfassungstheoretischen und ideengeschichtlichen Befunden. Ich möchte jetzt ganz bewußt zuspitzen: Vielleicht gelingt es mir ja, die Deutschen Staatsrechtslehrer mündlich ein wenig aus der Reserve zu locken, nachdem ich die Hoffnung schon aufgegeben habe, ich könne das mit meinen schriftlichen Versuchen erreichen. Ich behaupte: So gut wie alle unsere Vorstellungen über die Freiheit und die Grundpflichten, über die wir heute geredet haben, beruhen auf einem grandiosen Irrtum bei der Einschätzung der anthropologischen Befindlichkeit eines freien Menschen, - auf einer grandiosen Selbsttäuschung, die uns vor 
allem deshalb so schmeichelt, weil sie uns selbst suggeriert, wir seien selbständiger und autonomer als wir es in Wahrheit sind.

Je nachdem, wie man sich diese anthropologische Grundbefindlichkeit bewußt - oder noch viel wirksamer: unbewußt vorstellt, fallen auch die Vorstellungen über Freiheiten und Pflichten anders aus. Deswegen gehört das vorausgesetzte anthropologische Grundraster hierher. Wir stellen uns den Menschen vor als Individuum: frei, selbständig, autonom bis zu den viel angesprochenen Nichtstörungsschranken der Unterlassungsgrundpflicht. Selbstverständlich haben wir auch eine ganze Menge an Sozialpflichtigkeit auf das einzelne Individuum gepackt, um es ein bißchen in Pflicht zu nehmen: der einzelne nicht mehr selbstherrlich, sondern in seiner ,sozialen Gebundenheit". Meine These dagegen: Lange, bevor der andere zum Störer meiner Freiheit wird, ist er Voraussetzung meiner Freiheit. Meine Herren, wenn Sie jetzt hier nicht säßen, und ich redete in den leeren Saal hinein, das wäre witzig. Sie alle sind die Voraussetzungen dafür, daß ich meine Wissenschaftsfreiheit, Meinungsfreiheit usw. überhaupt ausüben kann. Sie sind jetzt und hier meine Freiheitsvoraussetzungen. Auch daß hier Licht brennt - ich bin abhängig davon. Wir sind alle voneinander abhängig. Je arbeitsteiliger die Gesellschaft ist, desto stärker sind wir voneinander abhängig. Wir sind und das ist die Grundbefindlichkeit - nicht selbständige autonome Individuen, sondern wir sind abhängig voneinander. Und unsere Freiheit ist eine Erscheinungsform dieser Abhängigkeit. Wir machen einander zu Instrumenten unserer Freiheit. Ich mache Sie zum Instrument meiner Redefreiheit, indem ich Sie zu Zuhörern mache. Ich kann und will Sie nicht zwingen! Aber Sie machen mich durch Ihr Zuhören erst frei.

Wenn das aber so ist: wenn Freiheit vielfach nicht nur ein Sich-Einigeln in Privatsphären und Intimsphären ist, sondern Freiheit durch andere; wenn die anderen Instrumente meiner Freiheit werden, etwa im Kaufvertrag, im Unternehmen, dann heißt „Wechselseitigkeit" etwas ganz anderes als bloß: „Ich achte deine Sphäre wie du meine." Es heißt dann eher: „Machst Du mich zum Instrument, dann will auch ich Dich zum Instrument haben. " Und wenn jemand ausdrücklich oder faktisch beansprucht, andere zum Instrument seiner Freiheit zu machen, dann müßte er eigentlich akzeptieren, daß der andere auch eine Art Anwartschaft hat, ihn selbst zum Instrument seiner Freiheit zu machen. 
Dies alles freilich ist noch keine Dogmatik. Das sind nur Hintergrundvorstellungen naturrechtlicher Art, wenn man will, oder ontologischer Art, die ich nur entgegensetze den individualistischen Hintergrundvorstellungen, die hinter unserem derzeitigen Freiheitsverständnis und unserem Pflichtenverständnis sitzen. Das ist mir ganz klar, daß das keine fertige Dogmatik ist! Es sind Vorstellungen, die, wenn Sie sie für richtig halten, irgendwann in die Auslegung des einen oder anderen Grundrechts oder z. B. des Sozialstaatsprinzips hineinfließen können als eine - vielleicht - adäquatere Vorstellung dessen, was Grundrechte und was Grundpflichten sind.

Roellecke: Zunächst: Herr Suhr, ich lasse mich provozieren. Ich bilde mir ein, nicht unreflektiert an das Menschenbild des autonomen Individuums anzuknüpfen, meine aber, daß es nützlich ist, in der verfassungstheoretischen und -dogmatischen Diskussion dieses Menschenbild vorauszusetzen. Man tut sich viel leichter. Wie man sich auch viel leichter tut, wenn man davon ausgeht, daß der Staat durch Revolution, durch Unrechtsakt fundiert wird, und nicht annimmt, er sei ein Geschöpf Gottes oder durch Staatsvertrag entstanden. Das ,,autonome Individuum" ist einfach eine Annahme, die man benutzt, um sich in der Diskussion zu verständigen. Daher kann ich Ihren Vorwurf so nicht akzeptieren.

Sodann: Die Asymmetrie von Rechten und Pflichten scheint mir der zentrale Ansatz für die Deutung des Verhältnisses von Grundrechten und Grundpflichten zu sein. Bisher habe ich freilich den Eindruck, als ob das Bekenntnis zu dieser Asymmetrie mehr ein Lippenbekenntnis sei. Deshalb zur Verdeutlichung: Zwischen Rechten und Pflichten gibt es einen fundamentalen Unterschied. Über Rechte kann man letztlich verfügen, auf Rechte kann man prinzipiell verzichten, auf Pflichten natürlich nicht. Pflichten kann man also nur verletzen, gegen Pflichten kann man nur verstoßen, wenn man nicht durch Dritte davon befreit wird. Ein System, das an Pflichten anknüpft, schafft daher eine viel radikalere, engere und festere Bindung der Bürger als ein System, das sich auf individuelle Rechte gründet. Ein System, das sich auf Rechte gründet, ist flexibler. Insofern ist eine Asymmetrie von Rechten und Pflichten eine notwendige Bedingung für einen freiheitlichen Staat. Wenn das aber richtig ist, dann, Herr Hofmann, bin ich nicht sicher, ob Sie den Gedanken der Asymmetrie noch durchhalten, wenn Sie in Ihrem Leitsatz 16 sagen, die Grundpflichten hätten im Gegenseitigkeitsprinzip und im Gleichheitssatz ihren Grund; denn das Gegenseitigkeitsprinzip und 
der Gleichheitssatz sind gerade Grundgedanken der Symmetrie. Leiten Sie also die Grundpflichten nicht aus einem spiegelbildlichen Ansatz ab? Die zweite Frage: Sie schreiben in Leitsatz 20: Die Grundpflichten entfalten verfassungsrechtliche Wirkung, indem sie zu setzendes Recht begründen. Das ist eine klare Legitimation für den Gesetzgeber. Wie verträgt sich diese aus den Grundpflichten abgeleitete Legitimation des Gesetzgebers mit seiner demokratischen Legitimation?

E. Klein: Ich möchte beginnen mit einer Ergänzung aus dem Bereich des internationalen Menschenrechtsschutzes. Die Präambeln der beiden UN-Menschenrechtspakte wurden, ich glaube von Herrn Häberle, schon erwähnt. Einschlägiger noch dürfte der Art. 29 der Allgemeinen Menschenrechtsdeklaration von 1948 sein, der in seinem Abs. 1 sagt, daß jedermann Pflichten gegenüber der Gemeinschaft hat, in der ihm allein die freie und volle Entwicklung seiner Persönlichkeit möglich ist. In einem zweiten Absatz wird dann ausdrücklich auf die Möglichkeit der Schrankenziehung für die Rechte und Freiheiten hingewiesen. Auf diese Differenzierung zwischen Pflichten und Schranken komme ich nachher noch zurück. Nun ist dieser Hinweis auf Pflichten gegenüber der Gemeinschaft hier ja nur sehr pauschal enthalten, und es ist deswegen kein Wunder, daß sich die zuständige Menschenrechtskommission innerhalb der Vereinten Nationen Gedanken gemacht hat, wie hier zu konkretisieren und zu spezialisieren ist. Man hat verschiedene Berichte vorgelegt, die das versucht haben - ich weise auf sie besonders deshalb hin, weil sich daraus sehr interessantes Material für unser Grundpflichtproblem ergibt. Noch interessanter aber - nur deshalb möchte ich darauf eingehen - erscheinen mir die Äußerungen der einzelnen Mitgliedstaaten, die mit diesen Berichten konfrontiert wurden und die sich daraufhin zu äußern hatten, was sie von einer solchen Entwicklung von Grundpflichten, von einer solchen Pflichtenkategorie überhaupt halten. Natürlich gab es, wie man sich vorstellen kann, sehr gegenläufige Stellungnahmen der Bundesrepublik Deutschland einerseits und der DDR andererseits, ganz in dem Sinne, wie Herr Götz in seinem Referat die in Ost und West unterschiedliche Freiheitskonzeption ja auch beschrieben hat.

In der Stellungnahme der Bundesrepublik ist große Skepsis gegenüber einer überhandnehmenden Inpflichtnahme des Individuums zu spüren - es wird dazu darauf hingewiesen, daß dem die grundsätzliche Freiheitskonzeption unserer Verfassung entgegensteht. Auf der anderen Seite müssen wir zur 
Kenntnis nehmen, daß es rechtsstaatliche Verfassungen mit Grundpflichten gibt, nicht zuletzt ja das Grundgesetz. Es ist einfach ein positiv-rechtlicher Befund, den wir entgegenzunehmen haben, daß es Grundpflichten jedenfalls in dem Sinne gibt, als es besonders hervorgehobene, in der Verfassung festgelegte, normierte Individualpflichten sind, die in einem engen Zusammenhang mit den Grundrechten stehen. Das ist nicht notwendig ein Widerspruch, ein prinzipieller Widerspruch, denn einen prinzipiellen Widerspruch gäbe es nur, wenn daraus ein allgemeiner Pflichtenstatus entstünde. Wohl aber sind mit dem allgemeinen Freiheitsstatus einzelne konkrete, auch auf der Verfassungsebene normierte Individualverpflichtungen vereinbar.

Wenn wir diesen Befund akzeptieren, meine ich, daß es die eigentliche Aufgabe ist, diese einzelnen konkreten Verpflichtungen in ein System zu bringen. Und es liegt natürlich nahe, daß man zur Bewältigung dieser dogmatischen Aufgabe auf das zurückgreift, was in der Grundrechtsdogmatik entwickelt wurde, insbesondere in der Dogmatik der Freiheitsrechte. Dennoch möchte ich vor einem solchen unmittelbaren Brükkenschlag warnen. Es gibt sicher mehrere Gründe. Ich nenne einmal vier: Erstens - ich erwähnte es schon - steht dieser unmittelbaren Gleichstellung entgegen, daß wir einerseits einen allgemeinen Freiheitsstatus neben den konkreten Freiheiten haben, aber eben keinen allgemeinen Pflichtenstatus. Zweitens - Herr Grimm hat wohl darauf aufmerksam gemacht - der einzelne ist auf die Grundrechte zur Sicherung seiner Freiheit in ganz anderer Weise angewiesen als der Staat auf die Grundpflichten angewiesen ist, um Individuen in Pflicht zu nehmen. Drittens ist zu Recht auf die starke Verbindung dieser Grundpflichten mit dem allgemeinen Gleichheitssatz hingewiesen worden. Wir wissen, daß der Gleichheitssatz ganz anders strukturiert ist als die Freiheitsrechte. Und schließlich meine ich auch nicht, daß man das Grundpflichtenproblem in die Grundrechtsdogmatik unmittelbar hineinziehen kann dadurch, daß man diese Grundpflichten nur als Erscheinungsformen der Grundrechtsschranken auffaßt. Ich bin ganz entschieden der Auffassung, wie es auch Herr Götz in seiner Zwischenbilanz vorgetragen hat, daß Grundpflichten den einzelnen Freiheitsrechten gegenüber nicht unter diesem starken Legitimationszwang stehen, wie es bei den Schranken dieser Freiheitsrechte der Fall ist. Von daher meine ich, und damit komme ich auf den Art. 29 der Allgemeinen Menschenrechtsdeklaration zurück, hat es einen Sinn, daß in dieser Bestimmung klar unterschieden wird zwischen Grundpflichten einerseits 
und Schranken andererseits. Aber gerade dies, daß hier differenziert werden muß, daß Grundpflichten und Grundrechtsschranken nicht in eins gesetzt werden dürfen, sollte uns diese Rechtsfigur Grundpflicht, jedenfalls ihrer Ausweitung mit einem gehörigen caveat versehen lassen. Danke schön.

Novak: In aller Kürze, weil meine Wortmeldung unmittelbar an Herrn Klein anschließen kann. - Ja, es ist notwendig, zu differenzieren; und ich glaube, daß in der Diskussion eine Unterscheidung verlorengegangen ist, die Herr Götz getroffen hat und die für die Frage, die uns so sehr beschäftigt, wichtig ist. Herr Götz hat neben den liberalen Grundrechten auch die politischen Rechte in die Betrachtung einbezogen. Wenn man nun, so meine ich, diese beiden Typen von Rechten gleichsam auf die Pflichtenseite transportiert, dann zeigt sich sofort, da 3 die Grundpflichten nicht völlig in Grundrechtsschranken aufgelöst werden können. Das mag bei den liberalen Grundrechten, ihren Einschränkungen und dementsprechenden Verpflichtungen möglich sein. Zwischen Wahlrecht und Wahlpflicht aber gibt es nur die Entscheidung: entweder - oder. Man kann nicht Wahlpflicht, Stimmpflicht und ähnliche politische Grundpflichten aus Grundrechtsschranken ableiten.

Kloepfer: Herr Hofmann, ich darf noch eine Frage zu Ihrer These 18 stellen. Vielleicht ist es etwas kurz formuliert, wenn Sie schreiben: Die Grundpflichten seien im wesentlichen grundrechtsfest, wobei wir zwei Schlupflöcher haben: einmal das Wesentlichkeitsschlupfloch und zum andern die Anführungszeichen, und natürlich noch als Voraussetzung die Möglichkeit, so wenig Grundpflichten anzunehmen, daß in der Tat das Problem sich möglicherweise selten stellt. Ich würde allerdings vor der Formulierung der Grundrechtsfestigkeit von Grundpflichten ebenso warnen wie umgekehrt vor der möglichen Formulierung einer Grundpflichtenfestigkeit der Grundrechte. Was überhaupt möglich sein könnte, wäre ja doch ein behutsamer Ausgleich zwischen den Gehalten, die in den Grundrechten enthalten sind und denjenigen Gehalten, die in den Grundpflichten zum Ausdruck kommen. Verfassungsrechtliches Ausgleichs-Instrumentarium kann dabei z. B. die Grundrechtsbeschränkung sein. Hierdurch stellt die Verfassung im Zusammenhang mit dem Übermaßverbot ein sehr ausdifferenziertes Instrumentarium bereit, um mögliche Konflikte zwischen Grundrechts- und Grundpflichtsgehalten zu lösen. Aber generell zu sagen: das eine geht vor, und sei es auch nur im wesentlichen, halte ich für problematisch. Vielleicht sind jedoch manche Vereinfachungen auch dadurch zu erklä- 
ren, daß in Thesen komplexere Gedankengänge notwendigerweise verkürzt werden müssen.

Rauschning: Ich möchte mich beim Vorstand für die Wahl des Themas bedanken und bei den Vortragenden und den meisten Beitragenden für den Tenor der Ausführungen: Fast einhellig wird eine erhebliche Zurückhaltung für die verfassungsrechtliche Dimension der Grundpflichten bekundet. Es ist gewiß nicht leicht für die Referenten, ein großes Referat auf der Staatsrechtslehrertagung zu halten mit der zurückhaltenden Aussage, daß es nur sehr wenige von den Gegenständen der Verhandlung, von den Grundpflichten, gibt. Die dogmatische Untersuchung und schon dieses Ergebnis - Seltenheit von Grundpflichten und Zurückhaltung bei der Herleitung im Verfassungsrecht - stellen einen wissenschaftlich bedeutenden Ertrag unserer Sitzung dar. In den Referaten und der Diskussion haben wir ein erhebliches $\mathrm{Maß}$ an Übereinstimmung feststellen können. Grundlegend ist zunächst die Feststellung, daß nicht nur keine Symmetrie zwischen Grundrechten und Grundpflichten gefordert werden kann, sondern, daß es sich auch nicht um eine do-ut-des-Beziehung oder um ein bedingendes Verhältnis handelt.

Zur Gehorsamspflicht als Grundpflicht darf ich vom Völkerrecht her auf ein paralleles Problem hinweisen: Ist der Satz „pacta sunt servanda“ ein Völkerrechtssatz oder ist er eine Voraussetzung des Völkerrechts? Entsprechend sehe ich die Gehorsamspflicht als Voraussetzung des Staates und nicht etwa als Grundpflicht an, und so kommen wir wirklich zu sehr wenig Grundpflichten von verfassungsrechtlicher Dimension. Auch können wir wieder als allgemeine Übereinstimmung feststellen, daß wir auch bei verfassungsrechtlich verankerten Pflichten zur Konkretisierung ein Gesetz brauchen.

Herr Hofmann, in einem Punkt möchte ich Sie noch zu einer Präzisierung herausfordern: Ich meine, daß wir nicht für ein belastendes Gesetz prinzipiell jeweils eine Legitimation in der Verfassung bedürfen, sondern daß wir auch, wenn es sich mit den Grundrechten vereinbaren läßt, pflichtbegründende Gesetze auch auf der Ebene des einfachen Gesetzes haben können. So können wir nur die besondere Herausgehobenheit dieser verfassungsrechtlich ausgesprochenen Pflichten feststellen, wir brauchen aber die Verfassungspflichten nicht umfassend und müssen nicht alle Pflichten verfassungsrechtlich begründen. Wir können außerdem dankbar feststellen, daß der Bereich der ethischen Pflichten, auch das Dienstethos, nicht in die Verrechtlichung einbezogen sind. Gewiß besteht eine all- 
gemeine Verpflichtung, den Staat mitzutragen, und dem Wahlrecht entspringt auch eine Wahlpflicht, die Meinungsfreiheit zielt - auch - darauf ab, daß man sich eine Meinung bilde; ich halte es aber für eine Stärke, daß diese Pflichten nicht in die Rechtspflichten einbezogen sind, ebensowenig wie der ehrenamtliche Dienst, der freiwillig geleistet wird, der den Staat trägt.

In zwei Punkten möchte ich gegen Ihre Ausführungen, Herr Hofmann, Widerspruch erheben: Ich sehe in Art. 79 Abs. 3 GG keine Garantie gegen die Änderung der verfassungsrechtlichen Grundpflichten; ich kann einfach den Verweis auf Grundpflichten in dieser Vorschrift nicht finden. Und weiterhin möchte ich Ihrer bei Leitsatz 31 vorgetragenen These widersprechen, daß in der Kalkar-Entscheidung eine ungeschriebene Grundpflicht verfassungsrechtlicher Art beschworen worden sei.

Breuer: Die beiden Referenten haben einen grundsätzlichen Konsens erkennen lassen, der sich in wenigen Worten zusammenfassen läßt: Es gibt keine Symmetrie - wie Sie formuliert haben, Herr Hofmann - zwischen Grundrechten und Grundpflichten. Grundrechte sind originär, Grundpflichten sind es nicht. Grundpflichten sind auf gesetzliche Ausprägung angewiesen, und wenn es Grundpflichten in unserer Verfassung gibt, dann sind sie nur in sehr differenzierter Weise angelegt. Dennoch teile ich eine gewisse Skepsis mit Herrn Erichsen zusammen, wenn ich mich frage, welche praktischen Konsequenzen sich aus diesen Erkenntnissen ergeben. Zunächst meine ich, daß man zwei Arten von Grundpflichten, jetzt im echten verfassungsrechtlichen Sinne verstanden, unterscheiden muß. Zum einen gibt es die Grundpflichten, die sich auf den zwischenmenschlichen Bereich beziehen; zum anderen haben wir über Grundpflichten diskutiert, die unmittelbar staatsgerichtet sein sollen, wie z. B. die Wehrpflicht, die Steuerpflicht und vielleicht auch die Pflicht zur Verfassungstreue.

Zum Bereich der zwischenmenschlichen Grundpflichten haben Sie, Herr Hofmann, die These vertreten, wir müßten die Grundpflicht als verfassungsrechtliche Figur einführen. Mir ist allerdings, offen gestanden, nicht klar geworden, ob damit eigentlich in den praktischen Konsequenzen etwas Neues gesagt sein soll. Bisher haben wir mit den Figuren der grundrechtsimmanenten Schranken, mit den Figuren der Grundrechtskollision, mit den Figuren objektiver Werte und des institutionellen Grundrechtsverständnisses versucht, Minimalpflichten aus der Verfassung herauszulesen, die die Frei- 
heitsausübung des einen einschränken, damit die Freiheit des anderen gewahrt werden kann. Bedeutet es also - das ist die Frage an Sie, Herr Hofmann - wirklich etwas Neues, wenn wir diese ganzen Denkkategorien und Probleme jetzt unter verfassungsrechtliche Grundpflicht bringen. Herr Götz, Sie haben in diesem Punkt jedenfalls theoretisch einen anderen Ausgangspunkt vertreten. Dies mag in der Tendenz meiner Bemerkungen liegen; ich frage aber, ob Sie Ihren Ansatz durchgehalten haben, denn was Sie in Teil III Ihres Referates über die Sozialpflichtigkeit, insbesondere des Eigentums, gesagt haben, berührt meines Erachtens doch wieder den Problembereich der zwischenmenschlichen Grundpflichten - falls es hier überhaupt Grundpflichten gibt.

Eine verfassungsrechtlich neue Perspektive könnte sich meines Erachtens - ich formuliere bewußt vorsichtig - für die unmittelbar staatsgerichteten Pflichten ergeben. Nun will ich nicht noch einmal die Debatte über die Wehrpflicht und über die Steuerpflicht aufgreifen. Wir haben indessen die Verfassungstreue allenfalls andiskutiert. Ich will diesen Punkt aber nicht untergehen lassen. Herr Götz hat meines Erachtens zu Recht gesagt, daß es eine allgemeine Verfassungstreuepflicht des Bürgers nicht gibt. Der Beamte hat indessen nach Art. 33 Abs. 4 und 5 des Grundgesetzes nach der höchstrichterlichen Rechtsprechung sehr wohl eine weitergehende positive Pflicht zur Verfassungstreue. Hier differieren offenbar die Standards der rechtlichen Inpflichtnahme auf der einen Seite des Bürgers, auf der anderen Seite des Beamten. Kritisch werden die differierenden Standards, wenn wir einmal an den beamteten Hochschullehrer denken, der die Wissenschaftsfreiheit nach Art. 5 Abs. 3 GG in Anspruch nimmt. Gilt für ihn nur der Minimalstandard des allgemeinen Bürgerstatus ohne eine positive Verfassungstreuepflicht oder gilt für ihn, weil er Beamter ist, die positive Verfassungstreuepflicht mit dem - aus meiner Sicht problematischen - Ergebnis, daß er sich in seiner Lehre als Historiker, als Soziologe, vielleicht auch als Jurist, positiv zu den Grundwerten des Grundgesetzes bekennen muß und keine kritischen Tendenzen verlautbaren lassen darf? Dies wäre eine kritische Frage zum Schluß, die sich an beide Referenten richtet.

Vorsitzender: Danke, Herr Breuer. Jetzt noch ein Kurzbeitrag von Herrn Oppermann, dann müssen wir die Diskussion abschließen. 
Oppermann: Nachdem sich nahezu jeder Zweite, wenn nicht noch mehr, zugunsten der „Asymmetrie" ausgesprochen haben, möchte ich doch einmal sagen, daß ich die Frage so zumindest für zweideutig, um nicht zu sagen, für gefährlich gestellt halte, Symmetrie oder Asymmetrie. Meines Erachtens ist es damit so ähnlich wie bei der Güterabwägung. Man kann nur im konkreten Fall zwischen Grundrecht und korrespondierender Grundpflicht abwägend im Einzelfall feststellen, wie die Gewichte verteilbar sind. Ich glaube nicht, daß es eine zwangsläufige Symmetrie gibt, wie immer sie auch im einzelnen gemeint sein mag, aber auch nicht, daß es sozusagen eine ,a priori'sche Asymmetrie" in diesem Zusammenhang unter jedem denkbaren Gesichtspunkt gibt.

Vorsitzender: Danke, Herr Oppermann. Ich darf jetzt den Referenten das Schlußwort geben. Zuerst bitte Herr Hofmann.

Hofmann: Meine Herren Kollegen, ich bitte um Nachsicht, $\mathrm{da} ß$ ich nicht zu allen Diskussionsbeiträgen, denen ich viele Anregungen verdanke, Stellung nehmen konnte, und daß ich das jetzt auch im Schlußwort nicht nachzuholen vermag. Aber doch wenigstens einige ganz kurze Bemerkungen darf ich noch anfügen. Ich bin Herrn Grimm immer noch eine Antwort auf seine Einwendungen schuldig. Zum Teil berühren sie sich mit dem ersten Einwand, den Herr Hollerbach vorgetragen hat, in gewisser Weise auch mit dem Votum von Herrn Kirchhof. Glücklicherweise sehe ich mich in der Lage, hier auf die Intervention von Herrn Isensee verweisen zu können. $\mathrm{Zu}$ Herrn Hollerbach, der ja eine sehr grundsätzliche Frage aufgeworfen hat, nämlich die Frage, ob es reicht, nur dieses Prinzip der Freiheit zu beschwören, was ja, so gesehen, nur aus der Negation lebt, der Negation von Bindungen, und keine Sinnerfüllung erkennen läßt. Sicher ist es so, daß von hier aus, wie Sie sagen, weiter gedacht werden muß. Es ist für mich persönlich überhaupt keine Frage, daß diese weitergehenden Probleme nicht nur diskussionswürdig, sondern der Diskussion höchst bedürftig sind. Ich bin allerdings auch der Meinung, daß hier der Bereich ist, der bei aller Wichtigkeit im liberalen Verfassungsstaat nicht mehr rechtssatzfähig faßbar ist. Auch Herrn Schuppert bin ich noch eine Bemerkung schuldig. Nur ein Wort: Ja, ich habe versucht, die Grundpflichten in ihrem Bezug zu Staatsaufgaben zu sehen; ich kann das also nur unterstreichen, was Sie diesbezüglich gesagt haben, muß auf der anderen Seite aber davor warnen, es in dem Sinne der Herleitung von Grundpflichten aus der Staatsraison zu verstehen. Das ist nicht mein Standpunkt. Ich meine, wenn, dann Herlei- 
tung aus der Verfassungsraison des Verfassungsstaates - und das ist etwas anderes. Eine kleine Ergänzung - wenn Sie erlauben, Herr Schuppert - noch zu dem, was Sie gesagt haben und was genau in dieselbe Richtung geht: Ich bin der Meinung, daß es, wenn man schon verfassungspolitisch diskutiert - ich knüpfe da an eine Ihrer Bemerkungen an -, es in der Tat wichtiger ist, daß Steuern wirklich von allen bezahlt werden, als da $\beta$ die allgemeine Steuerpflicht proklamiert und sehr komplizierte, folglich auch umgehbare Steuergesetze geschaffen werden. Zu Herrn Suhr: Ich stimme Ihnen völlig bei, wenn Sie bei ungeschriebenen Grundpflichten zur Vorsicht mahnen. Ich begrüße, daß Herr Suhr das Thema des Facettenreichtums des Pflichtenbegriffs noch einmal sehr differenziert aufgenommen hat, und möchte ihm versichern, daß meine Vorstellung von Freiheit nicht die der Freiheit eines isolierten Individuums ist. Herr Roellecke hätte mich fast in Verlegenheit gebracht durch seine überraschenden Fragen nach möglichen Inkonsequenzen im Leitsatz 16. Sein Einwand: Ist der Gedanke der Asymmetrie durchzuhalten, wenn ich ihn mit Denkfiguren der Symmetrie wieder abmildere? Ja, er ist durchzuhalten, wenn auch modifiziert und gemildert. Die Notwendigkeit der Modifizierung und Milderung ergibt sich daraus, daß diese Asymmetrie massenhaft auftritt und deswegen ein Bindemittel vorhanden sein muß. Aus logischen Gründen ist das nur mit Denkfiguren der Symmetrie zu gewinnen und nicht mit Denkfiguren der Asymmetrie. Zum Leitsatz 20: Natürlich habe ich bei der Formulierung von der Begründung des zu setzenden Rechts durch Grundpflichten auch an den Sinn von Legitimation gedacht. Zum Glück hat das Wort „,begründen“ ja noch eine andere Bedeutung, die hier nochmals anzusprechen oder zu entfalten nicht die Zeit ist. Im übrigen sehe ich auch keinen Widerspruch. Warum soll aus einer demokratischen Verfassungsgesetzgebung nicht demokratische Legitimation für den dann konstituierten Gesetzgeber erwachsen? Zu Herrn Kloepfers Bemerkung über meine These 18: „Im wesentlichen" muß drinstehen, weil sonst der Satz in sich nicht mehr stimmig ist. Daß ich das ,grundrechtsfest" in Anführungszeichen gesetzt habe, hat nichts damit zu tun, daß ich mir ein Hintertürchen sichern wollte, sondern geschah einfach deswegen, weil es ein Kunstwort ist, das sich an ein anderes, ganz bekanntes aus der Weimarer Zeit anlehnt. Um das zu kennzeichnen, steht es in Anführungszeichen. Zu Herrn Rauschning: Ja, Belastung ohne Gesetze ist möglich. Das ist nur ein Problem der Definition von Belastung. Das ist ja auch das Problem bei der von Ihnen noch einmal angeführten Frage der 
technischen Risiken. Das ist wirklich nur ein Problem der Definition von Belastungsgrenzen. Was die Verbindung der Aufhebbarkeit oder Abänderbarkeit von Grundpflichten mit Art. 79 Abs. 3 GG anlangt, so vertraue ich darauf, daß die Frage sich Ihnen nach der Lektüre des vollständigen Textes anders stellt. Zu Herrn Breuers Erkundigung nach den praktischen Konsequenzen: Diese Frage ist mir nicht neu und nicht fremd. Ich habe am Schluß meines Referats auch deutlich darauf hingewiesen, daß ich die praktische Konsequenz meiner Ergebnisse nicht sehr hoch einschätze. Insbesondere liegt mir die Behandlung völlig fern, daß mit der Figur der Grundpflicht irgendwelche Fälle besser zu lösen seien. Vor einer solchen Vorstellung habe ich ausdrücklich gewarnt. Allerdings darf ich gegen das, was Sie gesagt haben, einwenden: Wenn Sie - so etwa haben Sie formuliert - sagen: Wir hatten doch bisher auch Denkfiguren, mit denen wir - so wörtlich - Verpflichtungen aus der Verfassung herausgelesen haben, ja, warum dann nicht einmal nach der Kategorie dieser Verpflichtungen fragen? Mehr war nicht beabsichtigt. Das Thema lautete ja auch: Grundpflichten als verfassungsrechtliche Dimension. Ich meine, gerade bei sorgfältiger Beachtung und Bearbeitung dieser Thematik - jetzt spitze ich $\mathrm{zu}$ - durfte eigentlich gar nicht allzuviel praktisch Verwertbares herauskommen. Eine allerletzte Bemerkung zu Herrn Oppermann: Nein, ich bleibe dabei: konkrete Kollissionen mit Vorrang der Pflicht; aber apriorische, prinzipielle Asymmetrie von Recht und Pflicht - sonst, glaube ich, wäre der Verfassungsstaat der Freiheit am Ende.

Lassen Sie mich zum Schluß ein Wort des Dankes sagen an alle Diskussionsteilnehmer, denen ich viele Anregungen verdanke, ein Wort des Dankes weiterhin an den Vorstand, daß er dieses Thema auf die Tagesordnung gesetzt hat. Dank schulde ich dem Vorstand insbesondere dafür, daß er mich mit der Aufgabe des Koreferats betraut hat. - Wenn man, aus einer teils lutherischen, teils hugenottischen Familie stammend, auf ein Gelehrtenkonzil nach Konstanz geladen wird, um seine rechte Pflichtauffassung $\mathrm{zu}$ bekennen, so schließt das einige Bezüglichkeiten ein. Nach meiner Familientradition läge es nun nahe, zu schließen mit einem Wort von Christoph Martin Wieland: „Laß dir an dem Bewußtsein genügen, deine Pflicht getan zu haben, andere mögen es erkennen oder nicht." Aber dieses Wort von Wieland würde nicht die Empfindungen wiedergeben, die meine Arbeit begleitet haben - da paßt viel besser ein Vers von Rabindranath Tagore: „Und siehe, aus Pflicht ward Freude.«

Ich danke Ihnen. 
Vorsitzender: Herzlichen Dank, Herr Hofmann. Ich darf nun Herrn Götz um sein Schlußwort bitten.

Götz: Ich bedanke mich, daß ich auch noch das Wort bekomme, obwohl es schwer ist, in die getragene Stimmung der abschließenden Worte von Herrn Hofmann hinein noch einmal Prosa zu sprechen. Bitte, üben Sie sich in Ihrer Toleranzpflicht, wenn ich dies demnach - aber mit der mir hoffentlich zu Gebote stehenden Kürze - tun werde. Das erste Stichwort, auf das ich eingehen möchte, ist das der Rechtsvergleichung. Innerhalb der westlichen Verfassungen finden wir eine gewisse Expansion von Grundpflichten in den neuen südeuropäischen Verfassungen. Spanien und Portugal sind erwähnt worden, auch Griechenland gehört dazu. Es ist bemerkenswert, daß diese Pflichtenkataloge eine stark sozialstaatliche Tendenz haben. Das ist bei der portugiesischen Verfassung selbstverständlich, gilt aber auch für die übrigen Verfassungen. Man wird sagen müssen, daß diese sozialstaatliche Tendenz umso auffälliger ist, als der Sozialstaat in den betreffenden Ländern nur schwach entwickelt ist. Grundpflichten also als Programmatik. Im Gegensatz dazu schweigt sich die schwedische Verfassung von 1975 praktisch über Grundpflichten aus.

Das zweite ist noch einmal die hier kontrovers diskutierte Frage, wie weit die Grundrechtsschranken in die Thematik der Grundpflichten einzubeziehen seien. Meine vorsichtige Position, die in dem Leitsatz 2 zum Ausdruck gekommen ist, stützt sich - und ich danke Ihnen, Herr Klein, daß Sie das schon formuliert haben - zusammenfassend letztlich darauf, daß wir uns bei der Extraktion von Pflichten aus den Schrankennormen der Verfassung in die Gefahr begeben, einen reichhaltigen allgemeinen Pflichtenstatus zu entwickeln. Ich halte beispielsweise das Problem der Einhaltung von Sicherheit und Ordnung, auch das Problem der Friedenspflicht im Zusammenhang von unfriedlichem Verhalten etwa bei Versammlungen, am richtigsten und zuverlässigsten bei der herkömmlichen Schrankendogmatik aufgehoben - im Hinblick auf die Entwicklung, die diese unter dem Grundgesetz also durchlaufen hat, mit den starken Differenzierungen durch Übermaßverbot und Verhältnismäßigkeit. Ich habe natürlich, Herr Zippelius, nicht unterstellen wollen, daß Sie das beiseitewischen wollen. Ich habe nur Gefahren andeuten wollen, die aus meiner Sicht eintreten, wenn wir die Gemeinwohlschranken der Grundrechtsausübung in Grundpflichten umformulieren und umdeuten. Ich möchte aber noch einmal daran erinnern, daß ich, wie im Leitsatz 6 zusammenfassend formuliert ist, auch für die 
Grundrechtsausübung Pflichten anerkenne, Pflichten, die Beiträge zur Kollisionsmilderung, -vermeidung und -bewältigung darstellen sollen. Ich könnte mir denken, daß das Toleranzprinzip, Herr Hollerbach - das im übrigen natürlich umfassender erörtert werden müßte, als dies hier geschehen kann -in der Tat ein Punkt ist, über den wir uns im Rahmen meiner These 6 verständigen können. Ich möchte dann auf die Fragen von Herrn Breuer eingehen. Ich glaube nicht, daß die Auffassung von der Asymmetrie zwischen Grundrechten und -pflichten, die ich ja ebenfalls vertrete, durch die im Zusammenhang mit der Eigentumsgarantie gemachten Aussagen in Frage gestellt wird. Natürlich gibt es hier wechselseitige oder - wie Sie es genannt haben - zwischenmenschliche Pflichten. Solche Pflichten sind durch die gesetzliche Eigentumsordnung normiert. Auf die Frage nach der Verfassungstreue der beamteten Hochschullehrer würde ich bejahend antworten und unterlasse wegen der fortgeschrittenen Zeit dazu weitere Ausführungen. Herr Suhr hat den Gedanken der Entfaltung des Menschen durch den Menschen vorgetragen, der mir nicht fremd ist, weil ich davon ausgehe, daß die Entfaltung des Menschen ohnehin in der Gesellschaft, in der Interaktion, stattfindet und nie anders stattfinden kann. Ich bin Herrn Suhr dankbar dafür, da $\beta$ er uns daran erinnert hat, daß wir einige begriffliche Differenzierungen in das Pflichtenthema einbringen müßten: die Obliegenheit im Unterschied etwa zu Pflichtigkeit und Pflicht. Wenn wir- ich darf vielleicht Herrn Hofmann gleich miteinbeziehen - insgesamt nur von Pflicht gesprochen haben, dann haben wir nur abkürzend gesprochen, um nicht durch zu scharfe begriffliche Unterscheidungen von der allgemeinen Fragestellung abzulenken. Natürlich ist vieles nur Obliegenheit, etwa auch das, was ich als eine Pflicht zur Kollisionsvermeidung und Kollisionsbewältigung bei der Grundrechtsausübung bezeichnet habe.

So komme ich abschließend zu der Frage des Ertrages. Hier steht es natürlich dem Referenten nicht an, den Ertrag dessen, was vorgetragen wurde, selbst zu beurteilen. Das Anliegen, das ich verfolgt habe, war, bei aller Skepsis und Vorsicht doch aus Überzeugung, das Existenzrecht der Grundpflichten im geltenden Verfassungsrecht darzulegen, und zwar materialer Grundpflichten, nicht lediglich einer in die Nähe der formalen Grundpflicht rückenden Gehorsamspflicht, sondern Grundpflichten je spezifischen materialen Inhalts, die weder durch eine Generalklausel noch durch ein System verbunden sind, sondern die einzelne Pflichtelemente verfassungsrechtlicher öffentlicher Ordnung darstellen. Dies sind nicht, Herr Dagto- 
glou, Höchstpflichten. Die Grundpflichten, über die wir gesprochen haben, können durch andere gesetzliche Pflichten ergänzt werden, die dann ihrerseits dem Verfassungsmäßigkeitstext unter Heranziehung der Grundrechtsschrankennormen unterworfen sind. Aber es kam auf das Existenzrecht der materialen Grundpflichten an. Darüber hinaus ist vieles offen geblieben. Herr Hofmann hat eine ausdrückliche Kategorie offener Fragen aufgenommen, die bei mir ungeschrieben auch mitzudenken ist. Auch ich gehe davon aus, daß Fragen offen geblieben sind. Das gilt insbesondere für die von Ihnen, Herr Erichsen, aufgeworfenen Fragen eines Pflichtgehalts innerhalb der Medienstruktur. Ich gehöre selbst zu den ganz wenigen Öffentlichrechtlern, die sich noch nie über Fragen der Medien verbreitet haben, und habe auch nicht vor, diesen Zustand der Unschuld bei dieser Gelegenheit zu verlieren.

Ich möchte schließen mit meinem herzlich empfundenen Dank gegenüber allen, die die Referate einer so breit angelegten Diskussion für würdig gefunden haben, und danke dem Vorstand für den Vertrauenserweis, den ich darin erblicke, daß er mich mit dem Referat beauftragt hat.

Vorsitzender: Vielen Dank, Herr Götz. Wir sind damit am Ende der Beratungen angekommen. Ich möchte allen danken, die durch ihre Beiträge mitgewirkt haben, das Thema noch weiter $\mathrm{zu}$ vertiefen. Ich möchte aber auch denen danken, die fruchtbar geschwiegen und anregend zugehört haben. Was die beiden Referenten betrifft, so glaube ich, in Ihrer aller Namen sagen zu können: Es war uns die reine Freude, Herr Hofmann und Herr Götz, und dafür danken wir Ihnen sehr herzlich.

Damit schließe ich die Aussprache. 
